\title{
The Essential Elements of Adolescent-Friendly Care in School-Based Health Centers: A Mixed Methods Study of the Perspectives of Nurse Practitioners and Adolescents
}

\author{
Alison Moriarty Daley \\ University of Connecticut - Storrs, alisondaley@sbcglobal.net
}

\section{Recommended Citation}

Daley, Alison Moriarty, "The Essential Elements of Adolescent-Friendly Care in School-Based Health Centers: A Mixed Methods Study of the Perspectives of Nurse Practitioners and Adolescents" (2016). Doctoral Dissertations. 1124.

https://opencommons.uconn.edu/dissertations/1124 
The Essential Elements of Adolescent-Friendly Care in School-Based Health Centers: A Mixed Methods Study of the Perspectives of Nurse Practitioners and Adolescents

Alison Moriarty Daley Ph.D.

University of Connecticut, 2016

The majority of the morbidity and mortality among adolescents results from preventable causes including risk-taking behaviors and injuries. Preventive care for this population therefore includes anticipatory guidance and screening aimed at reducing these risks. However, the rates of engagement in preventive care decline steadily throughout adolescence. School-based health centers (SBHCS) have been identified as an adolescent-friendly community resource for preventive care. The purpose of this study was to identify the essential elements of adolescentfriendly care in SBHCs from the perspectives of nurse practitioners (NPS) providing care to adolescents in SBHCs and adolescents, as the consumers of these services. Complex adaptive systems (CAS) provided the philosophical and theoretical foundation for this study.

An explanatory sequential mixed methods study was conducted. The first phase consisted of a Delphi technique with an expert panel of NPs $(N=21)$ to identify the essential elements of adolescent-friendly care in SBHCs. In the second phase, a focus group study with adolescents was conducted $(N=30)$ to explain the Delphi results. Data from two phases were mixed in the final phase of the study.

This study generated expert opinion regarding the essential elements of adolescentfriendly health care in SBHCs. After four Delphi rounds, consensus was reached on 98-items (49\%; consensus level of .75). The results clustered into 6 essential elements: Confidentiality/ Privacy ( $n=8 ; 42 \%)$, Accessibility, $(n=15 ; 46.9 \%)$, SBHC Environment $(n=4 ; 23.5 \%)$, Clinicians/Staff ( $n=51 ; 58 \%)$, SBHC Clinical Services $(n=12 ; 37.5 \%)$ and Relationship Between the School and SBHC $(n=8 ; 66.7 \%)$. The adolescent focus groups provided data about what they liked about the SBHC, how the care differed from their other experiences, and explained the essential elements identified in the Delphi. Two overarching themes: Comfortable and Trusted Relationship emerged. The final phase mixed the data from the two phases. A 
Alison Moriarty Daley - University of Connecticut, 2016

conceptual model of adolescent-friendly care in SBHCs as a CAS is presented.

This study identified six essential elements and two overarching themes essential to the delivery of adolescent-friendly care in SBHCs. These findings contribute to a greater understanding of what adolescents, as consumers of health care services in SBHCs, need to engage in preventive care during adolescence. 
The Essential Elements of Adolescent-Friendly Care in School-Based Health Centers: A Mixed Methods Study of the Perspectives of Nurse Practitioners and Adolescents

Alison Moriarty Daley

B.S.N., Georgetown University, 1992

M.S.N., Yale University, 1994

\author{
A Dissertation \\ Submitted in Partial Fulfillment of the \\ Requirements for the Degree of \\ Doctor of Philosophy \\ at the \\ University of Connecticut
}

2016 
Copyright by

Alison Moriarty Daley 2016 
Doctor of Philosophy Dissertation

The Essential Elements of Adolescent-Friendly Care in School-Based Health Centers: A Mixed Methods Study of the Perspectives of Nurse Practitioners and Adolescents

\section{Presented by}

Alison Moriarty Daley, M.S.N., A.P.R.N., P.N.P.-B.C.

Major Advisor
E. Carol Polifroni

Associate Advisor

Cheryl T. Beck

Associate Advisor

Lois S. Sadler

University of Connecticut

2016 
I would like to acknowledge Sigma Theta Tau, Mu Chapter and the Connecticut Nurses' Foundation, Dr. Sheila Packard Memorial Scholarship, for funding this research.

My amazing and always supportive committee-

Drs. E. Carol Polifroni, Cheryl T. Beck, Lois S. Sadler, Arthur Engler, and Thomas Van Hoof. Words could never adequately express my gratitude. You have truly taught me to think and look at things differently. Thank you!

This research would not have been possible without the support of the NPs and adolescents who participated in this study as well as the agencies and school administrators who allowed the focus groups to be conducted. Mimi Snyder for being my fantastic research assistant.

Dr. Mikki Meadows-Oliver for your constant encouragement and frequent reminders to stay under my research umbrella.

Kevin, Aidan, Ailie, Annin, Abigail Grace and my parents--- Thank you for all your support, understanding, and encouragement along this journey. I love you! 
TABLE OF CONTENTS

APPROVAL OF THE DISSERTATION

ACKNOWLEDGEMENTS iv

LIST OF TABLES viii

LIST OF FIGURES $\quad$ ix

CHAPTER I

INTRODUCTION 1

Background and Significance $\quad 1$

Philosophical and Theoretical Foundations $\quad 5$

Research Aims $\quad 6$

Methods $\quad 8$

CHAPTER II

BACKGROUND AND REVIEW OF THE LITERATURE 10

$\begin{array}{ll}\text { Theoretical and Philosophical Framework } & 10\end{array}$

Structural and Functional Components of Complex Adaptive Systems 11

Adolescent Development $\quad 15$

$\begin{array}{ll}\text { Adolescent Health } & 16\end{array}$

Health Disparities Related to Access and Use of Preventive Care $\quad 17$

$\begin{array}{ll}\text { Social Disparities } & 18\end{array}$

$\begin{array}{ll}\text { Disparities Related to Adolescent Health } & 19\end{array}$

Relationship to Future Health $\quad 22$

Patterns of Preventive Health Care Utilization by Adolescents 23

$\begin{array}{ll}\text { Anticipatory Guidance and Preventive Counseling } & 26\end{array}$

Adolescents' Experiences and Preferences with Health Care Services $\quad 30$

Initiatives to Improve the Health of Adolescents 35

School-Based Health Centers 38

$\begin{array}{ll}\text { Characteristics of SBHCS } & 39\end{array}$

$\begin{array}{ll}\text { SBHC Models } & 39\end{array}$

Health and Mental Health Services Available in SBHCs 40

$\begin{array}{ll}\text { SBHC Effectiveness } & 40\end{array}$

Access Barriers for Adolescents in SBHCs 42

Nurse Practitioners $\quad 44$

$\begin{array}{ll}\text { Summary } & 45\end{array}$

CHAPTER III

RESEARCH DESIGN AND METHODS 46

Research Design $\quad 46$

Phase I: Delphi Study (Quantitative Phase) 49

Recruitment and Sample $\quad 49$ 
Delphi technique Data Collection and Analysis $\quad 50$

Phase II: Focus Groups (Qualitative Phase) 53

Recruitment and Sample $\quad 54$

Focus Group Method 56

Focus Group Data Analysis $\quad 57$

Mixing of Quantitative and Qualitative Data $\quad 59$

Approaches Used to Enhance Validity $\quad 59$

Quantitative Phase $\quad 59$

$\begin{array}{ll}\text { Qualitative Phase } & 60\end{array}$

Summary

61

61

CHAPTER IV

RESULTS 63

$\begin{array}{ll}\text { Quantitative Phase: Delphi Technique } & 63\end{array}$

Demographic Characteristics of the Sample $\quad 64$

$\begin{array}{ll}\text { Round } 1 & 66\end{array}$

$\begin{array}{ll}\text { Round } 2 & 67\end{array}$

$\begin{array}{ll}\text { Round } 3 & 69\end{array}$

$\begin{array}{ll}\text { Round } 4 & 71\end{array}$

$\begin{array}{ll}\text { Summary } & 72\end{array}$

Qualitative Phase: Focus Groups 76

$\begin{array}{ll}\text { Demographic characteristics of focus group participants } & 76\end{array}$

$\begin{array}{ll}\text { Focus Group Results } & 77\end{array}$

What do you like about coming to the SBHC? 77

How is the care you receive here different from other places you 80 go for care?

Essential Elements of Adolescent-friendly Care in SBHC 85

Summary 103

$\begin{array}{ll}\text { Mixing of Quantitative and Qualitative Data } & 104\end{array}$

$\begin{array}{ll}\text { Overarching Themes } & 105\end{array}$

Essential Elements of Adolescent-Friendly Care in SBHCs 106

$\begin{array}{ll}\text { Summary } & 116\end{array}$

CHAPTER V

DISCUSSION $\quad 117$

Essential Elements of Adolescent-friendly Care in SBHCs 120

$\begin{array}{ll}\text { Overarching Themes } & 120\end{array}$

Essential Elements of Adolescent-friendly Care 122

$\begin{array}{ll}\text { Implications } & 128\end{array}$

$\begin{array}{ll}\text { Clinical Practice } & 128\end{array}$

Professional Education $\quad 130$

$\begin{array}{lr}\text { Research } & 132\end{array}$

Health Policy 133

$\begin{array}{ll}\text { Strengths and Limitations } & 134\end{array}$

$\begin{array}{ll}\text { Conclusion } & 135\end{array}$

$\begin{array}{ll}\text { REFERENCES } & 137\end{array}$

APPENDICES

A. Delphi Technique Recruitment Flyer/Email 159 
B. Delphi Technique Invitation to Participate Letter 160

C. Delphi Technique Consent 161

D. Delphi Technique Demographic Questionnaire 164

E. $\quad$ Delphi Technique Round 1 Letter 165

F. Delphi Technique Round 1 Questionnaire 166

G. Delphi Technique Follow-up Letter $\quad 167$

H. $\quad$ Delphi Technique Reminder Letter 168

$\begin{array}{ll}\text { I. } & 169\end{array}$

$\begin{array}{ll}\text { J. Delphi Technique Round 2 Questionnaire } & 170\end{array}$

K. $\quad$ Delphi Technique Round 3 Letter 184

L. Delphi Technique Round 3 Questionnaire $\quad 185$

M. Delphi Technique Round 4 Letter 201

N. Delphi Technique Round 4 Questionnaire 202

O. Focus Groups Recruitment Poster 208

P. Focus Groups Recruitment Letter/Script 209

Q. Focus Group Parental Consent/Teen Assent Form 210

R. Focus Group Consent 18-19 years old 213

S. Focus Group Demographic Questionnaire 216

T. Focus Group Follow-up Recruitment Letter 217

U. $\quad$ Focus Group Ground Rules 218

V. Focus Group Questioning Route $\quad 219$

W. Focus Group List of SBHC Services 220

X. Comparison of NP and Adolescent Perspectives on Confidentiality and Privacy 221

Y. Comparison of NP and Adolescent Perspectives on Accessibility 223

Z. Comparison of NP and Adolescent Perspectives on SBHC Clinicians and Staff 226

AA. Comparison of NP and Adolescent Perspectives on Clinical Services 229

AB. $\quad$ Comparison of NP and Adolescent Perspectives on SBHC Environment 234

AC. $\quad$ Comparison of NP and Adolescent Perspectives on the Relationship Between 237 the SBHC and School 


\section{LIST OF TABLES}

1. Multiple Category Design for Focus Groups 55

2. Demographic Characteristics of NPs Participating in the Delphi Technique 65

3. Demographic Characteristics of the NP Practice Sites 66

4. Essential Elements of Adolescent-friendly Care in SBHCs Round 2 Results 67

5. Essential Elements of Adolescent-friendly Care in SBHCs Round 3 Results 69

6. Essential Elements of Adolescent-friendly Care in SBHCs Round 4 Results 71

7. Essential Elements of Adolescent-friendly Care in SBHCs 73

8. Demographic Characteristics of the Focus Group Participants 77

9. Importance of Each of the Essential Elements of Adolescent-friendly Care to Focus 86 Group Participants

10. Three Most Important SBHC Services Reported by Focus Group Participants 93

11. The Complexity of School-Based Health Centers 119 


\section{LIST OF FIGURES}

1. The Essential Elements of Adolescent-friendly Care in SBHCs Mixed Methods Procedural Diagram

2. Dendrogram of Essential Element of Confidentiality/Privacy

3. Essential Elements of Adolescent-friendly Care in SBHCs as a CAS Model 


\section{CHAPTER I \\ INTRODUCTION}

Adolescence is a healthy period of life for most teens in the United States. Much of the morbidity and mortality for this age group results from causes that are largely preventable including risk-taking behaviors and injuries (Miniño, 2010). Health care services that are designed to meet the needs of adolescents provide comprehensive health and mental health services that focus on screening, health education, and anticipatory guidance to lessen the impact of risk-taking behaviors, mental health concerns, substance use, obesity, risky sexual behaviors, and sexual identity concerns. Adolescence is also an important time for adopting health-promoting behaviors and life-styles that help to prevent acute and chronic illnesses during adulthood. Yet, many adolescents do not have access to or can participate in comprehensive primary care services. Less than half of teens ( $42-44 \%$ of $10-17$ year olds) in the United States had an annual well child visit in 2009 (Caldwell \& Berdahl, 2013). Even among those adolescents who had an annual preventive visit, less than half received the recommended anticipatory guidance and far fewer, $40 \%$, spent time alone with their provider to discuss more private concerns related to sexuality, reproductive concerns, substance use, and mental health concerns (Irwin, Adams, Park \& Newacheck, 2009). Lack of access to comprehensive health care services, including prevention counseling and anticipatory guidance, creates missed opportunities for early identification and intervention for at-risk teens and likely contributes significantly to the morbidity and mortality that occurs during and after adolescence.

\section{Background and Significance}

Preventive health care services are utilized less often for both male and female teens during adolescence than during childhood (Caldwell \& Berdahl, 2013). Time alone with a health care provider is a critical opportunity for the teen and clinician to discuss more private concerns including substance use, mental health, sexuality, and risk taking behaviors (Irwin et al., 2009). The decreased interactions with the health care services during adolescence, makes it all the 
more important to identify factors that may influence the use of health care services in this population. Within the existing research there are descriptions of many factors that facilitate or hinder access and utilization of health care by adolescents. Facilitating factors, collectively referred to as adolescent-friendly care, include the availability of multiple services by a consistent provider, easy accessibility to clinicians and agencies, confidentiality, and services that are developmentally appropriate (Coker et al., 2010; Fox, Philliber, McManus, \& Yurkiewicz, 2010; Gustafson, 2005; McIntyre, 2002; Sadler \& Daley, 2002). Lack of insurance, confidentiality concerns, lack of awareness regarding available services, and providers/health care services that are not responsive to the concerns of adolescents may negatively impact an adolescent's willingness or ability to seek services and ultimately result in missed opportunities for timely care and appropriate intervention (Ford, Bearman \& Moody, 1999; Ginsburg, Forke, Cnaan \& Slap 2002a; McKee \& Fletcher, 2006).

School-based health centers (SBHCs) have been identified as an adolescent-friendly community resource for comprehensive primary and mental health services for adolescents (Lofink et al., 2013; Strozer, Juszczak \& Ammerman, 2010) and are an important component of the safety net services available to adolescents (National Research Council and Institute of Medicine of the National Academies [NRC/IOM, 2009). Safety net agencies have two distinguishable and important characteristics: they provide services to everyone, regardless of their ability to pay and second, a significant proportion of the patients they serve are uninsured, receive Medicaid, or are vulnerable in other ways. These safety net agencies remove significant barriers to care (NRC/IOM, 2009).

The health care services available in SBHCs eliminate many of the barriers to health care services encountered by adolescents because they offer comprehensive services, are convenient, easily accessible, available without cost for those without insurance, confidential, and responsive to the specific needs of adolescents (Daley, 2012; Gustafson, 2005; Sadler \& Daley, 2002; Scudder, Pappa \& Brey, 2007; Strozer et al., 2010). In addition, teens can 
develop a relationship with a health care provider, which likely facilitates access to services for more private concerns including sexuality, mental health, and substance use/abuse and as a result earlier screening and treatment and less missed opportunities for health education, anticipatory guidance, and timely intervention, are possible.

SBHCs provide health and mental health services for many teens in the United States. NPs are most often providing the care in SBHCs as part of an interprofessional team that may include an administrative assistant, social worker, medical assistant, physician, nutritionist, physician assistant, substance abuse counselor, health educator, dental hygienist or dentist (Lofink et al., 2013). They often are sponsored by existing community health organizations such as hospitals, federally qualified health centers, local health departments, or private practices (Gustafson, 2005; Keeton, Soleimanpour, \& Brindis, 2012; Lofink et al., 2013). SBHCs are most often located within the school building or within close proximity to the school and are available to all students who attend the school through a signed parental consent (Gustafson, 2005; Lofink et al., 2013; Strozer et al., 2010).

Health care services provided to adolescents in SBHCs typically include physical examinations, immunizations, evaluation and management of acute and chronic illnesses, reproductive health services (pregnancy tests, screening and treatment for STIs and HIV, and in some SBHCs, condoms and contraception), individual and group mental health counseling, substance use/abuse screening, and referral (Lofink et al., 2013). Teens may access some or all of the services available and typically access is not contingent on insurance status or ability to pay for services (Strozer et al., 2010). For many adolescents, especially those who are uninsured, underinsured, or live in limited resource areas, SBHCs may be their only source of health and mental health care. This model of care allows teens access to services while they are in school, provides easy access for follow-up, and encourages teens to assume a more independent role in health care services by making their own appointments, communicating with 
the SBHC staff, and learning to become an active participant in health care services (Daley, 2011; Ginsburg et al., 2002b).

More than half of the existing SBHCs in the United States serve adolescents (NRC/IOM, 2009) and these services provide the opportunity to improve health care equity and outcomes through increased access and use of developmentally appropriate health and social services (NRC/IOM, 2009). SBHCs have demonstrated their effectiveness by increasing health and mental health care access (Britto, Klosterman, Bonny, Altrum \& Hornung, 2001; Slade, 2002), increasing health knowledge (Culligan, 2002; Kisker \& Brown, 1996), decreasing unnecessary emergency room visits (Anderson et al., 2004; Key, Washington, \& Husley, 2002), increasing time spent in school (McCord, Klein, Foy \& Fothergill, 1993; Strolin-Goitzman, 2010; Van Cura, 2010; Walker, Kerns, Lyon, Brun \& Cosgrove, 2010; Webber et al., 2003), and providing effective programs targeted at common sources of morbidity and mortality such as asthma, obesity, teen pregnancy, depression, and sexually transmitted infections (STIs) (Amin \& Sato, 2004; Ethier et al., 2011; Guo et al., 2005; Keeton et al., 2012; Lurie, Bauer \& Brady, 2001; Mansour, Rise, Toole, Luzader \& Atherton, 2008; McNall, Lichty \& Mavis, 2010; Webber et al., 2005; Webber et al., 2003; Zimmer-Gembeck, Doyle, \& Daniels, 2001). However, the services available in SBHCs vary greatly from state to state and even within communities (Strozer et al., 2010).

Most teens do not receive all aspects of recommended preventive health services (Irwin et al., 2009). Those who are underinsured, uninsured, or who encounter costly co-payments are even less likely to receive the recommended health care services (Simpson et al., 2005). Adolescents spend a significant amount of their time in school and therefore increasing the capacity and utilization of SBHCs is a logical step toward meeting both the unmet needs of this population as well as the anticipated demands on primary health care services created by The Patient Protection and Affordable Care Act (2010). Nurse Practitioners (NPs) are most often the health professionals providing care in SBHCs. However, very little is known about what they 
identify as most important for providing comprehensive adolescent-friendly care in SBHCs. Additionally, as the consumers of health care services from SBHCs, the adolescents' perceptions of the essential elements of the care they receive in SBHCs are not well represented in the literature.

\section{Philosophical and Theoretical Foundations}

Adolescence is a time of rapid physical, cognitive, and emotional change as well as increased independence as they transition from childhood to adulthood (Piaget, 1972).

Throughout this developmental process adolescents are discovering who they are as individuals and how their personal beliefs, values, opinions and preferences fit into their interactions with others, including the health care system. (Daley, 2012; Erikson, 1950). The relationships individuals have with the health care system are complex and influenced by a variety of factors. Health care services provided to teens, by necessity, need to be responsive and adaptive to their ever-changing physical, social, and developmental needs. Novel strategies are needed to address the unmet health care needs of adolescents.

A growing body of research literature is available that applies complexity science and complex adaptive systems theory to a diverse variety of clinical systems in an effort to consider systems as "living organisms" rather than machines (Begun, Zimmerman \& Dooley 2003; Tan, Wen \& Awaad, 2005). Rooted in mathematics and the sciences (physics, biology), complexity science has been used to understand interactive agents (components) that "adapt or learn as they interact" (Holland, 2006, p. 1). More recently complex adaptive systems theory has been applied to a variety of other disciplines including manufacturing, medicine, economics, management, health care systems and nursing to consider problems or phenomena with a different lens. Complex adaptive systems theory serves to explain phenomena through a holistic interplay of an entire system rather than a reductionist perspective of individual parts of a system (Cilliers, 2000; Holden, 2005) and allows for the identification of "the tiny differences 
that made a big difference in producing the 'new' system [in] contrast to the forces that allow systems to get 'stuck' in suboptimal solutions and interventions” (Begun et al., 2003, p. 279).

Complex adaptive systems contain multiple dynamic components poised to respond to the ever-changing needs of those accessing the health care system (Lindberg, Nash \& Lindberg, 2008). The essential inter-related elements of diversity, self-organization, embeddedness, distributed control, emergence, and coexistence between order and disorder allow a complex adaptive system to respond to the potential and ever changing needs of those accessing the health care system (Cilliers, 2000; Lindberg et al., 2008). The components of complex adaptive systems are commonly depicted as a web, reflecting the essential interconnectedness of the elements and the flexibility that the system must possess to survive. Examples of complex systems include a high school, hospital emergency department, ant hill, or SBHC. These systems operate "far from equilibrium" (Cilliers, 2000, p. 37) because a state of equilibrium prevents the system from responding, changing, or adapting as needed to meet the ever changing needs of the system. It is "the robust nature of complex systems, their capacity to perform in the same way under different conditions, that ensures their survival" (Cilliers, 2000, p. ix). Complex adaptive systems theory will provide the opportunity to more clearly understand the dynamic interplay among the unique health care needs of the adolescents using these services and the SBHC services available to adolescents, and whether current SBHC services eliminate gaps in health care services for this population (Cilliers, 2000; Lindberg et al., 2008; Wilson \& Holt, 2001).

\section{Research Aims}

The literature provides many important characteristics toward developing truly adolescent-friendly services. Currently, too few research studies have specifically examined the essential elements required to successfully provide adolescent-friendly care to teens in SBHCs. The perspectives of NPs providing care in SBHCs and the teens utilizing this care are important to understand so that SBHCs can emerge as a resource ready, willing, and able to address the 
new demand for primary care services. Much of the existing literature on health care services for adolescents focuses on physicians, services other than SBHC, and typically target a specific aspect of care or population of interest. Two important perspectives, those of the NPs providing care to teens in SBHCs and that of the adolescent patients seeking care in SBHCs, are noticeably absent in the literature. Gaining an increased understanding and more complete picture of all the factors that contribute to adolescent-friendly services, will allow SBHCs to better adapt to the needs of adolescents and assist to fill the gap that currently exists for most teens related to comprehensive adolescent health services.

Two critical components for understanding and adapting health care services to the needs of adolescents are the perspectives of NPs providing care to this population in SBHCs and the perspectives of adolescents seeking and receiving care in SBHCs. A common commitment to what is essential from these two perspectives will allow the SBHC and the care provided by the NP to be responsive to the health care needs of this population and ultimately provide services that are truly adolescent-friendly. Complex adaptive systems theory is particularly well aligned with the research questions in this mixed methods study because it represents the strengths of nursing (holism, non-linearity, emergence) and allows an analysis of the provision of adolescent primary care services in a new manner.

The purpose of this mixed methods study was to identify the essential elements of adolescent-friendly health care services provided to teens in SBHCs. This study addressed the following research questions:

1. What does an expert panel of NPs identify as the essential elements of providing adolescent-friendly health care services to teens in SBHCs?

2. What is the adolescent perspective on the essential elements of adolescent-friendly health care services specific to SBHCs?

3. How do the perspectives of NPs and adolescents compare regarding the essential elements of adolescent-friendly care in SBHCs? 


\section{Methods}

Mixed methods research has become an increasingly popular and accepted avenue to explore diverse research questions. Creswell and Plano-Clark (2011) define mixed methods research as a combination of quantitative and qualitative methods, a philosophy, and a research design orientation. This mixed methods study was designed to identify and understand the essential elements necessary for providing adolescent-friendly care to teens accessing SBHCs for their health care. An explanatory sequential mixed methods design was used to investigate the essential elements of adolescent-friendly care in SBHCs from the perspectives of an expert panel NPs and teens (Creswell \& Plano-Clark, 2011). The quantitative data were collected first and analyzed and then in the second, qualitative strand the researcher sought to explain the quantitative findings (Creswell \& Plano-Clark, 2011). The data from the second strand provided greater insights about the research questions and explained the results of the quantitative strand (Creswell \& Plano-Clark, 2011). The perspectives of the expert panel and the adolescents were then compared and contrasted to gain a better understanding of what is viewed as the essential elements in providing care in an adolescent-friendly manner to teens in SBHCs. A more robust analysis resulted from the combination of the quantitative and qualitative components of the mixed methods design and allowed the researcher to optimize the depth and breadth of understanding about adolescent-friendly care in SBHCs from these two perspectives (O'Caithlin, 2010). It is hoped that learning more about the essential elements of adolescent-friendly care from these two critical perspectives will allow SBHC services to be tailored to meet the needs and demands of the adolescents they serve.

There are many examples in the nursing literature of explanatory sequential mixed methods designs (Carter, Callaghan, Khaill \& Morres, 2012; Halcomb, Davidson, Griffiths \& Daly, 2008; Mark et al., 2010; Theuissen, Griensven van, Verdonk, Feron, \& Bosma, 2012). None were found that were related to the proposed study. To better understand the potential 
challenges of this research design, the limitation sections of each study were carefully considered in the planning of this proposal.

This dissertation will be presented in a traditional five chapter framework. The second chapter provides the conceptual framework and review of relevant literature. The methodology and study design are presented in Chapter III. The study results are provided in Chapter IV and are followed by a discussion of the study findings and the clinical and health policy implications of this research in Chapter V. 


\section{CHAPTER II}

\section{BACKGROUND AND REVIEW OF THE LITERATURE}

Chapter II provides the theoretical and philosophical framework for this mixed methods study. The current literature specific to adolescent development, health, and social disparities related to health care access, preventive health care utilization, adolescents' experiences with health care services, initiatives to improve adolescent health, school-based health centers, and the role of nurse practitioners in addressing the health care needs of adolescents are reviewed.

\section{Theoretical and Philosophical Framework}

This mixed methods study was developed using Complex Adaptive Systems as the guiding theoretical and philosophical framework. Adolescence is a time transition from childhood to adulthood and involves physical, cognitive, and emotional changes as well as increasing independence (Piaget, 1972). During adolescence, teens are faced with a multitude of decisions that influence their lives now and in the future. An important aspect of this developmental period is discovering who they are as individuals and how their personal beliefs, values, opinions, and preferences influence their relationships with other people and other aspects of their community, including the health care system. (Erikson, 1950; Daley, 2012). The interactions or experiences (schema) individuals have with the health care system are complex and influenced by a variety of factors. The health care services provided to teens therefore need to be responsive and adaptive to teens' physical, social, and developmental needs as well as their complex health and mental health needs.

Grounded in mathematics and science (physics, biology), complexity science has been used to understand agents (components) that "adapt or learn as they interact" (Holland, 2006, p. 1). A growing body of research literature has applied complexity science and complex adaptive systems theory to a diverse variety of clinical systems in an effort to consider systems as "living organisms" rather than machines (Begun et al., 2003; Tan et al., 2005). Complex adaptive 
systems contain multiple dynamic components poised to respond to the ever-changing needs of those accessing the health care system (Lindberg et al., 2008). The essential inter-related elements of diversity, self-organization, embeddedness, distributed control, emergence, and coexistence between order and disorder allow a complex adaptive system to respond to the potential and ever changing needs of those accessing the health care system (Cilliers, 2000; Lindberg et al., 2008). The components of a complex adaptive system are commonly depicted as a web, reflecting the essential interconnectedness of the elements and the flexibility that the system must possess to survive (Lindberg et al., 2008). Examples of complex systems include a high school, hospital emergency department, ant hill, or SBHC.

Complex adaptive systems theory seeks to explain phenomena through a holistic interplay of an entire system rather than a reductionist perspective of the individual parts of a system (Cilliers, 2000; Holden, 2005). These systems are dynamic in nature and, by necessity, operate "far from equilibrium" (Cilliers, 2000, p. 37). A state of equilibrium prevents the system from responding, changing, or adapting to the ever-changing needs of the system. It is "the robust nature of complex systems, their capacity to perform in the same way under different conditions that ensures their survival" (Cilliers, 2000, p. ix).

\section{Structural and Functional Components of Complex Adaptive Systems}

Complex adaptive systems include the elements of: diversity, self-organization, embeddedness, distributed control, coexistence between order and disorder and emergence (Cilliers, 2000). Each of the elements of complex adaptive systems will be explained using the example of a SBHC responding to a change in an immunization requirement for students. Diversity, the first element, allows the complex adaptive system to adjust to changes in the system or environment (Cilliers, 1998; Lindberg et al., 2008). An example of diversity in the $\mathrm{SBHC}$ is a change in the immunization requirements for adolescents that required an additional vaccination prior to the tenth grade. The services of the SBHC would need to adjust to accommodate this new requirement while continuing to offer the existing services. Each 
complex adaptive system is typically part of another, often larger or related complex adaptive system; this component is embeddedness (Cilliers, 1998; Lindberg, et al., 2008). SBHCs are typically a satellite clinic of a larger health care agency and also part of the school community. Self-organization is the ability of a system to adapt to outside forces, influences, or parameters and in turn develop internal systems, patterns or responses to these influences (Cilliers, 1998; Lindberg et al., 2008). For example, new appointments are scheduled for the teens who need the influenza vaccine in order to accommodate to the change in guidelines and to keep the teens from being excluded from school. Next, distributed control or shared governance, allows for the complex adaptive system to mutually problem solve and fully actualize the diversity of the complex adaptive system (Cilliers, 1998; Lindberg et al., 2008). Within the SBHC, an example of distributed control would be problem-solving with the office staff strategies to meet the new vaccination requirement while also meeting the other needs of the students using the clinic or negotiating with the school administration for students to have access to the SBHC during classes. In addition, the NP and the administrative assistant may refine the plan as it is set into motion to see if further adjustments need to be made to the schedule. The SBHC may also encounter new users of the SBHC who need the vaccination, but are unable to meet the requirement because of lack of appointment availability at their provider's office. However, even the best plans may cause order and disorder, another characteristic that exists simultaneously (Cilliers, 1998; Lindberg et al., 2008). The co-existence of order and disorder has been identified as a healthful characteristic of a complex adaptive system. Likely, most of the efforts to accommodate to the new vaccination requirement will be successful, but if supplies are limited, insurance coverage is an issue, or if students/parents are unware the vaccine is available at the SBHC, disorder will be created by missed appointments or unfulfilled vaccination requirements. What results from the experience with integrating a new vaccination recommendation into the $\mathrm{SBHC}$ is the emergence of a novel approach to the new demand or problem (Cilliers, 1998; Lindberg et al., 2008). The SBHC may need to not schedule wellness 
appointments until all the tenth graders desiring appointments have received their vaccinations or it may be better to schedule many ten-minute appointments throughout the day in addition to most of the regular appointments. A third option, would to ask for assistance from the school nurse in meeting this new demand.

From the example of a SBHC, it is apparent that complex adaptive systems operate at point "far from equilibrium" (Lindberg et al., 2008, p. 37). Equilibrium, or the status quo, causes the system to be unable to respond, change, or interact as necessary and may ultimately lead to decay of the complex adaptive system or complete randomness (Cilliers, 1998; Lindberg et al., 2008; Tan et al., 2005). In this example, equilibrium would have prevented the SBHC from meeting the health needs of the adolescents, would not have adjusted the appointment schedule to accommodate an increased volume of patients or time allotted for a visit, and would not have emerged from the experience with a new approach to the vaccine requirement. Instead, it would have sought to maintain the current pattern of patient care and not adapted to the new recommendation or needs of the agent using the SBHC.

The trick to survival of a complex system is to hover between too rapid, directionless change, and too little change, where unfriendly environmental forces might overtake it. Its best chance occurs at the edge of chaos, that is, the systems' point of maximum fitness and adaptability and their potentially worst scenario (Tan et al., 2005, p. 42). Unintended or unanticipated consequences of the SBHC responding to the new vaccination requirement may be small and hardly recognized. For example, a parent may subsequently enroll a patient's sibling in a SBHC because of their experience with the clinic. Other outcomes could include days missed from school by the tenth-graders because of a sore arm from the vaccine or conversely teens enjoying their experience with the SBHC and returning for other health related needs, such as contraception. All of these examples demonstrate non-linearity, which is the unanticipated outcome that results from the lack of predictability and selforganization (Cilliers, 1998; Lindberg et al., 2008). 
Learning is an important aspect of effective and sustainable systems because in order to survive the complex adaptive system must adapt to the ever changing needs of the system. Health care systems are composed of many interdependent and interrelated parts (Thompson, 1967). However, these parts are unpredictable, may be difficult to understand, and lack a readily recognizable structure. Interactions among the agents, especially when the agents are human, are also unpredictable and often appear unorganized and random because a pattern of response is not easily recognized. Agents within a complex adaptive system "scan their environment and develop a schema for action" (Tan et al., 2005, p. 38). This schema in turn causes an agent to act in linear and nonlinear ways with other elements of the complex adaptive system. The changes that occur to an agent's schema are described by Tan and colleagues (2005) as first, second, or third-order changes. First-order changes are those actions that allow the agent to observe and then adapt to a change. For example, the SBHC NP notices many teens coming in to the clinic requesting an influenza vaccine, however there is not enough vaccine to meet the new demand. The NP needs to order more vaccine immediately to meet the increased demand. Second-order changes occur when the agent purposefully changes their schema to better fit their observation. Because the influenza vaccine is a new requirement for school attendance, it is presented to teens as a requirement rather than an optional vaccine. Finally, third-order changes are those in which the schema either survives or ceases to exist (Tan et al., 2005). The two possible outcomes of a change in an agent's schema are either the agent becomes more robust and able to adapt to variations experienced within the complex adaptive system or the agent becomes more predictable and reliable in their interactions (Tan et al., 2005). If the NP incorporates the new vaccine requirement into the services at the SBHC, the supply of vaccine needed for the SBHC will be anticipated ahead of the next flu season and appropriate plans will be made regarding ordering and securing enough vaccine to meet the anticipated demand. In addition, the teens will anticipate that the $\mathrm{SBHC}$ will have the vaccine available when they need to have the vaccine the following year. However, if the schema 
ceases to exist, no advanced planning for the following flu season will occur and the complex adaptive system may be unable to meet the needs of the SBHC patients. Complexity science integrates the dynamic interactions between health care agencies and the individuals who engage in the clinical services offered by such agencies (Cilliers, 2000; Lindberg et al., 2008; Wilson \& Holt, 2001).

Complex adaptive systems theory provides the opportunity to understand the interplay of the clinical services available to adolescents through SBHCs, the unique health care needs of the adolescents using these services, and whether current SBHC services can provide a safety net of adolescent-friendly care and lessen the impact of health disparities for this population. Complex adaptive systems theory is particularly well aligned with this study because it represents the strengths of nursing (holism, non-linearity, emergence) and allows analysis of the provision of adolescent primary care services in a new manner and from the perspectives of the NPs providing care to adolescents in SBHCs and the adolescents as the consumers of SBHC services.

\section{Adolescent Development}

Adolescence represents a critical developmental transition from childhood to adulthood (11 to 21 years of age) and is accompanied by physical, cognitive, and psychosocial changes (Elster \& Kuznets, 1994; Hagan, Shaw \& Duncan, 2008). The timing and tempo of these changes vary from individual to individual. The physical changes associated with puberty include increased linear growth and the development of secondary sexual characteristics. These physical changes are accompanied by cognitive and neurobiological changes that influence the way adolescents think and make decisions. Adolescents transition from more concrete to more formal operational thought patterns that allow the teen to consider the perspectives of others, multiple possibilities or solutions, abstract concepts, different dimensions of a problem or situation as well as to think about thinking (Elkind, 1998; Hamburg, 1998; Piaget, 1952; 1972). Egocentrism and the imaginary audience, the adolescent's belief that 
everyone is thinking about them (because the teen is thinking about him or herself constantly), result from these new thought patterns (Elkind, 1998). The imaginary audience often leads teens to believe they are invulnerable to harm and that the normal laws of the universe apply to others but not to them. Adolescent brain research has demonstrated that the teen's prefrontal cortex or "executive decision-making center" continues to develop throughout adolescence into early adulthood and likely effects the teen's ability of perform executive functions including: balance and coordination, emotional balance, ability to engage in interpersonal communication, flexibility in verbal responses, empathy, insight, intuition, modulation of fear, and morality (Casey, Giedd \& Thomas, 2000; Giedd, 2004; Giedd et al., 1999; Siegel, 2007; Sowell, Siegel \& Siegel, 2011). These changes also contribute to their reaction to stress and participation in risktaking behaviors (Casey, Jones \& Hare, 2008; Weinberger, Elvevag, \& Giedd; 2005). Psychosocially, adolescence is a time of gradually increasing independence from their family and the development of a self-concept (Erikson, 1950; Steinberg \& Collins, 2011).

\section{Adolescent Health}

Teens in the United States, in general, are healthy. The majority of morbidity and mortality during this time is a result of risk-taking behaviors and injuries rather than chronic illness or disease. Accidental injury, homicide, and suicide are the leading causes of death for both male and female adolescents (Miniño, 2010). Teens face numerous health and social challenges associated with sexual experimentation, mental illness, substance use and abuse, poor dietary habits, and lack of exercise; all of which can have life-long consequences (U.S. Department of Health and Human Services [USDHHS], 2011a; b). Significant social and health disparities also exist for the adolescent population which may interfere with access to and use of preventive health care services (NRC/IOM, 2009). Many adolescents also face challenges related to social disparities including discrimination, stress, poverty, homelessness, involvement with foster care or the juvenile justice system, and sexual preference (Mulye et al., 2009; Price, McKinney, \& Braun, 2011). Primary health care services, screening, and anticipatory guidance 
provided to adolescents during routine health care visits are a positive mechanism for reducing the impact of social and health disparities (Hagan et al., 2008). Health care services for teen, therefore, focus on disease prevention and anticipatory guidance related to health risk behaviors with particular attention placed on tailoring services to be "adolescent-friendly" and address the unique needs of this population.

Ultimately, adolescent-friendly care allows teens to gradually assume an independent role in health services and aims to integrate health maintenance and prevention into a healthy lifestyle (Daley, 2012; Hofmann, 1992). Adolescent-friendly services attempt to lessen the impact of social and health disparities by providing accessible, comprehensive, developmentally appropriate, and confidential clinical services for all teens (Fox et al, 2010; Ginsburg et al., 2002b; Rosen, Elster, Hedberg, \& Paperny, 1997; Tylee, Haller, Graham, Churchill, \& Sanci, 2007). Often adolescents do not have access to services that are tailored to their specific needs and responsive to the manner in which they engage in care. This gap results in health disparities that prevent access to appropriate preventative health care services and create additional disparities related to teen pregnancy, STIs, obesity and inactivity, substance abuse and mental illness.

\section{Health Disparities Related to Access and Use of Preventive Care}

Current national guidelines recommend an annual preventive visit for all adolescents that includes a through history and physical examination, preventive screening, and anticipatory guidance (Elster \& Kuznets, 1994; Hagan et al., 2008; Rosen et al., 1997). Many teens face significant challenges that limit access to care.

Confidentiality is a significant concern for many adolescents and can present a barrier to accessing needed services especially for private concerns. Clinical guidelines for teens emphasize the need for time alone with a health care provider for appropriate screening, health care services and anticipatory guidance during preventative visits (Elster \& Kuznets, 1994; Hagan, et al., 2008). Less than $40 \%$ of adolescents report time alone with their provider at their 
last preventive visit, a time typically devoted to anticipatory guidance, screening for and referral of issues such as alcohol and substance use, sexuality, and mental health concerns (Edman, Adams, Park, \& Irwin, 2010; Irwin et al. 2009). Even fewer opportunities existed for those from low-income families, with public health insurance, and of Hispanic ethnicity (Irwin et al., 2009). Significant differences also exist between younger and older adolescents. Fifteen to 17 yearolds are more likely to have alone with a clinician than younger teens (12-14 years-olds) regardless of gender or racial/ethnic group identity (Edman et al., 2010). Overall, male adolescents had more opportunity for time alone with a clinician, especially during early adolescence (Edman et al., 2010). Hispanic adolescents were also less likely to spend time alone with a provider than white or black teens throughout adolescence (Edman et al., 2010).

\section{Social Disparities}

The lack of insurance coverage of either an adolescent or his/her parent places an additional risk for decreased access to health care services and ultimately creates missed opportunities for intervention and unmet health care needs (DeVoe, Tillotson \& Wallace, 2008). Adolescents who have a parent with stable health insurance are more likely to receive annual preventive health care visits (Davidoff, Dubay, Kenney, \& Yemane, 2003; Dombkowski, Lantz, \& Freed, 2004; Fronstin, 2011). Between 1998 and 2008 the number of insured children and parents decreased and is most evident among middle and low income families (Angler, DeVoe, Tillotson, Wallace, \& Gold, 2012). Nearly $30 \%$ of adolescents or an estimated three million children, with one insured parent were uninsured for some period of time in the previous year (DeVoe et al., 2008). Uninsured teens were more likely to be from low-income, single-parent families, Hispanic ethnicity, and living in the Southern or Western parts of the United States and have a parent who was unemployed or did not complete high school (DeVoe et al., 2008; Goedken, Urmie, \& Polgreen, 2014). These children/ adolescents were less likely to report their health as excellent (44.7\%) compared to those with insurance (49.8\%) (DeVoe et al., 2008). Lack of health insurance makes it more likely that a teen will not have a regular source of health 
care services. Recent evidence suggests that children and adolescents from single father homes and parents who have not had a recent health visit were less likely to have had a wellvisit in the past year (Goedken et al., 2014). A regular source of health care services is associated with increased likelihood of receiving comprehensive care including annual preventive care visits and confidential services (Scudder et al., 2007; Starfield \& Shi, 2004).

Teens who lack access to confidential preventive care and a reliable source of health care services face delays, missed opportunities and fragmentation of services (Berlan \& Bravender, 2009; Dobbs, Bates, \& Dorn, 2011; Dorgan, 2010; English \& Ford, 2007; Jones, Purcell, Singh, \& Finer, 2005; Yu, Bellamy, Schwalberg, \& Drum, 2001). Ultimately these disparities may place teens at higher risk for teen pregnancy, STIs, mental health conditions, substance abuse, and obesity (Ford et al., 1999; Klein et al., 2000).

\section{Disparities Related to Adolescent Health}

The rate of adolescent birth in the United States has steadily declined since 1991 to the lowest rate recorded in 2013 (26.5/1000 15-19 year-olds) (Martin, Hamilton, Oysterman, Curtain, \& Mathews, 2015). Although the rate of teen births (per 1,000 15-19 year olds) has declined overall, disparities exist with rates for Asian or Pacific Islander (API) and non-Hispanic white teens being lowest at 8.7 and 18.6 respectively, compared to the rates of Hispanic (41.7), non-Hispanic Black (39.0) and American Indian or Alaskan Native (AIAN) (31.1) teens (Martin et al., 2015). Teen mothers face numerous other health and social disparities including school failure and chronic poverty (Hoffman, 2006; Perper, Peterson \& Manlove, 2010).

The prevalence of many STIs is disproportionately higher among adolescents (Forhan et al., 2009). Teens represent only $25 \%$ of all those who are sexually active, yet account for $50 \%$ of all STIs diagnoses in the United States (Centers for Disease Control and Prevention [CDC], 2009). Female adolescents, 15 to 19 years-old, have the high rates of chlamydia and gonorrhea, with black and AIAN teens disproportionately affected in comparison to males the same age (CDC, 2009; Centers for Disease Control and Prevention and Indian Health Service, 
2012). Human papillomavirus, the most common STI, is often acquired by individuals during adolescence (CDC, 2009; 2015; Workowski \& Bolan, 2015). Increased prevalence for STIs exists for teens due to numerous biological, access, and behavioral factors (CDC, 2014a; Workowski \& Bolan, 2015). Biological factors, such as cervical ectopy, place adolescent females at greater risk for acquiring chlamydia (CDC, 2014a). Delays in accessing clinical services because of transportation issues, insurance status, cost of services, confidentiality concerns, and lack of adolescent specific services also place adolescents at increased risk for STIs (CDC, 2014a).

Behavioral factors such as inconsistent condom use, unprotected sex with multiple partners, young men having sex with men, intravenous drug use and teens living in juvenile detention facilities place adolescents at increased risk of acquiring a STI (CDC, 2009; 2014a; Workowski \& Bolan, 2015). STIs can result in life-long consequences of chronic disease (from HIV, human papillomavirus and herpes), infertility, chronic pelvic pain, and psychological distress (CDC, 2009). Thirty-three percent of all cases of pelvic inflammatory disease (PID) occur in adolescents (Shrier, 2008). Teens are at greater risk for developing PID than older women because of service and treatment delays, confidentiality concerns, lack of insurance, transportation issues, and difficulty navigating adult health care facilities (CDC, 2010; Workowski et al., 2015).

A large number (29.9\%) of adolescents in high school reported feeling of sad or hopeless daily over a two week period in the previous year (CDC, 2014b). This is of particular concern because depression and anxiety account for the largest single burden of disease worldwide (Mclntyre, 2002). Early diagnosis and treatment are essential to reducing chronic disease and suicide. Female teens (39.1\% versus 20.8\%) and Hispanic teens (female $47.8 \%$, male $25.4 \%$ ) were more likely to report feeling sad or hopeless and to report having seriously contemplated suicide in comparison to their peers (CDC, 2014b). Female teens $(22.4 \%$ versus male $11.6 \%)$, Hispanic females (26\%), and males (11.5\%) were most likely to consider suicide; 
suicide plans were more common among female teens (16.9\% versus $10.3 \%)$ and both Hispanic male (11.2\%) and female (20.1\%) adolescents (CDC, 2014b). During the past year, nearly $8 \%$ of adolescents reported at least one suicide attempt; these students were also more likely to be female ( $10.6 \%$ versus $5.4 \%$ male) and more likely to be Hispanic females (15.6\%) or males (6.9\%). Suicide rates are higher among Native American and Alaskan Native adolescents than any other racial or ethnic group and approach near epidemic levels (Dorgan, 2010). Bullying is a significant concern for $19.6 \%$ students who reported being bullied on school property and $14.8 \%$ reported being bullied electronically (CDC, 2014b). Bullying occurred at the highest rates at both school and electronically among white students (CDC, 2014b).

Alcohol, tobacco and marijuana are the most commonly used substances by teens; $41.1 \%$ of all adolescents report ever smoking a cigarette (CDC, 2014b). Daily smoking of more than ten cigarettes was more common for male (8.6\%) than female (6.3\%) teens (CDC, 2014b). Alcohol use, on at least one occasion, is very common among male and female adolescents with $66.2 \%$ reporting use (CDC, 2012). Hispanic females (75.6\%), Hispanic males (69\%) and 12th graders (male $74.9 \%$ and female $76.3 \%$ ) were most likely to report ever drinking alcohol (CDC, 2014b). Binge drinking (five or more drinks on one occasion) in the past 30 days was reported by $19.6 \% \%$ of female and $22 \%$ of male adolescents (CDC, 2012). Marijuana use (ever) was reported by $39.2 \%$ of females and $42.1 \%$ of males (CDC, $2014 \mathrm{~b}$ ). The use of cocaine (4.5 versus $6.6 \%$ ), ecstasy (5.5 versus $7.6 \%$ ), heroin (1.6\% versus $2.8 \%$ ) and methamphetamines (3 versus 3.4\%), and were all more commonly reported by males. Female teens were more likely to report inhalant use (10\% versus $7.9 \%)$ and use of hallucinogenic drugs (8.8 versus $7.1 \%)(C D C, 2014 b)$. Early diagnosis and treatment are essential to decreasing the rates of chronic use/abuse, drowning, motor vehicle accidents, and poisoning (Grossman, 2000; National Center for Injury Prevention and Control, 2006, Tsai, Anderson, \& Vaca, 2010). 
Poor dietary habits and lack of regular exercise are associated with obesity and the potential consequences of diabetes and heart disease (Reilly et al., 2003). Nationwide, 13.7\% of high school students reported they were obese, an upward trend from 10.6\% since 1999 (CDC, 2012; 2014b). In addition $16.6 \%$ of teens reported being overweight (CDC, 2014b). Obesity was reported among $16.6 \%$ of male and $10.8 \%$ female adolescents with the highest reports among black females (16.7\%) and Hispanic males (19\%) (CDC, 2014b). Nearly half (47.3\%) of teens reported 60 minutes of physical activity on five of the past seven days, males $(57.3 \%)$ were more active than females (37.3\%). However, $15.2 \%$ of adolescents reported that they did not participate in 60 minutes of physical activity once in the past 7 days. The rates of inactivity were highest overall among female teens (19.2\%) versus male teens (11.2\%) (CDC, 2014b).

Despite a national commitment that supports preventive health care services for adolescents, most teens do not receive all aspects of recommended preventive health services and significant disparities continue to persist (Irwin et al., 2009). Social disparities negatively impact access to preventative care and likely contribute to the rates of teen pregnancies, STIs,

obesity, inactivity, substance use/abuse, suicide, and undiagnosed mental illnesses found in this population. Those who are underinsured, uninsured, or encounter costly co-payments are even less likely to receive the recommended health care services. These risks are even higher for more vulnerable teens who face poverty, discrimination due to sexual preference or racial/ethnic background, live in limited resource areas, as well as those, who are homeless, involved in the juvenile justice system, or in foster care.

\section{Relationship to Future Health}

Adolescence is a critical time for shaping healthy lifestyles and identifying risk associated behaviors, and diagnosing medical conditions that can have a significant impact on an adolescent's health now and into adulthood (Yeung et al., 2014). The majority of morbidity and mortality for this group result from risk-taking behaviors and injury, rather than disease or 
chronic illness; accidental injury, homicide and suicide are the leading causes of death for both male and female adolescents (Miniño, 2010). Unhealthy eating and a lack of exercise can result in teens being overweight or obese, increase the likelihood of obesity in adulthood and premature mortality from hypertension, diabetes, stroke, and ischemic heart disease and other conditions including polycystic ovary syndrome and asthma (Freedman et al., 2005; Reilly \& Kelly, 2011). More than $80 \%$ of adult smokers began smoking as adolescents (USDHHS, 2012). Cigarette smoking and tobacco use is associated with a variety of health related consequences including cancer, lung disease, and cardiovascular disease (American Cancer Society, 2014). Unprotected sexual activity can result in STIs and unintended pregnancy. Fifty percent of all STIs in the United States occur among adolescents (CDC, 2009). If untreated, STIs can cause infertility and chronic pelvic pain (CDC, 2014a). In addition, STIs including HIV, herpes simples and hepatitis $B$, are chronic illnesses and although they can be managed to reduce symptoms and maximize health, can cause significant illness in adulthood. Almost 10,000 new cases of HIV were diagnosed in adolescents and young adults 15-24 in 2013 (CDC,

2015a). Mental health issues often emerge during adolescence and may cause chronic mental health issues, social isolation, school failure, and increased risk of substance abuse and suicide (Kessler, Berglund, Demler, Jin, \& Walters, 2005).

\section{Patterns of Preventive Health Care Utilization by Adolescents}

The Maternal and Child Health Bureau, the American Academy of Pediatrics and American Medical Association all recommend annual preventive visits for adolescents (AAP, 2008; Elster \& Kuznets, 1994; Hagen, Shaw \& Duncan, 2008). Various national surveys have examined the trends in well-adolescent preventive visits in the United States and factors that influence access and receipt of recommended care and anticipatory guidance. Much attention has been placed on the benefits of adolescents receiving an annual well-adolescent preventive visit, however the number of adolescents that actually receive this annual visit and recommended preventive counseling remain lower than recommended. 
Adolescent visits accounted for a mere $9.1 \%$ of all health care visits between 1994 and 2003 (Rand et al., 2007). Male and female adolescents have approximately even rates of preventive visits in early adolescence (13\%), however these numbers decrease significantly after age 16 and into late adolescence (6\% male and $3 \%$ female) which is the time associated with increased rates of risk-taking behaviors (Rand et al., 2007). Only 38\% of adolescents received an annual preventive visit in the past 12 months (Irwin et al., 2009). Those teens that were identified as poor (defined as $<200 \%$ federal poverty level) and uninsured in the past year were least likely to have received an annual preventative visit (Irwin et al., 2009).

Tsai, Zhou, Wortley, Shefer, and Stokley (2014) examined time trends in preventive visits by adolescents between 2003 and 2010 via the Commercial Trends and Encounters database. This data base includes insurance claims data of a nationwide sample of employees and their dependents covered by regional health plans and large self-insured employers. The proportion of adolescents (11-21 years) who made at least one preventive visit during the eight years studied increased from $24.6 \%$ in 2003 to $41.1 \%$ in 2010 (Tsai et al., 2014). In 2010, $37.6 \%$ of male and $44.6 \%$ of female adolescents had had a least one preventive visit in the eight year study period (Tsai et al., 2014). Similar to other studies, early adolescents (11-14 years old) were most likely to have received a preventive visit $(50.5 \%)$ in comparison to middle (15-17 year olds, 41.8\%) or late adolescents (18-21 year olds, 30.5\%) (Rand et al., 2007; Tsai et al., 2014). Geographic variations also were found. Teens living in the Northeast were most likely to receive a preventive visit $(61.8 \%)$ compared with teens living in the North Central $41.6 \%$, South $36.4 \%$, and West $35.8 \%$ regions of the United States (Tsai et al., 2014). The mean number of visits during the 8-year study period was 3.6 for males and 3.9 for females; however only $2.4 \%$ had an annual preventive visit (Tsai et al., 2014). Researchers also found that $13.8 \%$ of female and $18.2 \%$ of male adolescents had not had any preventive visits during the previous eight years (Tsai et al., 2014). 
Nordin, Solberg, and Parker (2010) examined preventive versus non-preventive visits among adolescents 11-18 years old and insured by a large health plan in Minnesota between 1998 and 2007. This study also compared rates of preventive and non-preventive visits among those insured by a commercial or governmental/Medicaid plan. Thirty percent of adolescents had no preventive visit in the 8-year study period (Nordin et al., 2010). The mean number of preventive visits for both insurance groups was highest among 12 year olds ( 0.42 commercial, 0.45 governmental) and ranged from 0.15 to 0.26 for commercially insured and 0.20 to 0.28 governmentally insured (Nordin et al., 2010). Similar to Tsai and colleagues (2014) the number of adolescents who had an annual preventive visit each year was very low with $1 \%$ of commercially insured and $2 \%$ of governmentally insured receiving an annual preventive visit (Nordin et al., 2010). Only $40 \%$ of adolescents, despite continuous insurance coverage, had a single preventive visit between the ages of 13 and 17 (Nordin et al., 2010).

Adams, Park, and Irwin (2015) compared rates of preventive visits among adolescents (10-17) across national surveys. Data were collected from three publically available data sources: National Health Interview Survey (CDC, 2011), Medical Expenditure Panel Survey (Agency for Healthcare Research and Quality, 2011), and National Survey of Children's Health (CDC, 2013). All included survey data from 2011 allowing for comparison of rates across surveys. The National Health Interview Survey and Medical Expenditure Panel Survey both used a subjective item from a parent/caregiver face-to-face interview asking if "During the past 12 months, did [alias] receive a well-child check-up, that is a general check-up, when he/she was not sick or injured?" or "During the past 12 months/Since [his/her birth] how many times did [sample child] see a doctor, nurse or other health care provider for preventive medical care such as a physical exam or well-child check-up? (fill in blank with \#)" respectively. The Medical Expenditure Panel Survey also used face-to-face interviews with parent/caregiver and a constructed measure from respondent reports of health care visits for immunizations, well-child visit, or general check-up. 
The results for this study varied greatly between surveys (Adams et al., 2015). Parents/caregivers past-year preventive visit reports ranged from 74.4\% (National Health Interview Survey) to $81.2 \%$ (National Survey of Children's Health) in the face-to-face interviews and $43 \%$ via a constructed measurement from medical visit data collected 2-3 times a year (Medical Expenditure Panel Survey) (Adams et al., 2015). Hispanic teens and those who were uninsured were least likely to take received a preventive visit in the past year (Adams et al., 2015). Female adolescents and those from the highest income group ( $\geq 400$ federal poverty level) were most likely to have received a preventive visit in the past year (Adams et al., 2015).

\section{Anticipatory Guidance and Preventive Counseling}

An important aspect of well-adolescent visits is anticipatory guidance and preventive counseling. The majority of morbidity and mortality during adolescence and adulthood results from high risk behaviors and lifestyle choices made during adolescence. Several studies have examined the amount and types of counseling received by adolescents during health encounters.

Rand, Auinger, Klein, and Weitzman (2005) examined the rate of counseling that occurred at well and acute visits and hypothesized that more counseling was likely to occur if the teen (11-21 years old) was seen by their primary care provider, spent more time with the physician, was known to a practice, and was seen in a private practice. This study found that the amount of counseling that occurred during the visits analyzed was far less than what is recommended by the American Academy of Pediatrics, American Medical Association, and American Academy of Family Physicians. Visits conducted by the adolescent's primary provider were only associated with the teen receiving more dietary counseling (Rand et al., 2005). Teens were more likely to be counseled during well-visits about less sensitive topics including diet/nutrition (28.2\%), exercise (22.9\%), and injury prevention (15.1\%) than to receive counseling regarding HIV/STD transmission (6.2\%), and family planning (10.2\%) (Rand et al., 2005). Counseling regarding diet/nutrition (71.5\%), exercise (51.8\%), HIV/STD transmission 
(14.4\%) and family planning/contraception (23.9\%) all occurred significantly more frequently at acute visits (Rand et al., 2005). Injury prevention (10.2\% versus 15.1\%) and tobacco use/exposure counseling (8.5\% versus $13.3 \%)$ were reported similarly at acute and well visits respectively (Rand et al., 2005). Visits that included counseling were found to be longer than visits that did not include any prevention counseling (Rand et al., 2005).

Irwin and colleagues (2009) examined the rates of anticipatory guidance provided during preventive visits specific to dental visits, eating healthy, exercise, seat belt use, helmet use and second hand smoke. Only $10.3 \%$ of teens (10-17 years old) received anticipatory guidance about all six topics (Irwin et al., 2009). Thirty percent received counseling specific to seat belt use, helmet use and secondhand smoke (Irwin et al., 2009). A greater number of adolescents received counseling related to dental visits (40.3\%), exercise $(40.6 \%)$, and healthy eating $(48.9 \%)$. This study found only $39.5 \%$ of teens (12-17 years old) spent any time alone with their doctor, a time typically devoted to screening and anticipatory guidance related to more sensitive topics including sexual activity, contraception, STIs, mental health concerns and substance use (Irwin et al., 2009). Hispanic teens although most likely to receive counseling in all six areas (13.9; White $9.8 \%$, Black, 10.3\%) were also least likely to spend time alone with their doctor (23.6\%; White 42.8\%, Black 38.9\%). Those from low income families (<200 federal poverty level) were less likely compared to those from higher income (27.6\% versus $47 \%$ ) families to have spent time alone with their clinician at their most recent visit (Irwin et al., 2009).

Akers and colleagues (2014) examined parental reports of preventive counseling that occurred during adolescent health visits. Anonymous surveys were sent to a convenience sample of parents $(n=358)$ who had accompanied their teen to a well visit at a general outpatient pediatric clinic between June and November 2009. The survey consisted of 22preventive health topics derived from national guidelines on adolescent preventive health and were vetted by a group of adolescent providers (Akers et al., 2014). The results revealed that overall parents reported discussion of all health prevention topics was low. Topics considered 
more sensitive, for example sexual orientation (16\%), pregnancy (20\%), condom use/safe sex (20\%) were discussed least often in comparison to more general topics including nutrition (50\%), exercise/sports (47\%) and seat belt/helmet safety $(40 \%)$ that were reported most often by parents (Akers et al., 2014).

In a related study, researchers examined adolescent and parental beliefs about confidentiality, beliefs and health topics discussed during the last preventive visit (Gilbert, Rickert, \& Aalsma, 2014). A secondary analysis was performed of a nationally representative online survey data (December 2012 to January 2013) of teens (13-17 years old, $n=500$ ) and their parents $(n=504)$. Sixteen percent of parents reported that their teen's entire visit was confidential and $30 \%$ reported that part of the visit was confidential. Eighty-eight percent of parents believed that their teen should be able to speak to their clinician alone and $39.6 \%$ felt that their presence during a visit restricted the conversation between the teen and provider. However, most parents (61.2\%) still preferred to be present for the entire visit. Among the visits in which the parent was not present for at least part of the visit, $44.1 \%$ reported that they had voluntarily waited outside, $24.4 \%$ were asked to wait outside by a physician, and $23.3 \%$ by their teen (Gilbert et al., 2014).

Fifty-one percent of teens reported that their last well visit was not confidential, only $10.4 \%$ reported their entire visit was confidential and an additional $35.5 \%$ reported part of the visit was confidential (Gilbert et al., 2014). Almost half (47.6\%) of teens believed the conversation with their provider would have been different if their parent was not in the room. Even among teens that had all or part of their visit without their parent present, almost half (44.5\%) believed that the discussion with their provider would be different if their parent was in the exam room (Gilbert et al., 2014). This study found that a greater number of preventive health topics were discussed when at least part or all the visit was performed confidentiality including nutrition/diet, exercise, issues at school, smoking, drugs and alcohol, sexual health, 
self-image, mental health and coping with stress. Only weight, vaccines and issues at home were unaffected by parental presence (Gilbert et al., 2014).

Parental views on what preventive counseling topics were most important for a health care provider to provide to their adolescents (9-17 years old) was studied by Dempsey, Singer, Clark and Davis (2009). Eighteen topics, from the Bright Futures Guidelines (Green \& Palfrey, 2002) and two items about confidentiality were evaluated by a random sample of parents $(N=$ 2006) via survey. Topics included: diet/nutrition, exercise/sports, physical changes of puberty, drug use, tobacco use, depression/suicide, obesity, sexual transmitted diseases, drinking, eating disorders, pregnancy prevention, relationships, abstinence, safety, violence, school performance, bullying and religion/faith. Parents rated preventive counseling specific to diet/nutrition (75\%), exercise/sports (67\%) and physical changes of puberty $(60 \%)$ highest (Dempsey et al., 2009). Counseling related to more sensitive topics were rated lower by parents: drug use (55\%), tobacco use (52\%), depression/suicide $(51 \%)$, sexual transmitted diseases (49\%), drinking (48\%), eating disorders (48\%), pregnancy prevention (41\%), relationships (36\%), abstinence (35\%), safety (32\%), and violence (28\%) (Dempsey et al., 2009). Gender differences existed related to topics also, parents of female teens were more likely to indicate the importance of anticipatory guidance related to eating disorders. Parents of male adolescents indicated tobacco use, drinking, safety, school performance and bullying were more important in comparison to parents of female adolescents (Dempsey et al., 2009).

Only $24 \%$ of the parents in this study believed that time alone with a provider was very important and almost half (46\%) wanted full disclosure of any confidential information shared with the health care provider to be shared with the parent despite awareness of adolescents' rights regarding confidentiality (Dempsey et al., 2009). Not surprising, parents who thought time alone with a provider was less important also were significantly more likely to desire all information about the visit disclosed (Dempsey et al., 2009). 


\section{Adolescents' Experiences and Preferences with Health Care Services}

Attitudes undoubtedly play an important role in an individual's willingness to participate in health care services. Triandis (1971) defines attitude as "an idea charged with emotion which predisposes a class of actions to a particular class of social interactions" (p.2). Attitudes arise from the combination of "affective, cognitive, and behavioral components that correspond, respectively, to one's evaluation of, knowledge of and predisposition to act toward the object of the attitude" (Wagner, 1969, p.7). Each of these three factors shape an adolescent's view of health care services and can influence future interactions or willingness to participate in preventive care. Negative attitudes can result in missed opportunities for intervention and the potential consequences of untreated health and mental health concerns.

An important aspect of the development and maintenance of adolescent-friendly health services is the involvement of the opinions in both the planning and evaluation of services. The World Health Organization (Mclntyre, 2002) emphasized the need to involve youth in planning and monitoring activities so that providers

Can be confident they are providing services in the right place, at the right time and in the right style. The involvement of adolescents in planning and monitoring delivers on their right to have their views heard. It also increases the confidence that other young people place in those services (Mclntyre, 2002, p. 29).

Several studies have focused on the opinions of adolescents related to their experience with preventive health care services. This section reviews the existing research on adolescents' experiences, satisfaction with, and preferences for health care services and provider interactions. No literature was located that addressed the perspectives of NPs related to the care of adolescents in SBHCs or primary care settings.

Fox, Philliber, McManus, and Yurkiewicz (2010) conducted a focus group study and follow-up surveys with disadvantaged adolescents from Chicago, Los Angeles, Miami, and the District of Columbia. ( $N=204$, ages 14 to 20$)$. This study explored adolescents' experiences 
and views on health care services. They were asked about health issues experienced by teens, their experiences receiving care, and then were charged with designing an ideal model of adolescent health care. These teens identified STIs, drugs and alcohol, teen pregnancy, peer pressure, violence, mental health concerns, obesity, poverty, homelessness, and the economy as the most important problems that either directly or indirectly impact health of teens (Fox et al., 2010). Health insurance and affordability of services were identified as important influences on access to care with a lack of insurance or costly co-payments contributing to missed opportunities to receive needed care (Fox et al., 2010). Adolescents identified various sources from which they received health care services including doctor's office, family planning, mental health, community and hospital clinics, school nurse, substance abuse programs, and the emergency room. The majority of the teens reported using different sites for different reasons (Fox et al., 2010). Although $60 \%$ of adolescents reported their doctor's office as their source of sick care they did not receive drug and alcohol counseling (83\%), mental health care (62\%), health education (60\%), or sexual health care (55\%) from this site (Fox et al., 2010). Most felt receiving care from multiple sites was a not ideal. However, they also expressed concerns about confidentiality and the distance they may need to travel to access services if they were all combined in a single health care agency (Fox et al., 2010).

The majority of teens reported negative health care experiences that were attributed to difficulty making appointments, long waits, and providers that were "too busy" (Fox et al., 2010, p. 5). Very few adolescents reported that their health care provider spent enough time with them $(14 \%)$ and $16 \%$ reported that their provider "never" spent enough time addressing their needs during a health care visit. Ideal services were described as those that were centrally located and easy to access by public transportation, near their home or school. Visits would best meet their needs if they were available both by appointment and on a walk-in basis. The teens described the importance of providers and clinic staff being friendly, knowledgeable, and caring (Fox et al., 2010). Nearly all of the teens thought having "everything under one roof" (Fox 
et al., 2010, p. 9) including reproductive and mental health services was ideal. Most of the teens also reported that this ideal model should include substance abuse services, drug testing, and rehabilitation services. Half of the teens included physical examinations and health and wellness services targeting nutrition and exercise (Fox et al., 2010). Some of the groups also discussed the inclusion of pharmacy, dental, laboratory, vision, and social services. Overall, the teens expressed that this "ideal" adolescent health care service model was likely to assist them in meeting their health care needs (Fox et al., 2010).

Adolescents' perceptions of the barriers to receiving health care were examined by Lim, Chhabra, Rosen, Racine, and Alderman (2012). Analysis of data from six focus groups that included 31 adolescents, 11-21 years old, revealed that most adolescents had difficulty making appointments and typically were told that the next available appointment was four or more weeks away. Teens complained that even when they had a scheduled appointment, wait times were excessive and was identified this as a significant factor that deterred them from seeking care (Lim et al., 2012). Teens were also unaware about their rights to receive confidential care related to drug use, pregnancy concerns, and STIs without parental consent or knowledge. Mental health issues were also rarely discussed, including feeling depressed or suicidal ideation by teens because they felt providers had little interest in these concerns and also limited knowledge (Lim et a., 2012). However, these teens were comfortable discussing mental health concerns with mental health professionals (Lim et al., 2012). Most expressed, with some exceptions of those teens that knew their provider well, that they did not trust their provider to keep sensitive information from their parent/guardian (Lim et al., 2012).

Coker et al. (2010) examined the perspectives of adolescents and their parents on ways to improve preventive health services. Seventy-seven publicly insured adolescents, ages 13-17, and 21 parents participated in a focus-group study. Adolescents identified provider level improvements included timeliness, confidentiality, reduced waiting times, and increased time spent with their clinician as important aspects of care (Coker et al., 2010). The teens described 
their encounters for physical examinations in great detail, however described little about adolescent-clinician communication or discussions regarding health related issues (Coker et al., 2010). Teens reported a lack of knowledge regarding the importance of preventive visits because they believed their bodies were healthy. The most important factor that encouraged the use of preventive care was a "good, continuous relationship with a clinician who respects their time and confidentiality" (Coker et al., 2010, p. 136). Parents echoed the opinions of the adolescents. The teens also identified the use of incentives, such as movie tickets, cash, and gift cards as a mechanism to encourage preventive visits. Parents also suggested reminder calls or letters, extended hours, and decreased time waiting for an appointment as important factors (Coker et al., 2010). Finally, the teens identified confidential conversations with a provider with whom they had a relationship with as an effective strategy to encourage private discussions about sensitive topics (Coker et al., 2010).

Sexual minority youth (lesbian, gay, bisexual, transgender and questioning youth [LGBTQ]) offered guidance to health care providers regarding what factors make them trust and feel safe with clinicians and health care agencies (Ginsburg et al., 2002b). This study used a mixed methods qualitative-quantitative design with surveys and focus groups. The adolescents $(N=94,14-23$ years old, $63 \%$ male) described many of the same concerns as all adolescents as their top priorities: confidentiality, respect, and honesty in their interactions with providers as well as clinicians who are well educated and paid attention to cleanliness of both the site and instruments. Other important aspects of care included not talking down to teens, listening, addressing fears, professionalism, and sensitivity (Ginsburg et al., 2002b). Several factors also related to LGBTQ teens specifically and included being nonjudgmental, not assuming teens have HIV or engage in risky behaviors, being clinicians educated about the gay lifestyle, and same-sex partner needs (Ginsburg et al., 2002b). Site-specific characteristics that enhanced teens' willingness to engage in services included a discreet staff, a choice of a male or female provider, staff diversity, and safe location within the community (Ginsburg et al., 2002b). Focus 
group results $(N=41)$ revealed that LGBTQ youth felt "they had the same basic needs as all youth and that meeting those needs was a prerequisite to meeting any special needs" (Ginsburg et al., 2002b, p. 410) and echoed the priorities reported in the surveys. The teens expressed strong concerns regarding being labeled by providers (Ginsburg et al., 2002b).

Ginsburg and colleagues (2002a) identified the health care provider characteristics important to urban ninth graders. These researchers used a quantitative survey to explore the perspectives of 2602 students in Philadelphia, Pennsylvania. These teens indicated that they desired a strong relationship with a provider, feeling physically and emotionally safe and the availability to turn to the provider for counseling as most important. In addition, provider honesty was considered a prerequisite to the development of a relationship (Ginsburg et al., 2002a).

Rosenfeld et al. (1996) explored the experiences, opinions and preferences of adolescents receiving primary care services through a focus group study with 20 urban adolescents. The teens in this study overwhelmingly reported being treated with dignity and respect, being listened to, having their concerns taken seriously as important aspects to the care they receive in primary care. The researchers emphasized that the delivery of care that is respectful, compassionate, and responsive to the needs of this population would increase the likelihood of teens revealing sensitive issues such as depression, sexual orientation, suicidal ideation, substance abuse, physical, sexual and emotional abuse to their doctor (Rosenfeld et al., 1996).

Schaeuble, Haglund, and Vukovich (2010) conducted a mixed methods study to describe how adolescents preferred to be treated in an outpatient clinical setting. In the first phase, 24 teens participated in focus groups discussions. The second phase consisted of an 82-item survey initially developed to evaluate the healthcare preferences of teens with chronic illness. The results of this study revealed four themes that described the adolescents' preferences related to health care services: forming a relationship, supporting independence, assuring confidentiality, and conveying caring (Schaeuble et al., 2010). This study highlights 
the importance adolescents place on positive health care interactions with their health care provider (Schaeuble et al., 2010).

\section{Initiatives to Improve the Health of Adolescents}

School health has been a priority since the beginning of public school education in the 1890 s as a mechanism to improve the health of children; initial efforts focused on the identification and prevention of infectious diseases, such as smallpox (Kort, 1984). This focus resulted in sick children being excluded from school until they received treatment or were determined to be healthy; many of these children, especially the poor, never returned to school because of lack of access to health care services (Kort, 1984). The Title I of Elementary and Secondary School Act of 1966 provided federal funding for the expansion of school health to disadvantaged populations because of the link between health and learning (Kort, 1984). In addition, amendments to Title 19 and the Social Security Act authorized early periodic screening, detection and treatment to facilitate the provision of physical examinations, well-child supervision, immunizations, and dental care to children and adolescents. School-based health

programs resulted from this federal funding. Further expansion of school-based health programs was facilitated by the Robert Wood Johnson Foundation in the 1970 s. Today nearly 2,000 SBHCs are operating across the United States and $82.7 \%$ provide primary care and mental health services to adolescents (Lofink et al., 2013).

In 1989, the U.S. Preventative Services Task Force (USPSTF) was convened by the U.S. Department of Health and Human Services, Office of Disease Prevention and Health Promotion to provide recommendations related to periodic health examination and to address the specific health risks associated with adolescence. Since 1998, the Agency for Health Care Research has sponsored the USPSTF and provides evidence-based guidelines for preventative health care in the United States (Rosen \& Neinstein, 2008). Several professional organizations have also provided recommendations regarding the care of children and adolescents, including the Guidelines for Adolescent Preventative Services (GAPS) (Elster \& Kuznets, 1994), Bright 
Futures (Green, 1994; Green \& Palfrey, 2002; Hagan et al., 2008), American Academy of Pediatrics (2008), and the Society of Health and Medicine (Morreale, Kapphahan, Elster, Juszczak, \& Klein, 2004; Rosen et al., 1997). The recommendations established by each of these groups are consistent and aim to increase health promotion and disease prevention among adolescents (Rosen \& Neinstein, 2008).

The Healthy People agenda began in 1990 as a national call to action for improving health and achieving health equity via measurable targets (Healthy People 2000, n.d.). Mortality, unintentional injury, violence, mental health and substance abuse, reproductive health, and prevention of adult chronic disease were targeted in Healthy People 2010 (USDHHS, 2000). Outcomes demonstrated positive gains in only two of the 21 objectives: seat belt use and fighting (Jiang, Kolbe, Seo, Kay, \& Brindis, 2011). Improvements were shown in teen pregnancy, tobacco, marijuana, and safety belt use, although all fell short of the desired targets (Jiang et al., 2011). No change was witnessed in the amount of physical activity adolescents engaged in and the obesity rates among teens increased (Jiang et al., 2011). Variability in outcomes was noted in geographic location, gender and ethnic/racial groups (Jiang et al., 2011). Data remain limited for teens considered high risk for negative health outcomes because of poverty, pregnancy, homelessness, incarceration, chronic illness or foster care. Healthy People 2020, added adolescent health as a distinct topic area for the first time and includes a target addressing annual wellness visits for adolescents (USDHHS, 2011a; b). Twenty-five percent of all the Healthy People 2020 objectives are relevant to the adolescent/young adults and provide a national agenda to reduce and eliminate health disparities (USDHHS, 2011a).

In 2002, The World Health Organization (WHO) published Adolescent Friendly Health Services: An Agenda for Change, to address the importance of an integrated approach to health care services for adolescents worldwide to assist them "to stay healthy and complete their journey to adulthood" (McIntyre, 2002, p. 3) and called for a united approach to delivering health 
care services to adolescents. This document not only defined what essential services were needed by adolescents but also identified how to meet the needs of this population by providing adolescent friendly services from a global perspective. WHO defined the gold standard for adolescent friendly health services as those that are "effective, safe and affordable, they meet the individual needs of young people who return when they need to and recommend these services to friends" (McIntyre, 2002, p. 25). In a subsequent document, Making Health Services Adolescent Friendly, WHO defined the components of adolescent-friendly services as described by the Quality of Care Framework (WHO, 2009; 2012). Adolescent-friendly health services are those that are:

Accessible. Adolescents are able to obtain the health services that are available. Acceptable. Adolescents are willing to obtain the health services that are available. Equitable. All adolescents, not just selected groups, are able to obtain the health services that are available.

Appropriate. The right health services (i.e. the ones they need) are provided to them. Effective. The right health services are provided in the right way, and make a positive contribution to their health. (WHO, 2012, p. 7-8).

These documents are intended to provide guidance for nations (WHO, 2009; 2012) to "standardize and scale up the coverage of quality health services to adolescents" (WHO, 2012, p. 5).

In 2006, the Committee on Adolescent Health Care Services and Models of Care for the Treatment, Prevention and Health Development was convened by the National Research Council (NRC), the Institute of Medicine (IOM) via the NRC/IOM Board on Children, Youth, and Families to study the provision of adolescent health care services in the United States and ultimately develop policy and research recommendations (NRC/IOM, 2009). Recommendations from this study were intended to "highlight critical health care needs, promising models of health 
services, and components of care that could strengthen and improve health services for adolescents and contribute to healthy adolescent development" (NRC/IOM, 2009, p. 2).

Adolescent Health: Think, Act, Grow is the newest national agenda from the Office of Adolescent Health. It represents a call to action for health care providers as well as any individuals and organizations that work with the nation's adolescents to support healthy adolescent development, improve health, reduce risky behaviors, improve engagement, and assist adolescents to transition successfully to adulthood (U.S. Department of Health and Human Services, Office of Adolescent Health, 2015).

Federal and state health law also focuses on the provision of health related services and confidentiality related to health services for adolescents. In the past several decades, legal support has grown specific to adolescent health services. All states have specific statutes that allow teens to provide consent for some health services under specific circumstances, however great variability exists from state to state (English et al., 2010). Even if a state allows a teen to consent for services, such as contraception, mental health, abortion or STI screening, these statutes do not guarantee access for teens without the financial resources or insurance coverage for these services (English, et al., 2010).

\section{School-Based Health Centers}

School-based health centers (SBHCs) have been identified as an adolescent-friendly community resource for comprehensive primary and mental health services for adolescents (Strozer et al., 2010). The Institute of Medicine report Adolescent Health Services: Missing Opportunities (NRC/IOM, 2009) identified SBHCs as an important component of the safety net services available to adolescents. These safety net agencies have two distinguishable and important characteristics: they provide services to everyone, regardless of their ability to pay, and a significant proportion of the patients they serve are uninsured, receive Medicaid or are vulnerable in other ways, and thus remove significant barriers to care (NRC/IOM, 2009). Most SBHCs (82.7\%) serve at least one grade of adolescents (NRC/IOM, 2009) and these services 
provide the opportunity to improve equity and outcomes through increase access and use of developmentally appropriate services (NRC/IOM, 2009).

\section{Characteristics of SBHCs}

SBHCs provide health and mental health services for many teens across the country. There are currently 1,930 SBHCs in 46 states, the District of Columbia, and the U.S. territories of Puerto Rico, Marshall Islands, and the Virgin Islands (Lofink et al., 2013). Half (54.2\%) are in urban areas and the rest are in rural (27.8\%), and suburban (18\%) locations (Lofink et al., 2013). Most SBHCs are in traditional school settings (81.3\%), however a growing number are in community (8.3\%), alternative (7.9\%) and charter schools (5.9\%) (Lofink et al., 2013). SBHCs are commonly sponsored by community health organizations such as hospitals (26.4\%), community health centers (33.4\%), or local health departments (13.3\%) and are located most often within the school building (94.4\%) or within close proximity to the school (Gustafson, 2005; Keeton, et al., 2012; Lofink et al., 2013).

\section{SBHC Models}

Three different SBHC staffing models currently exist. The first is a Primary Care Model and is staffed only by a primary care provider (NP, physician assistant, or physician). This model only provides primary care services. The second model, Primary Care \& Mental Health provides both primary care and mental health services. The staffing for this model includes a primary care provider who works in collaboration with a mental health professional (e.g. licensed clinical social worker, psychologist or substance abuse counselor). The final model, the most common and most comprehensive, is the Primary Care \& Mental Health Plus Model. This model includes a primary care provider, mental health professional and other complementary members of the health care team including health educators, dental health professional, social service case manager and/or nutritionist (Lofink et al., 2013). 


\section{Health and Mental Health Services Available in SBHCs}

SBHC services typically include physical examinations, immunizations, evaluation and management of acute and chronic illnesses, reproductive health services (pregnancy tests, screening and treatment for STIs and HIV, and in some condoms and contraception), individual and group mental health counseling, substance use/abuse screening, and referral (Lofink et al., 2013; Strozer et al., 2010). Health and mental health services are available to all students who attend the school through a signed parental consent (Gustafson, 2005; Strozer et al., 2010). Teens may access some or all of the services available and access is not usually contingent on insurance status or ability to pay for services (Strozer et al., 2010). For many adolescents, especially those who are uninsured, underinsured, or live in limited resource areas, SBHCs may be their only source of health and mental health care. This model of care allows teens access to services while they are in school, allows ready access to necessary follow-up, and affords teens with the opportunity to assume a more independent role in health care services by making their own appointments, communicating with the SBHC staff, and ultimately learning to become an active participant in their health care services (Daley, 2011; Ginsburg et al., 2002a).

\section{SBHC Effectiveness}

SBHCs have demonstrated their effectiveness by increasing health and mental health care access (Britto et al., 2001; Slade, 2002), increasing health knowledge (Culligan, 2002; Kisker \& Brown, 1996), decreasing unnecessary emergency room visits (Anderson et al., 2004; Key et al., 2002), and providing successful programs targeted at common sources of morbidity and mortality such as asthma, obesity, teen pregnancy, depression, and STIs (Amin \& Sato, 2004; Ethier et al., 2011; Guo et al., 2005; Keeton et al., 2012; Lurie et al., 2001; Mansour, Rise, Toole, Luzader \& Atherton, 2008; McNall et al., 2010; Webber et al., 2005; Webber et al., 2003; Zimmer-Gembeck et al., 2001). Impressive outcomes have also been identified related to the use and continuation of contraception, STI screening, absenteeism and hospitalization from asthma, immunization rates, and the early and continued use of mental health services (Allison 
et al., 2007; Amin \& Sato, 2004; Ethier et al., 2011; Guo et al., 2005; Lurie et al., 2001; Mansour et al., 2008; McNall et al., 2010; Minguez, Santelli, Gibson, Orr, \& Samant, 2015; Van Cura, 2010; Webber et al., 2005; Webber et al., 2003; Zimmer-Gembeck et al., 2001). However the services available in SBHCs, vary greatly from state to state and even within communities.

In a recent study, Gibson, Santelli, Minguez, Lord, and Schuyler (2013) examined the role of SBHCs in improving access to comprehensive health care services and improved quality of care. Data from two different high schools, one with and one without a SBHC were compared. The researchers found that students in the school with the SBHC were more likely to report having a regular provider (Gibson et al., 2013). A steady increase in the number of students that used the SBHC was shown from $10 \%$ of $9^{\text {th }}$ graders to $40 \%$ of $12^{\text {th }}$ graders (Gibson et al., 2013). SBHC users were more likely to report a greater awareness of confidentiality related to services (users $73 \%$, nonusers $54 \%$, no SBHC $42 \%$ ) and having had a checkup in the past year compared to nonusers (Gibson et al., 2013). Students in the SBHC school reported more often that during their last physical exam the health care provider had respect for their health concerns, explained things in a manner they could understand, and spent enough time with them during the visit (Gibson et al., 2014). SBHC users were also more likely to report discussions with their health care provider about family, school, emotions, future plans, diet, exercise, weight issues, sex, birth control, smoking, alcohol, and marijuana (Gibson, 2013). Finally, students attending the school with a SBHC reported greater willingness to use the clinic for reproductive, emotional or psychological concerns and for physical examinations or check-ups (Gibson, 2013). SBHC users were more likely to endorse having a SBHC in their school (95\% users, 85\% nonusers, 69\% non-SBHC school); the level of endorsement increased by grade $\left(71 \% 9^{\text {th }}\right.$ graders, $95 \% 12^{\text {th }}$ graders $)$ and likely reflects increasing familiarity with their SBHC (Gibson et al., 2013). 


\section{Access Barriers for Adolescents in SBHCs}

Despite the many positive aspects of SBHCs and their potential ability to lessen the impact of social and health disparities faced by teens, many still encounter barriers to accessing SBHC services. State health laws and the local policies of communities and school districts can impede access to many types of services. In the mid-1950s, states enacted statutes to allow teens to consent for care under specific circumstances. Since that time, every state has enacted health laws specific to adolescents either based on the minor's status or the type of care they are seeking (English et al., 2010). Additional variations to these laws is common and may include specific requirements to involve a parent, an age limit, types of health care providers or agencies that can provide a service, or financial responsibility (English et al., 2010). Many health care services can be provided by a health care provider, without parental consent, if the type of care sought by the teen is considered "within the mainstream of medical opinion, is not high risk, and is provided in a non-negligent manner, as long as the minor is an older adolescent who is capable of giving informed consent to the care and does consent" (English et al., 2010, p. 3). Emancipated minors are also allowed to consent for themselves in all states (English et al., 2010). All states have specific statutes that address emergency care, general medical care, contraception, pregnancy-related care, abortion, sexually transmitted infections, HIV/AIDS, reportable diseases, substance/alcohol care, and mental health related services. However, there is much variation from state to state in these statutes and access to services for adolescents without parental involvement. Many SBHCs face additional restrictions on services by funding, school districts, sponsors, health centers, and associated agencies (Lofink et al., 2013; Strozer et al., 2010). These restrictions, similar to state statues, often limit access to reproductive services including condoms and contraception. If these are available to teens, typically the inclusion of these services was negotiated during the planning phase of the SBHC (Lofink et al., 2013). Currently, $49.8 \%$ of SBHC serving adolescents are restricted from providing contraception onsite (Lofink et al., 2013). Other reproductive services are available 
less often than primary care and mental health services. Only $69.4 \%$ provide diagnosis and treatment of STIs-despite statutes in every state that allow teens to consent for testing and treatment (English et al., 2010), 64.5\% provide contraceptive counseling, 52.4\% follow-up services for contraception, 55.1\% HIV testing, 72.4\% sexual orientation education, and counseling, 62\% gynecological examinations, and 81.2\% pregnancy testing (Lofink et al., 2013). Access to mental health professionals is not available in $25 \%$ of SBHCs (Strozer et al., 2010). Barriers to HIV testing were identified by SBHC clinicians and administrators as cost (22.7\%), specimen transportation (21.1\%), and policies and procedures that prohibit testing (19.4\%) (Lofink et al., 2013). Half of SBHCs (53.2\%) offer substance abuse counseling (Lofink et al., 2013). Most SBHCs (90.1\%) report the availability of counseling related healthy eating, active living and weight management and management of chronic illnesses (89.6\%) including asthma and diabetes (Lofink et al., 2013).

Limitations on the services that adolescents can access confidentially are all too common and unfortunately are often directly related to the most common social and health determinates that affect adolescents. These layers of statutes and local policies cause inequities in the health care services available to for adolescents especially for those who have limited alternatives because of lack of alternative resources, financial limitations or insurance instability. For teens that have insurance, the limitations on SBHC services may not be an issue because they can access other community resources which may be able to fulfill their health needs. However, this does not guarantee these services are adolescent-friendly. They may be locations that are difficult to get to, have limited appointments at times convenient for teens, or have systems that involve multiple steps that are difficult to navigate. In addition, teens may be reluctant to be "seen" in community health care agencies for fear they will be discovered by family members or friends and their confidentiality jeopardized. For some, the cost of copays associated with health care encounters may present a financial barrier that does not typically exist in SBHCs. Adolescents who do not have insurance face an additional challenge-the free 
care provided by the SBHC may be their only option and limitations on available services certainly can increase the potential disparities they encounter.

\section{Nurse Practitioners}

NPs provide high quality care to diverse and often underserved populations across the United States. A 2002 systematic review focused on whether care provided by NPs was equivalent to that of physicians in primary care and found that NPs provide quality health care services that are at least as good, if not better, than physicians (Horrocks, Anderson \& Salisbury, 2002). More recently, Stanik-Hutt and colleagues' (2013) systematic review also found similar results: NPs provide high quality, safe, and effective care to children and adults across settings.

NPs have been instrumental in the growth and expansion of school-based health across the country since their inception and are most often the primary care provider in SBHCs (Keeton et al., 2012). Only one study was found that described patient satisfaction with care provided by NPs in SBHCs (Benkert et al., 2007). Benkert and colleagues (2007) explored patient satisfaction $(N=190)$ with SBHC services among 6th to 8th grade male $(44.1 \%)$ and female (55.9\%) adolescents receiving care in nurse-managed SBHC. The reported overall satisfaction with care was very high for first time and repeat users of care and both male and female teens. Being treated with respect, listened to, and the NP explaining aspects of care received the highest scores. These findings are similar to satisfaction scores reported by adult patients receiving care from NPs (Benkert et al., 2002; Mundinger et al., 2000). The satisfaction scores or 6th and 7th graders were higher overall than those of 8th graders (Benkert et al., 2007). The researchers postulate that this result may be a result of an increased ability to critically evaluate services, increased honestly or the greater analytical ability of older adolescents (Benkert et al., 2007). The decrease in satisfaction scores many also contribute to the decrease in participation in preventive services in middle and late adolescence. 


\section{Summary}

SBHCs have been identified as an important aspect of preventive health care services for adolescents across the United States especially for those who are at risk of not receiving recommended care because of a variety of health and social disparities. Despite a national agenda that supports preventive care for adolescents, drastic declines in the receipt of these services is found after early adolescence and into young adulthood. Preventive services are important for this population because much of the morbidity and mortality that occurs during adolescence is directly related to risk-taking behaviors and injuries rather than illness and chronic disease. The preventive visit provides the opportunity for the screening, early detection, and intervention related to risk-taking behaviors and injuries as well as early detection of health issues that can have a direct impact on health in adulthood. Currently, no research exists on what NPs, who provide the majority of care to adolescents in SBHCs, or the adolescents who are the consumers of SBHC services view as essential to their care experience. It is hoped that this research, grounded in complex adaptive systems theory, will allow services to be more specifically adapt to the unique needs of adolescents accessing SBHC services and assist in greater engagement for adolescents in preventive services throughout adolescence.

Chapter III provides a description of the research design for this explanatory sequential mixed methods study. The methods used for the Delphi technique, focus group study, and finally mixing of the data from each of the strands are presented in detail. 


\section{CHAPTER III}

\section{RESEARCH DESIGN AND METHODS}

The current study was designed to capture the perspectives of NPs and adolescents regarding the elements of adolescent-friendly care in school-based health centers. An explanatory sequential mixed methods design was conducted to capture these perspectives. The first strand was accomplished by a Delphi technique with an expert panel of NPs. The second strand was a focus group study with adolescents from six different high schools. The final phase mixed the data generated from the two strands of the study. The research design and methods follow.

\section{Research Design}

Mixed methods research has become an increasingly popular and accepted approach for exploring diverse research questions. Creswell and Plano-Clark (2011) define mixed methods research as a combination of quantitative and qualitative methods, a philosophy, and a research design orientation. Pragmatism provided the research paradigm for this mixed methods study and allowed the research questions to drive the study design and methods (Creswell \& Plano-Clark, 2011). Six key components are required for designing and conducting mixed methods studies. First, the researcher frames the study's procedures within the appropriate theoretical and philosophical lenses and then identifies a specific research design to direct the mixed methods study. Third the researcher identifies which strand(s) or phase(s) of the research will be prioritized in the study. Appropriate quantitative and qualitative data are collected to answer the research questions (components four and five) and then finally the researcher mixes and interprets the data from the two strands of the study.

This explanatory sequential mixed methods study was designed to identify and understand the essential elements necessary for providing adolescent-friendly care to teens accessing SBHCs for their health care from the perspectives of expert NPs and teens (Creswell \& Plano-Clark, 2011). The quantitative data were collected first and then were analyzed. In the 
second, qualitative strand, the researcher sought to explain the quantitative findings from the first strand (Creswell \& Plano-Clark, 2011). The data from the second strand provide greater insights about the research questions and explain the results of the quantitative strand (Creswell \& Plano-Clark, 2011). A more robust analysis results from the combination of the quantitative and qualitative components of the mixed methods design and allows the researcher to optimize the depth and breadth of understanding about adolescent-friendly care in SBHCs (Glogowska, 2011; O'Caithlin, 2010).

The first strand of this explanatory sequential mixed methods study consisted of a Delphi technique that generated consensus from an expert panel of NPs regarding the essential elements of adolescent-friendly care regarding the essential elements of adolescent-friendly care in SBHCs (quan) (Creswell \& Plano-Clark, 2011; Morse, 1991; 2003). The second strand was accomplished through a focus group study (QUAL) with adolescents and explained the results of the first strand in greater depth. The qualitative aspect was the dominant strand of the study. The results of each phase were then compared and contrasted to determine "what works" for preventive care for adolescents in SBHCs (Creswell \& Plano-Clark, 2011, p.41). The following research questions guided each phase of the study:

1. What are the essential elements of providing adolescent-friendly care to teens in SBHCs? (Quantitative)

2. What is the teen perspective on the essential elements of adolescent-friendly services specific to SBHCs? (Qualitative)

3. How do the perspectives of NPs and teens compare regarding the essential elements of adolescent-friendly care in SBHCs? (Quantitative and Qualitative)

Figure 1 provides a procedural diagram of this study. Institutional Review Board Approval from the University of Connecticut was granted in December 2013 for this study. 


\section{Strand}

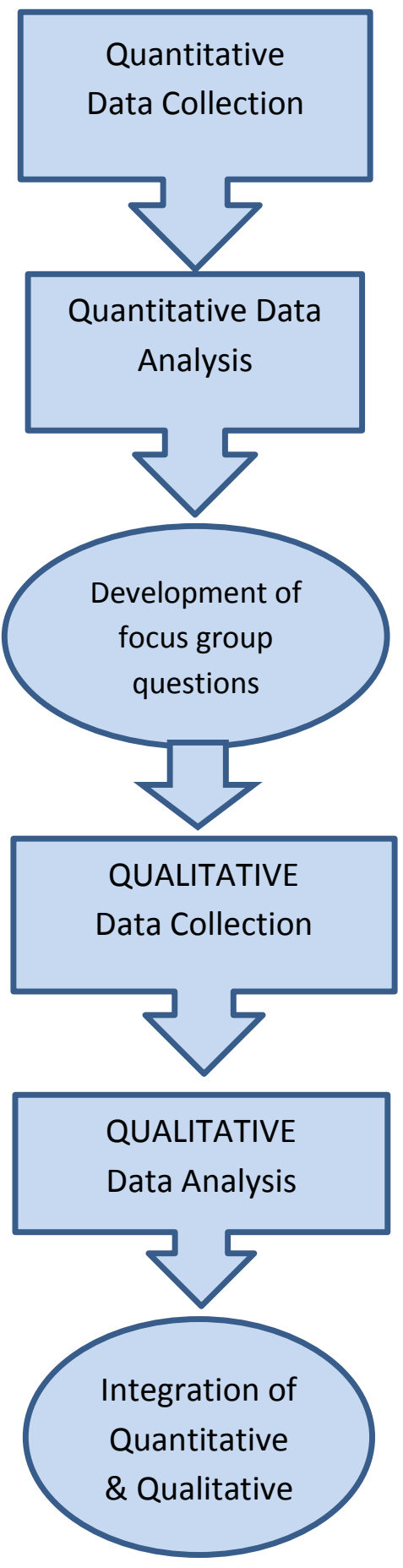

\section{Procedure}

What are the essential elements of providing adolescentfriendly care to teens in SBHCs?

Delphi method

SBHC NPs $(N=20)$

Open-ended question

Round 1: Qualitative Round

Round 2: Structured questionnaires; 5-point Likert scale Round 3: Structured questionnaire; 5-point Likert scale Round 4: Structured questionnaire; 5-point Likert scale

What is the teen perspective on the essential elements of adolescent-friendly services specific to SBHCs?

List of essential elements of adolescent-friendly care from expert panel of NPs working in SBHC used to develop questions for focus groups with teens Mock focus group, revise based on feedback

Recruitment Consent/Assent

Focus Groups with teens in SBHCs $(N=48)$

(Krueger\& Casey, 2008)

6 groups, 6-8 teens per group (1 male/female group for each age group 13-14, 15-17, 18-19)

Content Analysis (Krippendorff, 2013)

How do the perspectives of NPs and teens compare regarding the essential elements of adolescent-friendly care in SBHCs?

Interpretation and explanation of the quantitative and qualitative results

\section{Product}

Consensus from the experts regarding the essential elements for providing care for teens in SBHCs

Themes

Summary statistics descriptive/frequencies Consensus (.75+) List of essential elements of adolescent-friendly care

Focus group questioning route

Audio-recordings

Transcripts

Themes, relationships between or among ideas/concepts; patterns in the data

Discussion Implications Future research

Figure 1. The Essential Elements of Adolescent-friendly Care in SBHCs Mixed Methods Study Procedural Diagram 
There are many examples in the nursing literature of explanatory sequential mixed methods designs (Carter et al., 2012; Halcomb et al., 2008; Mark et al., 2010; Theuissen et al., 2012). None were found that were related to the proposed study. To better understand the potential challenges of this research design, the limitation sections of each quantitative and qualitative strand were carefully considered in the planning of this study.

\section{Phase I: Delphi Study (Quantitative Phase)}

A Delphi study design was used in Phase I of this mixed methods study to identify the essential elements of adolescent-friendly care from an expert panel of NPs providing care to teens in SBHCs. The Delphi method is a multistage survey used to achieve confidential expert consensus on an issue (Keeney, Hasson \& McKenna, 2011; McKenna, 1994).

Recruitment and sample. A homogeneous sample of experts working with teens in SBHCs from the Northeastern Region of the United States was identified and asked to participate in the study (Skulmoski, Hartman, \& Krahn, 2007). Inclusion criteria included national certification as a NP, a minimum of 3 years of experience providing health care in a $\mathrm{SBHC}$ with teens, national recognition as an expert in this area as evidenced by publication in a peer-reviewed journal, national presentation, the designation as a clinical expert through their professional organization, or other expert designation (e.g. years of experience, awards, experience educating NP students), and willingness to participate and commit to participation in all rounds included in the Delphi (Hallowell \& Gambatese, 2010; Skulmoski et al., 2007). Experts were recruited through two professional organizations: National Association of Pediatric Nurse Practitioners and National Assembly on School-Based Health Care through both personal contacts via either telephone or email and general listserv announcements seeking panelists. Identified experts were also asked to recommend other NPs who fit the inclusion criteria.

Interested NPs were initially contacted by the researcher either in person, by phone, or email. The purpose of the study, method, and time commitment to completing all rounds of the Delphi were explained to potential participants (Appendix A). Those that agreed to participate 
were sent, via email or mail, a cover letter (Appendix B), consent form (Appendix C), and demographic questionnaire (Appendix D) to complete and return to the researcher. Only those who met the inclusion criteria were invited to participate. The cover letter included a brief description of the study and Delphi process, an estimate of the anticipated time commitment, and researcher's contact information (Keeney et al., 2011). Once all the experts consented, a 3-digit identification number was assigned to each expert by the researcher to allow responses to each round to be linked and to protect the identities of participants from the other panelists. Recruitment continued until the desired sample of experts was reached and each had returned their consent and demographic questionnaire, and the researcher confirmed eligibility to participate. Participants were asked to return their forms to the researcher either by United States Postal Service or were given the option to return their forms via email attachment. Replacement postage was provided to participants who returned their forms via United States Postal Service. Twenty-two NPs returned their forms to the researcher. One NP was eliminated because she practiced outside the study region. She was contacted and forms returned to her by the researcher. Twenty-one NPs, one more than the approved sample, returned the consent and demographic forms. The last two NPs forms arrived via United States Postal Service on the same day. A protocol deviation was filed with the IRB because the recruitment had exceeded the approved sample size for the study.

Delphi technique data collection and analysis. Enrolled participants were sent a letter explaining the first round of the study (Appendix E) and the Round 1 Questionnaire (Appendix F). The first round of a Delphi technique began with an open ended question: "What are the essential elements to providing adolescent-friendly care in SBHCs?" and participants were asked to identify a minimum of five essential elements of adolescent-friendly care and return their questionnaire to the researcher. The experts were asked to complete the Round 1 Questionnaire and return it to the researcher within two weeks either by United States Postal Service or email attachment. A follow-up email sent to each participant one week later 
(Appendix G) to confirm receipt of the questionnaire and also to provide the NP a reminder of requested return date. If the questionnaire was not returned by the due date, a reminder was sent on the due date to each panelist (Appendix $\mathrm{H})$. Panelists were given an additional week to return the questionnaire.

Twenty panelists returned the Round 1 Questionnaire (95\% response rate from Round 1) via email attachment. The researcher combined all items returned from the expert panel into a single document. The responses of all experts were be examined by the researcher and advisor using content analysis (Krippendorff, 2013). Similar items were grouped together into themes. Elements were evaluated by the researchers to determine if they should be collapsed or remain separate (Keeney et al., 2011). Items that are obviously similar were combined into a single item. For example, "confidentiality" was listed by seven of the panelists. This item appeared once on the Round 2 Questionnaire. The 200 items were then sorted into six themes: Confidentiality/Privacy, SBHC Environment, Accessibility, Clinician/Staff, SBHC Services and Relationship with the School.

In Round 2 panelists were sent a letter with instructions (Appendix I) for Round 2 and the Round 2 Questionnaire (Appendix J) that consisted of the 200 items listed by the themes identified in Round 1. Panelists were asked to indicate on a 5-point Likert scale (1-strongly disagree, 2-disagree, 3-neither agree or disagree, 4-agree, 5-strongly agree), their individual level of agreement with each item on the list. Responses were then returned to the researcher via email. Panelists were asked to return the Round 2 Questionnaire within two weeks and were provided reminders at one week and on the due date as in the previous round. All twenty panelists (100\% response rate from Round 2 ) returned the Round 2 Questionnaire. Participant responses were collected and entered into SPSS20 Grad Pack by code number. All responses were entered twice prior to analysis and any inconsistent items corrected. Descriptive statistics and frequencies were run on all of the items. The level of expert panel agreement on each item was determined through statistical analysis. A minimum level of .75 agreement was chosen 
prior to data collection and indicated that the panelists either agreed or strongly agreed with the item (Chang, Gardner, Duffield \& Ramis, 2010; Keeney et al., 2011).

Similar to the previous rounds, each participant received a cover letter (Appendix K) with instructions and a questionnaire (Appendix L). The Round 3 Questionnaire consisted of all items from Round 2 Questionnaire however only the items that had not yet reached consensus were re-evaluated by the expert panel. Each item was marked with the panelist's score and the median group response (Keeney et al., 2011). Items that had reached consensus appeared in bold print on the questionnaire and were marked "CONSENSUS." The panelists in this round $(N=20)$ were asked to reconsider their individual response within the context of the group response. If they wished to change their response, they were instructed to mark their new response in the appropriate column. If their response remained unchanged from Round 2, the panelists could either leave the item blank or repeat their same score on each item (Keeney et al., 2011). Panelists were asked to return the Round 3 Questionnaire within two weeks and were provided reminders at one week and on the due date as in the previous rounds.

All 20 panelists returned the Round 3 Questionnaire (100\% response rate from Round 3) via email attachment. All responses were entered twice prior to analysis and any inconsistent items corrected. Descriptive statistics and frequencies were run on all of the items. Twenty-two items were very close to reaching consensus (.737) at the end of Round 3 and the decision was made to proceed with a fourth and final round. Keeney and colleagues (2011) recommend a fourth Delphi round if the expert panel is highly motivated and specialized in order to have as many items as possible reach consensus. This panel met both of these criteria because of their qualifications and high response rate to each round. The Round 4 Questionnaire consisted of only the 22 items that reached a .737 level of consensus. All items that had not reached this level were removed. The questionnaire also provided a list of all items that had reached consensus in the two previous rounds for the NPs information. 
Panelists received a letter (Appendix M) explaining this round and the Round 4 Questionnaire (Appendix N). The panelists were again provided with their individual score on each item and the median group response. They were asked to consider their response within the context of the group response. If they wished to change their response, they were asked to indicate their new score on the questionnaire or if they wished to leave their response unchanged to leave the item blank or indicate the same score in the appropriate column on the questionnaire. They were asked to complete and return the questionnaire within two weeks and were provided reminders as in the previous rounds at one week and on the due date. Nineteen panelists (95\% response rate from Round 3) returned the Round 4 Questionnaire. All of the responses were entered twice prior to analysis and any inconsistent items were corrected. Descriptive statistics and frequencies were completed on all of the remaining items.

\section{Phase II: Focus Groups (Qualitative Phase)}

The second phase consisted of a multiple-category design focus group study (Krueger \& Casey, 2009) to explain the essential elements of adolescent-friendly care identified by the experts through the Delphi study. Items that reached consensus were the primary focus, however participants were also asked if any elements were missing and about some items that had not reached consensus.

Focus group research provides the opportunity to gain in-depth understanding from several individuals about a research topic. Individuals are recruited who have a shared experience and are able to provide insight or opinion on a selected research topic. The focus group is guided by a moderator who asks the group a predetermined set of questions in a permissive and nonthreatening manner (Krueger \& Casey, 2009). Unlike the Delphi technique, a diversity of opinion is the goal of the focus groups. The strength of this type of research rests on the interaction among participants that occurs within the group context and provides depth of understanding (Krueger \& Casey, 2009). 
The focus group questions were derived from the results of the Delphi technique. The questions were reviewed by the researchers and an expert in adolescent primary care. All questions were field tested with two small voluntary groups of adolescents known by the researcher to both practice the questions and determine if the flow of the questions would work with groups of teens. Feedback was provided by the teens and the questions included in the questioning route adjusted to be as clear as possible and facilitate conversation among focus group participants.

Two interactive activities were incorporated into the focus group questions to increase engagement by the participants. The first involved asking the teens to distribute sticker dots on posters hung on the wall of each of the six essential elements of adolescent-friendly care identified through the Delphi technique. The researcher provided a brief explanation of each element to the group. Participants were given five sticker dots each to place on the posters of the six essential elements. They were instructed to think about this activity like the ratings given to movies or restaurants and to place as many dots as they wished on each poster to show how important they believed each element was to their experience in receiving care in the SBHC. The more sticker dots they placed on an item, the more important it was to them. The researcher explained that they could divide the sticker dots any way they wished: "if you think accessibility is most important to you, you could place five dots on that poster or you could place two dots on environment and three dots someplace else or one dot on five different posters."

The second interactive activity involved providing each focus group participant with a list of SBHC services (Appendix W). The researcher explained each of the items on the list and asked the focus group participants to circle the three most important items to them. The lists were then used to discuss the services available in the SBHC and the importance of each to the participants. The lists were collected from participants at the conclusion of the focus group.

Recruitment and sample. In an effort to include as much diversity of ideas of possible, a purposive sampling strategy was used to recruit six different groups of adolescents. Table 1 
displays the multiple category design for the focus groups. Two single-sex focus groups (1 male, 1 female) were conducted with teens from each age group (13-14, 15-17 and 18-19 years old) to maximize the diversity of opinion and comfort of participants (Krueger \& Casey, 2008). An effort was made to include adolescents from each of the counties in Connecticut that had SBHCs at the time of recruitment. Inclusion criteria consisted of teens who were 13-19 years old, English speakers, and used the SBHC for at least one visit. Focus groups were randomized by county by pulling the county from a hat. One county had only one SBHC and was unable to participate. A second county was then randomly selected as a replacement. Table 1

Multiple Category Design for Focus Groups

\begin{tabular}{lccc}
\hline & $13-14$ & $15-17$ & $18-19$ \\
\hline Male & 0 & 0 & 0 \\
Female & 0 & 0 & 0 \\
\hline $0=1$ focus group & & &
\end{tabular}

NPs working in high school SBHCs in Connecticut were contacted by the researcher through an email invitation and phone contact to request assistance in gaining access to the SBHC as a location for recruitment and for information on the appropriate channels to recruit teens to the study. The identified gatekeepers at the school (principal or assistant principal) were subsequently contacted with the endorsement of the NP from the SBHC, IRB approval for the study provided, and any of their questions or concerns addressed. Letters from each principal who provided permission to conduct the focus group study were collected from each site as well as permission from each agency responsible for the SBHC. Two of the sites accepted University of Connecticut Institutional Review Board (IRB) approval. The remaining four sites required agency-specific IRB approval; agency approvals to conduct the groups were granted in November 2014. Amendments were filed with the University of Connecticut IRB and 
approval was granted for the revised focus group questioning route and to proceed with this phase of the study at each of the six schools. The NPs from each SBHC were asked to hang recruitment posters (Appendix O) in their clinics, assisted the researcher in recruitment by asking teens who met the group inclusion criteria, if they would be interested in participating in a focus group, provided interested adolescents with the researcher's contact information and participation materials, and assisted in scheduling an appropriate date/time and location for the group. Those who met the inclusion criteria and wished to participate were be given a packet that contained a recruitment letter (Appendix $\mathrm{P}$ ) the appropriate parental consent /teen assent (Appendix Q) or teen consent for those 18-19 years old (Appendix R), and a demographic form (Appendix S) to complete and return to the SBHC or directly to the researcher by United States Postal Service prior to participation. A reminder of the date, time, and location of the focus group was provided to participants prior to the group (Appendix T).

Focus group method. Six focus groups, with 3-8 adolescents each, were conducted (Krueger \& Casey, 2008) between January and May 2015. The focus groups were held in each of the six schools participating in the study in locations convenient for the participants and conducive to conducting the group. Food was provided to participants during each focus group (e.g. pizza, sandwiches, or breakfast foods) and each participant received a $\$ 10$ gift card as a thank you for participation and either bus fare or a $\$ 5$ gas card to return home if the group was held after school and school transportation was not available to the participants.

Prior to each focus group, adolescents who wished to participate returned a completed parental consent (if less than 18 years old), assent, and demographic form to the SBHC. The forms were checked for completeness by the researcher and/or research assistant prior to the focus group session. Only adolescents with completed forms participated. Each group was anticipated to take approximately one hour. On the day of the focus group, the research assistant collected any outstanding consent and demographic forms and checked them for completeness. Participants were greeted when they arrived, encouraged to help themselves to 
refreshments, and introduced to the other participants. The researcher introduced the study to participants and proceeded with an explanation of the ground rules of the focus group (Appendix U).

The focus groups were audio-recorded using two devices. The research assistant kept careful notes of the discussion, kept track of the time, recorded pertinent observations that were not be able to be audio-recorded, and greeted late comers. The focus group questions proceeded according to the questioning route outlined in Appendix V. The Flesch-Kincaid score of the focus group questions was 76.6, grade level 5.3 (http://www.readability-score.com). At the conclusion of each focus group, the researcher provided a brief oral summary of the discussion, asked participants to confirm the content of the session, and asked if anything else needed to be included or changed before adjourning the group.

Focus group data analysis. Each of the audio-recordings was transcribed, word for word, by a transcriptionist. The researcher explained the importance of confidentiality of the audio-recordings and resulting transcripts to the transcriptionist. A confidentiality agreement was signed by the transcriptionist prior to receiving or transcribing the focus group conversations. All identifying information was omitted from the transcripts. The transcripts were compared to the audio files and any inaccuracies corrected. In addition, areas identified by the transcriptionist as "inaudible" or "unintelligible" were examined closely by the researcher and corrected in the transcripts when possible. Each corrected transcript was entered into a qualitative software program, Atlas.ti7, for analysis.

The researcher analyzed the data question by question and across transcripts using content analysis (Krippendorff, 2013). Content analysis is "a research technique for making replicable and valid inferences from texts (or other meaningful matter) to the contexts of their use" (Krippendorff, 2013, p. 382). For this study, the focus group transcripts (sampling units) were first read by the researcher to gain a general understanding of the data. Data were coded using recoding units; a process called unitizing in content analysis. A list of recording units or 
codes was created in the software program as the analysis proceeded. The researcher then reread and recoded the transcripts as needed for consistency across transcripts. Each recording unit was then looked at individually across the transcripts. Those items that were intuitively similar were clustered together into a theme. The researcher used diagrams called dendrograms to assist in the process of identifying and clustering like-responses into themes (Krippendorff, 2013). An example dendrogram for the essential element of Confidentiality/

\section{Privacy appears in Figure 2.}

Staff won't tell

\begin{tabular}{|c|c|c|}
\hline $\begin{array}{l}\text { Can make an appointment for yourself so do not have } \\
\text { to tell parent why want an appointment }\end{array}$ & \multirow[b]{4}{*}{ Confidential care } & \multirow[b]{5}{*}{$\begin{array}{l}\text { What Happens in the SBHC, } \\
\text { Stays in the SBHC }\end{array}$} \\
\hline Never leak anything & & \\
\hline Give choice to share with parents or not share & & \\
\hline Don't call your house & & \\
\hline $\begin{array}{l}\text { Can talk to them if something is wrong and don't } \\
\text { want to talk to your parents }\end{array}$ & & \\
\hline Keep it between them & & \\
\hline Don't want others to know results at school & & \\
\hline Understand limits of confidentiality agreement & & \\
\hline Look out for you if need to tell & & \\
\hline Won't tell my mom and I don't want them to & & \\
\hline Mental health & & \\
\hline STDs & Confidential services & \\
\hline Pregnancy or concern & & \\
\hline HIV & & \\
\hline Take you to the side to ask questions & & \\
\hline No family members to see you & & \\
\hline No family members answering phone & Private & \\
\hline Actual door, not a curtain & & A Private Setting \\
\hline They tell you from day one that it's private & & \\
\hline One person at a time & & \\
\hline Can be overheard if loud person & & \\
\hline Dental office so small feet stick out the door & Less private & \\
\hline
\end{tabular}

Figure 2. Dendrogram of the Essential Element of Confidentiality/Privacy

Following the completion of all the groups, the sticker dots on the posters of the essential elements of adolescent-friendly care were analyzed for each of the groups and for the entire sample. The lists of clinical services were also analyzed group by group and for the 
entire sample. The field notes taken by the researcher and a research assistant were used to supplement the transcribed data.

\section{Mixing of Quantitative and Qualitative Data}

The final phase of data analysis involved mixing of the data generated from the Delphi and focus groups and assessing how the data answer the study's research questions. A connected data analysis was utilized to explain the results (Creswell \& Plano-Clark, 2011). The inferences, interpretations, and conclusions were drawn from each of the strands of quantitative and qualitative components (Creswell \& Plano-Clark, 2011; Teddlie \& Tashakkori, 2009). In addition, the conclusions and interpretations that emerged from examination of data across the strands resulted in "meta-inferences" (Teddlie \& Tashakkori, 2009). A thematic content analysis of each category of the essential elements of adolescent-friendly care in SBHCs from the Delphi technique was conducted for comparison with the themes that emerged from the focus groups (Krippendorff, 2013). Data analysis was accomplished by comparing and contrasting the perspectives of the NPs and adolescents regarding the essential elements of adolescentfriendly care in SBHCs. The data generated from the focus groups also explained the elements of adolescent-friendly care provided by the expert panel of NPs. A thorough discussion of the findings is provided Chapter V.

\section{Approaches Used to Enhance Validity}

Potential threats to validity are common to all types of research methods. Careful attention to the procedures of each method was used to enhance the validity of results (Krueger \& Casey, 2008).

Quantitative phase. In the first phase of this study, a Delphi technique was used to identify the expert opinions of NPs working in SBHCs. The researcher carefully screened and matched the qualifications of those invited to participate in the expert panel with the inclusion criteria prior to participation. Maintaining the participant's confidentiality allowed each NP to express their own opinions as well as to honestly respond to the questionnaires without being 
influenced by the other members of the panel. Personal views and outside influences, such as newly released practice guidelines or highly publicized event, may influence the opinions of participant responses and the researcher paid attention to their possible influences as the data are interpreted (Keeney et al., 2011). Finally, the response rates and attrition of panel members can be influenced by the diversity of opinion and the ability to achieve consensus (Keeney et al., 2011). The researcher made every effort to keep participants engaged in the process and to complete all rounds of the study. Member checks, a process in which the researcher summarizes the results and asks the participants to confirm the results are an accurate reflection of their experience, are an inherent aspect of the Delphi technique and seek to gain consensus for the panelist and therefore serve as a mechanism to enhance the validity of the items (Creswell \& Plano-Clark, 2011).

Qualitative phase. The validity of focus group results was enhanced by pilot testing the questions with both content experts and adolescents to ensure they were understandable and produced the types of data required to answer the research questions (Krueger \& Casey, 2008). This is particularly important in focus groups that include adolescents as research subjects because the participants may be developmentally different from group to group and interpret the questions asked differently (Daley, 2013; Krueger \& Casey, 2008). The focus groups took place in a familiar location that was comfortable, convenient, and minimized concern of participants being overheard by peers, parents, school personnel, or SBHC staff (Krueger \& Casey, 2008). The multi-category design purposively split male and female adolescents and the ages of the participants to enhance sharing of ideas and minimize any of the teens from feeling selfconscious (Krueger \& Casey, 2008). The researcher has experience working with adolescents of both genders and the age groups included in this study, which enhanced the conversations within the groups. The researcher closely monitored the group discussion and clarified questions or the participant responses as needed. In addition, the research assistant was a doctoral student and was oriented to the focus group questions and flow of the group before this 
phase of the study began. At the end of each focus group, the researcher summarized the conversation and asked the adolescents if the summary captured the content of the focus group discussion and also allowed participants to add anything that was missing or needed correction (Krueger \& Casey, 2008). The researcher has been a NP working in a high school SBHC for over 20 years and her experience may shape the research study, findings, and interpretation (O'Caithlin, 2010; Onwuegbuzie \& Johnson, 2006). Therefore, transcripts from each group were analyzed by the student researcher and a senior researcher to enhance the interpretation and validity of the results (Krueger \& Casey, 2008).

Mixing of quantitative and qualitative data. Creswell and Plano-Clark (2011) identify numerous potential threats to the validity of mixed methods study results including issues related to data collection, data analysis, and interpretation. To avoid potential threats to the validity of the data, careful attention was paid to the procedures and collection of data in each phase of this study. The data were examined and closely linked to each of the research questions (Creswell \& Plano-Clark, 2011). Joint displays of data from both phases of the study aided the researcher in the analysis and interpretation of data. For example, the essential elements of adolescent-friendly care identified by the expert panel of NPs were compared with the quotes obtained from the adolescents in the focus groups; quotes were used to enhance the interpretation of the data (Creswell \& Plano-Clark, 2011).

\section{Summary}

This explanatory sequential mixed method study consisted of a quantitative first phase and a qualitative second phase. The quantitative phase was conducted using a Delphi technique with an expert panel of NPs from the Northeastern Region of the United States. The qualitative phase was accomplished through a focus group study with adolescents from high schools in Connecticut. Together the results from these two phases provide the perspectives of expert NPs and adolescents related to the essential elements of adolescent-friendly health care 
services provided in SBHCs. Chapter IV provides the results of both data collection phases of this study and then compares the perspectives of the NPs and adolescents. 


\section{CHAPTER IV}

\section{RESULTS}

This mixed method study was conducted as part of a program of research aimed at improving access to preventive adolescent-friendly health care services. The perspectives of nurse practitioners (NPs) as the providers of health care services for adolescents at schoolbased health centers (SBHCs) and the adolescents who engage in these services are absent in the research literature. Therefore, these important perspectives specific to the essential elements of adolescent-friendly care in SBHCs were the foci of this study.

An explanatory sequential mixed methods study design with a quantitative first round followed by a qualitative second round was utilized to answer the following research questions:

1. What does an expert panel of NPs identify as the essential elements of providing adolescent-friendly health care services to teens in SBHCs?

2. What is the adolescent perspective on the essential elements of adolescent-friendly health care services specific to SBHCs?

3. How do the perspectives of NPs and adolescents compare regarding the essential elements of adolescent-friendly care in SBHCs?

The first phase of the study was accomplished via a Delphi technique that elicited expert opinion from a panel of NPs and was aimed at identifying the essential elements of adolescentfriendly care in SBHCs. The second phase included a focus group study with adolescents from six different high schools. Participants were asked to discuss their perspective on various aspects of adolescent-friendly care identified through the Delphi technique. Finally, the perspectives of NPs and adolescents from each phase of the study were compared. Chapter III provided a detailed discussion of the methodology for this study.

\section{Quantitative Phase: Delphi Technique}

The quantitative first phase used a Delphi Technique consisting of four rounds with an expert panel of nurse practitioner (NPs) $(N=21)$ from the Northeastern Region of the United 
States. The Delphi technique began by first asking participants to identify a minimum of five aspects of adolescent-friendly care in SBHCs. The subsequent quantitative rounds asked the expert panel to rate the importance each characteristic identified in the first round until consensus was reached on an item.

Eligibility criteria for participation in the study included national certification as a NP, 3+ years of experience providing health care to teens in a SBHC, and expert status as a SBHC adolescent NP as evidenced by the publication of a paper in a peer-reviewed journal, national presentation, designation as an expert by their professional organization, or other evidence of expert status. Recruitment of potential participants occurred from January to April 2014. NPs from the Northeastern Region of the United States were invited to participate through a variety of sources that included professional organizations, state school-based health associations, personal contacts, and referrals. Thirty-five NPs were contacted directly and invited to participate. Eight agencies were also contacted and asked to send the recruitment flyer to any NPs that worked with adolescents in a SBHC via email or listserv. Twenty-two NPs returned consent and demographic forms via United States Postal Service or email attachment. One NP was eliminated by the researcher because she practiced in a SBHC outside the approved study region. The final two consents arrived via USPS on the same day and exceeded the approved sample size by one. A protocol deviation was submitted to the IRB. Twenty-one NPs were sent the Round 1 questionnaire (60\% participation rate).

\section{Demographic Characteristics of the Sample}

The NPs practiced in SBHCs in Connecticut (52.4\%), Massachusetts (19.1\%), New York (19.1\%), Pennsylvania (4.8\%), and Vermont (4.8\%). Sixty-seven percent practiced in high school SBHCs, $19 \%$ in middle school SBHCs, and 14\% in both middle and high school SBHCs. The SBHCs were sponsored by a hospital (38.1\%), community health center (33.3\%), community mental health agency $(9.5 \%)$, non-profit community agency $(14.3 \%)$ or the school (4.8\%). All the NPs were women, described themselves as white (95.2\%) or other (4.8\%), and 
were pediatric nurse practitioners (52.4\%), family nurse practitioners $(38.1 \%)$ or other practitioners $(9.5 \%)$.

The NPs in this study had been practicing as an NP for 3-35 years (mean=20.6 years) and in a SBHC for $4-30$ years (mean=13 years). They were certified by American Nurses Credentialing Center (61.9\%), Pediatric Nursing Certification Board (28.6\%), or other organizations (14.3\%). Expert status was self-described as publication of a paper in a peerreviewed journal (38.1\%), national presentation (28.6\%), expert status designation by their professional organization (38.1\%), or other (61.9\%) that included preceptor of NP students, length of experience, variety of experience working with teens in SBHCs, trainer for health care professionals through the health department, authorship of book chapters, and awards for excellence in nursing. Half of the NPs identified more than one area of expert status. Table 2 provides the demographic characteristics of the NPs and Table 3 provides the characteristics of their practice sites.

Table 2

Demographic Characteristics of NPs Participating in the Delphi technique $(N=21)$

\begin{tabular}{llrr}
\hline Characteristic & & $N$ & $\%$ \\
\hline Gender & Female & 21 & 100 \\
Race/Ethnicity & & & \\
& White & 20 & 95.2 \\
& Other & 1 & 4.8 \\
Certification & & & \\
& Pediatric NP & 11 & 52.4 \\
& Family NP & 8 & 38.1 \\
Certifying Agency & Other & 2 & 9.5 \\
& American Nurses Credentialing Center & 13 & 61.9 \\
& Pediatric Nursing Certification Board & 6 & 28.6 \\
& Other & 3 & 14.3 \\
& & & \\
Expert Status & Publication of Paper & 8 & 38.1 \\
& National Presentation & 6 & 28.6 \\
& Professional Organization Expert Designation & 8 & 38.1
\end{tabular}


Table 3

Demographic Characteristics of the NP Practice Sites

\begin{tabular}{llrr}
\hline Characteristic & & $N$ & $\%$ \\
\hline SBHC location & Connecticut & 11 & 52.4 \\
& Massachusetts & 4 & 19.1 \\
& New York & 4 & 19.1 \\
& Pennsylvania & 1 & 4.8 \\
& Vermont & 1 & 4.8 \\
Type of SBHC & High School & 14 & 67 \\
& Middle School & 4 & 19 \\
& Both & 3 & 14 \\
Sponsoring Agency & & \\
& Hospital & 8 & 38.1 \\
& Community Health Center & 7 & 33.3 \\
& Community Mental Health Agency & 2 & 9.5 \\
& Non-profit Community Agency & 3 & 14.3 \\
& School & 1 & 4.8 \\
\hline
\end{tabular}

\section{Round 1}

The Delphi technique began with a qualitative first round. The expert panel was asked "What are the essential elements of providing adolescent-friendly care in school-based health centers?" Participants were instructed to identify a minimum of five essential elements of adolescent-friendly care in SBHCs. The Round 1 Questionnaire (Appendix F) was sent to 21 participants via email and yielded a $95 \%(N=20)$ return rate. Each NP identified at least five essential elements (range 5-31; mean $=11.3$ ) of providing adolescent-friendly care in SBHCs. The items were collated and sorted. All obviously redundant items were eliminated from the list. Two hundred essential elements of adolescent-friendly care in SBHCs were identified by the expert panel. The elements were sorted into six categories: Confidentiality/Privacy $n=19$ (9.5\%), SBHC Environment $n=17(8.5 \%)$, Accessibility $n=32(16 \%)$, Clinician Staff $n=88$ (44\%), SBHC Clinical Services $n=32(16 \%)$, and Relationship with School $n=12(6 \%)$. The method used to sort the items into the six categories is described in detail in Chapter III. 


\section{Round 2}

The Round 2 questionnaire was constructed to include the 200 essential items of adolescent-friendly care from Round 1 . Items were separated into similar categories. Twenty Round 2 Questionnaires (Appendix J) consisting of 200 essential elements of adolescentfriendly care in SBHCs were sent to the 20 NPs that had returned the Round 1 Questionnaire with instructions on how to complete it. The NPs were asked to indicate on a 5-point Likert scale (strongly disagree [1], disagree [2], neither agree or disagree [3], agree [4], strongly agree [5]) their level of agreement with each of the 200 elements. All 20 (100\%) Round 2 questionnaires were returned by the NPs. The data from each of the questionnaires were entered into SPSS20 twice to insure accuracy of data entry. Any errors were corrected prior to data analysis. Frequencies and descriptive statistics were run on the dataset. Items were analyzed for consensus level of $75 \%$ or greater. Forty elements reached consensus (Table 4 ) from the following categories: Confidentiality/Privacy $n=6(31.6 \%)$, Accessibility $n=7(21.9 \%)$, Clinician Staff $n=21$ (23.9\%), SBHC Clinical Services $n=4$ (12.5\%), and Relationship with

School $n=2(1.7 \%)$.

Table 4

Essential Elements of Adolescent-friendly Care in SBHC Round 2 Results $(N=40)$

Ability to provide services in a manner that insures confidentiality from parents/guardians (e.g. reproductive care) within parameters of law Understanding of state laws, policies, and regulations regarding adolescents' rights.

Privacy of patient and provider so confidentiality is maintained and students feel safe to share.

Teens need to understand the scope of what can remain confidential and the limits of confidentiality.

Accessibility $(n=7)$

Appointment times and walk-in times have to be kept flexible to work around both school's ever changing schedules and teens' typical habits

\section{5}

75

75

(Table continues) 
(i.e. missing appointments, frequent re-scheduling, dropping in during lunch, or study hall.

The ability to be flexible and work with the student's schedule.

Willingness to reschedule an appointment if it doesn't work with the

teen's schedule

The health care provider needs to be available by using a combination

of walk-ins and appointments to maximize the ability to see patients in a timely manner.

Easy access to SBHC

Easy access to making appointments

Easy access to providers onsite

Clinicians/Staff $(n=21)$

Be very respectful

Courtesy \& respect by all staff

Greeting and communicating with teens at the front desk with respect

and sensitivity is as important as the conversations that happen during

clinic visits.

Experienced staff and providers well-versed with this population and

enjoy the challenges of working with this very dynamic age group.

Provider is friendly and respectful to the students.

Non-judgmental

Genuinely like to work with tweens and teens.

Judgment-free attitude expressed by providers/staff

Effective communication-non-judgmental, clear

75

Be non-judgmental in response to them, even when it is hard. 95

Unbiased Care $\quad 75$

Active listening 80

Trauma sensitive: Staff needs to understand the long term effects of $\quad 75$

trauma or second hand trauma exposure on a teenager.

Staff needs the knowledge and patience to work with teens with trauma $\quad 75$

histories

Ability to provide mental health services or help students access them 80

Provider has to be comfortable tackling the difficult issues-willing to

bring up and discuss sensitive issues and not back down when

something is important.

Discuss confidentiality

Healthcare providers/staff comfortable with age group

80

Competence-SBHC staff must be knowledgeable and competent in

adolescent development, clinical matters, and public health issues

related to youth

Trustworthiness

Staff attitude-respectful, supportive, honest, trustworthy, friendly

Availability of Point of Care Testing 95

Try to save trips to emergency room and keep teen in school 75

FREE services or ability to bill insurance agents without possibility of 85

EOB or bill going home.

Consistency of staffing: Not having floating or rotating providers to

75

enhance trust between patient and provider 
Relationship with School $(n=2)$

Coordinate with the school so staff will refer to you and not set up

barriers that won't allow kids to be seen. Especially get cooperation of

principals, secretaries, school nurses, guidance, and security

personnel.

Positive relationship with principal

\section{Round 3}

The Round 3 Questionnaire consisted of the essential elements that had not reached consensus in Round 2. The items that reached consensus in Round 2 were also included on the Round 3 Questionnaire but were marked to indicate that consensus had been reached for each of these elements by the expert panel (Appendix L). The Round 3 questionnaire provided each of the NPs their previous response and the median group response for each element. During this round the experts were asked to reconsider their response in the context of the group response. If they wished to change their response for an element they were instructed to do so using the same 5-point Likert scale as they had in Round 2. The Round 3 Questionnaire was sent to the 20 NPs that completed Round 2. Nineteen (95\%) Round 3 Questionnaires were returned and each item was entered into an SPSS20 database using the same procedure as Round 2 and then analyzed. An additional 39 elements reached consensus (Table 5): Confidentiality/ Privacy $n=2(10.5 \%)$, SBHC Environment $n=3(17.6 \%)$, Accessibility $n=6$ (18.8\%), Clinician /Staff $n=21$ (23.9\%), SBHC Clinical Services $n=2(6.3 \%)$, and Relationship with School $n=5(41.7 \%)$.

Table 5

Essential Elements of Adolescent-friendly Care in SBHC Round 3 Results $(N=39)$

Essential Element Consensus Level
$(\%)$

Confidentiality/Privacy $(n=2)$

Ability to provide services in a manner that insures confidentiality 78.9 from school staff for general issues in accordance with HIPPA guidelines 
Confidentiality for sensitive visits $\quad 78.9$

SBHC Environment $(n=3)$

Friendly

78.9

Environment that is welcoming to the LGBT community 78.9

An environment in which the student feels emotionally safe 84.2

Accessibility $(n=6)$

Open door policy $\quad 84.2$

Affordability $\quad 84.2$

Walk-in visits $\quad 84.2$

Perception that services are open to ALL teens, not just select $\quad 78.9$

groups

Open during school hours $\quad 89.5$

Ability see of the NP to see adolescent when they present for an 84.2

issue, regardless of insurance status, or insurance rules such as need for PCP referral

Clinician/Staff $(n=21)$

Don't embarrass them. They don't always show how sensitive they 89.5

are, but will feel it inside

Honoring/respecting teen's choice(s)

Respectful treatment

Teen needs to feel that we are not judging them as a person

Listen

Clarity of information

Positive approach rather than preaching (focus more on positive

qualities and build on them)

Culturally sensitive approach

Clinicians and staff need to feels a truthful concern for the teen

patients (students)

Need to have a strong LCSW to refer to and one who wants to

work collaboratively

Knowledge of adolescent trends regarding high risk behavior and

social norms

Adolescent-friendly

Awareness of adolescent development

Clinical knowledge/skills

84.2

89.5

89.5

84.2

78.9

84.2

SBHC staff must be committed to continual learning in adolescent

84.2

84.2

78.9

development, clinical matters and public health issues related to

youth

Interaction appropriate for developmental age

78.9

Understanding teen behavior

Honesty

Willingness to advocate for students in school for services SBHC is

allowed to offer

The ability to work independently as an APRN

78.9

78.9

89.5

84.2

Don't lie to them or go behind their back. Be honest as you can even in difficult or stressful situations

78.9

78.9

84.2

78.9

84.2

89.5

Clinical Services $(n=2)$

Affordable

84.2

SBHC should be able to handle the diverse needs of adolescents

78.9

(Table continues) 
Relationship with School $(n=5)$

A good relationship with both the school leadership and with staff

members goes a long way in ensuring the success of the SBHC

Good working relationship with school personnel

84.2

Coordination with school personnel (teachers, guidance

84.2

counselors, nurses, principals, coaches)

Good working relationship with school nurse

84.2

Positive relationship with school nurses. Often they can act as

78.9

gate keeper to the SBHC and if the school nurse is not supportive

78.9

of the SBHC it can affect the functioning of the SBHC.

\section{Round 4}

Twenty-three of the elements were very close to reaching consensus at the end of Round 3 achieving a level of $73.7 \%$ and therefore a fourth round was sent to each the 19 NPs that had completed the previous round. Fourth Rounds of the Delphi technique are indicated when the participants are highly motivated and specialized group in order to have as many items as possible reach consensus (Keeney et al., 2011). All of the items that had reached consensus in the previous rounds were removed from the Round 4 Questionnaire and placed in a list at the end of the questionnaire for the NPs to review. This was done to make the questionnaire easier to read and complete. Eighteen (95\%) of the NPs returned the Round 4 Questionnaire. Data were entered and analyzed using the same procedure used in Round 2 and 3. Nineteen additional elements reached consensus (Table 6): SBHC Environment $n=1$ (5.8\%), Accessibility $n=2(6.3 \%)$, Clinician/Staff $n=9(10.2 \%)$, SBHC Clinical Services $n=6$ (5.3), and Relationship with School $n=1(8.3 \%)$.

Table 6

Essential Elements of Adolescent-friendly Care in SBHC Round 4 Results $(N=19)$

Essential Elements
$\begin{gathered}\text { Consensus Level } \\ (\%)\end{gathered}$

SBHC Environment $(n=1)$

An environment in which the student feels safe 77.8 Accessibility $(n=2)$

Flexibility in scheduling to accommodate teens' want/need to be seen when a problem is occurring

(Table continues) 
Same day appointments

Clinician/Staff $(n=9)$

Collaborating with teens in decision-making (mutual goals)

83.3

It is important to listen before giving advice. Their big complaint

is that "nobody listens to them. They tell us what to do."

Socio-economic sensitive approach

83.3

Sensitive to needs

83.3

Compassion

77.8

Familiarity of community resources for students and families

77.8

Trust

94.4

A staff knowledgeable about growth and development

83.3

Understanding of adolescent development

83.3

Clinical Services $(n=6)$

Ability to provide comprehensive care, including reproductive

88.9

health/contraceptive care

Mental health screenings, referrals; mental health services

88.9

provided on-site through SBHC

Expert knowledge of reproductive care, pregnancy prevention,

83.3

OB/GYN services, and services that are offered in surrounding areas

Full range of services available: Preventative care,

83.3

immunizations, PE/Sports PE, Acute visits including

screening/testing STIs, pregnancy, Behavioral

Health/Dental/GYN on site

Dispense medications if necessary due to no insurance or

difficulty getting to a pharmacy

Reproductive health services or the ability to help students

easily and quickly access them

Relationship with School $(n=1)$

Understanding of the school/BOE policies and regulations (re:

educational rights, services provided by state, town or school)

77.8

100

77.8

\section{Summary}

Overall, 98 of the 200 (49\%) essential elements of adolescent-friendly care in SBHCs identified by the NPs in Round 1 reached consensus at a level of $75 \%$ or greater after four Delphi rounds (Table 7). Each of the categories had items that reached expert consensus:

Confidentiality/Privacy $n=8(8.2 \%)$, SBHC Environment $n=4(4 \%)$, Accessibility $n=15$

(15.3\%), Clinician/Staff $n=51$ (52\%), SBHC Clinical Services $n=12$ (12.2\%), and Relationship with School $n=8(8.2 \%)$. 
Table 7

Essential Elements of Adolescent-friendly Care in SBHC $(N=98)$

\begin{tabular}{|c|c|}
\hline Essential Elements & $\begin{array}{l}\text { Consensus Level } \\
(\%)\end{array}$ \\
\hline \multicolumn{2}{|l|}{ Confidentiality/Privacy $(n=8)$} \\
\hline Confidentiality & 95 \\
\hline Confidentiality perceived and real & 75 \\
\hline $\begin{array}{l}\text { Ability to provide services in a manner that insures confidentiality from } \\
\text { parents/guardians (e.g. reproductive care) within parameters of law }\end{array}$ & 95 \\
\hline $\begin{array}{l}\text { Understanding of state laws, policies, and regulations regarding } \\
\text { adolescents' rights. }\end{array}$ & 80 \\
\hline $\begin{array}{l}\text { Privacy of patient and provider so confidentiality is maintained and } \\
\text { students feel safe to share. }\end{array}$ & 75 \\
\hline $\begin{array}{l}\text { Teens need to understand the scope of what can remain confidential } \\
\text { and the limits of confidentiality. }\end{array}$ & 75 \\
\hline $\begin{array}{l}\text { Ability to provide services in a manner that insures confidentiality from } \\
\text { school staff for general issues in accordance with HIPPA guidelines }\end{array}$ & 78.9 \\
\hline Confidentiality for sensitive visits & 78.9 \\
\hline \multicolumn{2}{|l|}{ SBHC Environment $(n=4)$} \\
\hline An environment in which the student feels safe & 77.8 \\
\hline Friendly & 78.9 \\
\hline Environment that is welcoming to the LGBT community & 78.9 \\
\hline An environment in which the student feels emotionally safe & 84.2 \\
\hline \multicolumn{2}{|l|}{ Accessibility $(n=15)$} \\
\hline $\begin{array}{l}\text { Appointment times and walk-in times have to be kept flexible to work } \\
\text { around both school's ever changing schedules and teens' typical } \\
\text { habits (i.e. missing appointments, frequent re-scheduling, dropping in } \\
\text { during lunch or study hall) }\end{array}$ & 75 \\
\hline The ability to be flexible and work with the student's schedule & 85 \\
\hline $\begin{array}{l}\text { Willingness to reschedule an appointment if it doesn't work with the } \\
\text { teen's schedule }\end{array}$ & 80 \\
\hline $\begin{array}{l}\text { The health care provider needs to be available by using a } \\
\text { combination of walk-ins and appointments to maximize the ability to } \\
\text { see patients in a timely manner }\end{array}$ & 75 \\
\hline Easy access to SBHC & 80 \\
\hline Easy access to making appointments & 75 \\
\hline Easy access to providers onsite & 80 \\
\hline Same day appointments & 83.3 \\
\hline Open door policy & 84.2 \\
\hline Affordability & 84.2 \\
\hline Walk-in visits & 84.2 \\
\hline Perception that services are open to ALL teens, not just select groups & 78.9 \\
\hline Open during school hours & 89.5 \\
\hline $\begin{array}{l}\text { Ability see of the NP to see adolescent when they present for an } \\
\text { issue, regardless of insurance status, or insurance rules such as need } \\
\text { for PCP referral }\end{array}$ & 84.2 \\
\hline $\begin{array}{l}\text { Flexibility in scheduling to accommodate teens' want/need to be seen } \\
\text { when a problem is occurring }\end{array}$ & 83.3 \\
\hline
\end{tabular}


Clinician/Staff $(n=51)$

Be very respectful $\quad 75$

Courtesy \& respect by all staff $\quad 85$

Greeting and communicating with teens at the front desk with respect $\quad 75$

and sensitivity is as important as the conversations that happen

during clinic visits.

Experienced staff and providers well-versed with this population and 90

enjoy the challenges of working with this very dynamic age group.

Provider is friendly and respectful to the students. $\quad 90$

$\begin{array}{ll}\text { Non-judgmental } & 90\end{array}$

Genuinely like to work with tweens and teens. $\quad 80$

Judgment-free attitude expressed by providers/staff 75

Effective communication-non-judgmental, clear 85

Be non-judgmental in response to them, even when it is hard. 95

Unbiased Care $\quad 75$

Active listening $\quad 80$

Trauma sensitive: Staff needs to understand the long term effects of 75

trauma or second hand trauma exposure on a teenager.

Staff needs the knowledge and patience to work with teens with 75

trauma histories

Ability to provide mental health services or help students access them $\quad 80$

Provider has to be comfortable tackling the difficult issues-willing to 85

bring up and discuss sensitive issues and not back down when

something is important.

Discuss confidentiality

Healthcare providers/staff comfortable with age group

80

Competence-SBHC staff must be knowledgeable and competent in 75

adolescent development, clinical matters, and public health issues

related to youth

Trustworthiness

75

Staff attitude-respectful, supportive, honest, trustworthy, friendly

95

Don't embarrass them. They don't always show how sensitive they

89.5

are, but will feel it inside

Honoring/respecting teen's choice(s)

84.2

Respectful treatment

89.5

Teen needs to feel that we are not judging them as a person 89.5

Listen

84.2

Clarity of information

78.9

Positive approach rather than preaching (focus more on positive

84.2

qualities and build on them)

Culturally sensitive approach

84.2

Clinicians and staff need to feels a truthful concern for the teen 84.2

patients (students)

Need to have a strong LCSW to refer to and one who wants to work

78.9

collaboratively

Knowledge of adolescent trends regarding high risk behavior and

78.9

social norms

Adolescent-friendly

78.9

Awareness of adolescent development $\quad 78.9$

Clinical knowledge/skills

89.5

(Table continues) 
SBHC staff must be committed to continual learning in adolescent

development, clinical matters and public health issues related to

youth

Interaction appropriate for developmental age

78.9

Understanding teen behavior

78.9

Honesty

84.2

Willingness to advocate for students in school for services SBHC is

78.9

allowed to offer

The ability to work independently as an APRN

84.2

Don't lie to them or go behind their back. Be honest as you can even

89.5

in difficult or stressful situations

Collaborating with teens in decision-making (mutual goals)

83.3

It is important to listen before giving advice. Their big complaint is

88.9

that "nobody listens to them. They tell us what to do."

Socio-economic sensitive approach

83.3

Sensitive to needs

83.3

Compassion

77.8

Familiarity of community resources for students and families

77.8

Trust

94.4

A staff knowledgeable about growth and development

83.3

Understanding of adolescent development

83.3

Clinical Services $(n=12)$

Ability to provide comprehensive care, including reproductive

88.9

health/contraceptive care

Mental health screenings, referrals; mental health services provided

88.9

on-site through SBHC

Expert knowledge of reproductive care, pregnancy prevention,

OB/GYN services, and services that are offered in surrounding areas

Full range of services available: Preventative care, immunizations,

PE/Sports PE, Acute visits including screening/testing STIs,

pregnancy, Behavioral Health/Dental/GYN on site

Dispense medications if necessary due to no insurance or difficulty

getting to a pharmacy

Reproductive health services or the ability to help students easily and quickly access them

Availability of Point of Care Testing

Try to save trips to emergency room and keep teen in school

FREE services or ability to bill insurance agents without possibility of

EOB or bill going home.

Consistency of staffing: Not having floating or rotating providers to

enhance trust between patient and provider

Affordable

77.8

100

95

75

85

75

84.2

78.9

Relationship with School $(n=8)$

A good relationship with both the school leadership and with staff

84.2

members goes a long way in ensuring the success of the SBHC

Good working relationship with school personnel

84.2

Coordination with school personnel (teachers, guidance counselors, nurses, principals, coaches)

Good working relationship with school nurse

78.9

(Table continues) 
Understanding of the school/BOE policies and regulations (re:

educational rights, services provided by state, town or school)

Positive relationship with school nurses. Often they can act as gate

keeper to the SBHC and if the school nurse is not supportive of the

$\mathrm{SBHC}$ it can affect the functioning of the SBHC.

Coordinate with the school so staff will refer to you and not set up

barriers that won't allow kids to be seen. Especially get cooperation

of principals, secretaries, school nurses, guidance, and security

personnel.

Positive relationship with principal

\section{Qualitative Round: Focus Groups}

The second phase of this mixed method study was a focus group study with adolescents who were registered users of the SBHC in their school and had used the SBHC at least once. Six focus groups were conducted and were stratified by gender and age (13-14, 15-17 and 1819 year olds) in five counties in Connecticut.

The focus groups were audio-recorded and consisted of 3-8 teens each. Each group lasted between 28.5 and 63 minutes and followed a predetermined questioning route (Appendix V) that addressed the six overarching elements of providing adolescent-friendly care in SBHCs from the Delphi study. The research assistant greeted participants, collected consents, managed the audio-recorders, and took field notes during each session.

Demographic characteristics of focus group participants. Thirty adolescents participated in one of the six focus groups, $56.7 \%$ percent were male, $43.3 \%$ female. The mean age of the participants was 16.4 years (16.2 years female; 16.5 years male). All grades (9-12) were represented with $30 \%$ of participants in the $9^{\text {th }}$ grade, $10 \%$ in the $10^{\text {th }}$ grade, $23 \%$ in the $11^{\text {th }}$ grade and $55 \%$ in the $12^{\text {th }}$ grade. Participants were asked to write in their race/ethnicity on their demographic form, their responses were then categorized by the federal definitions for race and ethnicity. The sample was diverse; $30 \%$ identified themselves as being of two or more races/ethnicities. The demographic characteristics of the participants are provided in Table 8. 
Table 8

Demographics of the Focus Group Participants $(N=30)$

\begin{tabular}{lc}
\hline Characteristic & $\mathrm{N}(\%)$ \\
\hline $\begin{array}{l}\text { Gender } \\
\text { Female }\end{array}$ & $13(43.3)$ \\
Male & $17(56.7)$ \\
Grade & $9(30)$ \\
9 & $3(10)$ \\
10 & $7(23.3)$ \\
11 & $11(36.7)$ \\
12 & \\
Age Group & $9(30)$ \\
$13-14$ & $7(23.3)$ \\
$15-17$ & $14(46.7)$ \\
$18-19$ & $16(36.7)$ \\
Ethnicity & $12(40)$ \\
Hispanic or Latino & $2(6.7)$ \\
Not Hispanic or Latino & $7(23.3)$ \\
Unknown & $4(13.3)$ \\
Race & $10(33.3)$ \\
Black/African American & $9(30)$ \\
White & \\
Hispanic or Latino & \\
2 or more races/ethnicities &
\end{tabular}

\section{Focus Group Results}

After an icebreaker, each of the adolescent focus groups were asked what the teens liked about their SBHC and how the services provided differed from those provided by the school nurse or other health care agencies or offices in the community. This discussion was followed by six questions specific to the essential elements of adolescent-friendly care in SBHCs identified by the expert panel of NPs. A thematic analysis, question by question, is presented here.

What do you like about coming to the SBHC? Six themes emerged from the focus group discussion related to what the teens liked about their SBHC: Accessibility of Services, Attitude of the SBHC Staff, Competence of the NP, Confidential and Private Setting, Open Communication, and the Relationship Between the SBHC Staff and the Teen. 
Accessibility of services. Many of the teens reported that they used the SBHC because of the ease of making an appointment for a variety of needs including physical examinations, sports physicals, and immunizations that are requirements for playing sports and school attendance. "You don't have to go out of your way. They are just there for you whenever you need it." In addition, the care they received from the SBHC allowed them to stay in school rather than be sent home because they were not feeling well. "When you are not feeling well they actually try to make you feel better instead of like making you go home fast." Teens also did not need to leave school to go to an appointment at another health care agency. “So if you have tryouts one day and you need to get a physical, you don't have to leave school. You can go to school—stay inside school and get it done." The teens liked receiving a "quick physical, right when I need it" often without an appointment and much sooner than making an appointment elsewhere. Teens remarked also on being able to go to appointments alone and for more private concerns such as HIV or sexually transmitted disease (STD) screening.

Attitude of SBHC staff. Teens liked going to the SBHC because of the positive atmosphere created by the staff. The staff was described as "friendly," "smiling," "never rude," "nice" and "cool people" and who were able to leave their personal problems at home. The manner in which they were provided care made their experiences "comfortable."

I have been in the health center since sixth grade and they show more care and compassion...you are sitting there and they actually make you know friendship and you guys connect. Not just because you guys [SBHC staff] are younger or whatever, but you guys like understand that we are young and know the things we need to know.

The SBHC environment was viewed as less serious than other places they had received care and the teens appreciated the use of humor in their interactions with the staff. "They joke with you. You can't do that at a doctor's office....Everyone is all serious there."

Competence of the NP. The NP was viewed as someone willing and capable of making teens feel better and healing their illnesses or injuries. "It's basically a doctor's office at 
your school." The care was provided with the individual patient in mind. "They recommend you go and do things that would be beneficial to you." The teens described the NP as knowledgeable and competent because the NP practiced independently at the SBHC caring for the teens.

I feel like they have to know a little more than like, doctors. Because they are just by themselves here. So they kind of just kind have to like, base their own like, opinions on things. So I feel like they are like, more -- I don't know, they have more knowledge.

Part of the competence involved how the office was maintained: "it is clean." The teens explained that the staff always cleaned the examination table thoroughly and changed the paper between patients and in front of the teens. "When you leave...she will clean it [exam table] and sanitize the whole area down herself."

Confidential and private setting. The SBHC was viewed as a confidential and private setting which allowed teens to discuss more personal concerns because they went to their visits alone and scheduled their own appointments. "It's very private." "The confidentiality and privacy here is like, good and like, she'll never leak anything, like, the HIPAA laws won't be violated or things like that. And like he said, there is always a door that shuts." They liked that only one person was in the office at a time.

Other places it is kinda awkward... when you go there, it's like - you have to have someone with you. Maybe you don't want your family members to know, they are just there with you. They ask you questions [health care provider], but you might lie to them because the person is in there. Here, you can just come here without having to have anyone with you.

Open communication. The confidential and private setting facilitated communication between the NP and teens. "The people in the health center seem like cool people...you can open up to them." The teens felt the NP "paid attention" and that they were listened to by the SBHC staff. 
Well, one time I went [to a hospital] and they didn't understand what was wrong with my leg and I had fractured it before and I guess when I woke up, it kinda twisted. They didn't want to give no x-rays, they didn't want to do nothing. And here, they would try to figure it out. Like how it happened... which is more better, because you don't know what's going on in somebody else's body, but it's best to try understanding them.

The teens found it easy to "open up" and discuss their concerns especially if they wanted to talk privately. "They actually listen and they don't interrupt you when you are talking, and say 'no this is what is wrong with you.' They actually listen and find out everything." A female teen expressed that "[the NP] does a really, like, good job, making everyone feel comfortable...I could talk to her about anything---you know she always knows what to say."

Relationship with between SBHC staff and teen. Many of the focus group participants referenced the relationship they had with members of the SBHC staff. These relationships were valued by the teens and made the clinic a welcoming environment. The staff "gets to know you" and "know[s] when something is wrong." This relationship "makes you feel like family" or that you have a "personal doctor." Another teen referred to the NP as her "health mommy."

How is the care you receive here different from other places you go for care? Teens were asked how the care provided in the SBHC was different from the care they received elsewhere. The teens' responses to this question focused on care they received from the school nurse and other health care agencies or offices in their community. The differences identified between the SBHC and the school nurse clustered into two themes: Keep You In School and Not So Confidential or Private. Teens identified four themes, Accessibility, Trusted Relationship, Comfortable but Tiny, and SBHC Fosters Independence for Teens, as differences between the care they received at the SBHC and other places they had received health care in the community. 


\section{Differences between care provided in SBHC and School Nurse.}

Keep you in school. The most important difference identified by the teens was that they viewed the SBHC as providing care that allowed them to stay in school rather than being sent home. "When you are not feeling well, they actually try to make you feel better instead of like, making you go home fast." However, the teens explained that they understood the NPs goal was to keep you in school.

She's real strict about sending home. You have to be serious sick for her to send you home because if not, she is not sending you home. That is one of her big things. Like, she lets you know too -- if you start coming down often, asking her to go home, she lets you know right there and then, I don't send kids home unless you are dying or really hurt.

They felt the scope of services provided by the school nurse was more limited than that of the SBHC, however they recognized that the school nurses' "focus is different." "I feel like the school nurse is ...narrow as to what services they provide. But the school-based health clinic, it's like more broad." An example of this was provided by a teen with agreement from others in the group, "Yeah, the nurse can't really do much. Like the nurse will be like, oh you have a headache, well just go back to class or lie down for a couple of minutes and it usually doesn't help" or "like sometimes she doesn't even call your mom yourself. She will be like, 'just text your mother to call you'...That's just so like, not caring."

When you miss days of school, then you are behind and then you have to get on track with the other classmates and then a whole bunch of make-up work. And like-it just gets you confused, so you may as well stay at school and try to get help for your illness and just fight through the day.

Teens explained that they made the decision to go to the school nurse or SBHC based on what their needs were at the time and were more likely to go to the school nurse if they "needed an excuse." The SBHC provided them with more options, for example medication for a 
headache that could not be given by the school nurse without a written order. The participants felt because the treatment options were limited, that the nurse did not care and were often told "sorry sweetie there is nothing I can do." This was in contrast to the many options the teens were given by the SBHC NP to assist them in feeling better and staying in school.

Not so confidential or private. The environment of the SBHC was also seen as being different than the school nurses' office. "The nurse's [office] is always crowded." The school nurses' office was seen as less confidential because of the open space and many students in the office at one time.

That it's your business only and that she respects the fact that no one else should know and it's something between you and her that she is helping you with. Not like sometimes, like, I will go to the nurse and I will talk about something and I will overhear them talking about lingering topics about other kids that went in there and so on and so forth. Not really keeping it confidential and they don't care about it either. Like, they are talking about it and the students are walking in and they are listening and everything and they are saying names and so on and so forth. Like, when you go to Miss [name], she makes sure that everything you tell her or something that is going on, is not told to anyone. That it's for your eyes to see and for you guys to know.

This gave students a "bad vibe" and made their experience less comfortable. Students commented that the school nurses' office seemed less tidy than the SBHC office. However, the focus group participants commented that the school nurses' office was often larger and in a better location than the SBHC office.

\section{Differences between SBHC and other community health care services.}

Accessibility. All of the teens discussed the convenience of having the SBHC in the school. They felt the SBHC was "easy to get to" because it is located within the school building and allowed students to stay in school rather than need to leave school for an appointment elsewhere. "Don't need to wait two weeks to be seen for a cold, here you can be seen the next 
period." Appointments were scheduled during school time and did not interfere with their after school commitments. The wait both for an appointment and the time spent in the office waiting to be seen were "faster" in comparison to other sources of care. Appointments were available when they were needed and the teens felt they "can come as many times as they need to." Teens identified that the SBHC facilitated their ability to comply with school requirements including physicals for school and sports and immunizations. Services were also accessible because they were available without cost to the teen or their family. They "don't charge you." Mental health counseling, pregnancy tests, sexually transmitted disease (STD) testing were all noted to be services that were accessible through the SBHC but less accessible in the community. Teens commented that these were also services that they may forego if they had to go somewhere else because of concerns about confidentiality and privacy (Lehrer, Pantell, Tebb \& Shafer, 2007). STD/HIV testing could be done quickly and the "results are given right away." The teens felt that it was harder to trust mental health counselors outside of school because "there are no repercussions" if they did not keep their shared information confidential from other health care providers or their parents. Further discussion explained that because counselors in the community were outside the school building and the teens felt that if they shared private information with others there would not be consequences for the provider. However, if confidential information was shared by a counselor at school, the counselor would face negative consequences divulging confidential information. Crisis intervention was a service that was identified as valued and unique to the SBHC.

I wouldn't go to my real doctor about it...it would be really comfortable coming here. I think she would understand me, like she knows me and a little bit about me. So she would be like, oh, but why did this happen? Like, she already knows. She would have like a background.

Trusted relationship. Many of the focus groups discussed how the relationship they had with the SBHC staff was to the care they received. It was very important that they knew who 
they were going to see at each visit and felt the NP "was a second mom" or "companion." "You get the same person each time instead of like guessing." The staff "knows you" and viewed the care provided as "more personal" because they "show they care" were "compassionate" and had a "sweeter attitude" than their encounters with health care providers outside the SBHC. The teens also appreciated that the SBHC staff "don't treat you like a medical record" or view their position as "just a job." One adolescent explained

I feel like a lot of people go to my doctor... he sees a lot of people...every day. But here-she still sees like a lot of people like every day, but like, she remembers who I am...she will remember my face. Like, my doctor-I only go to him like, once every--whenever I have to so he really doesn't remember me...I'm kinda like a stranger to him. Here I don't feel like a stranger.

The familiarity with the NP helped the teen ask for what they needed.

You don't feel awkward about saying 'I'm getting a physical.' You don't feel awkward about doing it because one, you would be the only one in the room and two, when you are by yourself and you are bonded with the person you are working with, like who is giving the physical, it feels a lot less stressful.

Trust grew from the relationship teens had with the NP and other members of the SBHC staff. It's a trust you have in a person. You have to build a relationship with somebody in order for you to like, open up to them. So that takes time. But I do feel like that is important because you wouldn't tell somebody you don't trust something serious. Another teen added,

Especially if something happens to you and you don't want your mother to know, but you need to talk to somebody, you can talk to them. The more you trust the more you open up. Because you feel like the bond...how strong it is and how much you know and you feel you can trust that they won't sit there and go behind your back. 


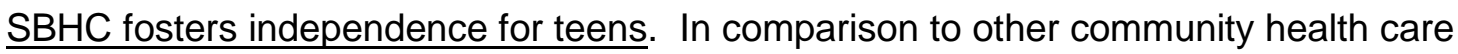
services, teens can make and attend appointments independently and "don't have to wait to for your parents to take you." They remarked on how the staff listened to them instead of their parents, they were able to fill out the forms (questionnaires), were able to "answer questions yourself," and most importantly "don't have to lie because your parent is in the room with you."

You don't have to-like lie to your parents about going to-like, scheduling an appointment for something else because you were too embarrassed by it. But you can go inside the school and do it instead of going to a hospital or clinic.

Comfortable but tiny. The environment of the SBHC was described as "tiny" by the male focus group participants. "It's kind of small. It's really small. When you step in the office there is nowhere to go." However, the environment was viewed as pleasant and comfortable. They liked that they knew who was going to be seen next, unlike larger health care agency where they could not determine who would be next as they waited in a crowded and chaotic waiting room. Also unlike other places, the waiting room in the SBHC was quiet. "Sometimes with your delayed wait, sometimes you will see people--something pleasant, other times, not so much. Some people just don't control their children...their kids are all over the place-they give you a migraine."

\section{Essential Elements of Adolescent-friendly Care in SBHCs}

Each of the essential elements of adolescent-friendly care identified through the Delphi technique was presented to each focus group. To better understand the importance of each of the elements, posters representing each essential element were hung on the walls of the focus group room. Participants were each given five sticker dots to distribute among six posters that were most important to them in any manner they wished. The researcher provided examples of how the sticker dots may be distributed to aid in understanding. A full explanation of the method used is described in Chapter III. Table 9 provides the number of sticker dots distributed by group that were placed on each of the essential elements of adolescent-friendly care in SBHCs. 
The responses were used to guide the discussion of each of the elements. The focus group participants were then asked six questions specific to the elements of adolescent-friendly care in SBHCs identified by the expert panel of NPs in the Delphi technique.

Table 9

Importance of Each of the Essential Elements of Adolescent-friendly Care to Focus Group Participants

\begin{tabular}{|c|c|c|c|c|c|c|c|}
\hline \multirow{2}{*}{$\begin{array}{l}\text { Essential Element } \\
\text { Dots* }\end{array}$} & \multicolumn{2}{|c|}{ 13-14 year olds } & \multicolumn{2}{|c|}{$15-17$ year olds } & \multicolumn{2}{|c|}{ 18-19 year olds } & \multirow{2}{*}{$\begin{array}{c}\text { Total } \\
(\%) \\
150\end{array}$} \\
\hline & $\begin{array}{l}\text { Female } \\
20\end{array}$ & $\begin{array}{l}\text { Male } \\
25\end{array}$ & $\begin{array}{l}\text { Female } \\
15\end{array}$ & $\begin{array}{c}\text { Male } \\
20\end{array}$ & $\begin{array}{l}\text { Female } \\
30\end{array}$ & $\begin{array}{l}\text { Male } \\
40\end{array}$ & \\
\hline Confidentiality/Privacy & 6 & 7 & 6 & 6 & 12 & 11 & $\begin{array}{c}48 \\
(32 \%)\end{array}$ \\
\hline Accessibility & 6 & 5 & 3 & 5 & 2 & 7 & $\begin{array}{c}28 \\
(18.7 \%)\end{array}$ \\
\hline Clinicians \& Staff & 2 & 5 & 0 & 1 & 6 & 7 & $\begin{array}{c}21 \\
(14 \%)\end{array}$ \\
\hline SBHC Services & 3 & 2 & 2 & 6 & 3 & 5 & $\begin{array}{c}21 \\
(14 \%)\end{array}$ \\
\hline SBHC Environment & 1 & 4 & 4 & 0 & 7 & 4 & $\begin{array}{c}20 \\
(13.3 \%)\end{array}$ \\
\hline $\begin{array}{l}\text { Relationship Between } \\
\text { SBHC \& School }\end{array}$ & 2 & 2 & 0 & 2 & 0 & 6 & $\begin{array}{c}12 \\
(8 \%)\end{array}$ \\
\hline
\end{tabular}

*Total number of sticker dots provided to each focus group. Each participant was given 5 sticker dots to distribute on the posters of the essential elements of adolescent-friendly care. The total number of sticker dots on each poster are reported by group.

Confidentiality and Privacy. The focus group participants were asked "What does confidentiality and privacy in the SBHC mean to you?" Two themes emerged related to confidentiality and privacy: What Happens in the SBHC Stays in the SBHC and A Private Setting. This category was selected by all the focus groups and was the essential element that was selected most frequently by the participants (Table 9).

What happens in the SBHC, stays in the SBHC. The discussion regarding the confidentiality and privacy quickly focused on the importance of confidential relationship the 
teen had with the SBHC staff. A female teen explained "Whatever happens in Vegas, stays in Vegas. Whatever happens there, stays there." The teens felt comfortable discussing their concerns because the staff "won't tell." However, the teens were aware and accepting of the limitations of the confidentiality agreement that existed to keep them safe. In comparison to other places they had received care, they were confident that the staff would not call or talk to their parents unnecessarily. Care related to mental health counseling, pregnancy, STDs, and HIV were provided as examples of services that needed to be confidential for teens and sought after at the SBHC because of the confidentiality provided specific to these services at the SBHC.

It means everything, because say you were in a situation where you tested positive for a disease, you wouldn't want the [health care provider] or whoever was in there to go out and spread the information. So I feel like privacy is everything and confidentiality. Make sure everything is kept between you two, because you don't know how personal it is.

Another teen added, "especially because it's a school, you go here, like every day so you know a lot of people and don't want your results to be known to others."

A private setting. Several environmental factors related to the SBHC enhanced privacy for teens. Teens explained "if you want to tell them something personal, they pull you to the side instead of like, you talking out loud and then keeping everything to themselves." Being able to be seen one at a time with the door shut provided a more private setting. The location of the SBHC also facilitated teens to call the clinic or go for an appointment without being recognized by a family member. However, teens also identified situations that made their experience in the SBHC less private. The SBHCs walls were thin and

You could hear like, say you were in exam room one, you can hear what they are saying in exam room two. So it's not that very private and confidential because if somebody is a loud person, you could hear everything they are saying. 
In addition, teens explained that when they were seen for dental services in one $\mathrm{SBHC}$, that the exam room was really tiny so their feet stuck out of the door when they were in the dental chair. "It all depends on who you hang out with in school also, about your shoes. Say your friend is in there and they see your shoes, they automatically know who is in there. Like, you get no privacy." None of the teens expressed that they were reluctant to use the services of the SBHC because of concerns about their privacy.

Accessibility. Focus group participants were asked "What makes this SBHC easy for you to use?" Four themes emerged during the focus group discussions specific to accessibility: Positive Energy, Location, Location, Location, Flexibility, and Services are Available When We Need Them. Accessibility was the second most commonly chosen essential element of adolescent-friendly care (Table 9).

Positive energy. Teens emphasized during the discussion that the SBHC had a "positive energy, positive impact" that felt the staff was "friendly and chill...always glad to help you." The staff seemed willing to help with any and all issues the teen presented with and their needs were well taken care of by the staff.

Location, location, location. The location of the SBHC was really important to the teens. "I like how it's already in my school, I'm in school every day... it's just right there for me to use." Transportation was an obstacle that often got in the way of accessing services outside of school however, because of the SBHCs' location “you don't have to drive to other places, you just have to stay here and just go" and "when your parents work a lot, they don't have time to bring you, you can just come here and get it done." Participants also remarked that the SBHC was located in an easy to get to location within the school itself that facilitated getting there to make appointments.

Flexibility. The teens liked that the SBHC provided them with choices regarding their care. The NP was described as “flexible, if you don't want to do something, she will offer you something else." "She's [the NP] not like, one, two or three. She is, A, B, C, D and E." In 
addition, the staff was viewed as working with the teen to provide the care they needed and finding solutions to continue care over the summer if needed. An adolescent described the social worker problem-solving how to continue counseling for him over the summer when he was not it school.

We [social worker and teen] started out like, me going down to him and talking to him. It started late, it started last week. So he said, like, during the summer time, like, he was going to find a way, like, to get a hold of me.

Services are available when we need them. Teens across the groups talked about the SBHCs ability to get students in for a variety of services "fast" with "no lines" "Can get it done right there and then or only wait a few days" which was in contrast with what they experienced with their community providers. "We can go there any time, we don't have a limited amount of visits. We can just go and now I found out that it's free. We don't get charged for visits." If the NP was not available at the time the teen needed an appointment, the staff would provide the teen with an appointment at a convenient time often the same day or would call them down to the clinic when the NP was available to see them. Urgent needs identified by the teens included sick visits, "physicals for sports that week," new student physicals, STD screening, acute mental health needs, and the evaluation of injuries or illnesses. Teens that were sick explained that they would either come to school and be seen by the NP and then get sent home if necessary or call and speak to the NP for advice about their illness. "If you are sick here, you can just call like the night before and they will say 'come in.' They will even write you like excusing you from school here." Access by phone was enhanced by the sponsoring clinic forwarding their call to the SBHC. Many of the students also had access to services during the summer either at the SBHC or the sponsoring agency. The one aspect that seemed to sometimes interfere with access to the SBHC was the need for students to get a pass to go to the SBHC. If they did not have a pass, they were typically sent back to their class to get one. However, a visit at the SBHC was felt to be viewed by teachers as "more credible" excuse for 
missing class than visits to the school nurse. Lastly, services were provided without cost to patients which increased accessibility for the teens for a variety of issues and especially for those teens without insurance.

Clinicians and staff. The focus groups were next asked "Which of the staff members at the SBHC is most helpful to you? How are they helpful?" The SBHC staff was often discussed as a single entity without a lot of delineation between the roles of the medical assistant, NP, and social worker. Responses from this question focused on four themes Makes Me Feel Comfortable, Takes Care of My Needs, Knows Me, and Reliable. The participants provided numerous examples of how they had experienced helpfulness by the SBHC staff. "They are always ready to help, no matter what and they are always open to help you to the fullest and not take shortcuts." This essential element, clinician and staff, accounted for $14 \%$ of the dots allocated to the six essential elements (Table 9). One teen exclaimed "When it's she [the NP] helpful?"

Makes me feel comfortable. The SBHC staff was described as being very friendly, cheerful, outgoing and therefore made the environment comfortable to be in. Above all, the teens felt respected, listened to, and treated "like an adult." Their confidentiality and privacy was protected by the SBHC staff. One student explained,

She always asks you why you are coming [medical assistant]. So if it's very private, she will understand and....we like stepped out and I told her what it was about so she could tell the NP and I felt fine... like I trust you.

They felt that the staff understood their perspective. "She treats you like she is in your own shoes at the moment."

Takes care of my needs. The focus group participants felt their needs were addressed on an individual basis and specific to their needs. "He's [medical assistant] just always helpful in rescheduling my appointments and making sure that I am up-to-date on certain things. He always asks me how I am doing." An important part of the care was health education. "They 
give you a lot of information and knowledge about a lot of things." An example was provided by another adolescent, "She [dental hygienist] talks you through like how many times you are supposed to floss or how many times is good for you." Others discussed how the NP revisited discussions with teens about ongoing health needs such as contraception or safer sex.

I was sexually active with my boyfriend at one point and was having sex without condoms and -- at first we was, but I realized he was trying to get my pregnant. So I just went to the school health center and I was like, [name] pop that shot. And then right there and then. She got it ready... because they basically know my whole life story. Like, that is who I go to talk to. So you know, she has been telling me about birth control because I have been telling her about my boyfriend and she has been drilling it in my head constantly. Every time I walked in there, she will be like, 'Have you thought about birth control?' I used to tell her no. So when I went in, she was happy. I call her Mom number two. That is my health mommy.

Teens appreciated that whatever they needed, the SBHC staff was willing to help. "They make you want to come back." In addition, in some instances more than one staff member was aware of a teen's needs or current situation and provided additional support if the other staff member was not available. "Everyone has to be up-to-date. So if it's like something major, like if you're getting abused or whatever."

Knows me. Teens felt well cared for because they were able to be seen consistently by the same people and the staff actually remembered their concerns and could "be even more helpful the next time" they were seen. Students mentioned that they found having a relationship with the SBHC helpful because they could trust the staff with their concerns and develop a relationship. “She wouldn't just worry about you that one time and forget. She will remember it from last year...and be more helpful." This was in contrast to other places they had gone for care. 
It feels good walking into this place and seeing that same person every time because when I used to go to my doctor, there would be a different lady at the desk every time and it's just like-- gosh, I have to tell you my whole life story. And it's just like here, like, oh, hey, [name] I'm just going to bring up your information. 'Oh, what's wrong? Why do you need to be here?' Like, it's better here."

Reliable. The NPs were helpful by being "very persistent" in following up on student concerns, making sure they were feeling better, and that they had been able to obtain prescriptions from the pharmacy of appointments from the places they were referred to for additional services.

And if the medicine that she was giving you wasn't strong enough, she would give you something a bit stronger.... if it didn't work the first time, then she would try again harder the next time. She wouldn't give up.

The teens described the NP as doing what she says she is going to do. "She don't forget anything and if she tells you, 'I'm going to give you the results the next day'...she makes sure it is done." Another teen explained that the NP following up with them, even in a more casual manner was really important.

I'm walking down the hallway and I'm in a bad mood and the [NP] from the school-based health center walks up to me and asked me how my arm is doing. That just made my whole day. I feel a lot better now.'

SBHC services. Focus group participants were each given a list of all the services available in SBHCs and were asked to circle the three services that were most important to them personally. The researcher went over the list with each group and explained each item and provided examples, if needed, for each item to enhance understanding by the participants. The choices made by the adolescents were used to guide the discussion on the services they felt were most important to provide in the SBHC. The sheets were collected after the 
discussion. Table 10 summarizes participant responses related to which SBHC were most important to them. Two participants circled four items on the list.

Table 10

Three Most Important SBHC Services Reported by Focus Group Participants

\begin{tabular}{|c|c|c|c|c|c|c|c|}
\hline \multirow{2}{*}{ Number of participants } & \multicolumn{2}{|c|}{ 13-14 year olds } & \multicolumn{2}{|c|}{ 15-17 year olds } & \multicolumn{2}{|c|}{ 18-19 year olds } & \multirow[t]{2}{*}{ Total (\%) } \\
\hline & $\begin{array}{c}\text { Female } \\
4\end{array}$ & $\begin{array}{c}\text { Male } \\
5\end{array}$ & Female & $\begin{array}{c}\text { Male } \\
4\end{array}$ & Female & $\begin{array}{c}\text { Male+ } \\
8\end{array}$ & \\
\hline \multicolumn{8}{|l|}{ SBHC Service } \\
\hline $\begin{array}{l}\text { Physical examinations } \\
\text { for school, sports, or } \\
\text { camp }\end{array}$ & 2 & 1 & 1 & 2 & & 2 & $8(9 \%)$ \\
\hline Routine check-ups & 2 & 1 & & 1 & 1 & 4 & $9(10 \%)$ \\
\hline $\begin{array}{l}\text { Treatment of acute } \\
\text { illnesses or injuries } \\
\text { (colds, sore throats, } \\
\text { rash) }\end{array}$ & & 2 & 1 & 1 & 1 & 3 & $8(9 \%)$ \\
\hline $\begin{array}{l}\text { Care of chronic } \\
\text { illnesses (asthma, } \\
\text { diabetes) }\end{array}$ & & 4 & 1 & & 1 & 3 & $9(10 \%)$ \\
\hline Immunizations & & 2 & & & & 3 & $5(5 \%)$ \\
\hline Mental health care & 2 & & & 1 & 2 & 3 & $8(9 \%)$ \\
\hline $\begin{array}{l}\text { Reproductive care } \\
\text { (pregnancy tests, } \\
\text { contraception } \\
\text { counseling, condoms) }\end{array}$ & 2 & 2 & 2 & 2 & 4 & 1 & $13(14 \%)$ \\
\hline $\begin{array}{l}\text { STD/HIV testing and } \\
\text { treatment }\end{array}$ & & 1 & & 3 & 5 & 3 & $12(13 \%)$ \\
\hline $\begin{array}{l}\text { Nutrition counseling/ } \\
\text { Weight counseling }\end{array}$ & & & & 1 & 1 & 1 & $3(3 \%)$ \\
\hline Crisis intervention & 2 & & 1 & & 1 & & $4(4 \%)$ \\
\hline $\begin{array}{l}\text { Prescriptions and } \\
\text { dispensing of } \\
\text { medications }\end{array}$ & 1 & 2 & 2 & 1 & 2 & 1 & $9(10 \%)$ \\
\hline Laboratory testing & & & 1 & & & 1 & $2(2 \%)$ \\
\hline $\begin{array}{l}\text { Individual, group, family } \\
\text { counseling }\end{array}$ & & & & & & & 0 \\
\hline $\begin{array}{l}\text { Health education } \\
\text { Classroom } \\
\text { presentations }\end{array}$ & 1 & & & & & & $\begin{array}{l}1(1 \%) \\
0\end{array}$ \\
\hline Dental care & & & & & & 1 & $1(1 \%)$ \\
\hline $\begin{array}{l}\text { Referral and follow-up } \\
\text { to specialty care }\end{array}$ & & & & & & & 0 \\
\hline
\end{tabular}


Reproductive care (14\%) and STD/HIV testing and treatment (13\%) were the services chosen most frequently by the teens. Reproductive care and Prescriptions and dispensing of medications were listed in the top three services across all groups. None of the participants ranked Classroom presentations, Referral and follow-up to specialty care, or Individual, group or family counseling in their top three services. Only students in the youngest and oldest groups chose immunizations.

Ten of the available services listed in Table 10 were discussed in the focus groups. Students were asked to choose which services they wished to discuss within the focus group. The teens' opinions regarding the importance of the various services available in the SBHC were diverse. A student commented "A lot of these are really good for me. I appreciate the school-based health center."

Physical examinations. Physical examinations were an important aspect of the care provided in the SBHC. Students discussed the importance of having physical examinations available to meet school requirements as well as for sports participation and to attend camp. The ability to have the visit "right when you need it" and at the school facilitated timely access. Sometimes it's hard for people to get...physicals. Especially since like the whole Obamacare thing - a lot of people lost their ....insurance. So I mean this is like a free and easy way to do it.

Treatment of acute illnesses or injuries. Students from all the focus groups discussed instances in which they were either sick or injured and needed to be evaluated and treated at the SBHC. Examples of acute health care needs that the teens sought care for in the SBHC included colds, sore throats, musculoskeletal injuries, acute asthma exacerbations, and infections.

That is every day with colds and sore throats and stuff like that. Especially in school you come into contact with people daily. And so I feel like you need to get treated ASAP and 
it's good that they [the SBHC staff] are there for that, so you don't spread it around the school.

The teens were impressed by the NP remembering them, the details about their medical conditions, and the NPs willingness to follow-up with them to see how they were feeling.

[She] would take the time out of their day to...call you out of class or when they see you in the hall to come and ask how you are or if you still need any help or if it got better from when she helped you.

If a teen needed further evaluation for a medical concern, the NP would make a referral to a community agency or specialty service and make sure it was scheduled.

Immunizations. Many of the teens reported accessing immunizations from the SBHC either to meet school requirements or to help protect them from infections that may affect their health now or in the future. Specifically, influenza vaccine, $\mathrm{H} 1 \mathrm{~N} 1$, and human papillomavirus vaccines were identified as important vaccinations that they had received through the SBHC.

Mental health. Counseling services provided to students in the SBHC were identified as important aspects of the care in SBHC. Students received regularly scheduled appointments for ongoing counseling. "I picked mental health care because um, they really talk to you and help you if you are feeling bad about yourself or something." Others described acute mental health needs that required immediate intervention.

Because there are times where I have mental breakdowns in school. Like I have anxiety and stuff, so I have moments where like—my heart starts racing and I start crying out of nowhere and it's because I can't breath and stuff like that. Then I start thinking stupid things that I shouldn't and now there is somebody here that can actually see me and help me calm down. It helps me more now because I don't have to wait and try and do it on my own inside the school. I have somebody who I can see instead of waiting until I get out of school. And then it's like hours from now and then it's just pointless. I want 
somebody who I can come and talk to automatically and I don't do something stupid because my mind is racing.

The support provided through the SBHC allowed students to continue attending school and remarked that it would be difficult to continue without the services they received.

Crisis intervention. Participants identified crisis intervention as a unique service provided through the SBHC. "My grandfather died recently" was an example given for this category. Others recounted family situations that had precipitated their initial visit to the SBHC. Students described that the "team" took care of them in collaboration often with the school staff when a crisis occurred so that they always had access to support services as needed during the school day.

Reproductive care. All of the focus groups discussed various aspects of the reproductive care provided in the SBHCs, including pregnancy tests, STD/HIV testing and treatment, access to contraception, condoms, and prevention education. The teens remarked on the confidentiality related to this type of care and how it allowed them to access services more comfortably.

Okay, I'm not going to be shy about it, the pregnancy one because I definitely would not go to my real doctor about that situation. Definitely not. And I don't know but here I'm very comfortable with talking about that stuff with her [the NP].

Prevention was a focus of the counseling and included abstinence, safer sex, and the prevention of pregnancy and STDs/HIV. Teens stated the staff "drills it into my head constantly."

I think it is a good idea, the fact that they give out condoms and stuff like that, to make sure that they prevent pregnancies and things that they care take care of. They want the kids to have a future and not become parents at an early age.

Teens commented that it was important for the SBHC to have STD treatment available because "won't go to my real doctor for that" because of fears that their confidentiality would be 
compromised by the clinician. The importance of fast and easy access to STD/HIV testing was explained by a female adolescent

We are all sexually active... and we may have a boyfriend or we may do other partners, but like, I remember I didn't trust my boyfriend at one point that I'm with now. So, one time we did it without a condom and instead of going to ...the hospital, waiting, making an appointment, I came here the next day, asked her to do, she pricked me, sent it in and the next day it was back--instead of sitting here and waiting a long time. Because it is scary thing to think about.

Male teens commented that it was easier to get condoms in the community because they were not available at their SBHC. "I think it is easier to get condoms out in the community than to get them in a health center...yep, you can go to any gas station, any Walmart." Despite the fact that condoms were not available in one of the clinics, the teens still thought that the SBHC would give them to them "if we really needed them." "I mean, I'm sure if you were like, hey l've been having a lot of unprotected sex, they would be like here, here is a condom."

Laboratory tests. The availability of laboratory test focused on STD and HIV testing and pregnancy tests. "I think honestly the most important one would be the STD/HIV because it would be good to know that you don't have anything and could find a way not to catch it." Participants appreciated how quickly they could receive STD testing and get the results at the SBHC, which eased their worries about having an STD after risky behavior. The importance of STD screening was emphasized to all students by the SBHC so frequently that it was regular aspect of the care they received in comparison to other places they received care where it was a more optional aspect of services.

I did STD and HIV testing, because, I feel like-well here you kind of have to be tested and other places, not really, it's more of your decision. So, I feel like that is good, because it's better safe than sorry. 
The younger adolescents debated if STD/HIV services should be available at all in the SBHC because teens their age "shouldn't be doing that."

If I were to put something at the bottom of the list it would be STD. Or not STD, but HIV testing. Because if you do that, that is your own problem, personally. Because you shouldn't be taking that risk-those risks at this age anyway, so. And that should be your own problem.

However, in the end, they also agreed that if teens needed STD/HIV testing it should be available for those students who need it in the SBHC.

Prescriptions and dispensing of medications. Discussion regarding medications focused on the availability of medications if they needed them during school for pain from injuries or headaches, for an asthma exacerbation, or if they needed contraception. It was an important service not available in the school nurse's office and often allowed them "to take care of my problem" and remain in school rather be sent back to class or home for the day. "If you need a certain medication prescribed for you, you can just go right down and get it, instead of having to be picked up by an ambulance or your parents at the school." "It's important also that she does it and doesn't tell you 'Oh go to your real doctor so he can write you this [prescription]'...she can do this for you." The NPs often also sent prescriptions to a local pharmacy for pick-up after school and made sure the prescription was covered by insurance prior to the teen leaving the clinic. Teens described that it was important to be able to get prescriptions independently.

If there is something wrong with me, I can just go to CVS and like pick it up and my mom doesn't really have to know. I mean my mom knows everything about when...I get a prescription... but it is nice think about that she could do that.

The NP also would provide medication for students without insurance "to get you through," which was viewed as important and different than other places they have been for care. One teen explained her experience, 
I didn't have health insurance, right? And I thought I had cancer because I had this thing in my boob, that is still being checked. I went to the hospital and they didn't want to see me because I have no health insurance. So I came here and they saw me and they actually gave me pills for it and stuff so the pain can stop. So I think that's important... when its serious things like that. How are you not going to see me if I'm telling you, I think I have cancer! I was freaking out.

Nutrition/weight counseling. Both male and female adolescents identified the importance of nutrition and weight counseling in their top three services. "I picked nutrition counseling and weight counseling because...I feel like they [SBHC NP] do it [nutrition and weight counseling] just to benefit you...its more personalized." Adolescent girls described the importance of this type of counseling because of personal struggles they had had with their weight while taking various methods of contraception. The SBHC staff was supportive and motivating to them to change their diet and exercise habits so they could avoid gaining weight or to help them lose weight appropriately.

SBHC environment. The essential element of the SBHC Environment was discussed following the question: "Think about this SBHC as a place, what do you like about it?" The $\mathrm{SBHC}$ was described both in physical terms and in terms of how they felt when they entered the space. Two themes emerged: Comfortable But Tiny, and Good Vibes. Fewer of the teens felt the SBHC Environment was important in comparison to the other elements, $13.3 \%$ of the sticker dots were allocated to the SBHC Environment (Table 10).

Comfortable but tiny. The SBHC space was described by several of the groups as a small space that was sometimes difficult to negotiate especially among the male teens. They explained they "Need to take your backpack off before you enter the door" "and [it was] hard to sit down sometimes." However, most described the SBHC as comfortable, attractive, and that the size of the clinic did not deter them from using the services of the SBHC. Cleanliness of the space was emphasized across the groups. One teen explained "so with it looking decent and 
clean and everything, you are going to be like, okay, maybe they are going to do what they are going to do and everything."

The female teens and some of the male teens enjoyed the health education materials that hung on the walls and felt that the manner that materials were presented enhanced both their understanding of various health topics and made them think, although they mentioned that the posters were not changed often. "You really get into it [reading the posters], the way they put in the little comments...so you start going around and you want to read it." One group also described enjoying the art work that was done by the students and hung on the walls of the clinic. The male teens, preferred artwork that was not health related

To help take your mind off of -- I personally don't want to walk into a nurse's office or a school-based health place and just see like, a picture of guy with corroded arteries and drinking and doing other drugs. I don't want to see that. I want to see something calming. They felt that the SBHC staff "already said it enough" and did not need to display the same health information on the walls that had been discussed during their visits.

The male teens also described their desire to have a larger space that had several exam rooms to increase the capacity of the clinic and make it more accessible. Visibility within the school was also viewed as important. The teens suggested that the lack of signage outside the clinic and the SBHC's location within the building may make it difficult for new students to find the clinic and recounted their experiences going to the SBHC for the first time and having difficulty finding the office. "You would be like on a journey, because you would be like 'where is the school-based health center?"

Good vibes. The teens described the $\mathrm{SBHC}$ as a place that gave "good vibes." "Their vibe, they give a feeling the way they help you." The clinic is "comfortable walking into. Like my heart is not beating." The atmosphere was relaxed and felt safe. "They don't even have to say anything, you just walk in and you just feel like, oh, I'm home." The demeanor of the SBHC staff was a key component to the teens feeling welcomed and accepted. 
They are always smiling. Like there is not like one moment where they are not smiling and it's just like - when you walk in there, you automatically feel like, cheered up, because they are like happy people. They are good people.

The staff was also described as "really loving and kind," understanding, and not judgmental. A teen explained "You feel like you have a strong connection after...one visit" and that the staff remembers you the next time you come in for an appointment. They also felt that their problems, no matter how small, were addressed with the appropriate amount of attention and as often as needed.

I come here for a lot of really little things. I will have a paper cut and I will come in and she will be like 'what's going on?' I'm like 'I have a paper cut.' She's [the NP] like, 'oh okay.' But my doctor would be like, 'Why are you coming here?'

Relationship between the SBHC and school. The essential element of adolescentfriendly care, Relationship Between the SBHC and School, was posed to the focus groups with the question "Does the relationship the SBHC staff has with the school staff including the principal, nurse, or teachers matter to you? Can you give me an example of how it matters?" The focus group discussions regarding the relationship between the SBHC and the school focused on three themes: The School Supports the SBHC, Working Collaboratively, and All Teacher's Don't Know About the SBHC. This essential element of adolescent-friendly care (Table 9) was chosen the least by the focus group participants (8\%).

The school supports the SBHC. The teens felt there was a very positive relationship between the school and the SBHC. "I feel like if they didn't have a good relationship, they wouldn't still be here." School staff including teachers, coaches, and the school nurse referred teens for care at the SBHC. "If they know something is wrong with you, they will tell you to go to the school-based health center." Peers, who had previously used the SBHC were also an important source of referral. "Well one of my friends...she said...they are really good there and they are trying to help her." The adolescents explained that the school advertised the services 
of the SBHC through overhead announcements especially when sports or school physicals were due. New students were also often referred to the SBHC for their physicals and the teens were impressed that the school staff had communicated their need to the SBHC staff and they were greeted by name when they arrived for their appointment. Typically no resistance was felt by students who wished to go to the SBHC during class time. Students also felt that if they were going to or returning from the SBHC it was a more "credible" reason for missing class than if they had been at the school nurse's office and that their health need was seen as important by the teacher.

After you go down there for the first time, when you come back with the signature and you show it to the teacher that you were at [the SBHC], they know, it was nausea and that you actually had a valid reason to go down there. You are not lying to them. You are telling the truth. She is like a really credible source...It makes it easier for those students that aren't so credible to get the credibility that they need to get the care that they need.

Working collaboratively. The school nurses and the SBHC were viewed as supporting each other in the care of students. Many of the teens were referred by the school nurse the first time they were seen in the SBHC.

Yeah, they help each other out...when I first came here, before I was signed up [for the $\mathrm{SBHC}]$, I went to the school nurse because...I felt really lightheaded and I felt sick. My throat was just killing me. So I went to the nurse and um they couldn't really do anything about it and then I didn't know that I had the papers signed for here [SBHC] and it turned out that I did. So they sent me over here and they both went and check me and stuff. So they like, helped each other out. They work together.

The school nurses often sent teens to the clinic when they felt they needed additional care or medications. Students remarked that they were told to "Make sure you stop by the school health center just to make sure, because they know better." 
All teachers don't know about the SBHC. Despite the positive support the school and school nurse provided to the SBHC and its use by the teens many described a lack of knowledge by teachers related to the services of the SBHC. "I'm not sure the teachers understand...I think they think it's basically like the nurse." Some had encountered teachers who had no idea that the school had a SBHC. For example, one student asked "'Can I go to the health center?' And they [the teachers] are like, 'the what?'” Others explained that they knew this because when they received a pass to go to the SBHC "they just write "nurse"' on the pass.

However, teachers who were aware of the SBHC services were supportive of students accessing the services. "The past few times I have been in class and people are like 'I don't feel good' They [tell them] 'go to the school-based health center.' They don't even say the nurse anymore." A teen explained that once she was ill and a teacher brought her to the SBHC for evaluation. 'She stopped her whole class to bring me down here. I was like 'Oh my God.' She said 'I'm going to help you and I'm going to get you help."'

\section{Summary}

The focus group analysis provides this mixed method study with the perspective of adolescents who have been consumers of the health care services provided in SBHCs. Each of the essential elements of adolescent-friendly care identified in the first phase of this study was discussed by the focus group participants. Confidentiality and privacy were most important to the teens and framed their willingness to engage in services and the types of services they sought. Feeling comfortable and connected to the SBHC staff facilitated their use of the SBHC. Accessibility was found to be a key factor to timely access to care for both school requirements and individual health, mental health and dental services and fostered an independent role in health care services. The atmosphere of the SBHC, as well as the attitude of the staff toward the adolescents, influenced their willingness to engage in the services of the SBHC. The school staff members, including the school nurse, were sources of referral for the SBHC as well as endorsement for the services. 


\section{Mixing of Quantitative and Qualitative Data}

The final phase of this explanatory sequential mixed methods study involved answering the research question "How do the perspectives of NPs and adolescents compare regarding the essential elements of adolescent-friendly care in SBHCs?" This was accomplished by comparing and contrasting the perspectives of the expert panel of NPs and adolescent focus group participants regarding the essential aspects of adolescent-friendly care in SBHCs using thematic content analysis (Krippendorff, 2013). Figure 3 provides a conceptual model of the essential elements of adolescent-friendly care in SBHC from the perspectives of the NPs providing care to adolescents and the adolescent receiving the services provided through the SBHC. The model is depicted as a web, typical of complex adaptive systems (Lindberg et al., 2008). The web is supported by the overarching themes of comfortable and trusted relationship and includes the six elements of complex adaptive systems and the six essential elements of adolescent-friendly care.

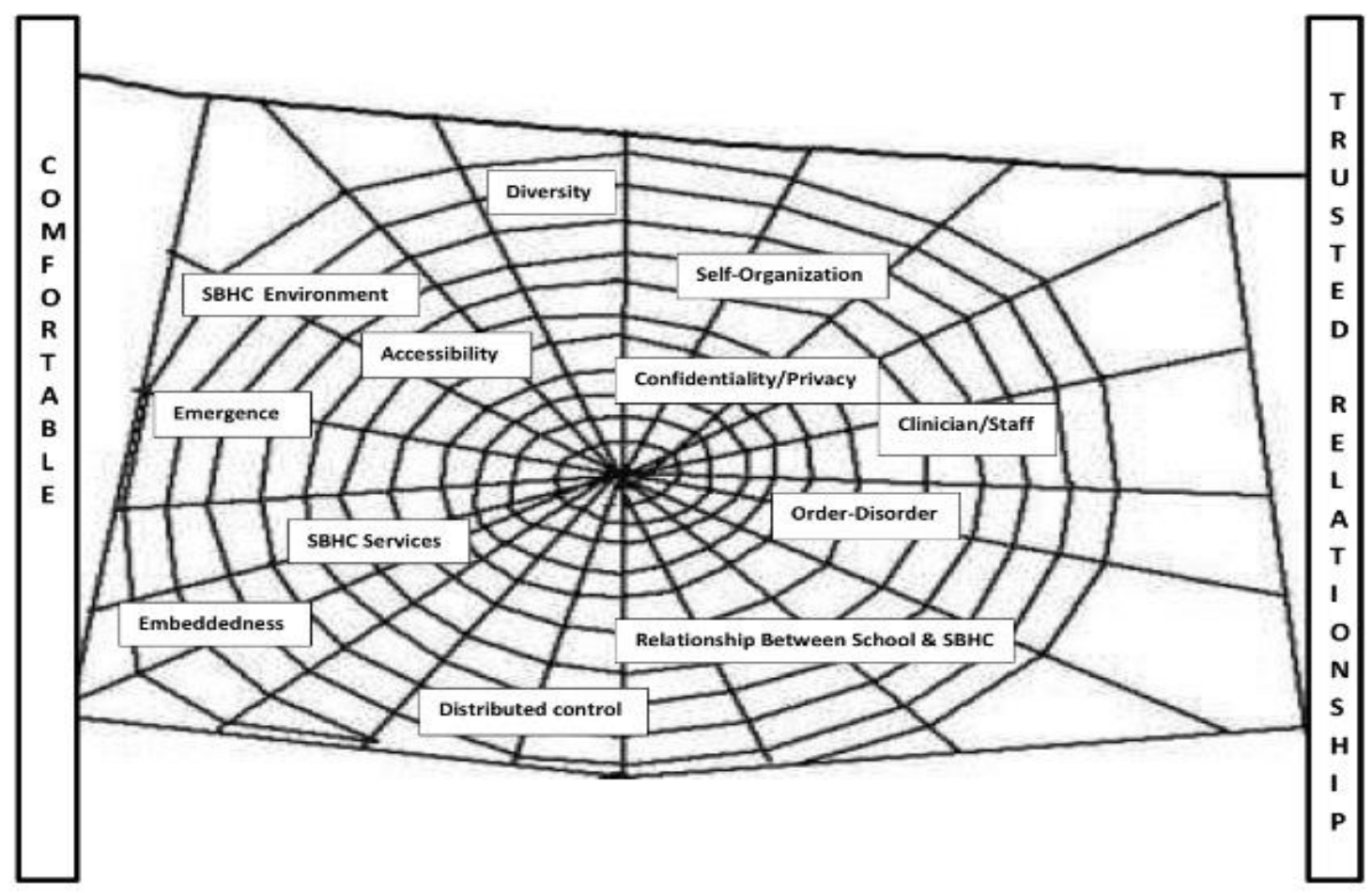

Figure 3. Essential Elements of Adolescent-Friendly Care in SBHCs as a Complex Adaptive Systems Model 


\section{Overarching Themes}

The analysis revealed two overarching themes that linked the six essential elements to providing adolescent-friendly care in SBHCs. These overarching elements emerged throughout the six essential elements. Teens need to be both comfortable to receive and return for SBHC services and to develop a trusted relationship with the SBHC staff.

Comfortable. First and foremost the teens needed to be comfortable in all aspects of their interactions with the SBHC staff. They described the necessity of the office providing a "good vibe" when they walked in to either make an appointment or receive any of the clinical services available at the SBHC. Comfort was enhanced by helpful, smiling staff who greeted the teens genuinely and were interested in helping them with any issue no matter how large or small. Comfort was also enhanced by the confidentiality and privacy that was extended to the teen. They felt that the more their information was protected the more they were willing to share their concerns or engage in services with the staff. Even small gestures, for example, not asking why the teen needed an appointment in front of others assisted in making them feel safe and comfortable. In addition, the teens understood their rights regarding confidentiality and were confident that the staff "would not leak" anything that was shared. Privacy added to their level of comfort. The accessibility of services, allowed the teens to get care when they needed it without being seen by others in the outside community. The diversity of services available in the SBHC further aided teens in the timely access to services for more sensitive concerns. The teens viewed the endorsement of the SBHC by staff, coaches, school nurse, and peers as further evidence that the SBHC was a safe and reliable place to receive care. The teens engaged in services as they became more comfortable with the staff, which allowed them to share their concerns and have their health and mental health care needs addressed. The expert panel also identified that being comfortable caring for adolescents and being able to comfortably address their unique needs as essential to adolescent-friendly services in SBHCs. 
Trusted relationship. Second, the presence of trusted relationship between the adolescent and SBHC staff was essential to truly adolescent-friendly services. The teens discussed how this relationship developed over time and was enhanced by continuity that existed in the SBHC. Many described the NP as their friend, confidant or "second mother." Treating the teens with respect and as important partners in the health care relationship served to enhance the relationship. The teens expressed that the more they were bonded with their provider the more they were willing to engage in services and share about their concerns with the NP. Honoring both their privacy and confidentiality further developed this trusted relationship. The NP "doing what she said she would do" and remembering the unique needs of each of the SBHC patients made the teens trust the NP. The expert panel of NPs also recognized that continuity was an important aspect of adolescent-friendly services in SBHCs however did not reach consensus on specific items related to developing clinical relationships with their adolescent patients.

\section{Essential Elements of Adolescent-friendly Care in SBHCs}

Confidentiality and privacy. Both the NPs and adolescents identified confidentiality and privacy as essential aspect of adolescent-friendly care in the SBHC. Two themes described Confidentiality and Privacy: What Happens in the SBHC, Stays in the SBHC and A Private Setting. Appendix X provides the NP and adolescent perspectives on confidentiality and privacy.

What happens in the SBHC, stays in the SBHC. The NPs and adolescents agreed that confidentiality is an important aspect of health care services. The NPs indicated that it was their responsibility to know the health laws that applied to adolescents and the limits of the confidentiality agreement. In addition, the NPs recognized that the perception of confidentiality by the teens was important. Clinical services, especially those that were more sensitive, needed to be protected from parents and guardians as well as school personnel. The 
adolescents described confidentiality as an important factor in their decisions about seeking care and discussing concerns with the SBHC staff.

Adolescents were aware of the limits of the confidentiality agreement and felt that if the SBHC staff needed to share information with a parent or guardian that they were "looking out for them." They discussed that the confidential nature of their relationship allowed them to seek care independently and communicate openly about their concerns. Many examples were provided specific to how their confidentiality was protected by the SBHC staff. These included the ability to make their own appointments, the staff not calling their house, "never leaking anything," and giving the teens choices about what information was or was not shared with others. Similar to the opinion of the NPs, more sensitive concerns including mental health, STDs, pregnancy and HIV were services that needed to be kept confidential.

A private setting. The NPs felt that the SBHC setting needed to be a place where both the patient and the provider could interact confidentially and the teens would feel safe to talk with the NP. The teens provided a lot of specific examples about how their privacy was either protected or potentially placed in jeopardy. They liked that the SBHC office had a wall or "door that shuts" and provided more privacy than a curtain. However, thin walls potentially allowed their conversations to be overheard by others. The SBHC protected their privacy also by being in the school and not out in the community where they could be seen by others entering a health care agency or their voice being recognized by a family member who may answer the phone when they called for an appointment. The teens recognized that friends may see them in the clinic and know that they were receiving care. However, this did not deter them from continuing to receive care in the $\mathrm{SBHC}$.

Accessibility. The two groups had views that were similar regarding accessibility to the $\mathrm{SBHC}$, however there were notable differences as well. Overall, five themes emerged related to accessibility (Appendix Y): Inclusive Environment, Positive Energy, Flexibility, Location, Location, Location and Services Available When Needed. 
Inclusive environment. The NPs identified the theme of Inclusive Environment as essential element of adolescent-friendly services. Services provided through the SBHC needed to be for all students and not perceived as a place for only selected students or groups. The adolescent girls commented that "even the boys" were regularly using the SBHC.

Positive energy. The teens discussed the importance of their perception that the SBHC was a positive environment because the staff was friendly and welcoming. "I just walk in and she is always friendly and chill, always be glad to help you." They felt that the staff was there to be helpful to them which provided "A positive energy, it's a positive impact" for the teens.

Flexibility. Both groups identified the theme of flexibility. For the NPs, flexibility focused on accessibility of appointments that needed to be available despite complicated schedules of both the students and the school. The NPs felt they needed to have appointments available through numerous mechanisms including walk-in visits, urgent visits and scheduled appointments. In addition, the NPs recognized the importance of needing to be flexible and rescheduling appointments for teens so that they could access services when they needed them. The theme of flexibility was described differently by the focus group participants. They described that the NP provided them with options regarding their care and included them in decisions about what may work best for them. The staff also was flexible in providing appointments for the teens during the summer so that they could continue their care.

Location, location, location. The teens spoke about how important the location of the SBHC was to them and specifically, that the SBHC was located in the school building and in a central location that made it accessible to them. "I like how it's already at the school, I'm in school every day. So like, it's just right there for me to use." This was particularly important because it allowed teens to remain in school and receive the care they needed especially for students with working parents who would have a difficult time getting to an appointment elsewhere. However, the teens explained "they [SBHC staff] are really helpful, the school 
should find a better place for them to have an office" so that more students could find the clinic more readily.

Services available when needed. Both groups discussed accessibility in terms of services being available when they were needed and not at some point in the distant future. The NPs felt that the SBHC was open during the school day and provided easy access to appointments for the teens. They had an "open door" policy that allowed students to access the SBHC when they needed care. Access was enhanced because the services were offered free of charge to the teens without insurance and for those with insurance a referral for services was not needed to receive care in the SBHC. The teens spoke more specifically about accessing services "fast" when they needed care for a variety of reasons that included sick visits, evaluation of injuries or illnesses and physicals for school or sports. If the staff was busy seeing other teens, they would either wait for a short period of time or return to class and be called down when the staff was available. The staff was also available to them in the summer and via phone if they needed assistance for a health or mental health concern. The accessibility of services was described as "a safety net because there is a nurse [NP] here full time, rather than partial." which was a different experience than being in a school that did not have a SBHC or full-time nurse and relied on the school's office staff to fill this role when they were not in the building.

SBHC clinicians and staff. The SBHC Clinicians and Staff essential element of adolescent-friendly care was most important to the NPs. Most of the items $(n=51 ; 52 \%)$ that reached consensus in the Delphi Technique were from this element. In contrast, teens allocated $14 \%$ of their sticker dots to this category. However they spoke extensively about their SBHC staff members during the focus groups. The perspectives of the NPs and teens were focused in different yet complementary areas. Seven themes emerged (Appendix Z): Showing Respect, Makes Me Feel Comfortable, Working Together, Helps Me, Knows Me, Competence, and Reliable. 
Showing respect. The NPs identified the importance of genuinely liking to work with tweens and teens and being very respectful to the teens they cared for in the SBHC. This was accomplished by greeting and communicating with teens with sensitivity and compassion from the time they entered the clinic and throughout their visit. Care needed to be provided in an unbiased, judgment-free, culturally, and socio-economically sensitive manner by all staff members. The NPs emphasized the need to be honest and truthful with their teen patients even in difficult or stressful situations.

Makes me feel comfortable. This theme echoed the thoughts of the NPs in the Showing Respect theme. The teens wanted to be respected, greeted in a friendly and welcoming manner, and talked with by the staff. They appreciated that the SBHC staff had an understanding for what they were experiencing and showed their respect for them by being interested in what they were concerned about during their visits. The teens also identified the importance of the SBHC staff respecting their privacy as an aspect of making them feel comfortable.

Working together. This theme described the importance of the NP and teen establishing a health care partnership. The NPs felt that it was essential to collaborate with their adolescent patients and work together toward health-related goals. Communication and providing information clearly were key aspects to effectively working together. The NPs stressed listening to teens, especially before providing advice, and endorsed a positive approach versus preaching at them.

Helps me. The teens described their interactions with the SBHC staff in terms of helpfulness. They were assisted by the staff in numerous ways that included simple tasks like scheduling appointments to more complex needs including health education, care for chronic illnesses, and mental health counseling. 
Knows me. Teens also identified the importance of the relationship they had with the SBHC staff. This relationship was a key aspect to their willingness to access health care services in the SBHC and to return for care as needed.

You feel comfortable with the same person because you have been going to them for so long and you know that they have kept your information private. They already know you, so you don't have like a different doctor each time and you have to tell them every time... what is wrong with you.

Competence. The NPs stressed the importance of being a knowledgeable and competent health care provider for adolescents. Competence was further defined by their clinical knowledge and skills specific to the needs of adolescents. A strong knowledge of adolescent development and the unique needs of this population were emphasized. In addition, the NPs need to advocate for the needs of teens and familiar with community resources available to support their patients was viewed as essential. The ability to provide or assist teens to access mental health services and provide trauma-sensitive care were emphasized as important roles.

Reliable. The final theme, Reliable, described the teens' view on the important role the NP provided with persistently following up with the teen to insure they were improving or were able to get the medication they needed. Reliability was also demonstrated by the NP referring teens for appropriate services in a timely and seamless fashion as needed.

Clinical services. Both groups identified the diversity of clinical services as an essential aspect of adolescent-friendly care. The NPs identified five themes of Comprehensive Care, Reproductive Care, Mental Health Care, Easy Access to Services, and Consistent Provider related to SBHC Clinical Services. The adolescents' perspective focused on specific services, and similar to the NPs, also identified Mental Health and Reproductive Care as important aspects of the care available in the SBHC. Appendix AA provides the NP and adolescent perspectives. 
Comprehensive care. The NPs identified that providing a full range of services to adolescents in the SBHC was an important aspect of care to meet the diverse needs of their adolescent patients. These services included preventive care, immunizations, physical examinations, acute care visits, screening for sexually transmitted infections, pregnancy tests, reproductive care, contraception, behavioral health, and dental care. The teen perspective echoed the services identified by the NPs and included physical examinations, immunizations, acute visits, mental health, reproductive care, pregnancy tests and counseling, STD testing and treatment, laboratory testing, and dental care. They also added nutrition and weight counseling, crisis intervention, and referrals for specialty services to their perspective of what services were important in SBHCs. The teens also recognized that even if they did not need a service now others students may benefit from it or they may need it in the future.

Mental health. Mental health care access was an area highlighted by the NP expert panel. They felt that mental health services, including screening, on-site counseling and referrals to additional mental health services, should be to be available to students at the SBHC. Similarly, the adolescents' perspective emphasized access to mental health services for them in the SBHC. The teens also identified that the SBHC was instrumental in providing the support the teen needed to remain in school. The focus group participants felt that Crisis Intervention was a unique service available to them in the SBHC and was identified as an entry point to SBHC services for teens.

Reproductive care. The NPs' perspective related to quick and easy access to reproductive health care services through the SBHC. They also emphasized the need for the NP to be knowledgeable about providing reproductive care including pregnancy prevention in the context of the SBHC as well as the services available in the community for the adolescent to access if contraception or reproductive care was not available at the SBHC. Teens were more specific and identified the need for counseling to prevent pregnancies and STDs that occurred 
repeatedly and over time. They also thought the availability of contraception and condoms was an important aspect of the clinical services available in the SBHC.

Easy access to services. Easy access to SBHC services was enhanced by the availability to provide point of care testing. Access was also enhanced by the affordability of services and the ability to provide services for free or to directly bill insurance. The NPs also identified providing medications to students through the clinic directly increased easy access. The adolescents remarked that it was easier to go to the SBHC for a medication (e.g; albuterol for asthma) than to have a parent come to the school with the medication or to need to be brought to the hospital via ambulance. The teens also liked that they could go to the pharmacy independently for a prescription provided through the SBHC without involving a parent. For teens without insurance, the SBHC also allowed them to get the medications they needed without cost, which would not have been possible otherwise without cost to them or their family.

Consistent provider. The last theme identified by the NPs related to SBHC Services was the importance of a consistent provider and avoiding "floating" providers. They felt this enhanced a more trusting relationship between the teen and health care provider.

SBHC environment. The essential elements of adolescent-friendly care in SBHC related to the SBHC environment included three themes: Welcoming to All Teens, Comfortable but Tiny, and Good Vibes. Appendix AB includes the perspectives of the NPs and adolescents.

Welcoming to all teens. This theme was identified by the NP expert panel and focused on the importance of the SBHC providing a friendly and welcoming environment that fostered inclusivity for all students. In addition, it was essential for the teens to feels safe, both emotionally and physically, when they received care in the SBHC.

Comfortable but tiny. The teens described the SBHC environment as "comfortable but tiny" however it was clean and organized. "It makes me feel like safe. It makes me feel like I won't contract anything." The appearance of the SBHC enhanced the teens' belief that they would be taken care of appropriately. The size of the SBHC and the examination rooms was 
commented on by the male adolescents however, did not interfere with their willingness to access care in the clinic. The artwork and posters on the wall met with mixed reviews, the female adolescents felt that this added to the atmosphere of the clinic and provided the opportunity to learn about their health. The male adolescents preferred non-health related pictures to increase their comfort level. The thin walls and small exam rooms did cause concern that their privacy and confidentiality may be compromised in the SBHC, however this did not interfere with the teens' willingness to engage in services.

Good vibes. The final theme related to the SBHC environment centered on how the teen felt when they entered the SBHC. Similarly to the first theme Welcoming to All Teens described by the NPs, the teens stated that they felt safe and comfortable in the SBHC. The staff facilitated this by being friendly, "really loving and kind," nonjudgmental and understanding. The staff was viewed allowing the teens to come for care as they needed, regardless of how big or small their concern was. "When you walk in here, you just automatically feel like, cheered up, because they are just like, happy people. They are good people."

Relationship between the SBHC and school. The final essential element of adolescent-friendly care was the Relationship Between the SBHC and the School. Three themes emerged: Working Collaboratively, The School Supports the SBHC, and All Teachers Don't Know About the SBHC (Appendix AC).

Working collaboratively. The NPs identified the importance of the SBHC staff and the school staff, including the principal, teachers, security staff, secretaries, staff, and school nurse, having a positive working relationship. Part of this relationship hinged on the NPs familiarity with the school and board of education policies and regulations and how they pertained to the care provided by the SBHC staff. The school staff was described as the gatekeepers for student access to the SBHC and without a positive relationship the students would be less likely to be referred for care, receive the services of the SBHC, or for the SBHC to function 
successfully. The NPs also identified the importance of coordination of services between the school and SBHC.

The adolescents identified the very important working relationship between the school nurse and the SBHC. Many examples were discussed in which the school nurse was the person who endorsed the SBHC and encouraged the student to seek further evaluation for their medical issue through the SBHC. "She talked me into it. She was like, they are good people there. And then I went in."

The school supports the SBHC. The teens described the many ways their school supported the SBHC. The relationship was seen as a positive. "I feel like if they didn't have a good relationship, they wouldn't still be here." However, they also commented on not really witnessing interactions between the school staff and SBHC. The services of the SBHC were also advertised by the school via overhead announcements. Referrals were made by the school especially to fulfill requirements for school entry and inclusion. Coaches and athletic trainers sent students for sports physicals and evaluations of sports-related injuries. Others described that instead of being sent to the school nurse when they were sick, that they were now sent directly to the SBHC instead. Many commented that their first visit to the SBHC resulted from a member of the school staff endorsing the SBHC and recommending they access the services provided by the SBHC. Peers were a positive mechanism for referral for services, especially those that had positive experiences with the SBHC.

All teachers don't know about the SBHC. Across the focus groups, teens described situations in which they discovered that their teacher had little or no knowledge of the existence of the SBHC or the services available to students. "I think they just think it's basically like a nurse, just the nurse to them basically." However, there was great variability in this knowledge from teacher to teacher and from school to school. The NPs did not identify knowledge about the SBHC by the teachers or staff as an essential element of adolescent-friendly care. 


\section{Summary}

The analysis of the focus group data provides a perspective that will contribute to some understanding of the adolescent perspective related to the care they receive in SBHC. All of the essential elements of adolescent-friendly care identified by the expert panel were also important to the adolescent participants. Confidentiality and privacy were most important to the teens, however they spoke eloquently about the factors that made the SBHC accessible, the diversity of available clinical services, and the SBHC environment. The importance of feeling comfortable in order to access and return for services was emphasized by the focus group participants. Comfort was achieved by "the vibe" that the SBHC provided within their interactions with teens and included being respectful, welcoming, and happy to see them. This was further facilitated by the staff allowing the teens to have access to care when they felt they needed it and at whatever frequency was necessary. The importance of establishing and maintaining a relationship with the SBHC staff facilitated access to care and their willingness to seek care for more sensitive issues such as mental health and reproductive health concerns. The adolescents emphasized the need to be known by their provider and for the NP to individualize their care specific to their unique needs. The Relationship Between the SBHC and School was viewed as least important to their health care experience, however this element was identified as a key factor in both learning about the services available and accessing care in the SBHC.

The NPs and adolescents provided complementary perspectives on adolescent-friendly care in SBHCs. These important perspectives are discussed within the context of the current literature and the potential clinical and health policy implications related to this research study in Chapter V. 


\section{Chapter V}

\section{Discussion}

This explanatory sequential mixed methods study was conducted to better understand the perspectives of an expert panel of NPs caring for adolescents in SBHCs and adolescents as the consumers of SBHC services. Both of these perspectives are currently missing from the existing research literature. Adolescents are a healthy population with the major sources of morbidity and mortality attributed to preventable causes including the consequences of risktaking behaviors and injuries (Miniño, 2010). Health care services for adolescents are designed to provide teens with health education and anticipatory guidance to decrease the morbidity and mortality in this population. Increased attention to adolescent health care services has occurred in the past decade however, the rates of preventive visits decrease steadily throughout adolescence just as many of the sources of morbidity and mortality increase in this population. For example, the rates of sexual activity steadily increase throughout adolescence with $30 \%$ of $9^{\text {th }}$ graders to $64.1 \%$ of 12 th graders reporting sexual activity (CDC, 2014b). Unprotected sex can have significant consequences that include unintended pregnancy and sexually transmitted infection. The rates of alcohol, tobacco and substance use also increase throughout adolescence and can lead to motor vehicle accidents, drowning, and dependence (CDC, 2014b).

Less than half of teens receive an annual preventive visit and those that lack insurance, lack awareness regarding available services, or encounter providers and health care systems that are not responsive to the concerns of adolescents are even more likely not to engage in appropriate preventive health care services and as a result miss opportunities for timely care and appropriate intervention (Caldwell \& Berdahl, 2013; Ford et al., 1999; Ginsburg, 2002a; McKee \& Fletcher, 2006). Even among those adolescents who had an annual preventive visit, less than half received the recommended anticipatory guidance and far fewer, $40 \%$, spent time alone with their provider to discuss more private concerns related to sexuality, reproductive 
concerns, substance use, and mental health concerns (Irwin et al., 2009). Lack of access to comprehensive health care services, including prevention counseling and anticipatory guidance, creates missed opportunities for early identification and intervention for at-risk teens and likely contributes significantly to the morbidity and mortality that occurs during and after adolescence. Therefore, identifying the essential elements of adolescent-friendly care from the perspective of both the NPs and adolescents was a critical next step to designing health care services that are dynamic and responsive to the diverse needs of adolescents.

Complex adaptive systems theory provided the theoretical and philosophical underpinnings for this study. Complex adaptive systems theory seeks to explain phenomena through a holistic interplay of an entire system rather than a reductionist perspective of individual parts of a system (Cilliers, 2000; Holden, 2005) and allows for the identification of "the tiny differences that made a big difference in producing the 'new' system [in] contrast to the forces that allow systems to get 'stuck' in suboptimal solutions and interventions" (Begun et al., 2003, p. 279). Current systems that provide adolescents with preventive care need to be examined from new and different perspectives to determine how health care providers can better meet the needs of the people they serve. The goal of this research was to identify what was essential in providing and receiving adolescent-friendly care in SBHCs.

The SBHCs as a complex adaptive system contain multiple dynamic components poised to respond to the ever-changing needs of those accessing this health care system (Lindberg et al., 2008). The essential inter-related elements of diversity, self-organization, embeddedness, distributed control, emergence, and coexistence between order and disorder allow the SBHC to adapt and/or respond to the potential and ever changing needs of those adolescents accessing this health care system (Cilliers, 2000; Lindberg et al., 2008). The components of complex adaptive systems are necessarily interconnected, dynamic, and flexible to insure the survival of the SBHC. The SBHC functions far from equilibrium and allows the system to respond, change, and adapt as needed to meet the ever changing needs of the system. It is "the robust nature of 
complex systems, their capacity to perform in the same way under different conditions, that ensures their survival" (Cilliers, 2000, p. ix). Complex adaptive systems theory provides the opportunity to more clearly understand the dynamic interplay among the unique health care needs of the adolescents using these services, the SBHC services available to adolescents, and how current SBHC services can lessen gaps in preventive health and mental health services for this population (Daley, 2012; Cilliers, 2000; Lindberg et al., 2008; Wilson \& Holt, 2001). Table 11 provides examples of the complex adaptive system elements in SBHCs.

Table 11

The Complexity of School-Based Health Centers Complex Adaptive Systems Element $\quad$ SBHC as a Complex Adaptive Systems: Properties and Examples

Diversity

Variety of health (e.g. physical examinations, immunizations, reproductive care), mental health (e.g. individual \& group counseling, crisis intervention, dental services available

Embeddedness Located in school, health system, school district, and state.

Order-Disorder

The availability of services change as needs of individual and/or population change; appointments scheduled/rescheduled as needed and available on a on a walk-in basis to meet the adolescents' and school's schedule

Self-organization

Flexible and responsive to the health and mental health needs of adolescents, their family, the school, and as issues emerge in the community

Distributed control Collaborative clinical relationships with adolescents, parents, school staff, and school nurse; referrals to $\mathrm{SBHC}$ by school staff/nurse; referrals to/from community agencies

Emergence

The services of the SBHC adjust or change to meet the needs of the adolescents; gaps in care recognized and services adjusted to better meet the needs of adolescents, school, or community

Note. Adapted from "Rethinking school-based health centers as complex adaptive systems: Maximizing opportunities for the prevention of teen pregnancy and sexually transmitted infections," by A. M. Daley, 2012, Advances in Nursing Science, 35(2), p. e41. Copyright 2012 by Wolters Kluwer Health | Lippincott Williams \& Wilkins. 


\section{Essential Elements of Adolescent-Friendly Care in SBHCs}

The findings of this study support a conceptual model for Adolescent-Friendly Care in School-Based Health Centers (Figure 3) as a complex adaptive system. Two overarching themes and six essential elements, were identified in this study, that were essential to adolescent-friendly care in SBHCs. These eight aspects were interconnected. This dynamic interplay among the elements described the patient care experience in SBHCs for adolescents. The discussion of each of these aspects with connections to the existing literature follows.

\section{Overarching Themes}

Feeling comfortable was an overarching and foundational aspect of entering into and continuing care in the SBHC. It was found throughout the essential themes and was a necessary factor for teens to participate and remain engaged in the SBHC. Familiarity and acceptance by the SBHC staff promoted a sense of openness and belonging for the teens. Feeling comfortable, rather than nervous or awkward, allowed adolescents to access appointments for a variety of health and mental health services. Respect for and understanding of the adolescents' rights specific to confidentiality and privacy promoted the sharing of more sensitive concerns (Ginsburg et al., 2002b; Schaeuble et al., 2010). An understanding and belief that the clinician and staff would keep the teen's information safe enhanced their comfort and willingness to reveal additional information or concerns. The SBHC environment also enhanced adolescents' sense of comfort by providing privacy during visits. Accommodating to meet each individual adolescent's needs made their experience personal. All of these factors provided a very positive mechanism for encouraging teens to access the health and mental health services as they needed them.

Feeling accepted, a sense of belonging, and being connected are important developmentally to teens as they navigate adolescence. It appears to have allowed them to enter not just the physical space of the SBHC but to emerge into a health care experience and 
relationship with the SBHC clinicians/staff specific to their individual needs and on their own terms.

Health care providers need to be aware and committed to the important role they play in facilitating or hindering adolescents' engagement in health care services through attention to comfort and being comfortable. Preventive health care is essential to present and future health and healthy behaviors. The interactions teens have as they are learning to navigate the health care system more independently likely will shape their attitudes toward these health and mental health services now and in the future.

A trusted relationship was also an overarching theme found throughout the essential elements and grew directly from the adolescents' comfort with the NP and other members of the staff within the SBHC. This relationship was personal and dynamic. It grew over time and was enhanced by providers taking the time to listen to and get to know the adolescents. The trusted relationship also allowed the teen to "open up and trust" that their needs would be addressed appropriately and their information kept confidential. The NPs recognized the importance of consistent staff to care for teens and trust as essential elements of adolescent-friendly care. However, the NPs did not identify the importance of the development of professional clinical relationships with adolescents as an essential element of adolescent-friendly care.

Trusted relationships with clinicians appear to have a central role in adolescents' willingness to engage in health care services especially related to more private concerns that are often the sources of morbidity and mortality for this population (Brown \& Wissow, 2009; Cabana \& Jee, 2004; Coker et al., 2010; Klostermann et al., 2005; McKee et al., 2006; Rubin et al., 2010; Schaeuble et al., 2010; Starfield, Shi, \& Maanko, 2005). SBHCs are unique in the ability to foster continuity and the development of trusted relationships between clinicians and adolescents because of their accessibility and diversity of services specifically tailored to meet the needs of adolescents. Health care agencies that overlook or disregard the importance of this relationship and the preference of adolescents for continuity in their care may be missing 
the mark, especially for adolescents. Systems that allow teens to see providers they want to see and trust to take care of their health likely will enhance engagement in preventive care for this population (Lau, Adams, Irwin \& Ozer, 2013; Nordin et al., 2010; Mclntyre, 2002; O’Malley, 2004; Waibel, Henao, Aller, Vargas, \& Vazquez, 2012; The National Alliance to Advance Adolescent Health, 2010).

\section{Essential Elements of Adolescent-friendly Care}

The NPs and teens shared very similar views about the need for all health care services provided in the SBHC to be confidential and private. State minor consent laws specifically address confidentiality and under what circumstances a teen can receive care independently (English et al., 2010). The NPs emphasized the importance of the ability to self-organize by understanding and facilitating access to confidential care. Confidentiality was a critical consideration for adolescents, especially those that are seeking care for more private concerns. Time alone with a health care provider afforded the opportunity for these topics to be addressed (Irwin et al., 2009). Unlike other primary care offices, teens most typically come to their visits alone, when they need care, and have the opportunity to discuss any concerns they may have with the clinician and receive appropriate anticipatory guidance, screening, and early intervention. The complex adaptive system is able to respond to their needs by scheduling appointments when the teen feels it is necessary and has the capacity to follow-up with adolescents on a more frequent basis.

The privacy of the SBHC environment was an important aspect of care for both NPs and teens. Privacy was enhanced by staff responding with sensitivity to the individual needs of the adolescent. For example, closing doors during visits and speaking privately with patients to understand why they needed an appointment enhanced patient privacy. The NPs recognized and attempted to eliminate potential intrusions on confidentiality, such as explanation of benefits or bills being sent to the teen's home. 
Teens eloquently discussed the inclusion and exclusions of the confidentiality agreement that existed between them and the SBHC staff. They clearly understood the limits and exceptions of this agreement. The SBHC staff members are effectively educating adolescents about confidentiality and their rights as consumers of health care services specific to their needs now or with future needs. Health care providers caring for adolescents across settings need to be knowledgeable and willing to protect the rights of adolescents related to confidentiality. Potential sources that may place adolescents' confidentiality rights in jeopardy need to be addressed by health care providers, health care systems, and health policies (self-organization).

Accessibility to health care services is a key factor that can influence adolescents' access to health care services within the SBHC. The SBHC complex adaptive system is responsive to the linear and nonlinear manner teens sought services (WHO 2009; 2012). Accessibility focused not only on the location (embeddedness) and ease of access to the services offered at the SBHC, but also the positive and inclusive atmosphere. The staff made students comfortable by being welcoming, friendly, and willing to help and by offering a diverse variety of services. The SBHC experience is likely very different than walking into a very crowded or unwelcoming environment in which teens are barely greeted by a receptionist behind a sliding glass window or needing to negotiate a complicated phone trees to make an appointment. Teens know the routine of the SBHC and are aware of "the rules of engagement." They can anticipate who will see them and how long they typically may wait to be seen before their appointment. In addition, the staff adapted to the teens needs and allowed them to return to class and come back at another time to lessen the amount of time they were waiting to be seen.

The location of the SBHC within the school building (embeddedness) provided reliable and predictable access for adolescents. The NPs recognized how important it was to be flexible with both scheduling and rescheduling appointments; a luxury not often afforded to adolescents and providers at other sites within the community. Teens also could contact the SBHC on days 
they were not in school for health guidance and to schedule appointments and even recognized the connection between the host agency and SBHC. Certainly, the SBHC removed transportation barriers and the need for parents to take time off from work to bring their teen to their primary care provider. None of the participants commented on the lack of availability of services on weekends, vacations, or in the evening, a commonly expressed concern of the medical community related to SBHCs as health care homes (O'Leary et al., 2014). In addition, teens referenced many services that they would choose not to access in the community or "at their regular doctor" because of concerns related to their confidentiality. These services included contraception, pregnancy tests, STD testing and mental health counseling. Their concerns are similar to those reported in other studies that have found that teens often delay or forego needed care because of confidentiality concerns (Ford \& Moody, 1999; al., Lehrer et al., 2007; McKee \& Fletcher, 2006). SBHC have the added benefit of providing care to all adolescents, regardless of their ability to pay or insurance status (Gustafson, 2005).

Flexibility from the adolescents' perspective also involved collaborative decision-making and reflected the distributed control within the complex adaptive system. This flexibility is likely a departure from the more secondary role they have assumed as children in pediatric services and the more paternalistic style they may have experienced being told when to return for their next appointment or what they must do to get better without regard to their individual preferences. This collaboration allowed adolescents to be more active participants in their health care, an important aspect of their development (Daley, 2012; Ginsburg et al., 2002a).

SBHCs encompass the multiple dynamic components necessary to respond to the everchanging needs of the adolescent accessing them (Lindberg et al., 2008). The results of this study describe a health care system that offers adolescents diverse health care services that include physical examinations, immunizations, care for acute and chronic illnesses, mental health services, reproductive care (e.g; pregnancy tests, contraception, condoms), STD testing and treatment, HIV counseling and testing, and crisis intervention. The individual needs of the 
teens were met by the SBHC staff, these needs changed over time (coexistence of order and disorder) and the SBHC was able to respond to the individual needs of those accessing services. Reproductive care and mental health were both identified as key aspects of comprehensive services. Teen pregnancy and undiagnosed/untreated mental health conditions both contribute significantly to academic failure and school drop-out (Kent et al., 2011; Shuger, 2012).

Reproductive services were essential elements of adolescent-friendly care in the SBHC and these services were often the reason for male and female adolescents accessing SBHC services. However, comprehensive reproductive care was not always available in the SBHC. The teens identified that many of the SBHCs did not offer condoms or hormonal contraception on-site. These results are consistent with national data that indicate that only half $(50.2 \%)$ of SBHCs that serve adolescents offer contraception on-site (Lofink et al., 2013). School district policy was the most common reason for the exclusion of condoms and contraception from the services available at the SBHCs (Lofink et al., 2013). These restrictions are often more restrictive than local health policy and create a gap in services for adolescents.

The national declines in the teen pregnancy and birth rates have been attributed to increased access and use of contraception in this population (Martin et al., 2015; Santelli, Lindberg, Finer, \& Singh, S., 2007; Santelli, Orr, Lindberg, \& Diaz, 2009). Research reveals access to reproductive services does not increase sexually activity but rather increases rates of reproductive care including STI screening, pregnancy and STI prevention counseling, and consistent use of contraception (Amin \& Sato, 2004; Ethier et al., 2011; Zimmer-Gembeck et al., 2001). The lack of onsite availability of contraception in SBHCs has been found to cause significant barriers to obtaining contraception in a timely fashion (Daley, 2011; 2012; Daley \& Polifroni, 2015; Zimmer-Gembeck et al., 2001). Adolescents who had access to on-site dispensing of contraception were significantly more likely than teens who do not have access to contraception, to select contraceptive method sooner after a family planning visit and use a 
selected method consistently for 90 days or more than those adolescents without access (Zimmer-Gembeck et al., 2001).

Male adolescents self-reported rates of sexual activity throughout high school are higher than female adolescents (CDC, 2014b). Adolescent males are particularly at risk of not receiving comprehensive sexual and reproductive health care services and likely to receive fewer of these services throughout adolescence as the number of preventive visits in this population also declines (Irwin et al., 2009; Marcel, Wibblesman \& Seigel, 2011). Primary care providers are three times more likely to take a sexual health history and discuss condoms twice as often with female than male adolescents (Lafferty et al., 2002; Lafferty, Downey, Shields, Holan, \& Lind, 2001). The SBHCs in this study were a valued resource for adolescent males to receive STD and HIV counseling and testing, human papillomavirus immunizations, and reproductive education individually, in small groups, and through classroom presentations. The males in this study also discussed the frequent prevention counseling they received specific to abstinence, safer sex, unintended pregnancy, and STDs. However, because condoms were not available in some of the SBHCs they relied on other sources in the community for condoms including gas stations and department stores.

The lack of access to condoms and contraception for male and female adolescents in SBHCs sends a very mixed message to teens and is an obstacle to self-organization within the complex adaptive system. The SBHCs are providing and emphasizing education specific to safer sex and encouraging STD/HIV testing however the NPs are often restricted from providing teens with condoms and contraception to assist them to engage in safer sex practices (Daley, $2011 ; 2012)$

Mental health services, including crisis intervention, were also specifically identified by the expert panel of NPs and focus group participants. Similar to reproductive care, mental health needs often served as an entry point to SBHC services for adolescents. Nationwide, an estimated $20 \%$ of adolescents (13-18 years old) are affected by a mental health condition; far 
fewer receive mental health services (Merikangas et al., 2011; Murphey, Barry \& Vaughn, 2013). Seventy-five percent of all mental illnesses begin prior to age 24 and the time from the onset of symptoms to intervention is often 8-10 years (Kessler et al., 2005; Schwarz, 2009). Adolescents with a mental illness are much more likely to not complete high school (Kent et al., 2011). SBHC have been identified as an essential clinical service for the early identification and treatment of adolescents with mental health conditions (Murphey et al., 2013).

The next essential element, SBHC Environment, focused on the importance of the feeling adolescents experienced when they came to the SBHC. The "good vibes" experienced by the adolescent were a result of the teens feeling safe and comfortable in the SBHC. They were allowed and encouraged to return often. NPs stressed the importance of the SBHC being safe inclusive space of all teens. Many teens appreciated health education materials that "made them think," however others preferred to have artwork that was calming and not healthrelated. Cleanliness was important to the adolescents and served as a quality indicator of the services provided. This finding is consistent with other studies conducted with adolescents in different health care settings (Ginsburg et al., 2002a; b). The location and size of the SBHC was remarked upon by many of the adolescent, however did not deter them from seeking services. The size and location of the SBHC likely indicates that the SBHC was added to the existing school building rather than considered in the architectural plans for the building.

The SBHC clinicians and staff were identified as an essential element of adolescentfriendly services. Outgoing, respectful, nonjudgmental, and interested staff were essential to getting teens both enter the SBHC for care and return again for care (Benkert et al., 2007; Ginsburg et al., 2002a; b; Rosenfeld et al., 1996). Adolescents valued reliable, competent staff, who took the time to get to know them, and personalized the care they received. The NPs recognized the importance of "genuinely liking" adolescents, being knowledgeable about adolescent development, nonjudgmental, respectful, trustworthy, and sensitive to teens' emotions. 
The organizational relationship between the SBHC and school was an area of more importance for the NPs than for the adolescents. The NPs discussed the significance of the seamless and positive relationships between the SBHC and the school. The success of the SBHC was dependent upon the endorsement of various members of the school staff. The school nurse was an essential aspect of this relationship and a major source of referral to the SBHC and represented a shadow system within the complex adaptive system. The relationship between the school nurse and the SBHC in this study was described in a very collaborative manner with each having important but distinct roles with the adolescents. The most important was the ability for the teens to use the SBHC to take care of any health-related issues they may have to remain in school rather than be sent home by the school nurse or staff. In addition, the teens in this study explained that they were likely to come to school if they were sick to be evaluated by the NP rather than miss school. This finding provides further evidence that SBHCs decrease early dismissals for those students enrolled in services and increase the time spent in school. Van Cura (2010) found that students not enrolled in SBHC services lost three times more seat time than those enrolled in a SBHC.

\section{Implications}

This study has numerous potential implications on clinical practice, the education of health professionals, research, and health policy specific to adolescent-friendly care in SBHCs.

\section{Clinical Practice}

A surprising finding from this study was the divergent perspectives of the NPs and adolescents regarding the development of trusted relationships between teens and their health care providers and staff and its impact on adolescents' willingness to engage in clinical services. The Healthy People 2020 target for annual well visits for adolescents is $75.6 \%$ for $10-17$ year olds. To meet this target, health care agencies, especially those that involve adolescents, need to incorporate mechanisms to enhance continuity and access to the provider a teen wishes to see, not the person that was assigned to them, their parent chose, or the clinician that had the 
next opening. Adolescents need to be allowed to choose a provider they feel comfortable with and trust to take care of their health and mental health needs.

Continuity of care and the development of a trusted relationship with adolescents provides many advantages for both the adolescent and the health care provider. This relationship affords the clinician with the opportunity to know the teen over time and become familiar with their concerns, what has or has not worked for them in the past, and provides a more holistic view of the adolescent's health in conjunction with other factors that may contribute to their health and mental health including their family dynamics, peer relationships, or medical conditions. This is very much in contrast to a one-time interaction in which the provider care just for the concern presented on that day and may miss other important issues that need also to be addressed. The repeated history taking by every new provider is clinical time that could be better spent providing anticipatory guidance and screening. Teens in this study remarked that they "don't have to tell my whole story every time, they know me." It can also be argued that care may also improve if clinicians are connected to their patients, feel more of a responsibility toward outcomes, than when they are required to see patients once and likely never again, and ask the more difficult questions. Research has also demonstrated that continuity improves adolescents willingness to return for visits, allowed teens to trust their health care providers, and feel more comfortable discussing health related concerns (Brown \& Wissow, 2009; Cabana \& Jee, 2004; Coker et al., 2010; Klostermann et al., 2005; McKee et al., 2006; Rubin et al., 2010; Schaeuble et al., 2010; Starfield, Shi, \& Maanko, 2005).

Time is a precious and a seemingly disappearing entity in clinical practice. Adequate time to provide adolescents with appropriate anticipatory guidance, screening, and referrals are a central component to adolescent-friendly services. Health care providers that care for adolescents need to advocate for the appropriate amount of time to be allocated for adolescent preventive visits. Less time likely translates into less comprehensive services and less attention to more difficult issues. The adolescents and NPs in this study both identified the importance of 
being able to devote the necessary amount of time to address the concerns of this population. Further studies are needed to evaluate the role that shorter versus longer appointment times have on the provision of adolescent-friendly care and the incorporation of recommended anticipatory guidance and screening into visits.

Teachers have been identified as an important source of referral to SBHC services especially for students without health insurance, with chronic illnesses, and other acute illnesses (Wade, Mansour, Guo, Huentelman, Link \& Keller, 2008). Teens in this study remarked on the lack of awareness about the SBHC, the services available, and the differences between the SBHC, and the school nurse by their teachers. This is an area to be explored further and strategies developed to include teachers as a referral source for students who may not otherwise be familiar with the SBHC. Teachers, because of their frequent and continuous contact with students, are in an excellent position to notice the needs of their students and to make timely referrals for needed services to the SBHC (Wade et al., 2008). Simple strategies including inviting teachers to tour the SBHC and education regarding the services available can remove additional barriers for teens accessing care in a timely manner.

\section{Professional Education}

An understanding of the unique development needs of adolescents is a critical aspect of health care provided to this population. Adolescence represents an important transitional period between childhood and adulthood that effects physical, cognitive, and psychosocial development (Elster \& Kunzets, Erikson, 1950; 1994; Piaget, 1972). Adolescents are also learning how to navigate the world, including the health care system, and become increasingly independent throughout this developmental period (Erikson, 1950; Daley, 2012). Health care services are not one-size-fits-all and need to be tailored to meet the specific needs of the population served (Daley, 2011; 2012; Sadler \& Daley, 2002). Providers and staff need to be aware of the important role adolescent development plays in engagement in health care services. However, negotiating the healthcare system is not intuitive. Health care providers 
need to educate and provide adolescents with the opportunity to learn how to assume a more active role in their health care by communicating their needs and concerns to their health care provider, scheduling their own appointments, asking questions, and returning for follow-up services.

The education of health care professionals, across disciplines, needs to incorporate the unique health and developmental needs of adolescents with particular attention to reproductive and mental health. Healthy People 2020 also calls for an increase in practicing primary care providers including NPs, physician assistants, and physicians. However, recent studies of selfassessed competencies specific to adolescents' health care needs and evaluations of health care services point to the "limitations and inadequacies of current training in adolescent health" (Lawrence, Gootman, \& Sim, 2009, p. 246) and the need to improve the quality of professional education in this area (Fox et al., 2009; Mason, Ahlers-Schmidt \& Stuart-Hilgenfeld, 2010). The low rates of engagement in preventive care by adolescents and young adults necessitate health care providers from all disciplines as well as clinical staff to be trained to meet the unique needs and expectations of teens so that opportunities for their engagement in health care services in SBHCs and beyond will be maximized (Caldwell \& Berdahl, 2013; Lau et al., 2013; Rand et al., 2007).

Most SBHCs are staffed with both a licensed clinical social worker (LCSW) and a NP who can provide assessment of mental health needs for adolescents. Twenty-five percent of SBHC do not provide mental health services for adolescents and depend on referrals to outside agencies or the school to address the adolescent's needs. Both the NP and LCSW, however, may also be limited in their ability to respond to the mental health needs of this population (NRC/IOM, 2009). NP education, until more recently, has included only basic mental health training although additional educational opportunities and certifications are readily available. LCSWs provide students with individual and group counseling however lack the ability to provide more comprehensive assessments or prescribe medication for their clients. Mental 
health services, specific to SBHCs, have been found to promote early and continued use of mental health services among adolescents (Kisker \& Brown, 1996; Slade, 2002; Weist, Paskewitz, Warner, \& Flaherty, 1996). Due to the increased demands for mental health services and the lack of engagement in community mental health services among adolescents creative strategies are needed and should include increased primary care-based training for NPs, increased availability of services through the SBHC, and the integration of more specialized collaborations with psych-mental health NPs, psychiatrists, and psychologists into the services available at the SBHC.

\section{Research}

Research needs to focus on adolescents' health care experience and how their interactions with the health care system can be enhanced and incorporated into a healthy lifestyle throughout adolescence and beyond. Further research is needed to document adolescent satisfaction with SBHC services including reproductive care and mental health services. Currently, only one study exists related to adolescent views on SBHC services provided by a NP (Benkert et al., 2007). The roles of comfort and the relationship between the health care provider and the adolescent need further exploration to determine the impact they have on engagement with $\mathrm{SBHC}$ services and well as continued engagement in preventive care now and into young adulthood. Many barriers have been identified in the literature specific to adolescents and health care services, however little is known about what may influence adolescents' willingness to engage in SBHC services.

Annually many teens are excluded from school participation because they have not met the required physical examination and immunization requirements. SBHCs likely play a significant role in preventing school exclusion. Research focused on the exclusion rates of adolescents participating in SBHC services compared to those who are not engaged in SBHC services are needed to evaluate the impact they have on school exclusion related to health requirements for attendance. In addition, the adolescents in this study frequently remarked on 
their ability to obtain a sports physical in a timely manner that allowed them to try out for high school sports. Obesity and inactivity are significant health concerns for many adolescents. Further research on the impact SBHCs have on encouraging sports participation and facilitating involvement need to be explored.

Guo, Wade, Pan, and Keller (2010) validated the cost effectiveness of SBHC and the lessening heath disparities and facilitated increased "seat time" at school. Further studies are needed to evaluate the impact of engagement in preventive care throughout high school and its influence on continued engagement in preventive health care into young adulthood. Currently, the rates of preventive visits among young adults are even lower than those of adolescents especially for those without health insurance (Adams et al., 2015). Young adulthood is a critical time for maintaining a healthy lifestyle and preventing illness and disability. Determining the impact of positive experiences with health care services and health care providers during adolescence and its role in continued engagement in preventive care is an important next step for the health of this population.

\section{Health Policy}

The important role of SBHCs on the health and mental health of the nation's adolescents has been recognized by professional organizations and through governmental and state funding to increase their capacity (NRC/IOM, 2009; Patient Protection and Affordable Care Act 2010). SBHC have shown their effectiveness in providing health and mental health services to teens. However, SBHCs are often not afforded the opportunity to be designated as a health care home in many states and as a result suffer from the lack of reimbursement for the services provided within the SBHC. Only 13 states have enacted Medicaid policies that assure reimbursement for SBHC services (School-Based Health Alliance, 2015). Increased attention and documentation on what differences SBHCs make to the health and education of the nation's youth are necessary for the continued growth of SBHC capacity. Building capacity in the SBHCs will also require larger spaces and more staff to accommodate and adapt to the growing needs of the 
patient population accessing services. Data are not currently available beyond the local level on how many visits and the types of visits that are made annually to SBHCs nationwide, this assessment is crucial to increasing funding for the expansion of these services.

Limiting access to needed reproductive services delays access to contraception and condoms and increases the risk for unintended pregnancies and STDs, both of which can have a significant impact on an adolescent's life now and in the future. Healthcare providers need to advocate for adolescents' rights related to the contraceptive access and reproductive services in SBHC. At the very least these services should be congruent with the services available within the state. Additional restrictions on services, particularly reproductive care, do not allow the health care providers to best meet the needs of this population. NPs need to advocate for these restrictions to be eliminated and allow a more comprehensive approach to care.

\section{Strengths and Limitations}

This study used an explanatory sequential mixed methods design that allowed the researcher to obtain the perspectives of NPs and adolescents specific to the essential elements of adolescent-friendly care in SBHC. This is the first research study to capture these two perspectives. The two research methods complemented each other and allowed a deeper understanding of the quantitative data from the first phase of the study (Creswell \& Plano-Clark, 2011). This method also provided the opportunity to compare and contrast the perspectives of the NPs and adolescents and gain a greater understanding of what is essential for the delivery of adolescent-friendly care in SBHC.

As a purposive sample of NPs for Delphi technique and adolescents for the focus groups was used for this study, only the most interested NPs and adolescents likely participated in each phase of the study and may not have fully captured all of the possible responses to the research questions (Polit \& Beck, 2012). Both phases occurred in the Northeastern Region of the United States and may not have adequately captured the perspectives of NPs and adolescents from other areas of the country however there was much diversity in the samples and SBHC sites 
used in this study. Adolescents were asked their perspective on the essential elements identified by the NPs, the results may have been different if the adolescents had been asked to identify what they thought were the essential elements of adolescent-friendly care in SBHCs. This is an area for further research.

\section{Conclusion}

Adolescents, in general, are a healthy population. The majority of the morbidity and mortality during adolescence result from largely preventable causes including risk-taking behaviors and injuries. Preventive health care services are an important mechanism for assisting adolescents to remain healthy and avoid many sources of morbidity and mortality now and into adulthood. This is accomplished through anticipatory guidance, screening, early intervention and regular engagement in preventive services. SBHCs are important community resource for addressing the health care needs of adolescents. This study provides the unique perspectives of NPs and adolescents regarding what are the essential elements of adolescentfriendly care in SBHCs.

The results of this study support the criteria established by the World Health Organization (2012) toward making health care services adolescent-friendly. However, additional factors including adolescents feeling comfortable and having a trusted relationship with a health care provider were found to be essential to adolescent-friendly care in SBHCs. Greater emphasis needs to be placed on confidentiality and privacy, as these were found to be most important to teens.

The NRC/IOM (2009) has called for new approaches to be developed that address the unique health care needs of teens to decrease the health and social disparities that currently exist. Learning is a key component of any system's ability to adapt and ultimately survive; adolescent health services and SBHCs are no exception. Small changes have the potential to make a big impact on the health care experiences of adolescents. Current models of health care need to be reconsidered to meet the unique and dynamic needs of the people they serve- 
adolescents need more, not less time to have their needs met. Clinicians need to have availability and commitment to establish trusted relationships with adolescents.

SBHCs represent a model that should be considered for adoption across settings to better meet preventive health needs of this population throughout adolescence. New attention focused on the importance of professional health care partnerships with adolescents, strategies to increase their comfort, and the unrestricted access to health care services, including reproductive and mental health, are needed to improve engagement in preventive health care services in this population and ultimately decrease many of the preventable cause of morbidity and mortality for this population. 


\section{References}

Adams, S. H., Park, J., \& Irwin, C. E. (2015). Adolescent and young adult preventive care: Comparing national survey rates. American Journal of Preventive Medicine, 49, 238-247. doi: 10.1016/j.amepre.2015.02.022

Akers, A. Y., Davis, E. M., Jackson Foster, L. J., Morrison, P., Sucato, G., Miller, E., \& Lee, M. (2014). Parental report of receipt of adolescent preventive health counseling services from pediatric providers. Patient Education and Counseling, 94, 269-275. doi:

10.1016/j.pec.2013.10.003

Allison, M. A., Crane, L. A., Beaty, B. L., Davidson, A. J., Melinkovich, P., Kempe, A. (2007). School-based health centers: Improving access and quality of care for low-income adolescents. Pediatrics, 120, e887-894. doi: 10.1542/peds.2006-2314

American Academy of Pediatrics Committee on Adolescence. (2008). Achieving quality health services for adolescents. Pediatrics, 121, 1263-1270. doi: 10.1542/peds.2008-0694

American Cancer Society. (2014). Tobacco-related cancer fact sheet. Retrieved from http://www.cancer.org/cancer/cancercauses/tobaccocancer/tobacco-related-cancer-factsheet

Amin, R. \& Sato, T. (2004). Impact of a school-based comprehensive program for pregnant teens on their contraceptive use, future contraceptive intention, and desire for more children. Journal of Community Health Nursing, 21, 39-47.

Anderson, M. E., Freas, M. R., Wallace, A. S., Kempe, A., Gelfand, E. W. \& Liu, A. H. (2004). Successful school-based intervention for inner-city children with persistent asthma. Journal of Asthma, 41, 445-453.

Angler, H., DeVoe, J. E., Tillotson, C., Wallace, L., \& Gold, R. (2012). Trends in health insurance status of US children and their parents, 1998-2008. Maternal and Child Health Journal, 5, 1-9. doi: 10.1007/s10995-012-1142-4 
Agency for Healthcare Research and Quality. (2011). Medical expenditure panel survey. Rockville, MD: Author. Retrieved from http://meps.ahrq.gov/mepsweb

Begun, J., Zimmerman, B., \& Dooley, K. (2003). Health organizations as complex adaptive systems. In S. M. Mick and M. Wyttenbach (Eds.), Advances in health care organization theory (pp. 253-288). San Francisco, CA: Jossey-Bass.

Benkert, R., Barkauskas, V., Pohl, J. M., Corser, W., Tanner, C., Wells, M. \& Nagelkirk, J. (2002). Patient satisfaction outcomes in nurse-managed centers. Outcomes Management, $6,174-181$.

Benkert, R., George, N., Tanner, C., Barkauskas, V. H., Phol, J. M., \& Marszalek, A. (2007). Satisfaction with school-based teen health center: A report card on care. Pediatric Nursing, 33, 103-109.

Berlan, E. D. \& Bravender, T. (2009). Confidentiality, consent, and caring for the adolescent patient. Current Opinion in Pediatrics, 21, 450-6. doi: 10.1097/MOP.0b013e32832ce009

Britto, M. T., Klostermann, B. K., Bonny, A. E., Altum, S. A., \& Hornung, R. W. (2001). Impact of a school-based intervention on access to health care for underserved youth. Journal of Adolescent Health, 29, 116-124.

Brown, J. D. \& Wissow, L. (2009). Discussion of sensitive health topics with youth during primary care visits: Relationship to youth perceptions of care. Journal of Adolescent Health, 44, 48-54. doi:10.1016/j.jadohealth.2008.06.018

Cabana, M. D. \& Jee, S. H. (2004). Does continuity of care improve patient outcomes? Journal of Family Practice, 53, 974-980.

Caldwell, J. \& Berdahl, T. (2013). Trends in well-child visits: United States, 2002-2009. Statistical brief \#419. Rockville, MD: Agency for Healthcare Research and Quality. Retrieved July 31, 2015 from http://meps.ahrq.gov/mepsweb/data_files/publications/st419/stat419.shtml 
Carter, T., Callaghan, P., Khaill, E. \& Morres, I. (2012). The effectiveness of a preferred intensity exercise programme on mental health outcomes of young people with depression: A sequential mixed method evaluation. BMC Public Health, 12, 187-192. doi: 10.1186/14712458-12-187.

Casey, B. J., Giedd, J., \& Thomas, K. (2000). Structural and functional brain development and its relation to cognitive development. Biological Psychology, 54, 241-257.

Casey, B. J., Jones, R. M. \& Hare, T. A. (2008). The adolescent brain. Annals of the New York Academy of Sciences, 1124, 111-126. doi: 10.1196/annals. 1440.010

Centers for Disease Control and Prevention. (2009). Sexually transmitted disease surveillance, 2008. Atlanta, GA: US Department of Health and Human Services, CDC. Retrieved from http ://www.cdc.gov/std/statso8/su rv2008-complete.pdf

Centers for Disease Control and Prevention. (2010). Sexually transmitted diseases treatment guidelines, 2010. MMWR, 59, 1-110. Retrieved from http://www.cdc.gov/MMWr/preview/mmwrhtml//r5912a1.htm

Centers for Disease Control and Prevention. (2011). National Health Interview Survey. Retrieved from www.cdc.gov/nchs/nhis.htm

Centers for Disease Control and Prevention and Indian Health Service. (2012). Indian prevention health surveillance report--Sexually transmitted diseases 2009. Atlanta, GA: US Department of Health and Human Services. Retrieved from http://www.cdc.gov/std/stats/lHS/l HS-Surv-Report2009.pdf

Centers for Disease Control and Prevention. (2013). National Center for Health Statistics, State and Local Area Integrated Telephone Survey 2011-2012 National Survey of Children's Health frequently asked questions. Retrieved from http://www.cdc.gov/nchs/slaits/nsch.htm

Centers for Disease Control and Prevention. (2014a). Sexually transmitted disease surveillance 2013. Atlanta, GA: U.S. Department of Health and Human Services. 
Centers for Disease Control and Prevention. (2014b). Youth risk behavior surveillance-United States, 2013. MMWR, 63(4), 1-168. Retrieved from http://www.cdc.gov/mmwr/pdf/ss/ss6304.pdf?utm_source=rss\&utm_medium=rss\&utm_ca mpaign=youth-risk-behavior-surveillance-united-states-2013-pdf

Centers for Disease Control and Prevention. (2015a). HIV surveillance report, 2013 (vol. 25). Retrieved from http://www.cdc.gov/hiv/library/reports/surveillance/.

Centers for Disease Control and Prevention. (2015b). Human papillomavirus. In J. Hamborsky, A. Kroger, S. Wolfe (Eds.), Epidemiology and prevention of vaccine-preventable diseases, (13th ed., pp. 175-186). Washington D.C.: Public Health Foundation.

Chang, A. M., Gardner, G. E., Duffield, C. \& Ramis, M. (2010). A Delphi study to validate an advanced practice nursing tool. Journal of Advanced Nursing, 66, 2320-2330. doi: 10.1111/j.1365-2648.2010.05367.x

Cilliers, P. (2000). Complexity \& postmodernism: Understanding complex systems. NY: Routledge

Coker, T. R., Sareen, H. G., Chung, P. J., Kennedy, D. P., Weidmer, B. A. \& Schuster, M. A. (2010). Improving access to and utilization of adolescent preventive health care: The perspectives of adolescents and parents. Journal of Adolescent Health, 47, 133-142. doi:10.1016/j.adohealth.2010.01.005

Creswell, J. W. \& Plano-Clark, V. L. (2011). Designing and conducting mixed methods research (2nd ed.). Washington, DC: Sage.

Culligan, V. (2002). Connecticut Association of School-Based Health Centers patient satisfaction survey summary. North Haven, CT: Connecticut Association of School-Based Health Centers.

Daley, A. M. (2013). Adolescent-friendly remedies for the challenges of focus group research. Western Journal of Nursing Research, 35, 1043-59. doi: 10.1177/0193945913483881 
Daley, A. M. (2012). Rethinking school-based health centers as complex adaptive systems: Maximizing opportunities for the prevention of teen pregnancy and sexually transmitted infections. Advances in Nursing Science, 35(2), e37-e46.

Daley, A. M. (2011). Contraceptive services in SBHCs: A community experience in creating change. Policy Politics Nursing Practice. 12, 208-214. doi: 10.1177/1527154411431967

Daley, A. M. \& Polifroni, E. C. (2015).The lived experience of nurse practitioners providing contraceptive care to adolescents in school-based health centers. Unpublished manuscript. University of Connecticut School of Nursing. Storrs, CT.

Davidoff, A., Dubay, L., Kenney, G., \& Yemane, A. (2003). The effect of parents' insurance coverage on access to care for low-income children. Inquiry, 40, 254-268.

Dempsey, A. F., Singer, D. D., Clark, S. J., \& Davis, M. M. (2009). Adolescent preventive health care: What do parents want? The Journal of Pediatrics, 155, 689-694. doi: 10.1016/j.jpeds.2009.05.029

DeVoe, J. E., Tillotson, C., \& Wallace, L.S. (2008). Uninsured children and adolescents with insured parents. Journal of the American Medical Association, 300, 1904-1913. doi:10.1001/jama.2008.516.

Dobbs, M., Bates, J. \& Dorn, L. (2012). Adolescents and the medical home: An analysis of the National Survey of Children's Health. Journal of Adolescent Health, 50, S86. doi: 10.1016\%2Fj.jadohealth.2011.10.227

Dorgan, B. I.. (2010). The tragedy of Native American youth suicide. Psychological Services, 7, 213-218. dol: $10.1037 / \mathrm{a} 0020461$

Dombkowski, K. J., Lantz, P. M., \& Freed, G. L. (2004). Role of health insurance and a usual source of medical care in age-appropriate vaccination. American Journal of Public Health, 94, 6, 960-966. 
Edman, J. C., Adams, S. H., Park, M. J., \& Irwin, C. E. (2010). Who gets confidential care? Disparities in a national sample of adolescents. Journal of Adolescent Health, 46, 393-395. doi: 10.1016/j.jadohelath.2009.09.003

Elkind, D. (1998). Cognitive development. In S. B. Friedman, S. K. Schonberg, E. M. Alderman \& M. M. Fisher (Eds.), Comprehensive adolescent health (pp. 24-26). St. Louis MO: Mosby.

Elster, A. B. \& Kuznets, N. J. (1994). AMA guidelines for adolescent preventive services (GAPS): Recommendations and rationale. Baltimore, MD: Williams \& Wilkins.

English, A., Bass, L., Boyle, A.D., \& Eshragh, F. (2010). State Minor Consent Laws: A Summary. Chapel Hill, NC: Center for Adolescent Health \& the Law.

English, A. \& Ford, C. (2007). More evidence supports the need to protect confidentiality in adolescent health care. Journal of Adolescent Health, 40, 199-200.

Erikson E. (1950). Childhood and society. New York: Norton.

Ethier, K. A., Dittus, P. J., DeRosa, C. J., Chung, E. Q., Martinez, E. \& Kerndt, P. R. (2011). School-based health center access, reproductive healthcare, and contraceptive use among sexually experiences high school students. Journal of Adolescent Health, 48, 562565.

Ford, C.A., Bearman, P.S. \& Moody, J. (1999). Foregone health care among adolescents. JAMA. 282, 2227-34. doi:10.1016/j.jadohealth.2006.09.015

Forhan, S. E., Gottlieb, S. L., Sternberg, M. R., Xu, F., Datta, S. D, McQuillan, G. M., Markowitz, L. E. (2009). Prevalence of sexually transmitted infections among female adolescents aged 14 to 19 in the United States. Pediatrics, 124, 1505-1512.

Fox, H. B., Philliber, S. G., McManus, M. A. \& Yurkiewicz, S. M. (2010). Adolescents' experiences and views on health care. Washington, DC: The National Alliance to Advance Adolescent Health. 
Freedman, D. S., Kettel, L., Serdula, M. K., Dietz, W. H., Srinivasan, S. R., Berenson, G. S. (2005). The relation of childhood BMl to adult adiposity: The Bogalusa Heart Study. Pediatrics, 115, 22-27.

Fronstin, P. (2011). Sources of health insurance and characteristics of the uninsured: Analysis of the March 2008 current population survey. Employee Benefit Research Institute Issue Brief, 362, 1-35.

Gibson, E. J., Santelli, J. S., Minguez, M., Lord, A., \& Schuyler, A. C. (2013). Measuring school health center impact on access to and quality of primary care. Journal of Adolescent Health, 53, 699-705.

Giedd, J. N (2004). Structural magnetic resonance imaging of the adolescent brain, Annals of the New York Academy of Science, 1201, 77-85.

Giedd, J. N., Blumenthal, J., Jeffries, N., Castellanos, F., Lui, H., Zijdenbos, A., et al. (1999). Brain development during childhood and adolescence: A longitudinal MRI study. Nature, 2, 861-863.

Gilbert, A. L., Rickert, V. I., \& Aalsma, M. C. (2014). Clinical conversations about health: The impact of confidentiality in preventive adolescent care. Journal of Adolescent Health, 55, 672-677. doi: 10.1016/j.jadolhealth.2014.05.06

Ginsburg, K. R., Forke, C. M., Cnaan, A. \& Slap, G. B. (2002a). Important health provider characteristics: The perspectives of urban ninth graders. Developmental and Behavioral Pediatrics, 23, 237-243.

Ginsburg, K. R., Winn, R. J., Rudy, B. J., Crawford, J., Zhao, H. \& Schwarz, D. F. (2002b). How to reach sexual minority youth in the health care setting: The teens offer guidance. Journal of Adolescent Health, 31, 407-416.

Glogowska, M. (2011). Paradigms, pragmatism and possibilities: Mixed-methods research in speech and language therapy. International Journal of Language and Communication Disorders, 46, 251-260. doi: 10.3109/13682822.2010.507614 
Goedken, A. M., Urmie, J. M. \& Polgreen, L. A. (2014). Factors related to receipt of well-child visits in insured children. Journal of Maternal Child Health, 18, 744-754. doi: 10.1007/s10995-013-1301-2

Green, M. (1994). Bright futures: Guidelines for the health supervision of infants, children and adolescents. Arlington, VA: National Center for Education in Maternal Child Health.

Green, M. \& Palfrey, J. (2002). Bright futures: Guidelines for the health supervision of infants, children and adolescents ( $2^{\text {nd }}$ ed.). Arlington, VA: National Center for Education in Maternal Child Health.

Grossman, D. C. (2000). The history of injury control and epidemiology of child and adolescent injuries. The future of children: Unintentional injuries in childhood. Los Altos, CA: David and Sheila Packard Foundation.

Guo, J. J., Jang, R., Keller, K. N., McCracken, A. L., Pan, W., Cluxton, R. J. (2005). Impact of school-based health centers on children with asthma. Journal of Adolescent Health, 37, 26674.

Guo, J. J., Wade, T. J., Pan, W., \& Keller, K. N. (2010). School-based health centers: Costbenefit analysis and impact on health disparities. American Journal of Public Health, 100, 1617-1623.

Gustafson, E. (2005). History and overview of school-based health centers in the US. Nursing Clinics of North America, 40, 595-606. doi:10.1016/j.cnur.2005.08.001

Hagan, J. F., Shaw, J. S., \& Duncan, P. M. (2008). Bright futures: Guidelines for the health supervision of infants, children and adolescents (3rd ed.). Elk Grove Village, IL: American Academy of Pediatrics.

Halcomb, E. J., Davidson, P. M., Griffiths, \& Daley, J. (2008). Cardiovascular disease management: Time to advance the practice nurse role? Australian Health Review, 32, 4455. 
Hallowell, M. R. \& Gambatese, J. A. (2010). Qualitative research: Application of the Delphi method to CEM research. Journal of Construction Engineering and Management, 136, 99107.

Hamburg, B. A. (1998). Psychosocial development. In S. B. Friedman, S. K. Schonberg, E. M. Alderman \& M. M. Fisher (Eds.), Comprehensive adolescent health (pp. 27-38). St. Louis, MO: Mosby.

Healthy People 2000. (n.d.). Historical record of Healthy People 2000. Retrieved from http://odphp.osophs.dhhs.gov/pubs/hp2000

Hofmann, A. (1992). Managing adolescents and their parents: Avoiding pitfalls and traps. Adolescent Medicine: State of the Art Reviews, 3, 1-11.

Hoffman, S. (2006). By the numbers: The public cost of teen childbearing. Washington, DC: National Campaign to Prevent Teen Pregnancy.

Holden, L. M. (2005). Complex adaptive systems: concept analysis. Journal of Advanced Nursing, 52, 651-657.

Holland, J. H. (2006). Studying complex adaptive systems. Journal of Systems Science and Complexity, 19, 1-8.

Hillis, S. D., Joesoef, R., Marchbanks, P. A., Wasserheit, J., Cates, W., Westrom, L. (1993). Delayed care of pelvic inflammatory disease as a risk factor for impaired fertility. American Journal of Obstetrics and Gynecology, 168, 1503-9.

Horrocks, S., Anderson, E., \& Salisbury, C. (2002). Systematic review of whether nurse practitioners working in primary care can provide equivalent care to doctors. British Medical Journal, 324, 819-825.

Irwin, C. E., Adams, S. H., Park, J. \& Newacheck, P.W. (2009). Preventive care for adolescents: Few get visits and fewer get services. Pediatrics, 123, e565-572. 
Jiang, N., Kolbe, L. J., Seo, D. E., Kay, N. S. \& Brindis, C. D. (2011). Health of adolescents and young adults: trends in achieving the 21 Critical National Health Objectives by 2010. Journal of Adolescent Health, 49, 124-32.

Jones, R. K., Purcell, A., Singh, S., \& Finer, L. B. (2005). Adolescents' reports of parental knowledge of adolescents' use of sexual health services and their reactions to mandated parental notification for prescription contraception. Journal of the American Medical Association, 293, 340-348.

Keeney, S., Hasson, F., \& McKeena, H. (2011). The Delphi technique in nursing and health research. New Delhi, India: Wiley-Blackwell.

Keeton, V., Soleimanpour, S. \& Brindis, C. D. (2012). School-based health centers in an era of health care reform: Building on history. Current Problems in Pediatric and Adolescent Health Care, 42, 132-156. doi: 10.1016/j.cppeds.2012.03.002

Kent, K. M, Pelham, W. E., Molina, B. S. G, Siblet, M. H., Waschbusch, D. A., Yu, J., Gnagy, E. M., Biswas, A., Babinski, D. E., \& Karch, K. M. (2011). The academic experience of male high school students with ADHD. Journal of Abnormal Child Psychology, 39, 451-462.

Kessler, R. C., Berglund, P., Demler, O., Jin, R., \& Walters, E. E. (2005). Life-time prevalence and age-of-onset distribution of DSM-IV disorders in the National Co-morbidity Survey Replication. Archives of General Psychiatry, 62, 593-602.

Key, J. D., Washington, E. C., \& Hulsey, T. C. (2002). Reduced emergency room utilization associated with school-based clinic enrollment. Journal of Adolescent Health, 30, 273-278.

Kisker, E. E. \& Brown, R. S. (1996). Do school-based health centers improve adolescents' access to health care, health status, and risk-taking behavior? Journal of Adolescent Health, 18, 335-343.

Klein, J. D., Woods, A. H., Wilson, K. M., Prospero M., Greene, J., Ringwalt, C. (2000). Homeless and runaway youth's access to health care. Journal of Adolescent Health, 27, 331-339. 
Klostermann, B. K., Slap, G. B., Nebrig, D. M., Tivorsak, T. L., \& Britto, M. T. (2005) Earning trust and losing it: Adolescents' views on trusting physicians. The Journal of Family Practice, 54, 679-687.

Krippendorff, K. (2013). Content analysis: An introduction to its methodology (3rd ed.). Thousand Oaks, CA: Sage Publications.

Kort, M. (1984).The delivery of primary health care in American public schools, 1890-1980. Journal of School Health, 54, 453-457.

Krueger, R. A. \& Casey, M. A. (2009). Focus groups: A practical guide for applied research (4th ed.). Washington, D.C.: Sage Publications.

Lafferty, W. E., Downey, L., Holan, C. M., Lind, A., Kassler, W., Tao, G. Irwin, K. (2002). Provision of sexual health services to adolescent enrollees in Medicaid managed care. American Journal of Public Health, 92, 1779 -1783.

Lafferty, W. E., Downey, L., Shields, A. W., Holan, C. M., \& Lind, A. (2001). Adolescent enrollees in Medicaid managed care: The provision of well care and sexual health assessment. Journal Adolescent Health, 28,497-508.

Lau, J. S., Adams, S. H., Irwin, C. E. \& Ozer, E. M. (2013). Receipt of preventive health services in young adults. Journal of Adolescent Health, 52, 42-49.

Lawrence, R. S., Gootman, J. A., \& Sim, L. J. (2009). Adolescent health services missing opportunities. Washington, DC: The National Academies Press.

Lehrer, J. A., Pantell, R., Tebb, K., \& Shafer, M. (2007). Foregone health care among U.S. adolescents: Associations between risk characteristics and confidentiality concerns. Journal of Adolescent Health, 40, 218-226. doi: 10.1916/j.jadolhealth.2006.09.015

Lim, S. W., Chhabra, R., Rosen, A., Racine, A. D. \& Alderman, E. M. (2012). Adolescents' views on barriers to health care: A pilot study. Journal of Primary Care and Community Health, 3, 99-103. doi: 10.1177/2150131911422533 
Lindberg, C., Nash, S. \& Lindberg. C. (2008). On the edge: Nursing in the age of complexity. Bordentown, New Jersey: PlexusPress.

Lofink, H., Kuebler, J., Juszczak, L., Schlitt, J., Even, M., Rosenberg, J., \& White, I. (2013). 2010-2011 School-Based Health Alliance census report. Washington, DC: School-Based Health Alliance.

Lurie, N., Bauer, E. J., \& Brady, C. (2001). Asthma outcomes at an inner-city school-based health center. Journal of School Health, 71, 9-16.

Mansour, M. E., Rose, B., Toole, K., Luzader, C. P., \& Atherton, H. D. (2008). Pursuing perfection: An asthma quality improvement initiative in school-based health centers with community partners. Public Health Reports, 123, 717-30.

Marcell, A. V., Wibbelsman, C., Seigel, W. M. \& The Committee on Adolescence (2011). Male adolescent sexual and reproductive health care. Pediatrics, 128, e1658-1676. doi: 10.1542/peds.2011-2384

Mark, H., Sherman, S. G., Nanda, J., Chambers-Thomas, T., Barnes, M., Rompalo, A. (2010). What has changed about vaginal douching among African American mothers and daughters? Public Health Nursing, 27, 418-424.

Martin, J. A., Hamilton, B. H., Oysterman, M. J. K., Curtain, M. A., Mathews, T. J. (2015). Births: Final data 2013. National Vital Statistics Report, 64, 1-68.

Mason, B. R., Ahlers-Schmidt, C. R., \& Stuart-Hilgenfeld, M. (2010). Adolescent patients: Who is providing their care? Clinical Pediatrics, 49, 805-808. doi: 10/1177/0009922810363611: McCord, M. T., Klein, J., Foy, J. M., \& Fothergill, K. (1993). School-based clinic use and school performance. Journal of Adolescent Health, 14, 91-98.

Mclntyre, P. (2002). Adolescent friendly health services: An agenda for change. Oxford, UK: World Health Organization. 
McKee, D. \& Fletcher, J. (2006). Primary care for urban adolescent girls from ethnically diverse populations: Foregone care and access to confidential care. Journal of Health Care for the Poor and Underserved, 17, 759-774. doi:10.1353/hpu.2006.0131

McKenna, H. (1994). The Delphi technique: A worthwhile approach for nursing? Journal of Advanced Nursing, 19, 1221-1225.

McNall, M. A., Lichty, L. F, Mavis B. (2010). The impact of school based health centers on the health outcomes of middle school and high school students. American Journal of Public Health, 100, 1604-1610.

Merikangas, K. R., He, J., Burstein, M.E., Swendsen, J., Avenevoli, S., Case, B., Georgiades, K., Heaton, L., Swanson, S., Olfson, M. (2011). Service utilization for lifetime mental disorders in U.S. adolescents: Results from the National Comorbidity Survey Adolescent Supplement (NCS-A). Journal of the American Academy of Child and Adolescent Psychiatry, 50, 32-45.

Miniño, A. M. (2010). Mortality among teenagers aged 12-19 years: United States, 1999-2006. NCHS Data Brief, no. 37. Hyattsville, MD: National Center for Health Statistics. Retrieved from http://www.cdc.gov/nchs/data/databrief/db37.pdf

Minguez, M., Santelli, J. S., Gibson, E., Orr, M., \& Samant, S. (2015). Reproductive health impact of a school health center. Journal of Adolescent Health, 56, 338-344.

Morreale, M. C., Kapphahan, C., Elster, A. B., Juszczak, L., \& Klein, J. D. (2004). Access to health care for adolescents and young adults: Position paper of the Society for Adolescent Medicine. Journal of Adolescent Health, 35, 343-344.

Morse, J. M. (1991). Approaches to qualitative-quantitative methodological triangulation. Nursing Research, 40, 122-123.

Morse, J. M. (2003). Principles of mixed methods and multimethod design. In A. Tashakkori \& C. Teddlie (Eds.). Handbook of mixed methods in social and behavioral research (pp.189208). Thousand Oaks, CA: Sage. 
Mulye, T. P., Park, M. J., Nelson, C. D., Adams, S. H., Irwin, C. E. \& Brindis, C. D. (2009).

Trends in adolescent and young adult health in the United States. Journal of Adolescent Health, 45, 8-24. doi:10.1016/j.adohealth.2009.03.013

Mundinger, M. O., Kane, R. L., Lenz, E. R., Totten, A. M., Tsai, W., Cleary, P. D., Friedewald, W. T., Siu, A. L. \& Shelanski, M. L. (2000). Primary care outcomes in patients treated by nurse practitioners or physicians: A randomized trial. Journal of the American Medical Association, 283, 59-68. doi:10.1001/jama.283.1.59.

Murphey, D., Barry, M. \& Vaughn, B. (2013). Mental health disorders. Childtrends, 2013-1, 1-10. National Center for Injury Prevention and Control. (2006). Water-related injuries: Fact sheet. Atlanta, GA: Centers for Disease Control and Prevention.

National Research Council and Institute of Medicine of the National Academies. (2009). Adolescent health services: Missing opportunities. Washington, DC: The National Academies Press.

Nordin, J. D., Solberg, L. I., \& Parker, E. D. (2010). Adolescent primary care visit patterns. Annals of Family Medicine, 8, 511-516. doi: 10.1370/afm.1188

O'Caithlin, A. (2010). Assessing the quality of mixed methods research: Toward a comprehensive framework. In A. Tashakkori \& C. Teddlie (Eds.), Sage handbook of mixed methods in social and behavioral research, (2nd ed., pp. 531-555). Thousand Oaks, CA: Sage Publications, Inc.

O’Leary, T., Lee, M., Federico, S., Barnard, J., Lockhart, S., Albright, K., Shmueli, D., Allison, M. A., Kempe, A. (2014). School-based health centers as patient-centered medical homes. Pediatrics, 134, 957-964. doi: 10.1542/peds.2014-0296

O'Malley, A. (2004). Current evidence on the impact of continuity of care. Current Opinion in Pediatrics, 15, 693-699. doi: 10.1097/01.mop.0000142488.67171.02

Onwuegbuzie, A. J. \& Johnson, J. B. (2006). The validity issue in mixed research. Research in Schools, 13, 48-63. 
Patient Protection and Affordable Care Act, Pub. L. No. 111-148, §2702, 124 Stat. 119, 318-319 (2010).

Perper, K., Peterson, K. \& Manlove, J. (2010). Diploma attainment among young teen mothers.

Washington, DC: Child Trends. Retrieved from http://www.childtrends.org/files/child_trends 2010_01_22_FS_diplomaattainment.pdf

Piaget, J. (1952). The origins of intelligence in children. New York, NY: International Universities Press.

Piaget, J. (1972). Intellectual evolution from adolescence to adulthood. Human Development, 15, 1-12.

Polit, D. F. \& Beck, C. T. (2012). Nursing research: Generating and assessing evidence for nursing practice $\left(9^{\text {th }}\right.$ ed.). Philadelphia, PA: Lippincott, Williams \& Wilkins.

Price, J. H., McKinney, M. A., \& Braun, R. E. (2011). Social determinants of racial/ethnic disparities in children and adolescents. The Health Educator, 43, 2-12.

Rand, C. M., Auinger, P., Klein, J. D. \& Weitzman, M. (2005). Preventive counseling at adolescent ambulatory visits. Journal of Adolescent Health, 37, 87-93. doi:

10.1016/j.jadohealth.2005.02.008

Rand, C. M., Shome, L. P., Albertin, C., Aunginer, P., Klein, J. D., \& Szilagyi, P. G. (2007). National health care visit patterns of adolescents: Implications for delivery of new adolescent vaccines. Archives of Pediatric and Adolescent Medicine, 161, 252-259.

Reilly, J., Methven, E., McDowell, Z., Hacking, B., Alexander, D., Stewart, L., \& Kelnar, C. (2003). Health consequences of obesity. Archives of Diseases in Childhood, 88, 748-752. doi: $10.1136 /$ adc.88.9.748

Reilly, J. J. \& Kelly, J. (2011). Long-term impact of overweight and obesity in childhood and adolescence on morbidity and premature mortality in adulthood: Systematic review. International Journal of Obesity, 35, 891-898. doi: 10.1038/ijo.2010.222 
Rosen, D., Elster, A., Hedberg, V., \& Paperny, D. (1997). Clinical preventive services for adolescents: Position paper of the Society for Adolescent Medicine. Journal of Adolescent Health, 21, 203-214. doi: 10.1016/S1054-139X(97)00116-X

Rosen, D. \& Neinstein, L. (2008). Preventive health care for adolescents, (pp.44-80). In L. Neinstein (Ed). Adolescent health care: A practical guide ( $5^{\text {th }}$ ed.). New York: Lippincott Williams and Wilkens.

Rosenfeld, S. L., Fox, D. J., Keenan, P. M., Melchiono, M. W., Samples, C. L. \& Woods, E. R. (1996). Primary care experiences and preferences of urban youth. Journal of Pediatric Health Care, 10, 151-160.

Rubin, S. E., McKee, D., Campos, G., \& O'Sullivan, L. F. (2010). Delivery of confidential care to adolescent males. Journal of American Board of Family Medicine, 23, 728-735. doi: 10.3122/jabfm.2010.06.100072

Sadler, L.S. \& Daley, A. M. (2002). A model of teen-friendly care for young women with negative pregnancy test results. The Nursing Clinics of North America, 37, 523-535.

Santelli, J.S., Orr, M., Lindberg, L.D. \& Diaz, D.C. (2009). Changing behavioral risk for pregnancy among high school students in the United States, 1991-2007. Journal of Adolescent Health, 45, 25-32. doi:10.1016/j.jadohealth.2009.04.017

Santelli, J. S., Lindberg, L. D., Finer, L. B. \& Singh, S. (2007). Explaining recent declines in adolescent pregnancy in the United States: The contribution of abstinence and improved contraceptive use. American Journal of Public Health, 97(1), 150-6. doi:10.2105/AJPH.2006.089169

Schaeuble, K., Haglund, K. \& Vukovich, M. (2010). Adolescents' preferences for primary care provider interactions. Journal of Specialists in Pediatric Nursing, 15, 202-210.

School-Based Health Alliance. (2015). School-based health care state policy survey. Washington, D.C.: School-Based Health Alliance. Retrieved from 
http://www.sbhc4all.org/school-health-care/aboutsbhcs/school-based-health-care-statepolicy-survey.

Schwarz, L. (2009). Adolescent mental health in the United States. New York, NY: National Center for Children in Poverty Mailman School of Public Health Columbia University.

Scudder, L., Papa, P. \& Brey, L.C. (2007). School-based health centers: A model for improving the health of the nation's children. The Journal for Nurse Practitioners, 8, 713-720.

Shrier, L. (2008). Pelvic inflammatory disease. In L. Neinstein (Ed.). Adolescent health care: $A$ practical guide (5th ed., pp. 819-822). New York: Lippincott Williams and Wilkins.

Shuger, L. (2012). Teen pregnancy and high school dropout: What communities can do to address these issues. Washington, DC: The National Campaign to Prevent Teen and Unplanned Pregnancy.

Siegel, D. J. (2007). The mindful brain: Reflection and attunement in the cultivation of wellbeing. New York, NY: W. W. Norton.

Simpson, L., Owens, P. L., Zodet, M. W., Chevarley, F. M., Dougherty, D., Elixhauser, A., \& McCormick, M. C. (2005). Health care for children and youth in the United States: Annual report on patterns of coverage, utilization, quality, and expenditures by Income. Ambulatory Pediatrics, 5, 6-e20. doi: 10.1367/A04-119R.1

Skulmoski, G. J., Hartman, F.T., Krahn, J. (2007). The Delphi method for graduate research. Journal of Information Technology Education, 6, 1-21.

Slade, E. P. (2002). Effects of school-based mental health programs on mental health service use by adolescents at school and in the community. Mental Health Services Research, 4, 151-166.

Sowell, E. R., Siegel, A. W. \& Siegel, D. J. (2011). Adolescent brain and cognitive changes. In M. M. Fisher, E. M. Alderman, R.E. Kreipe \& W. D. Rosenfeld (Eds.), Textbook of adolescent health care (pp. 32-37). Elk Grove Village, IL: American Academy of Pediatrics. 
Stanik-Hutt, J., Newhouse, R. P., White, K. M., Johantgen, M., Bass, E. B., Zangaro, G., Wilson, R., Fountain, L., Steinwachs, D. M., Heindel, L., \& Weiner, J. P. (2013). The quality and effectiveness of care provided by nurse practitioners. The Journal for Nurse Practitioners, 9, 492-500.

Starfield, B. \& Shi, L. (2004). The medical home, access to care, and insurance: A review of evidence. Pediatrics, 113, 1493-1498.

Starfield, B., Shi, L. \& Maanko, J. (2005). Contribution of primary care health systems and health. Milbank Quarterly, 83, 457-502.

Steinberg, L. \& Collins, W. A. (2011). Adolescent psychosocial development. In M. M. Fisher, E. M. Alderman, R.E. Kreipe \& W. D. Rosenfeld (Eds.), Textbook of adolescent health care (pp. 39-44). Elk Grove Village, IL: American Academy of Pediatrics.

Strolin-Goltzman, J. (2010). The relationship between school-based health centers and the learning environment. Journal of School Health, 80, 153-159.

Strozer, J., Juszczak, L. \& Ammerman, A. (2010). School-based health centers: National census school year 2007-2008. Washington, D.C.: National Assembly on School-Based Health Care.

Tan, J., Wen, H. J., \& Awaad, N. (2005). Health care and services delivery systems as complex adaptive systems: Examining chaos theory in action. Communications of the ACM, 48, 3644.

Teddlie, C. \& Tashakkori, A. (2009). Foundations of mixed method research: Integrating quantitative and qualitative approaches in the social and behavioral sciences. Thousand Oaks, CA: Sage.

The National Alliance to Advance Adolescent Health. (2010). Strengthening preventive care to better address multiple health risks among adolescents (Report No. 5). Washington, DC: Author. 
Theuissen, M., Griensven van, I., Verdonk, P., \& Bosma, H. (2012). The early identification of the risk factors on the pathway to school drop-out in the SIODO study: A sequential mixed methods study. BMC Public Health, 12, 1033-1049. doi: 10.1186/1471-2458-12-1033

Thompson, D. (1967). Organizations in action. New York: McGraw Hill.

Triandis, H. C. (1971). Attitudes and attitude change. New York: Wiley.

Tsai, V. W., Anderson, C, L. \& Vaca, F. E. (2010). Alcohol involvement among young female drivers in US fatal crashes: unfavorable trends. Injury Prevention, 16, 17-20. doi:10.1136/ip.2009.022301

Tsai, Y., Zhou, F., Wortley, P., Shefer, A., \& Stokley, S. (2014). Trends and characteristics of preventive care visits among commercially insured adolescents, 2003-2010. The Journal of Pediatrics, 164, 625-30. doi: 10.1016/j.peds.2013.10.042

Tylee, A., Haller, D. M., Graham, T., Churchill, R., Sanci, L. A. (2007). Youth-friendly primarycare services: How are we doing and what more needs to be done? Lancet, 369, 1565-73.

U.S. Department of Health and Human Services, Office of Adolescent Health. (2015). Adolescent Health: Think, Act, Grow Playbook. Washington, D.C.: U.S. Government Printing Office. Retrieved August 7, 2015 from http://www.hhs.gov/ash/oah/tag/playbook.pdf

U.S. Department of Health and Human Services. (2000). Healthy People 2010 (2nd ed.). Washington, DC: U.S. Government Printing Office. Retrieved from http://www.healthypeoplegov/2010

U.S. Department of Health and Human Services. (2011a). About healthy people. Retrieved from http://www.healthypeople.gov/2020/about/default.aspx

U.S. Department of Health and Human Services. (2011b). Adolescent health. Retrieved from http://www.healthypeople.gov/2020/topicsobjectives2020/overview.aspx?topicld=2

U.S. Department of Health and Human Services. (2012). Preventing tobacco use among youth and young adults: $A$ report of the Surgeon General. Atlanta, GA: U.S. Department of 
Health and Human Services, Centers for Disease Control and Prevention, National Center for Chronic Disease Prevention and Health Promotion, Office on Smoking and Health. Retrieved from http://www.surgeongeneral.gov/library/reports/preventing-youth-tobacco$\underline{\text { use/full-report.pdf }}$

U.S. Preventive Services Task Force. (1989). Guide to clinical preventive services: An assessment of the effectiveness of 169 interventions. Baltimore, MD: Williams and Wilkins. Retrieved from http://wonder.cdc.gov/wonder/prevguid/p0000109/p0000109.asp\#head0030000000000000

Van Cura, M. (2010). The relationship between school-based health centers, rates of early dismissal from school, and loss of seat time. Journal of School Health, 80, 371-377.

Wade, T. J., Mansour, M. E., Guo. J. J., Huentelman, T., Line, K., \& Keller. K. N. (2008). Access and utilization patterns of school-based health centers at urban and rural elementary and middle schools. Public Health Reports, 123, 739-50.

Wagner, R. V. (1969). The study of attitudinal change: An introduction. In R. V. Wagner and J. J. Sherwood (Eds.), The study of attitudinal change (pp. 1-18). Belmont, CA: Brooke Cole.

Waibel, S., Henao, D., Aller, M. B., Vargas, I., \& Vasquez, M. L. (2012). What do we know about patients' perceptions of continuity of care: A meta-synthesis of qualitative studies. International Journal for Quality in Health Care, 24, 39-48.

Walker, S. C., Kerns, S., Lyon, A. R., Brun, E. J., \& Cosgrove, T. J. (2010). Impact of schoolbased health center use on academic outcomes. Journal of Adolescent Health, 46, 251257.

Webber, M. P., Carpiniello, K. E., Oruwariye, T., Lo, Y., Burton, W. B., \& Appel, D. K. (2003) Burden of asthma in inner-city elementary school children: Do school-based health centers make a difference? Archives of Pediatric and Adolescent Medicine, 157, 125-9. 
Webber, M. P., Hoxie, A. M., Odlum, M., Oruwariye, T., Lo, Y., \& Appel, D. (2005). Impact of asthma intervention in two elementary school-based health centers in the Bronx, New York City. Pediatric Pulmonology, 40, 487-93.

Weinberger, D., Elvevag, B., \& Giedd, J. (2005). The adolescent brain: a work in progress. Washington, DC: The National Campaign to Prevent Teen Pregnancy.

Weist, M. D., Paskewitz, D. A., Warner, B. S., \& Flaherty, L. T. (1996). Treatment outcome of school-based mental health services for urban teenagers. Community Mental Health Journal, 32, 149-57.

Wilson, T. \& Holt, T. (2001). Complexity science: Complexity and clinical care. British Medical Journal, 323, 685-688.

Workowski, K. A. \& Bolan, G. A. (2015). Sexually transmitted diseases treatment guidelines, 2015. MMWR, 63, 1-140. Retrieved from http://www.cdc.gov/std/tg2015/tg-2015-print.pdf

World Health Organization. (2009). Quality assessment guidebook: A guide to assessing health services for adolescent clients. Geneva, Switzerland: Author. Retrieved from http://whqlibdoc.who.int/publications/2009/9789241598859_eng.pdf

World Health Organization. (2012). Making health services adolescent friendly: Developing national quality standards for adolescent friendly health services. Geneva, Switzerland: WHO Press.

Yeung, L. F., Shapira, S. K., Coates, R. J., Shaw, F. E., Moore, C. A., Boyle, C. A., Thacker, S. B. (2014). Rationale for periodic reporting on the use of selected clinical preventive services to improve the health of infants, children, and adolescents-United States. MMWR, 63(02), 3-13. Retrieved from http://www.cdc.gov/mmwr/preview/mmwrhtml/su6302a2.htm

Yu, S. M., Bellamy, H. A., Schwalberg, R. H., Drum, M. A. (2001). Factors associated with use of preventive dental and health services among U.S. adolescents. Journal of Adolescent Health, 29, 395-405. 
Zimmer-Gembeck, M. J., Doyle, L. S., \& Daniels, J. A. (2001). Contraceptive dispensing and selection in school-based health centers. Journal of Adolescent Health, 29, 177-185. 


\section{Appendix A \\ University of Connecticut \\ Volunteers Wanted for a Research Study \\ The Essential Elements of Adolescent-Friendly Care in \\ School-Based Health Centers}

The aim of this research study is to identify what are the essential elements of adolescent-friendly health care services provided to teens in school-based health centers (SBHCs) from the perspective of nurse practitioners. This study will use a Delphi technique via email to reach expert consensus on this topic. This research method will use a series of 3 or 4 questionnaires over the course of 6-8 weeks. Each questionnaire will take approximately 30 minutes to complete.

Expert Nurse Practitioners who have national certification as a NP, have $3+$ years of experience providing health care to teens in SBHCs AND are considered an expert in SBHC adolescent health (for example, published a paper in a peer-reviewed journal, given a local/national presentation, or are designated as an expert by their professional organization) are invited to participate in this study.

Participation is voluntary, results are confidential.

To learn more about this study please contact:

Alison Moriarty Daley, MSN, APRN, PNP-BC at alison.moriarty@uconn.edu or

860-XXX-XXXX

This research will be conducted under the direction of

E. Carol Polifroni, EdD, RN,

University of Connecticut School of Nursing 
Appendix B

\title{
Delphi Technique Invitation to Participate Letter
}

\author{
Study Title: The Essential Elements of Adolescent-Friendly Care in School-Based Health Centers \\ Dear [NAME]:
}

As an expert nurse practitioner, you are being invited to participate in a research study to identify the essential components of adolescent-friendly health care services in school-based health centers. Your input is very important to this research endeavor.

The study will utilize the Delphi method which consists of three sequential questionnaires (also called rounds) aimed at achieving consensus among an expert panel of participants. Each questionnaire will be emailed to you and you will be asked to return your response within two weeks. Simple directions will be provided with each questionnaire. Your responses will remain confidential and not shared with the other members of the expert panel. If you agree to participate, a consent form describing the study and a demographic questionnaire will be sent to you for you to complete. After the receipt of the consent and demographic forms, the first questionnaire will be sent to you. The amount of time required to complete each questionnaire will vary by participant, but is estimated to no more than 30 minutes. There are no correct or incorrect answers to the questions asked; rather I am seeking your expert opinion on the essential elements of adolescent-friendly health care.

This study has been approved by the University of Connecticut Institutional Review Board. Your participation in the study is completely voluntary and you may withdraw at any time if you wish. We are not aware of any risks or complications that could occur from your participation. If you agree to participate, the consent form will provide you with the contact information for reporting any complaints you have about the study or your participation. The completed questionnaires and your individual responses will remain anonymous to the other participants. Only the research team will have access to your questionnaires. Each questionnaire will be identified with a unique code so that your responses can be linked together. All files will be kept in the researcher's office in a locked file when not in use. Data generated from this study will be reported as aggregate data; no names or individual clinics will be identified.

If you would like to participate in this study, please reply to this email by [DATE]. I am happy to answer any questions you may have about the study or your participation (alison.moriarty@uconn.edu or 860-XXX-XXXX). Thank you.

Sincerely,

Alison Moriarty Daley, MSN, APRN, PNP-BC

University of Connecticut 


\section{Appendix C \\ University of Connecticut Consent Form for Partcipation in a Reseach Study}

Principal Investigator: Carol Polifroni, Ed.D., RN

Student Researcher: Alison Moriarty Daley, MSN, APRN, PNP-BC

Study Title: The Essential Elements of Adolescent-Friendly Care in School-Based Health Centers

Introduction

You are invited to participate in a study to identify the essential elements of adolescent-friendly health care in school-based health centers. A Delphi technique will be utilized to gain consensus among a national panel of experts. As a school-based health nurse practitioner, I am very interested in your perspective on adolescent-friendly care. I am graduate student in nursing at the University of Connecticut and will be conducting this research as part of my dissertation.

Why is this study being done?

The purpose of this study is to identify the essential elements of adolescent-friendly health care services provided to teens in school-based health centers.

What are the study procedures? What will I be asked to do?

Your participation in this study will require a brief demographic questionnaire followed by three questionnaires that will be provided sequentially over the course of several weeks. The initial questionnaire (Round 1 ) will ask you to identify elements of adolescent-friendly health care and the subsequent questionnaires (Rounds 2 and 3) will ask you to indicate on a 5-point Likert scale (strongly disagree to strongly agree) your level of agreement with a composite list of all responses from Round 1. The goal is to reach consensus on the elements considered essential to providing adolescent-friendly health care in school-based health centers from a panel of national experts.

\section{What are the risks or inconveniences of the study?}

While I believe participation does not involve any risk to you, if you do not want to answer a question or you feel uncomfortable, you are free to skip a question or no longer participate in the study for any reason. The only inconvenience is the amount of time the questionnaires take, about 30 minutes each.

What are the benefits of the study?

Although you may find it interesting to participate in this study, there will be no direct benefit to you from your participation.

\section{Will I receive payment for participation? Are there costs to participate?}

There are no costs and you will not be paid to be in this study. 
How will my personal information be protected?

The following procedures will be used to protect the confidentiality of your data. The Delphi technique requires participants to receive the surveys for each round and return their responses via email. Please be aware that email is not a secure method of transmission. We will do our best to protect the confidentiality of the information we gather from you but we cannot guarantee $100 \%$ confidentiality. Your confidentiality will be maintained to the degree permitted by the technology used. Specifically, no guarantees can be made regarding the interception of data sent via the Internet by any third parties. The student researcher will keep all study records (including any codes to your data) in a locked file. Research records will be labeled with a code. The code will be derived from a numeric three digit code that reflects how many people have enrolled in the study. A master key that links names and codes will be maintained in a separate and secure location. The master key and questionnaires will be destroyed after 3 years. All electronic files (e.g., database, spreadsheet, etc.) containing identifiable information will be password protected. Any computer hosting such files will also have password protection to prevent access by unauthorized users. Only the members of the research staff will have access to the passwords. Data that will be shared with others will be coded as described above to help protect your identity. At the conclusion of this study, the researchers may present and/or publish their findings. Information will be presented in summary format and you will not be identified in any publications or presentations.

You should also know that the University of Connecticut Institutional Review Board (IRB) and the Office of Research Compliance may inspect study records as part of its auditing program, but these reviews will only focus on the researchers and not on your responses or involvement. The IRB is a group of people who review research studies to protect the rights and welfare of research participants. We will do our best to protect the confidentiality of the information we gather from you but we cannot guarantee $100 \%$ confidentiality. Your confidentiality will be maintained to the degree permitted by the technology used. Specifically, no guarantees can be made regarding the interception of data sent via the Internet by any third parties.

\section{Can I stop being in the study and what are my rights?}

You do not have to be in this study if you do not want to. If you agree to be in the study, but later change your mind, you may drop out at any time. There are no penalties or consequences of any kind if you decide that you do not want to participate. You do not have to answer any question that you do not want to answer.

\section{Whom do I contact if I have questions about the study?}

Take as long as you like before you make a decision. We are happy to answer any question you have about this study. If you have further questions about this project you may contact me, the student researcher, at Alison Moriarty Daley at (860-XXX-XXXX) or the principal investigator, Carol Polifroni, EdD, RN (860)$X X X-X X X X$. If you have any questions concerning your rights as a research subject, you may contact the University of Connecticut Institutional Review Board (IRB) at (860)-486-8802. 


\section{Consent Form for Participation in a Research Study Wuniversity of Connecticut}

Principal Investigator: E. Carol Polifroni, Ed.D., RN

Student Researcher: Alison Moriarty Daley, MSN, APRN, PNP-BC

Study Title: The Essential Elements of Adolescent-friendly Care in School-Based Health Centers Documentation of Permission:

I have read this form and decided that I will give my permission to participate in the study described above. Its general purposes, the particulars of my involvement and possible risks and inconveniences have been explained to my satisfaction. I understand that I can withdraw at any time. My signature also indicates that I have received a copy of this permission form. Please return this form to Alison Moriarty Daley, MSN, APRN, PNP-BC by (insert date).

Participant Signature:

Print Name:

Date:

Signature of Person

Print Name:

Date:

Obtaining Consent 
Appendix D

\section{Delphi Technique Demographic Questionnaire}

Name:

Degrees:

Address:

Gender: $\quad$ Race/ethnicity:

Place of Employment:

Address:

Sponsoring Agency: Hospital Community Health Center Health Department

Other

How many years have you been a NP? How many years have you practiced in a SBHC?

Are you a (please circle choice) PNP

FNP

ANP

Other

Certification: ANCC PNCB Other

Please check all that apply I have published a paper in a peer-reviewed journal I have given a national presentation I have been identified as an expert by my professional organization Other evidence of expert status as a SBHC NP caring for teens

Thank you for completing this demographic questionnaire. Please return the questionnaire by [DATE]. 
Appendix $\mathrm{E}$

\section{Delphi Technique Round 1 Letter}

Dear [NAME],

Thank you for agreeing to participate in "The Essential Elements of Adolescent-friendly Care in School-Based Health Centers" study. Your expert opinion is critical to this endeavor.

Included in this letter are the Round I instructions and questionnaire. The aim of this study is to gain consensus on the essential elements of adolescent-friendly care. Please read the instructions carefully and complete the Delphi questionnaire as fully as you can. It is also important that you complete the demographic questionnaire at the end of the questionnaire which will allow me to provide you feedback throughout the study.

Please return the completed questionnaire by [DATE] via email at alison.moriarty@uconn.edu. If you have any questions or would like to discuss the study further, please contact me directly either by email or phone at 860-XXX-XXXX.

Thank you for agreeing to participate in this study.

Sincerely yours,

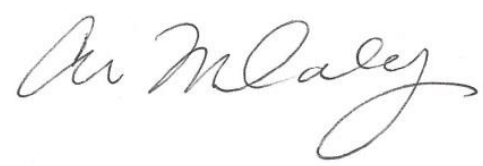

Alison Moriarty Daley, MSN, APRN, PNP-BC University of Connecticut, Doctoral student 
Appendix F

CODE \#

The Essential Elements of Adolescent-friendly Care in School-Based Health Centers

\author{
Delphi Technique Round 1 Questionnaire
}

Please list your response to the following question in the space below. There are no correct or incorrect answers. Answers do not need to be in any particular order.

Question: What are the essential elements associated with providing adolescent-friendly health care in school-based health centers? Please list a minimum of $\mathbf{5}$ elements. 
Appendix G

Delphi Technique Follow-up Letter

Dear Expert Panel Member:

Re: The Essential Elements of Adolescent-friendly Care in School-Based Health Centers

The Round__ questionnaire was sent to you via email on [DATE]. Please complete the questionnaire and return it to me by [DATE].

Thank you for your continued participation in this study, your expert opinion is essential to this study.

If you have any questions or did not receive the questionnaire, please contact me at either by email

(alison.moriarty@uconn.edu) or phone at 860-XXX-XXXX.

Sincerely yours,

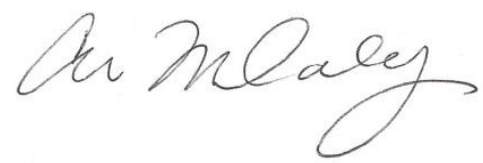

Alison Moriarty Daley, MSN, APRN, PNP-BC

University of Connecticut, Doctoral student 
Appendix $\mathrm{H}$

Delphi Technique Reminder Letter

Dear Expert Panel Member:

\section{Re: The Essential Elements of Adolescent-friendly Care in School-Based Health Centers}

Thank you so much for agreeing to participate in this study. This is a reminder that the Round questionnaire was due on [DATE]. I have not received your questionnaire. If you have already returned the survey, please contact me as soon as possible. If you have not had the opportunity to complete it, I have attached the Round questionnaire to this email for you. Please complete it and return to me by [DATE] via email at alison.moriarty@uconn.edu.

Your expert opinion is critical to this study. Thank you for your continued participation in this study. If you have any questions, please contact me at either by email or phone at $860-\mathrm{XXX}-\mathrm{XXXX}$.

Sincerely yours,

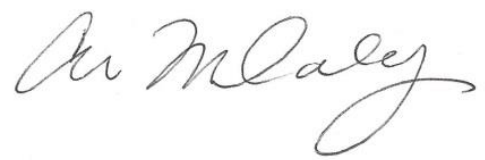

Alison Moriarty Daley, MSN, APRN, PNP-BC University of Connecticut, Doctoral student 
Appendix I

\section{Delphi Technique Round 2 Letter}

Dear Expert Panel Member:

\section{Re: The Essential Elements of Adolescent-friendly Care in School-Based Health Centers}

Thank you so much for returning the Round 1 Delphi questionnaire. Enclosed is the Round 2 questionnaire. This questionnaire is completed differently from Round 1. Please read the instructions carefully and complete the Delphi questionnaire as fully as you can.

Please return the Delphi Round 2 questionnaire by [DATE] via email at alison.moriarty@uconn.edu. If you have any questions, please contact me at either by email or phone at 860-XXX-XXXX.

Thank you again for your continued participation in this study.

Sincerely yours,

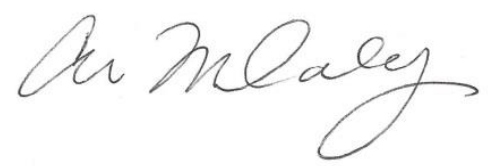

Alison Moriarty Daley, MSN, APRN, PNP-BC

University of Connecticut, Doctoral student 


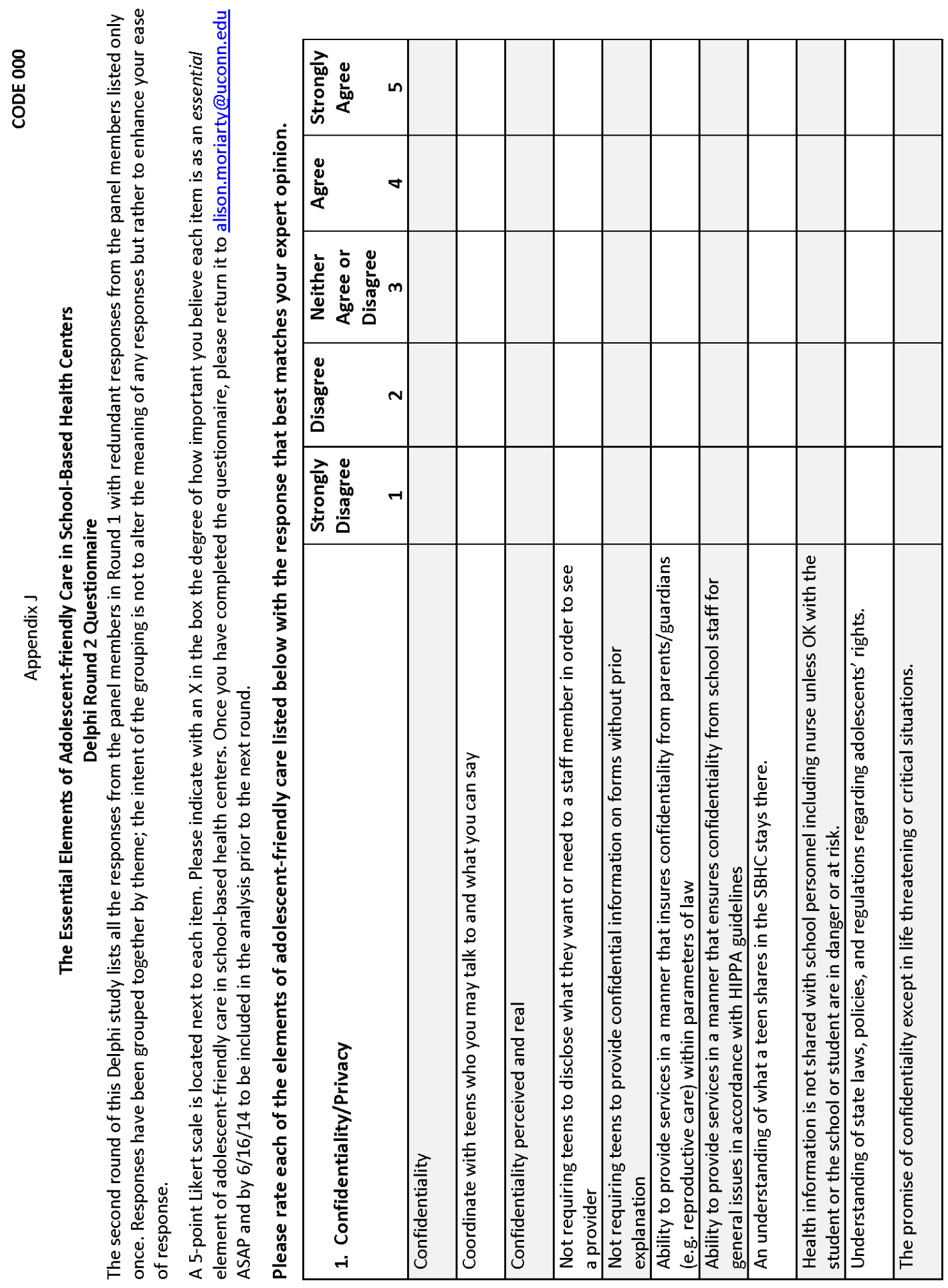



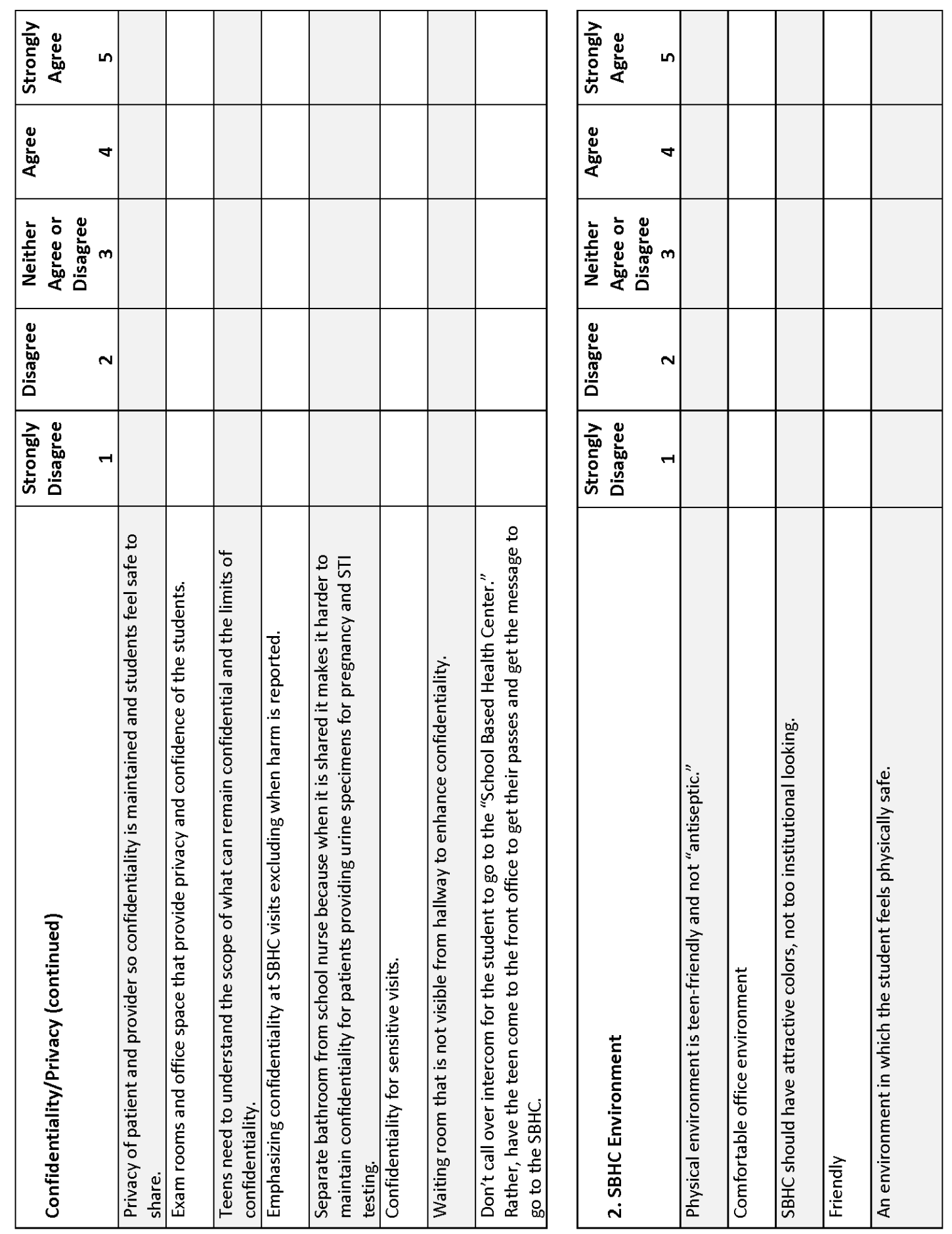


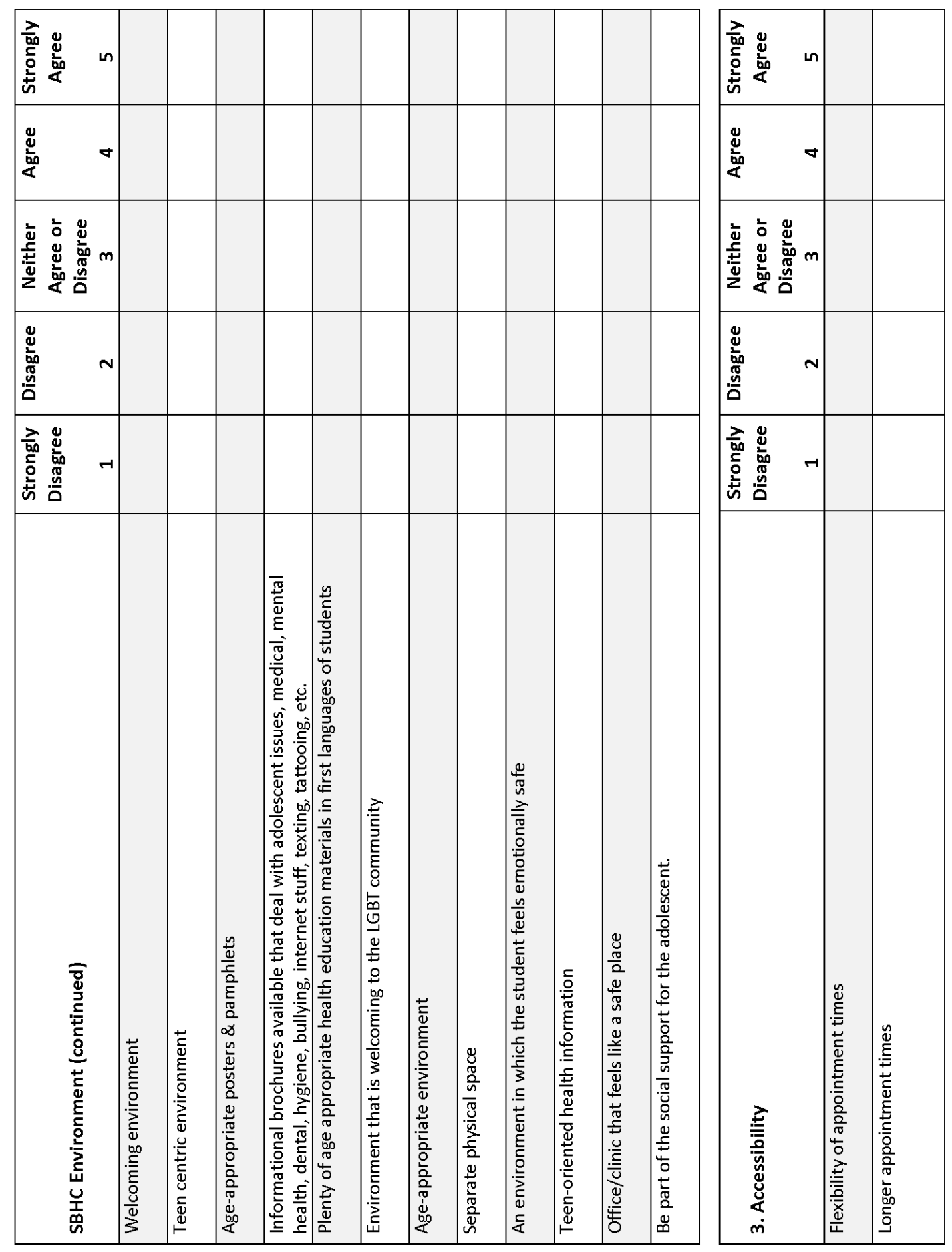




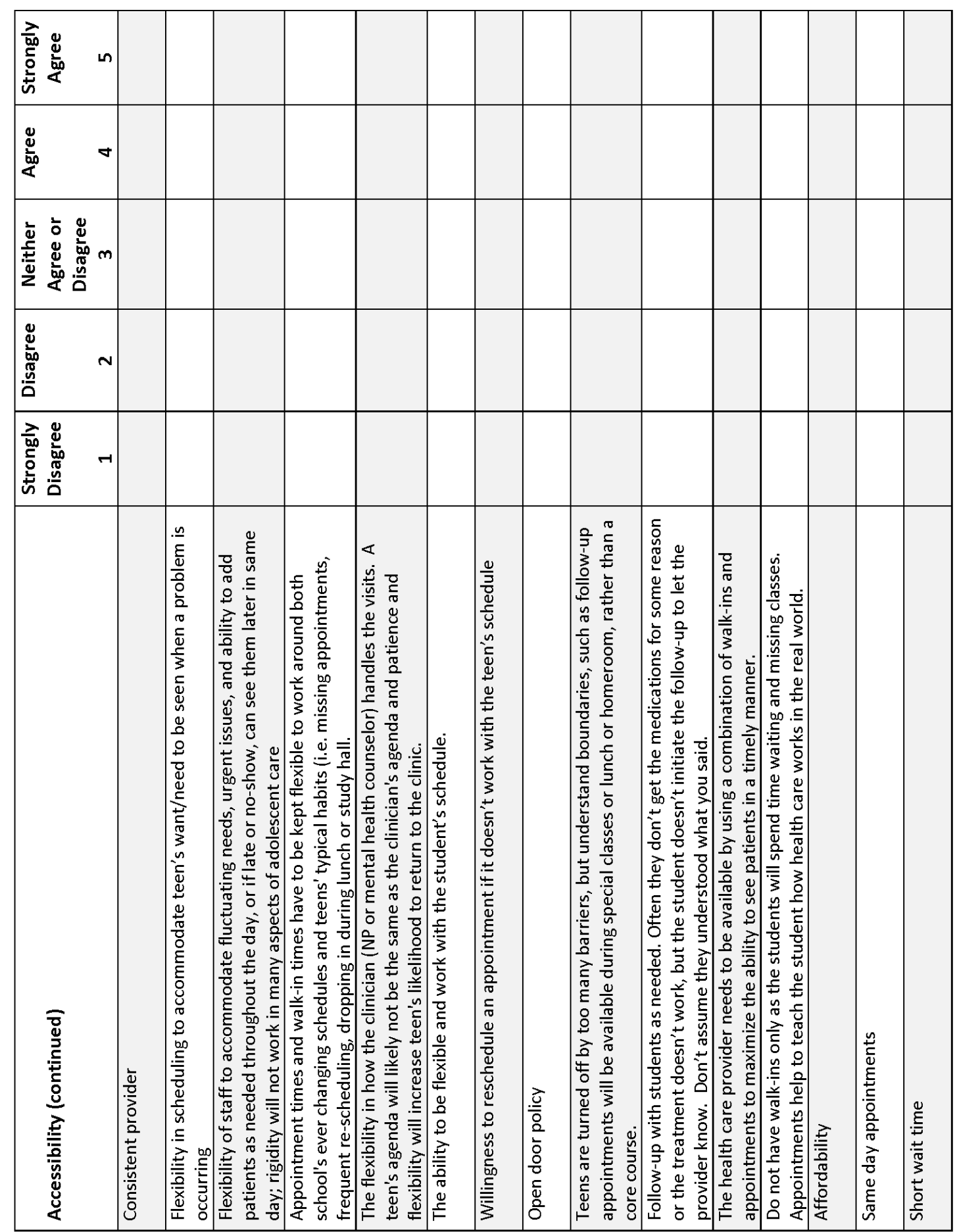




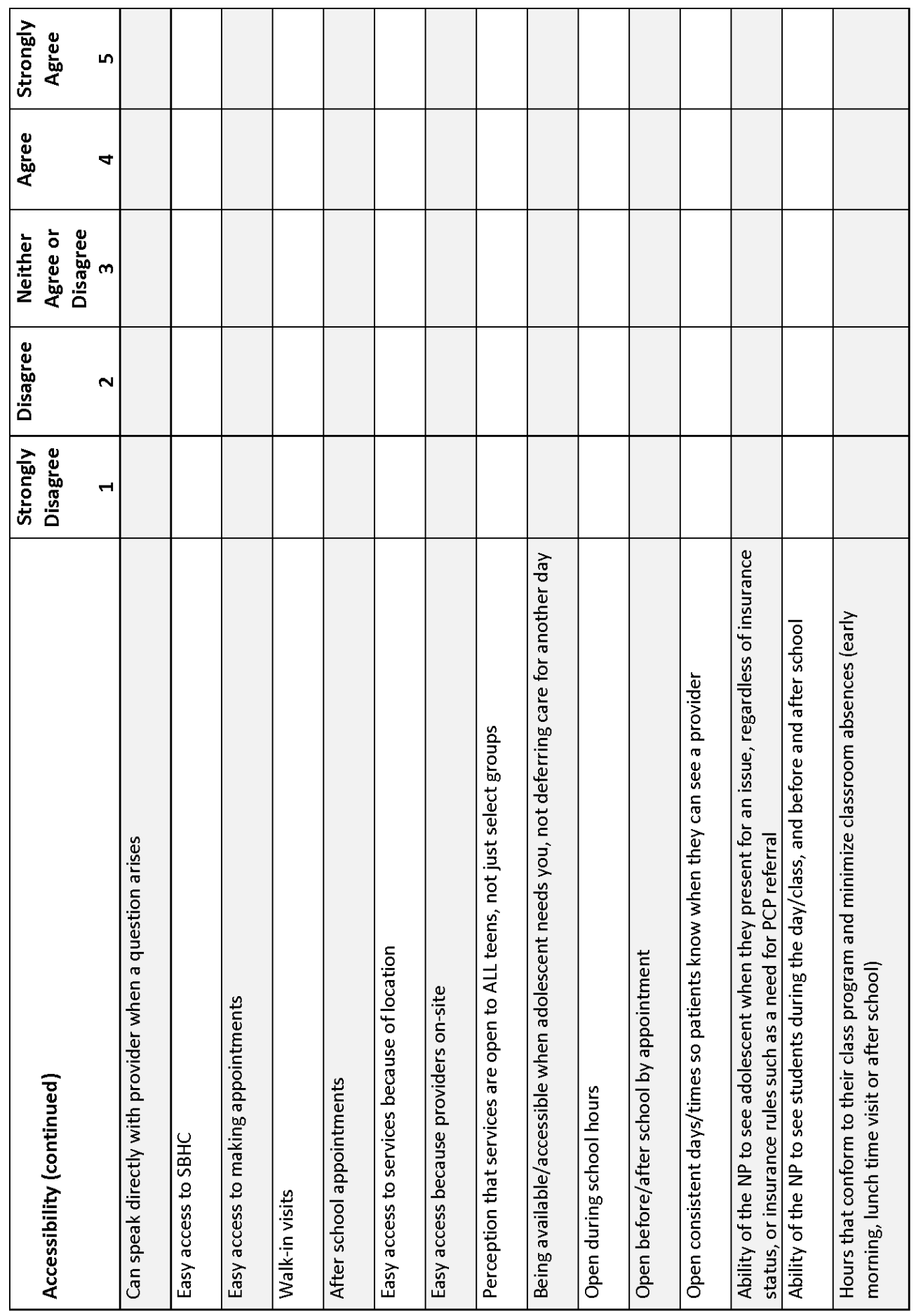




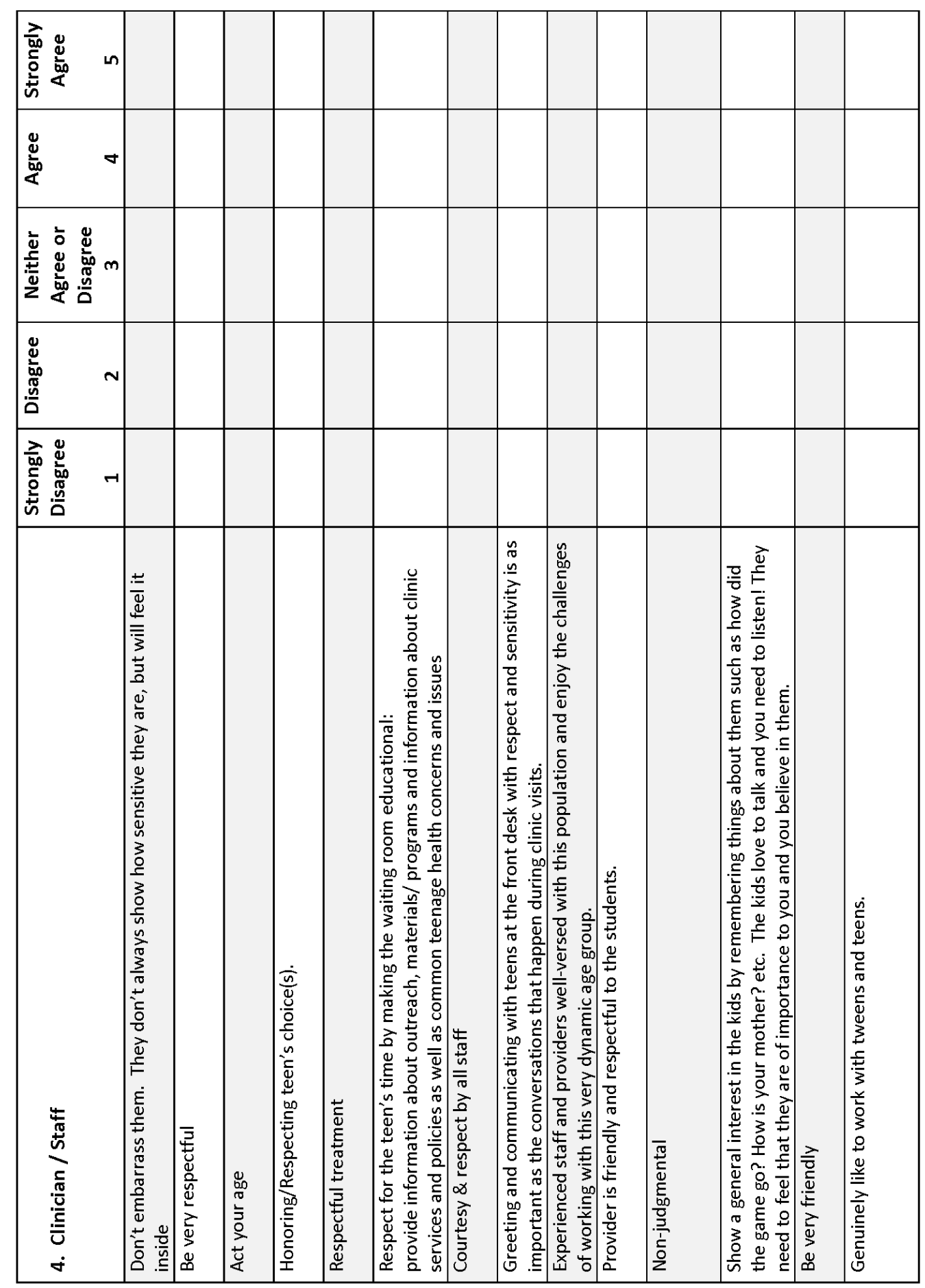




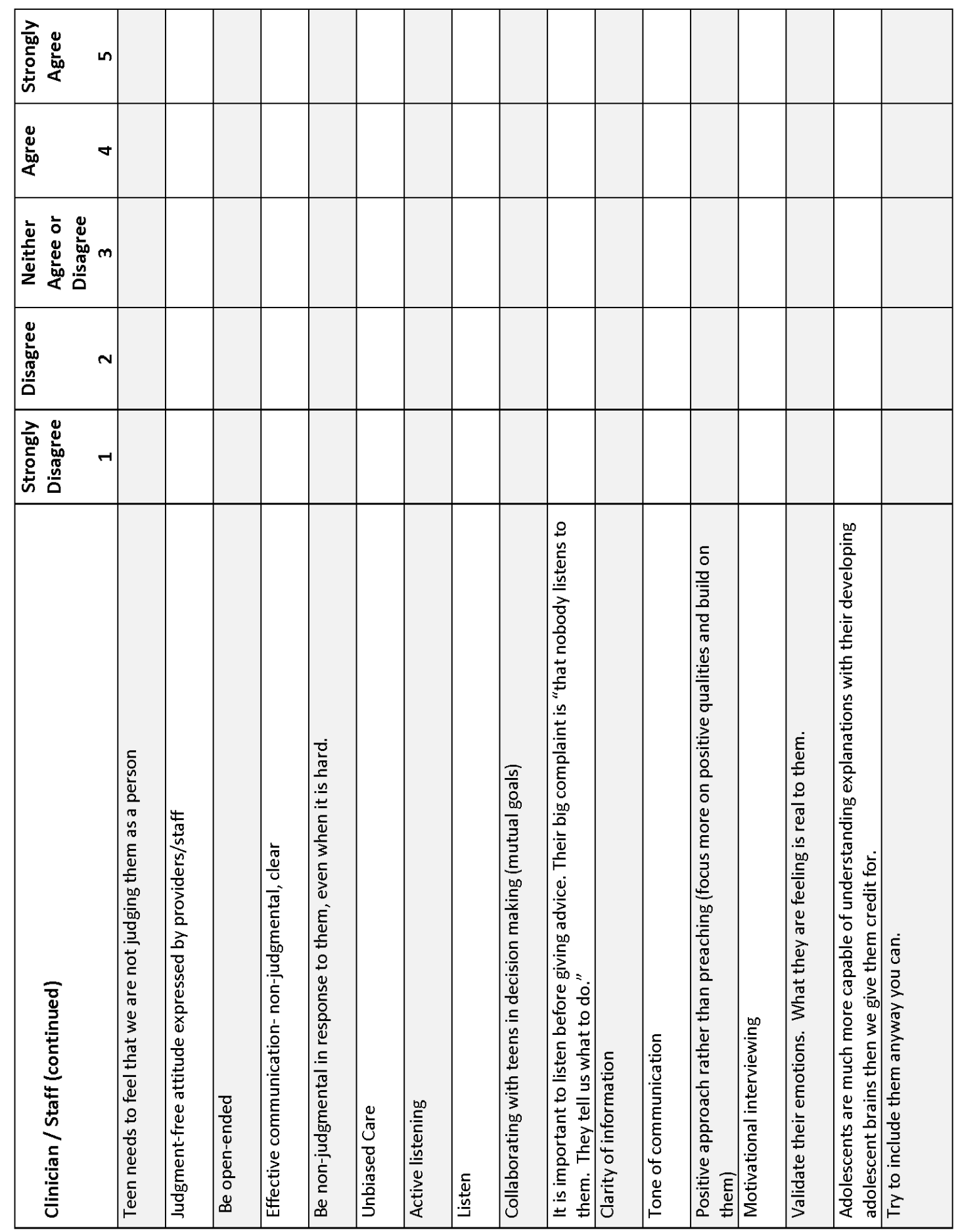




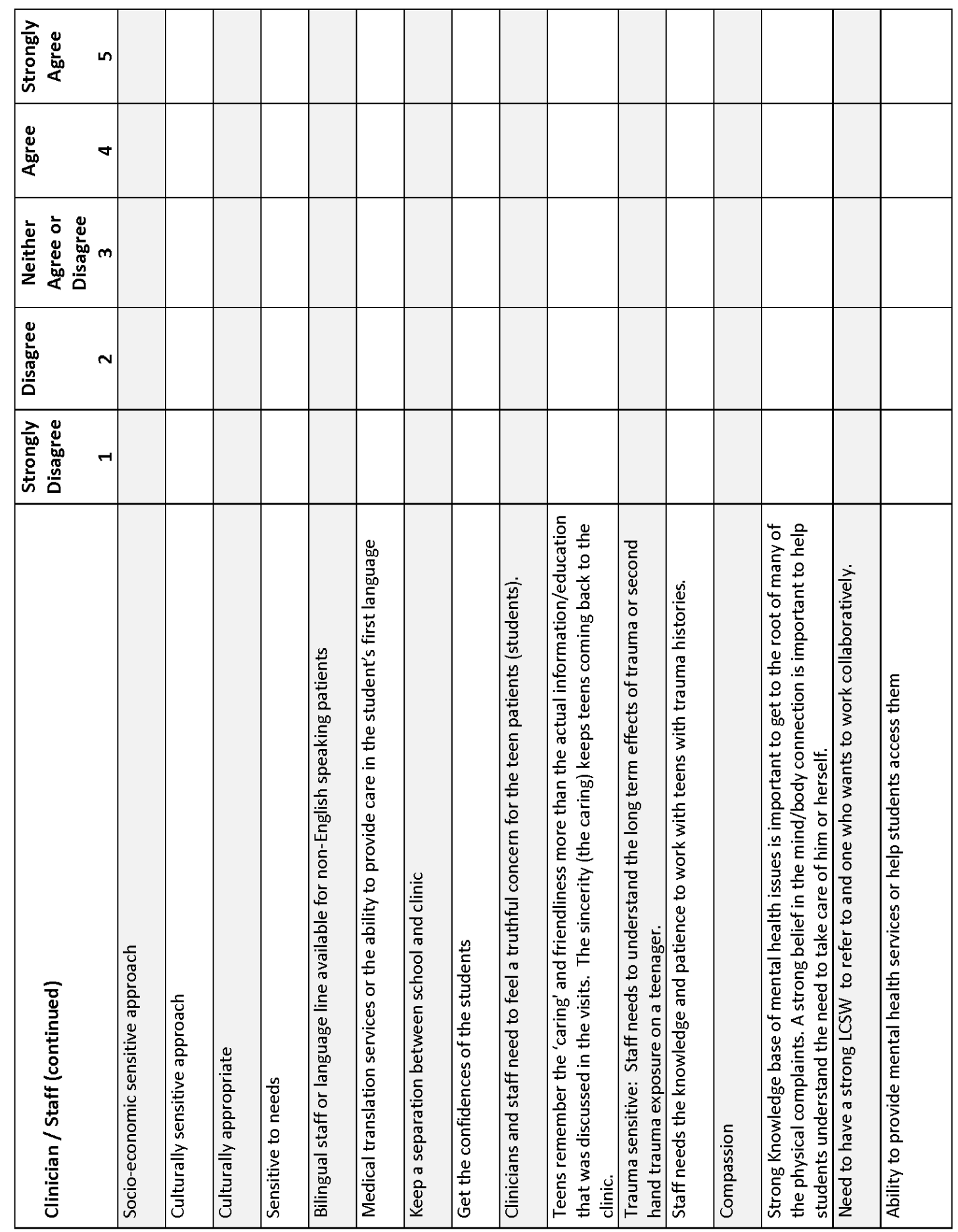




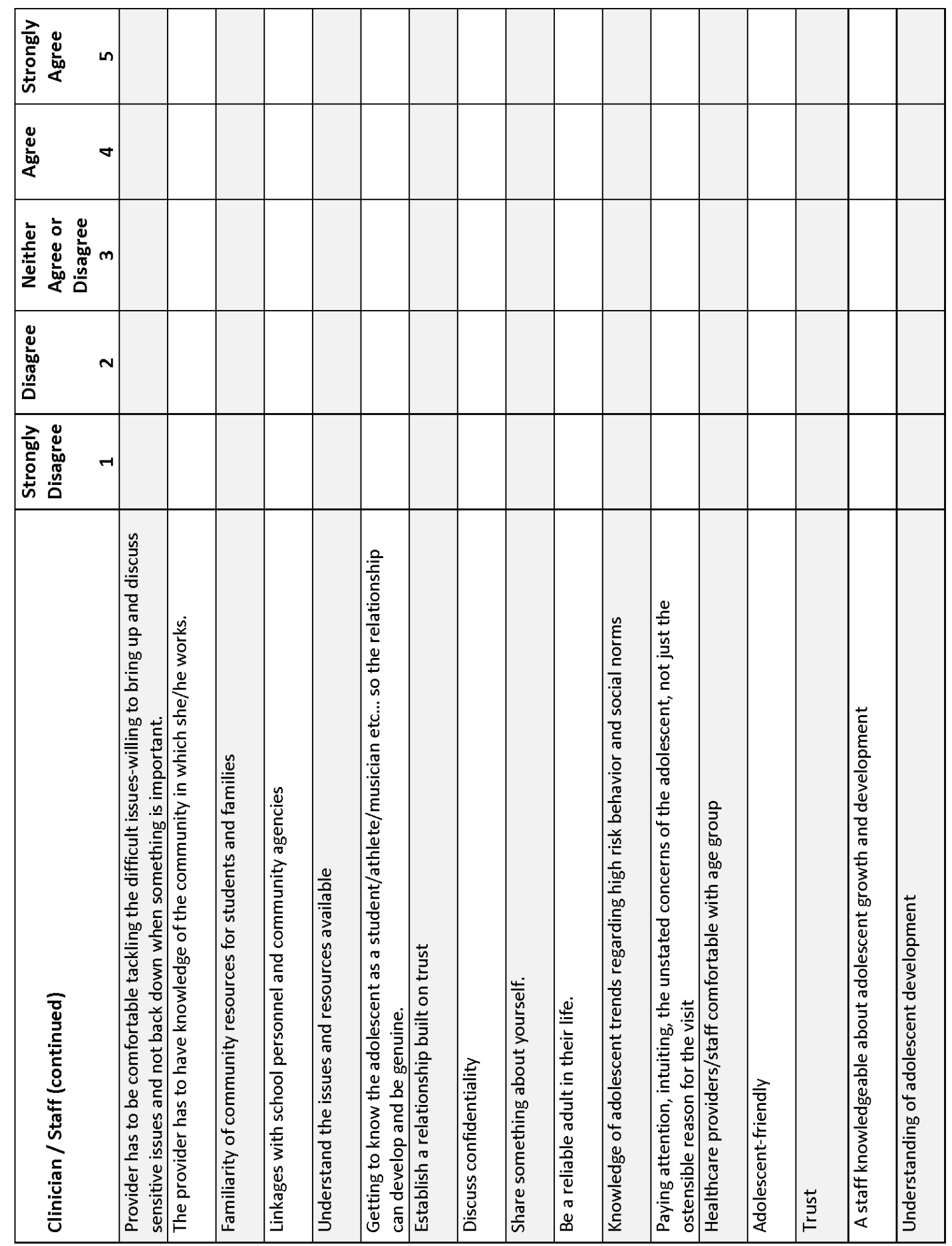




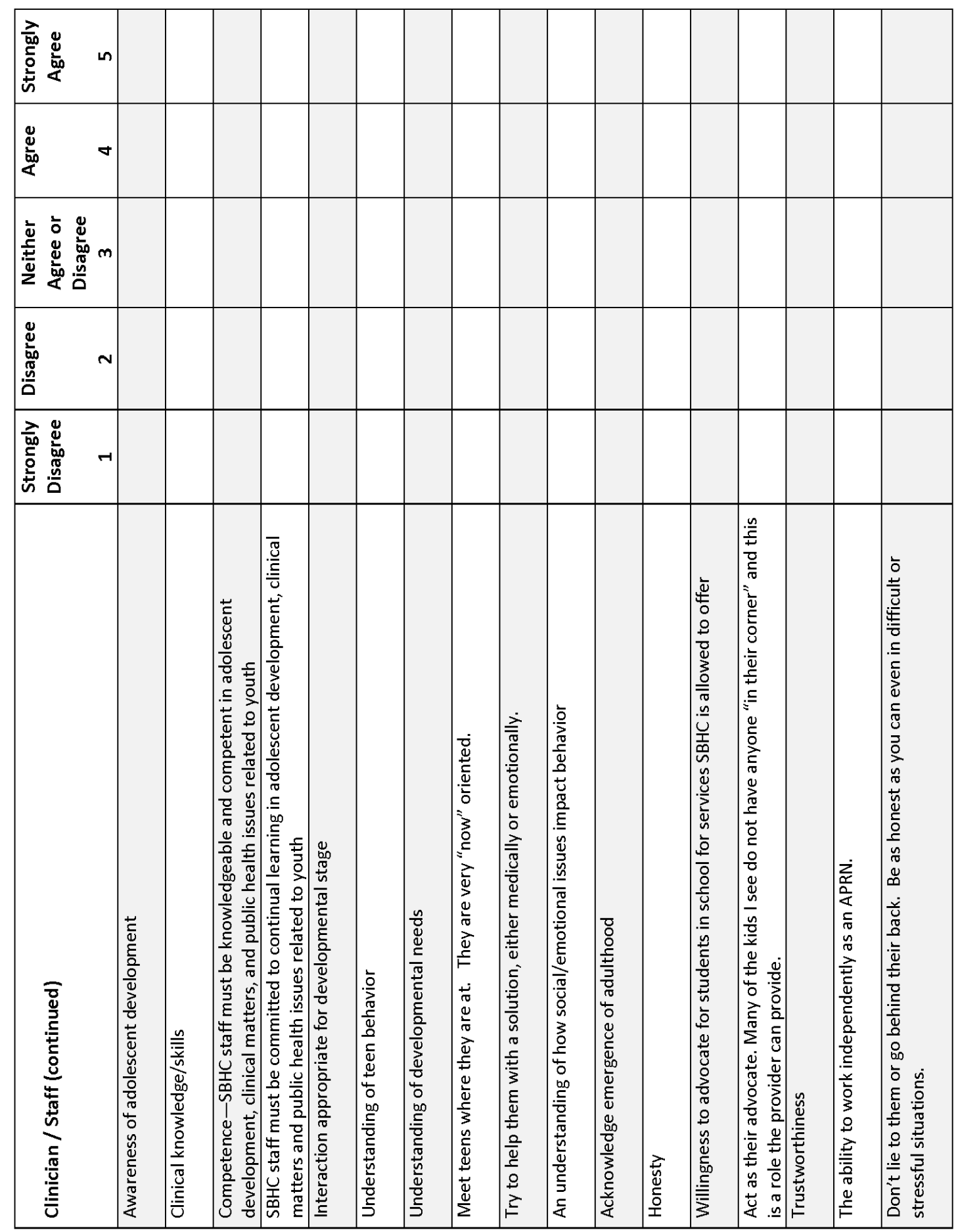



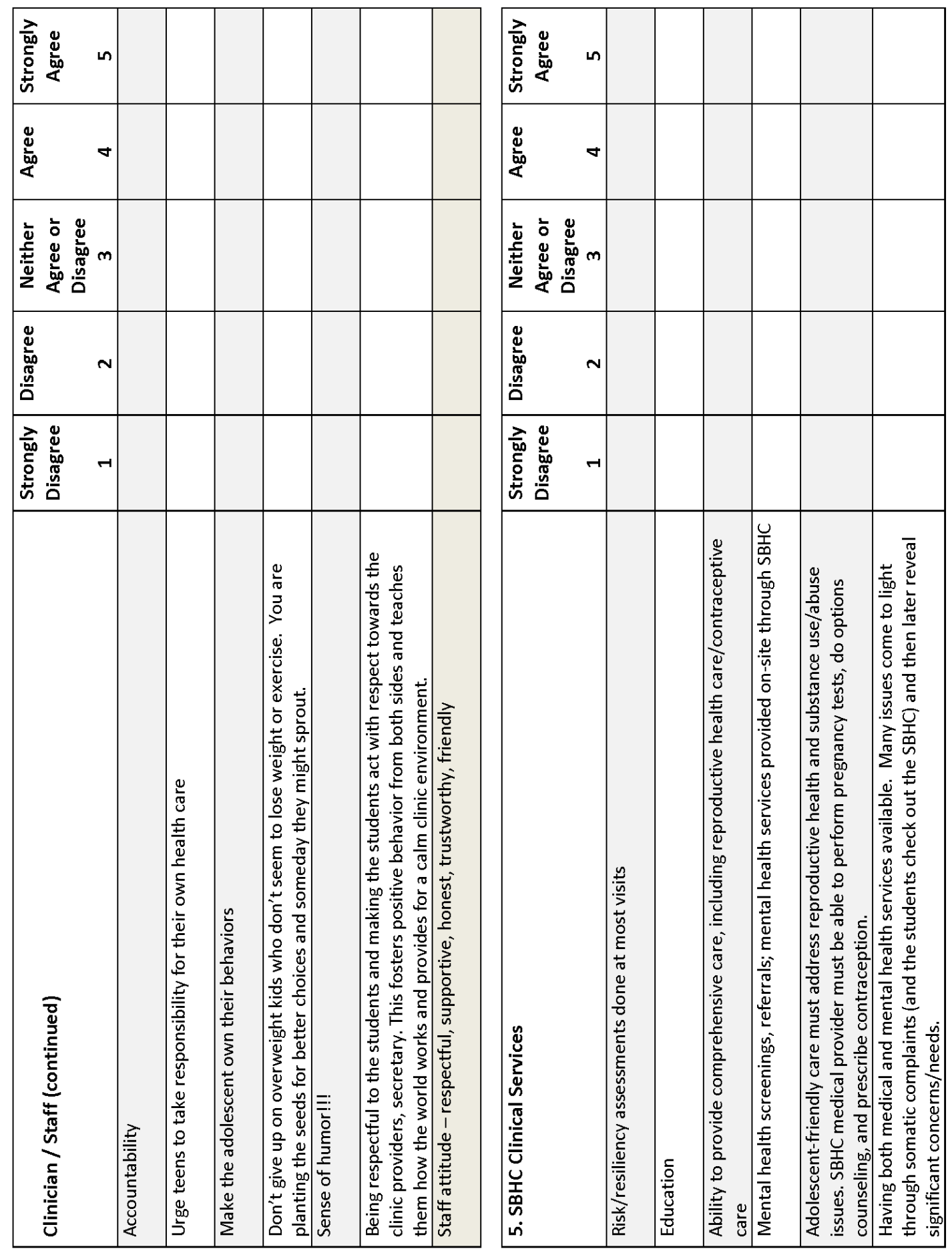


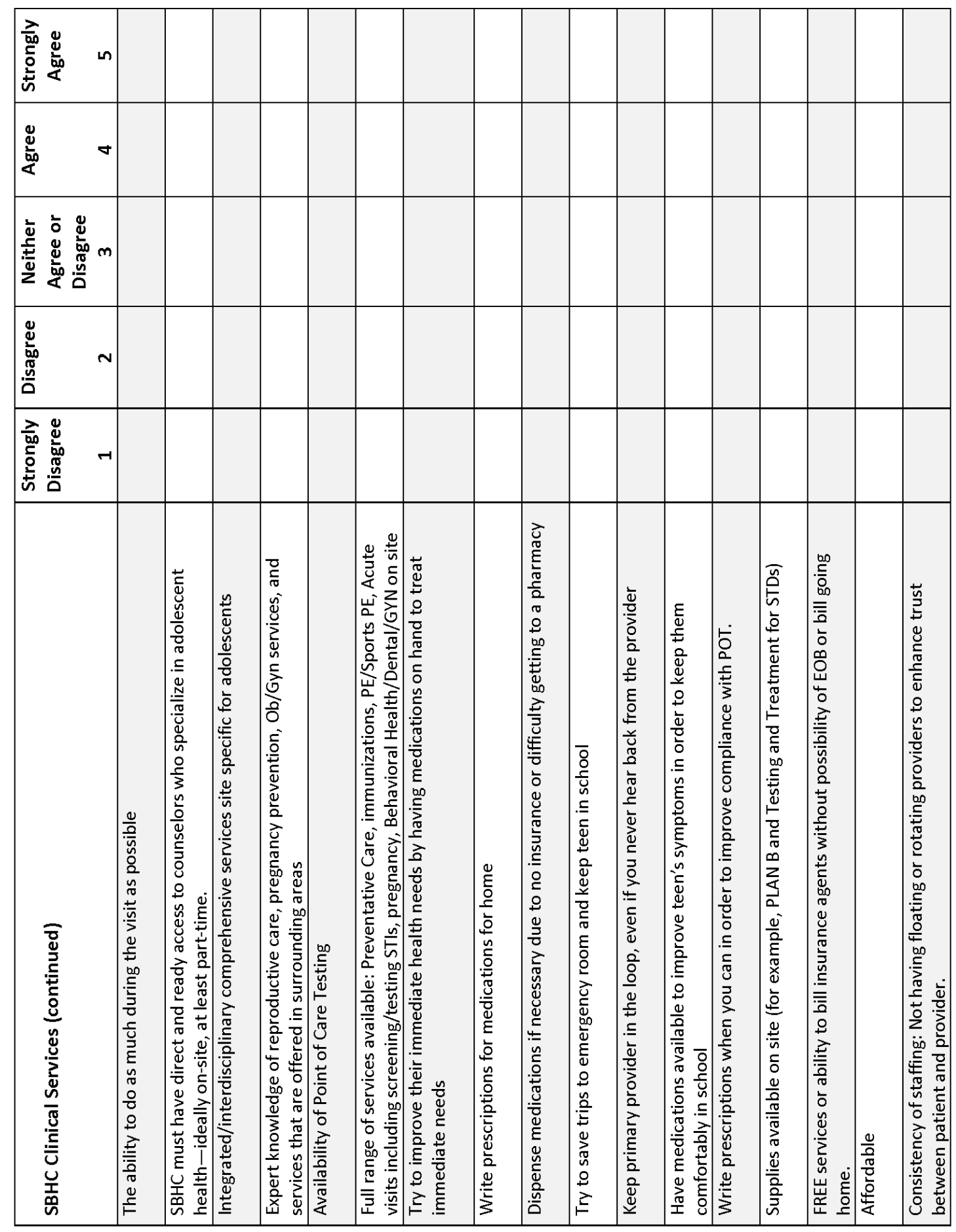



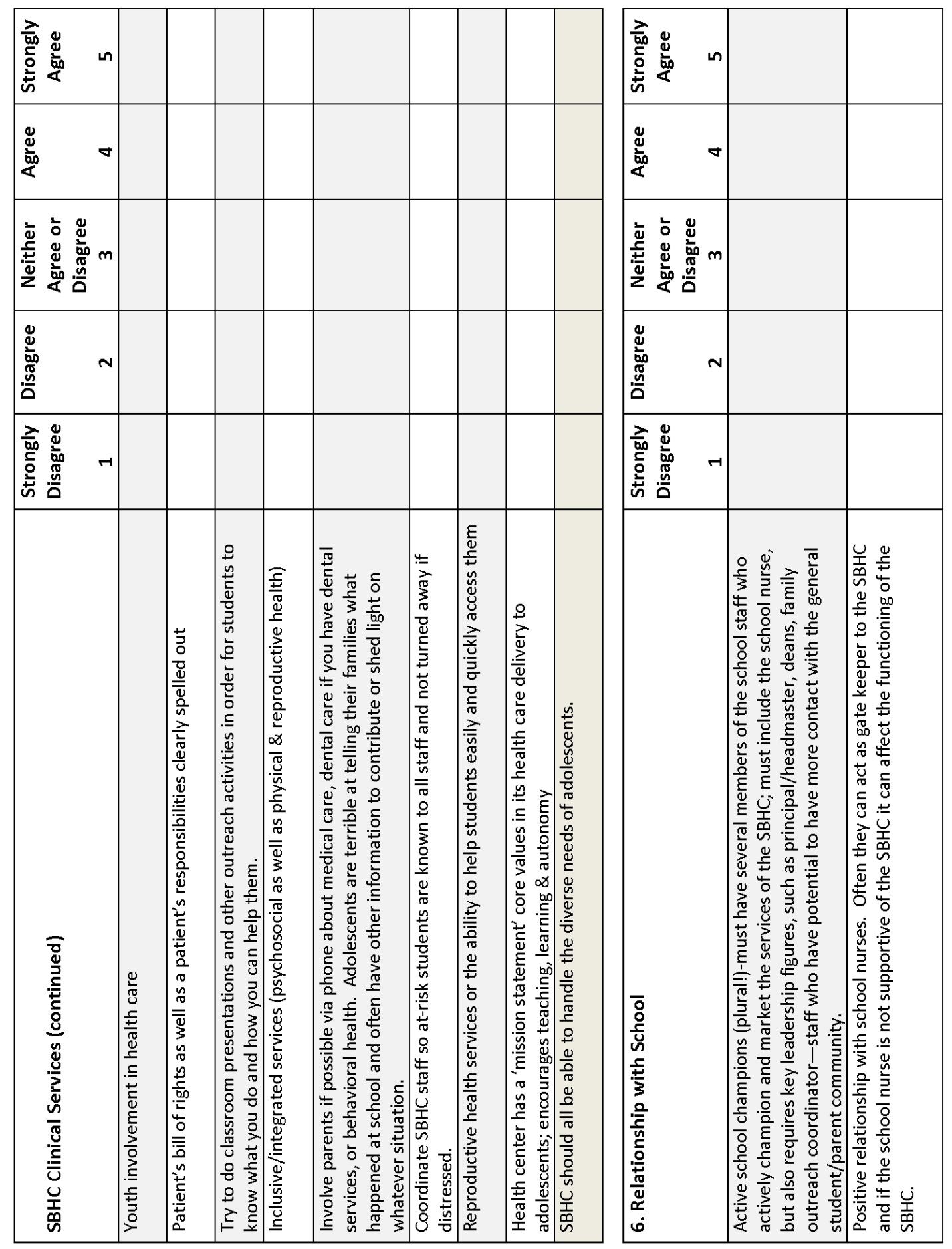


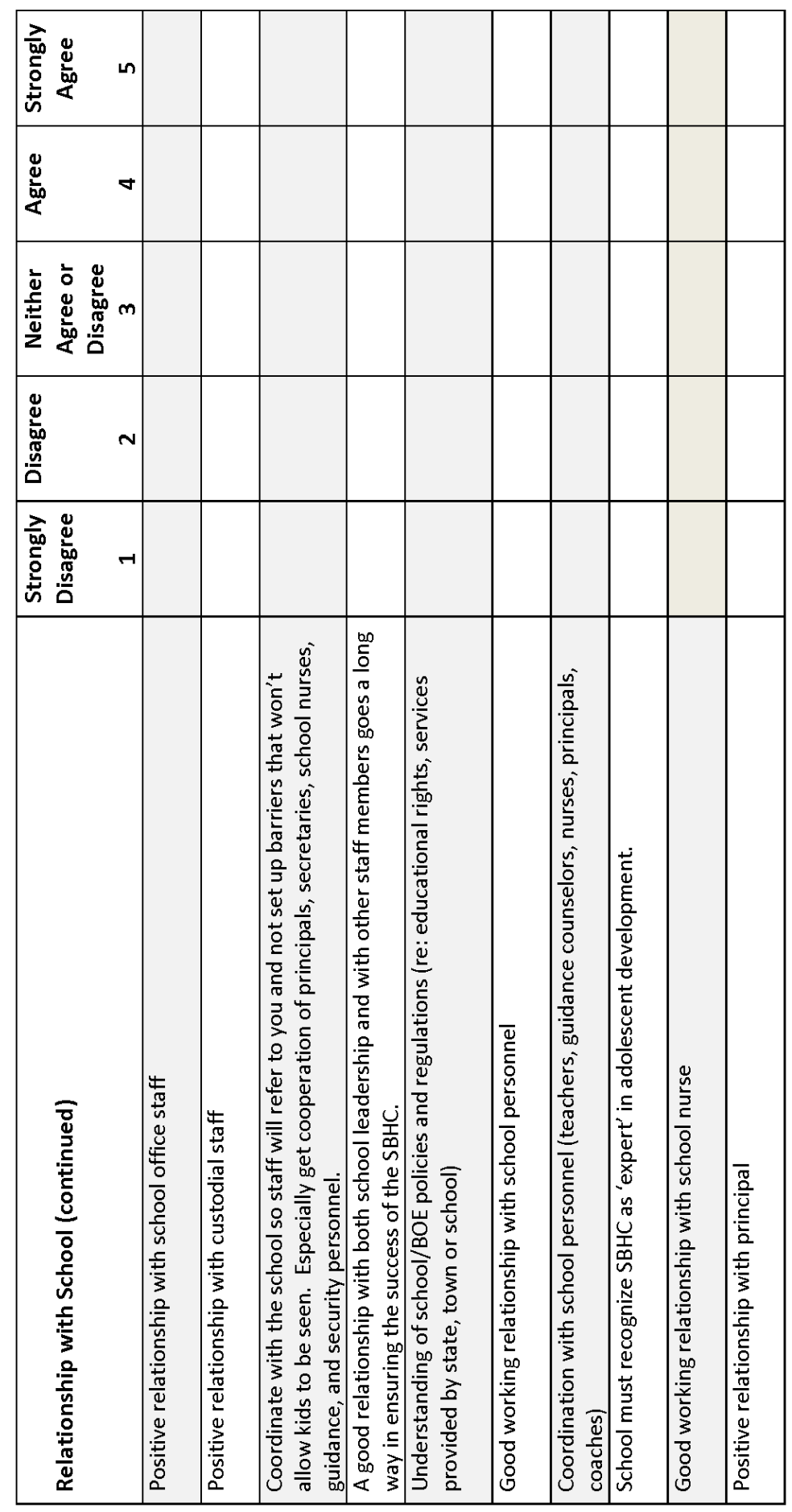

$\overrightarrow{3}$
0
$\frac{1}{1}$
$\frac{1}{1}$
$\frac{1}{1}$ 


\section{Appendix K}

\section{Delphi Technique Round 3 Letter}

Dear Expert Panel Member,

Re: The Essential Elements of Adolescent-friendly Care in School-Based Health Centers

Thank you for returning the Delphi Round 2 questionnaire. You will find the Round 3 (or 4) questionnaire attached. The questionnaire for this round includes the items you rated in Round 2 (or 3 ) and both the panel response and your individual response to each item. Those that appear in bold type have already reached consensus. It does not mean that they are the most important, only that they have reached consensus first.

The instructions for this round and the questionnaire are attached. The questionnaire and instructions for this round are different from the previous rounds. Please read the instructions carefully and complete the questionnaire as fully as you can.

If you could return the completed questionnaire by [DATE] via email to alison.moriarty@uconn.edu, I would be most grateful. If you have any questions or need clarification, please contact me either by email or 860-XXX-XXXX.

Thank you for your continued participation in this study, your expert opinion is invaluable.

Sincerely yours,

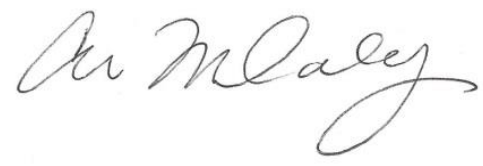

Alison Moriarty Daley, MSN, APRN, PNP-BC

University of Connecticut, Doctoral student 


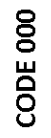

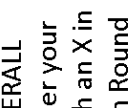

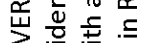

ठ

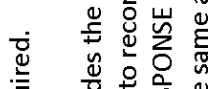

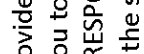

늘

言突

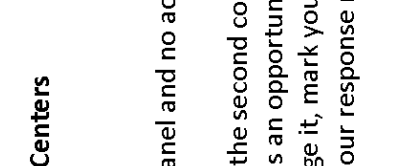

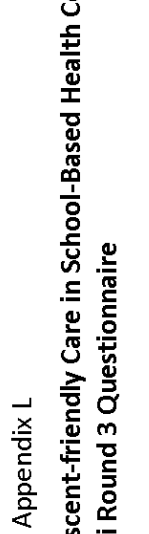

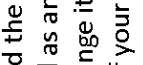

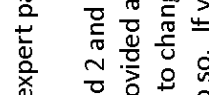

들 은 응

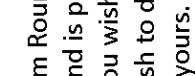

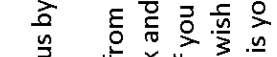

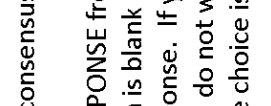

峞

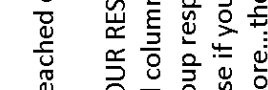

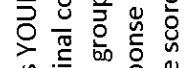

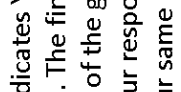

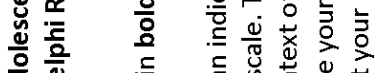

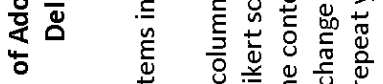

压.

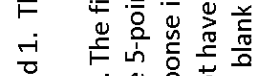

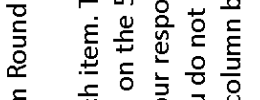

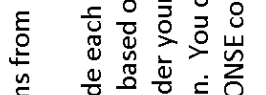

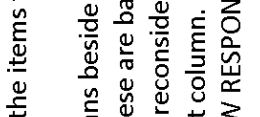

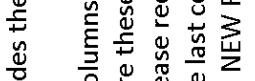

然

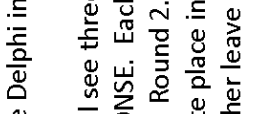

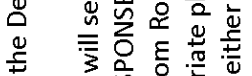

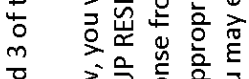

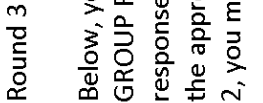

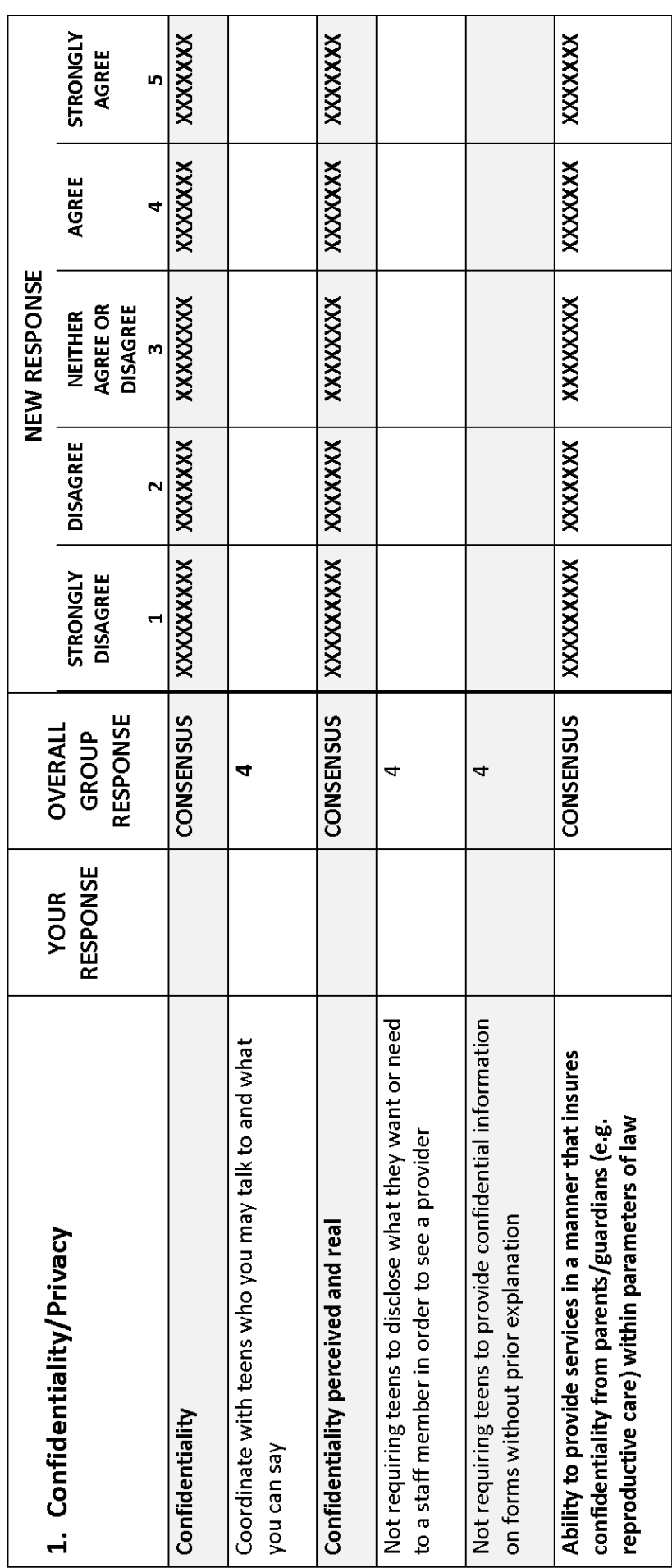




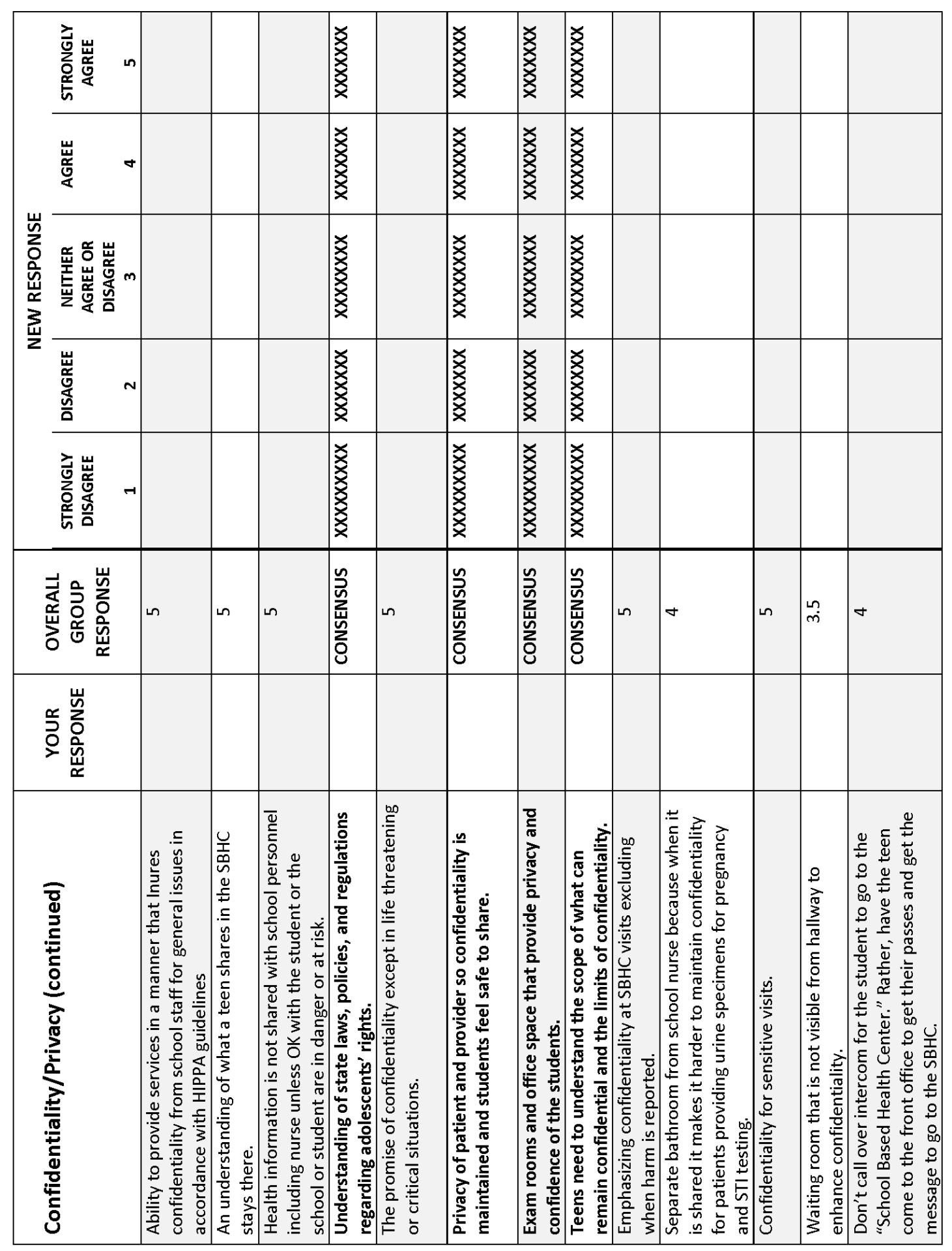




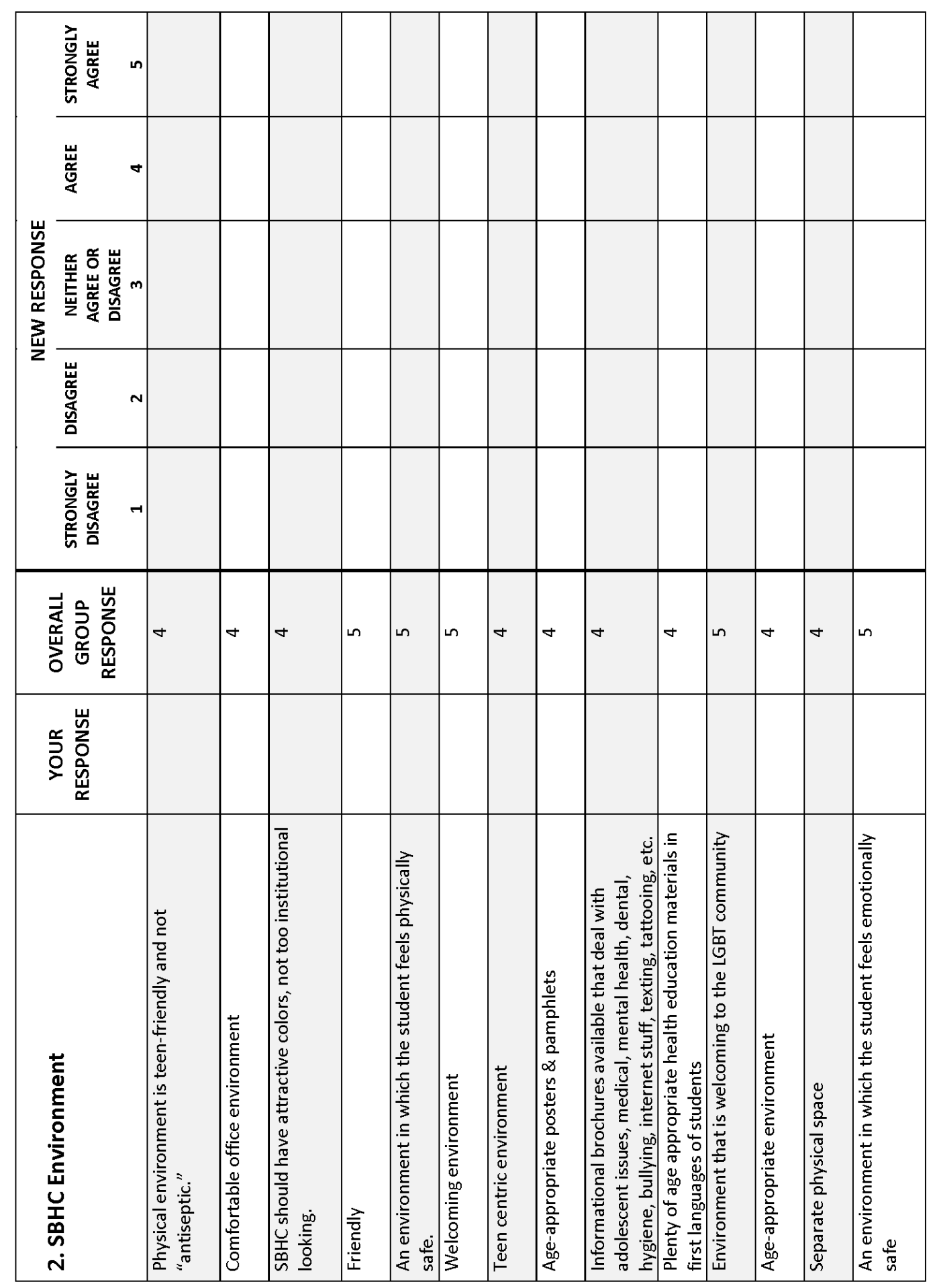




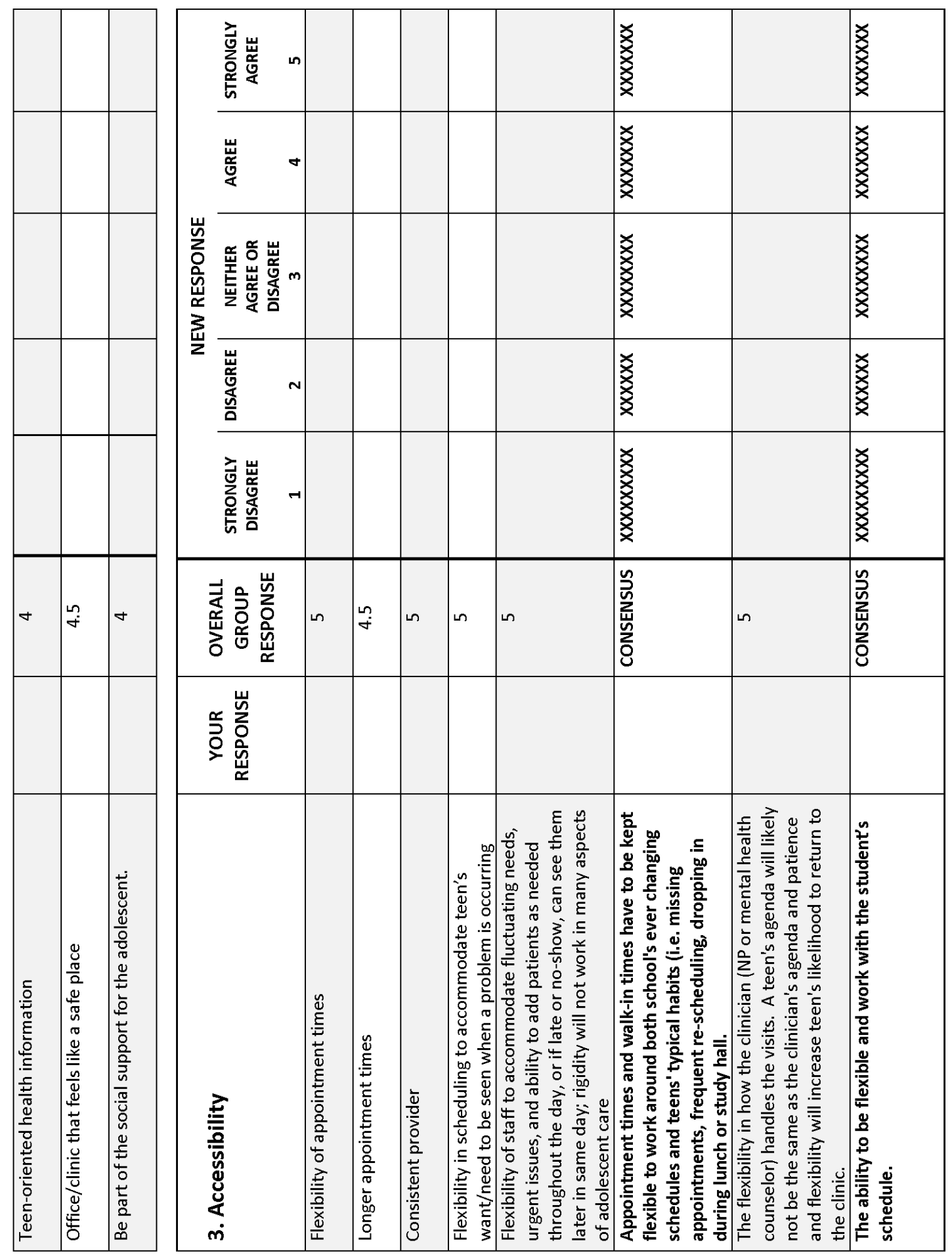




\begin{tabular}{|c|c|c|c|c|c|c|c|c|c|c|c|c|}
\hline 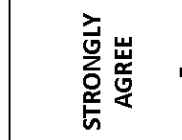 & 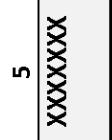 & & & & 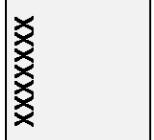 & & & & & & 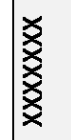 & 兏 \\
\hline 崖 & $+\mid \begin{array}{l}x \\
\substack{x \\
x \\
x} \\
x\end{array}$ & & & & $\begin{array}{l}x \\
x \\
x \\
x \\
x \\
x\end{array}$ & & & & & & $\begin{array}{l}\underset{x}{x} \\
x \\
x \\
x \\
x\end{array}$ & $\begin{array}{l}x \\
x \\
x \\
x \\
x \\
x\end{array}$ \\
\hline 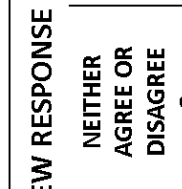 & $m \mid \begin{array}{l}x \\
x \\
x \\
x \\
x \\
x \\
x \\
x\end{array}$ & & & & 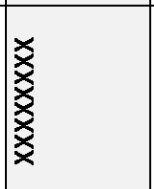 & & & & & & 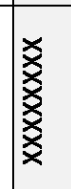 & $\begin{array}{l}x \\
x \\
x \\
x \\
x \\
x \\
x \\
x\end{array}$ \\
\hline 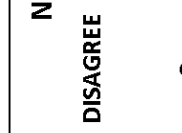 & $N \mid \frac{\substack{x \\
x}}{x}$ & & & & 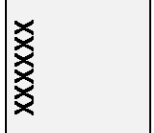 & & & & & & 爻 & $\begin{array}{l}x \\
x \\
x \\
x \\
x \\
x\end{array}$ \\
\hline 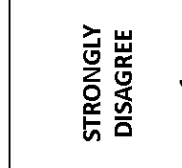 & 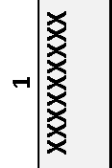 & & & & 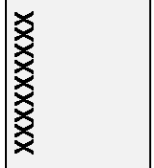 & & & & & & $\begin{array}{l}x \\
x \\
x \\
x \\
x \\
x \\
x \\
x \\
x\end{array}$ & $\begin{array}{l}x \\
x \\
x \\
x \\
x \\
x \\
x \\
x \\
x \\
x\end{array}$ \\
\hline 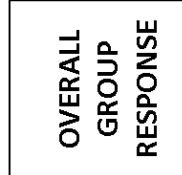 & 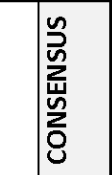 & in & o & to & 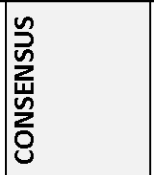 & A & in & in & o & in & 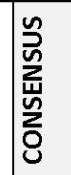 & 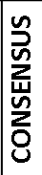 \\
\hline 号 & & & & & & & & & & & & \\
\hline 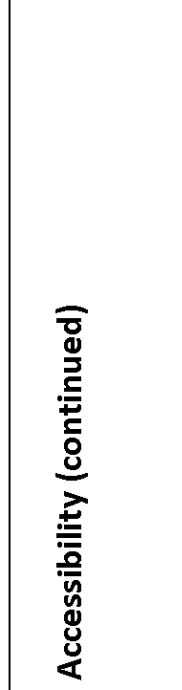 & 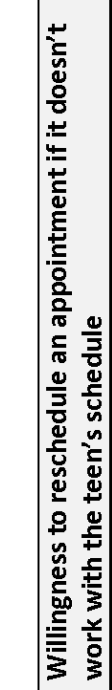 & 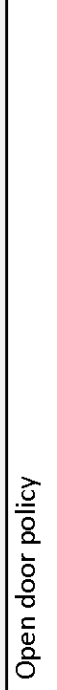 & 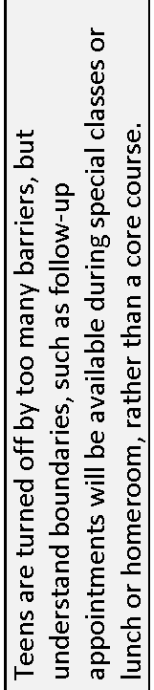 & 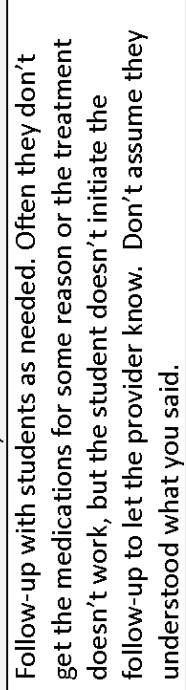 & 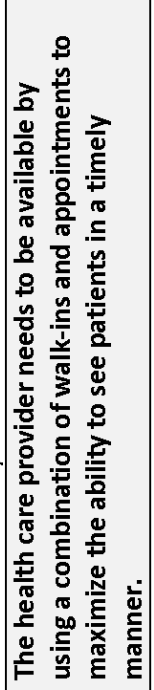 & 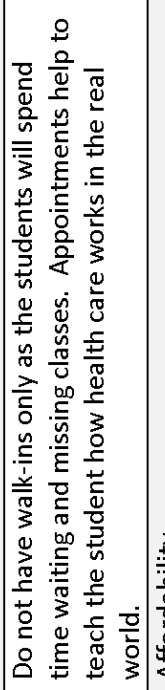 & \begin{tabular}{|l}
$\frac{3}{3}$ \\
$\frac{3}{0}$ \\
$\frac{\pi}{0}$ \\
0 \\
$\frac{9}{4}$ \\
$\frac{1}{4}$
\end{tabular} & 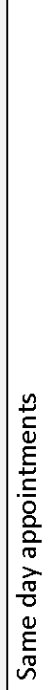 & 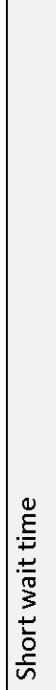 & 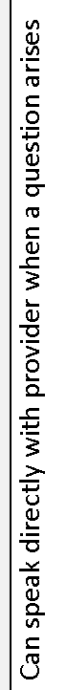 & 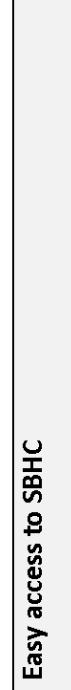 & 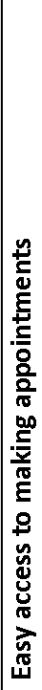 \\
\hline
\end{tabular}




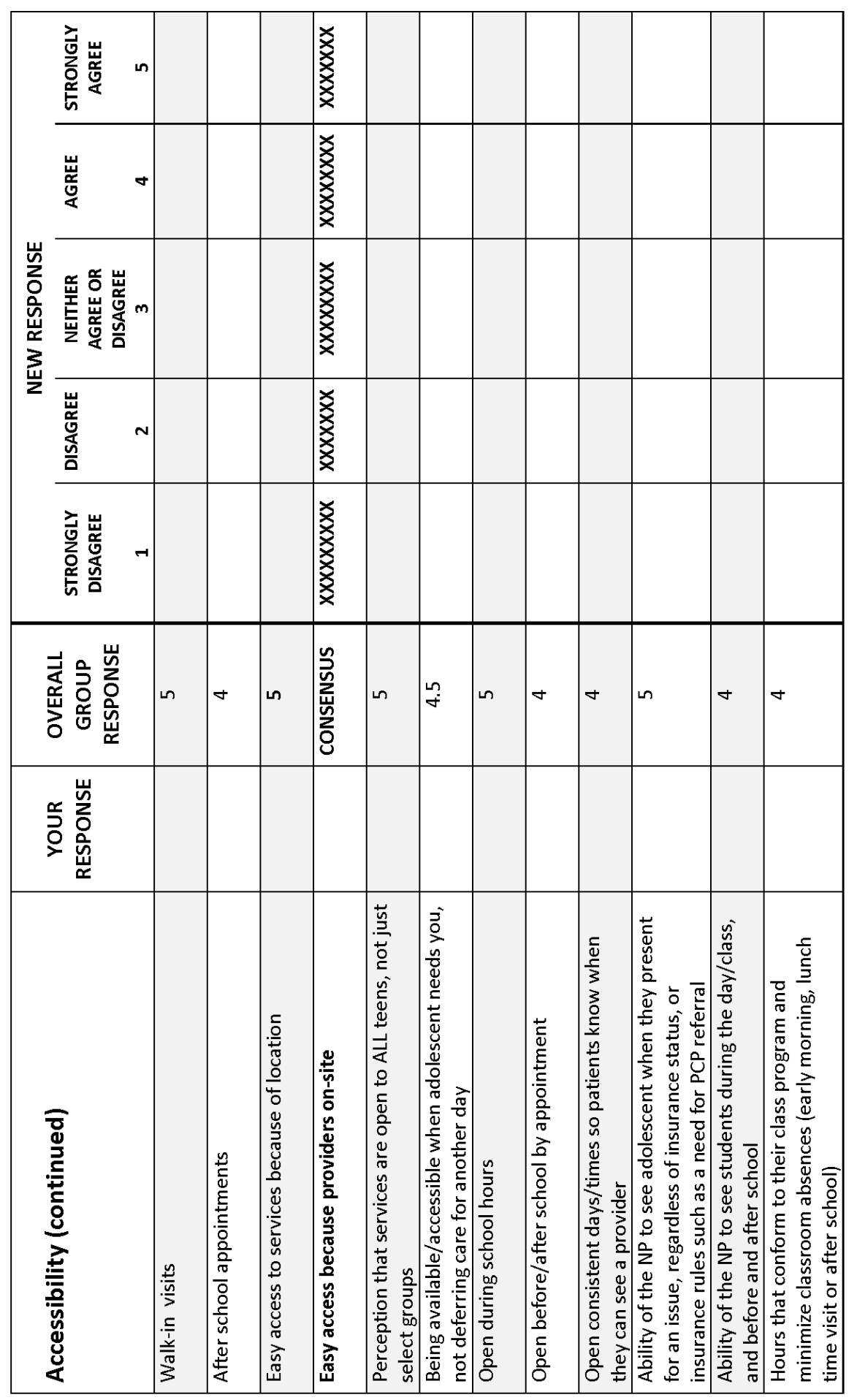




\begin{tabular}{|c|c|c|c|c|c|c|c|c|c|c|c|c|}
\hline 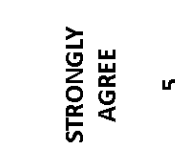 & 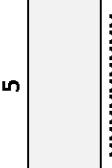 & 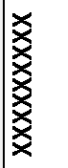 & & & & & \begin{tabular}{|l}
$\mid x$ \\
$x$ \\
$x$ \\
$x$ \\
$x$ \\
$x$ \\
$x$ \\
$x$ \\
$x$ \\
$x$
\end{tabular} & 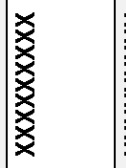 & 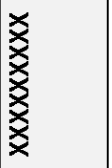 & 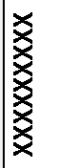 & 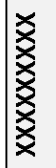 & \\
\hline 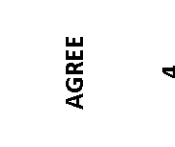 & $\sigma$ & 爻 & & & & & $\begin{array}{l}x \\
x \\
x \\
x \\
x \\
x \\
x \\
x \\
x\end{array}$ & $\begin{array}{l}x \\
x \\
x \\
x \\
x \\
x \\
x \\
x\end{array}$ & 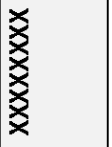 & 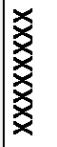 & 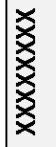 & \\
\hline 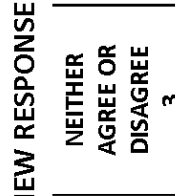 & & 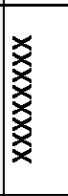 & & & & & $\begin{array}{l}x \\
x \\
x \\
x \\
x \\
x \\
x \\
x\end{array}$ & 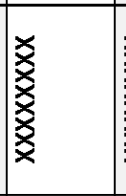 & 爻 & 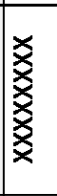 & 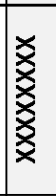 & \\
\hline 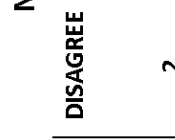 & N & 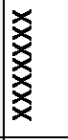 & & & & & $\begin{array}{l}x \\
x \\
x \\
x \\
x \\
x \\
x \\
x\end{array}$ & $\begin{array}{l}x \\
x \\
x \\
x \\
x \\
x \\
x \\
x\end{array}$ & 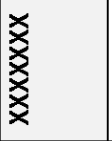 & 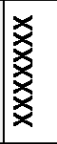 & 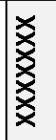 & \\
\hline 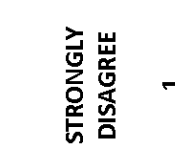 & - & 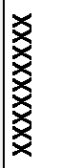 & & & & & \begin{tabular}{|cc}
$x$ \\
$x$ \\
$x$ \\
$x$ \\
$x$ \\
$x$ \\
$x$ \\
$x$ \\
$x$
\end{tabular} & 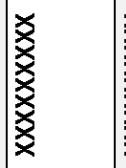 & 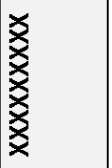 & 泈 & 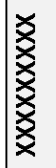 & \\
\hline 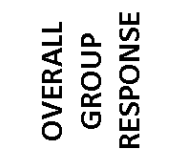 & in & 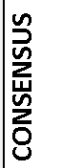 & $\stackrel{n}{+}$ & in & in & o & 吕 & 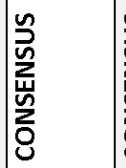 & 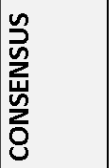 & 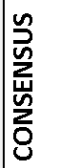 & 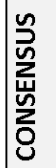 & nn \\
\hline \multicolumn{13}{|l|}{ 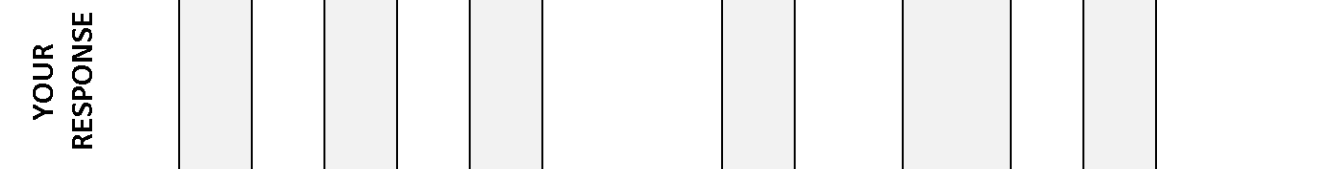 } \\
\hline 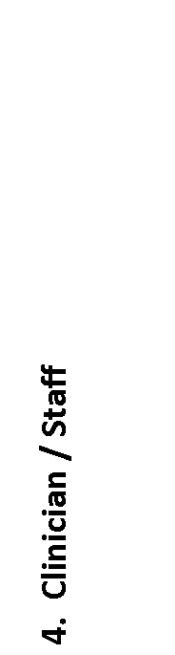 & 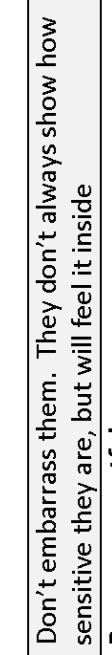 & 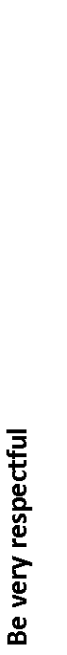 & 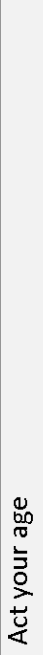 & 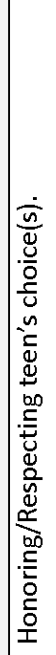 & 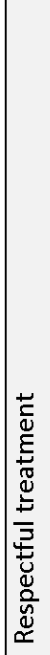 & 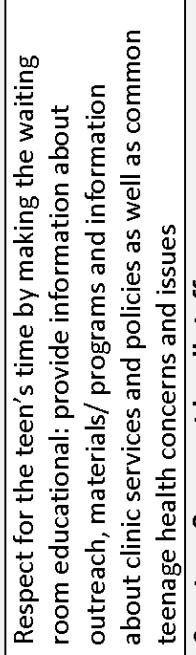 & 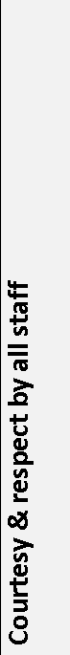 & 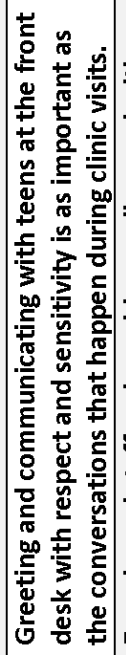 & 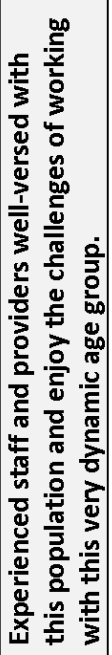 & 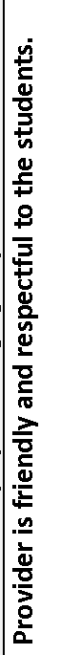 & 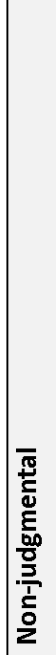 & 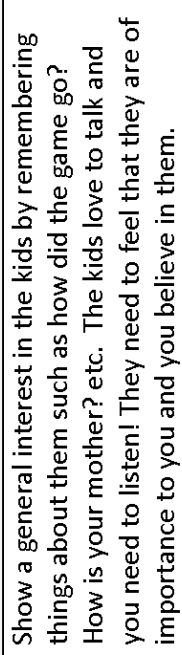 \\
\hline
\end{tabular}




\begin{tabular}{|c|c|c|c|c|c|c|c|c|c|c|c|c|c|c|c|c|}
\hline 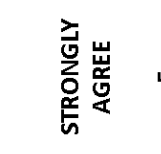 & n & 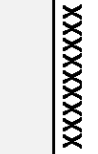 & & $\begin{array}{l}x \\
x \\
x \\
x \\
x \\
x \\
x \\
x \\
x\end{array}$ & & 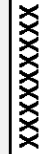 & 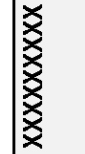 & 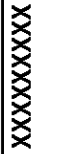 & 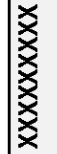 & & & & & & & \\
\hline 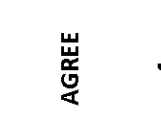 & $\nabla$ & |শ্ত্তে & & $\begin{array}{l}x \\
x \\
x \\
x \\
x \\
x \\
x \\
x \\
x\end{array}$ & & 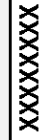 & 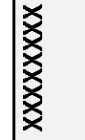 & 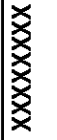 & 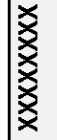 & & & & & & & \\
\hline 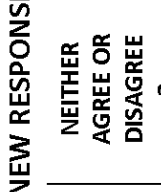 & & 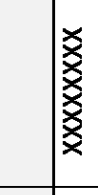 & & $\begin{array}{l}x \\
x \\
x \\
x \\
x \\
x \\
x \\
x \\
x\end{array}$ & & 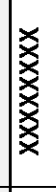 & 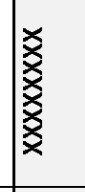 & 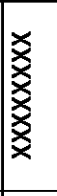 & 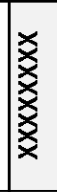 & & & & & & & \\
\hline 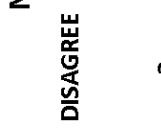 & $N$ & 㸚 & & 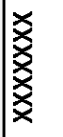 & & 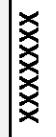 & 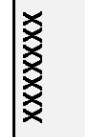 & 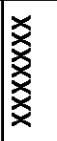 & 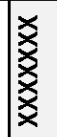 & & & & & & & \\
\hline 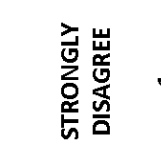 & $\neg$ & 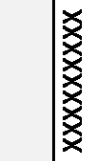 & & 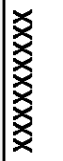 & & 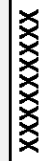 & 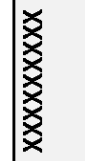 & 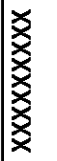 & 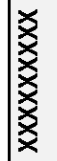 & & & & & & & \\
\hline 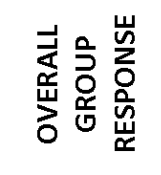 & in & 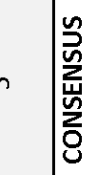 & in & 恣 & or & 瓷 & 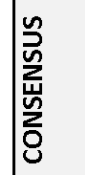 & 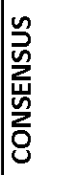 & 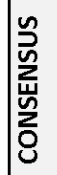 & in & in & in & in & in & Ln & in \\
\hline 옹 & & & & & & & & & & & & & & & & \\
\hline 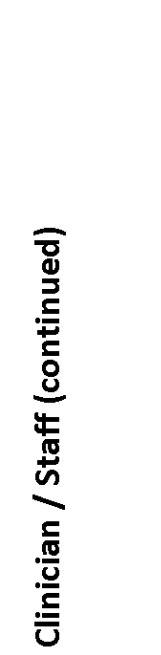 & 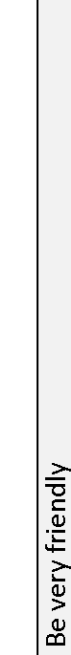 & 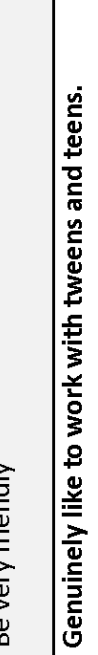 & 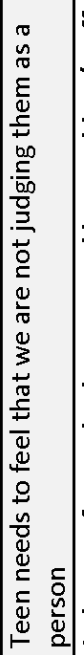 & 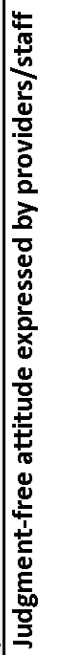 & 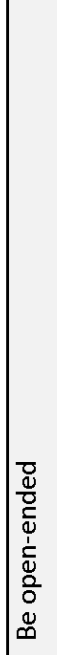 & 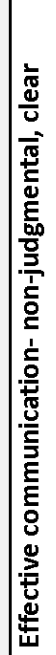 & 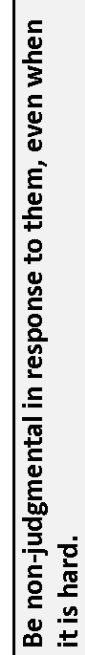 & 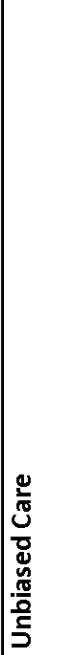 & 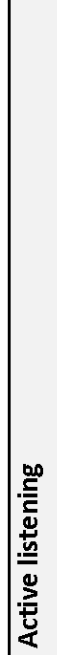 & 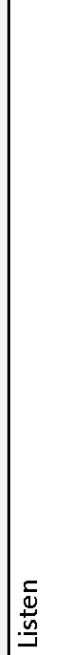 & 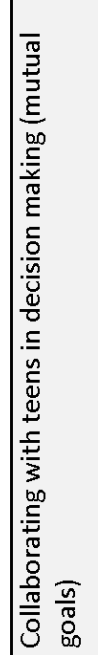 & 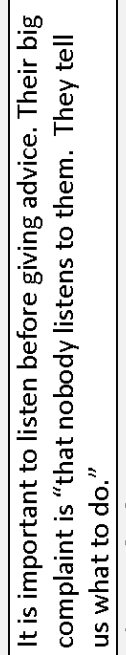 & 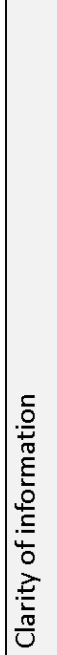 & 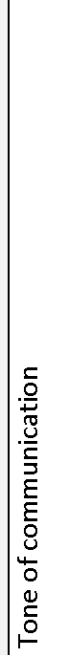 & 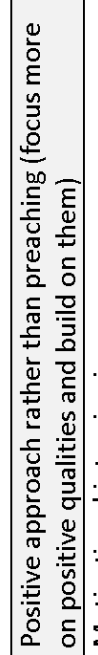 & 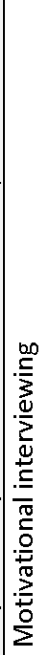 \\
\hline
\end{tabular}




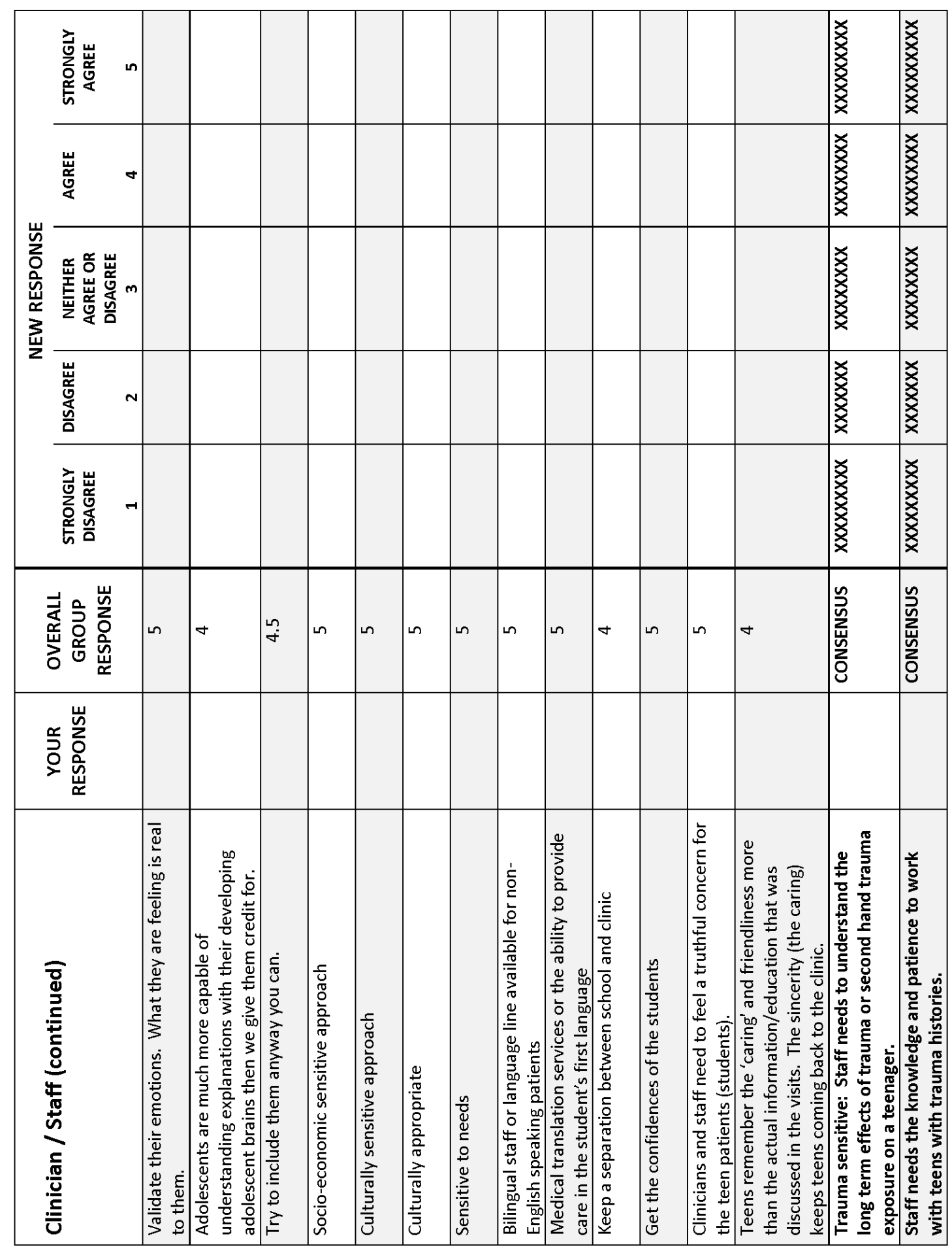




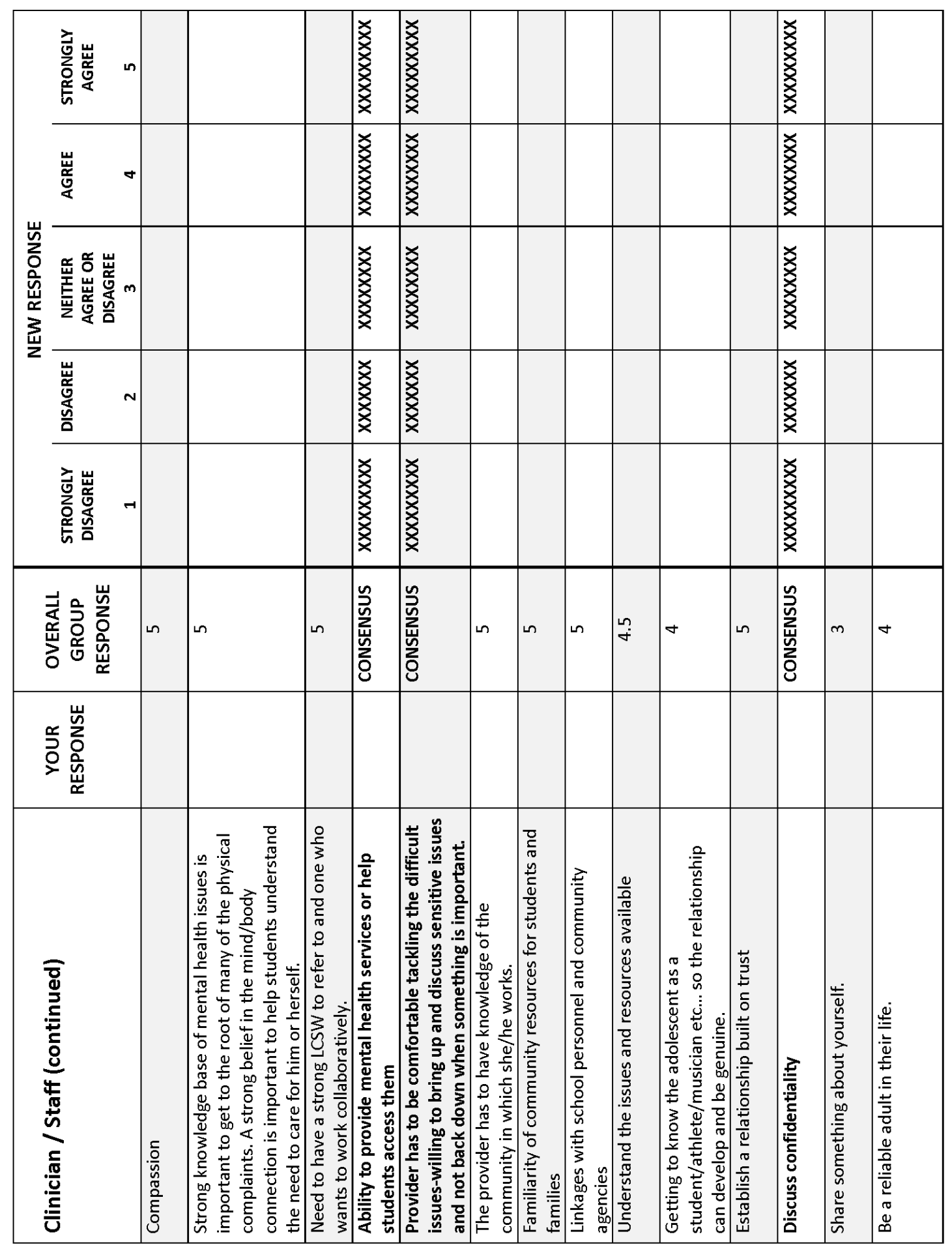




\begin{tabular}{|c|c|c|c|c|c|c|c|c|c|c|c|c|c|c|c|}
\hline 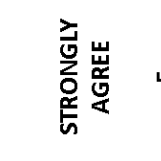 & ـ & & 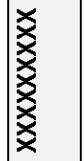 & & & & & & & 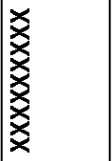 & & & & & \\
\hline 嵌 & & & 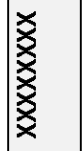 & & & & & & & 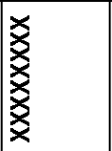 & & & & & \\
\hline 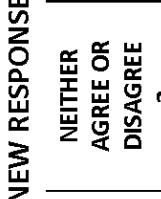 & & & $\begin{array}{l}x \\
x \\
x \\
x \\
x \\
x \\
x \\
x\end{array}$ & & & & & & & 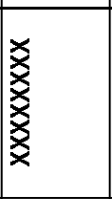 & & & & & \\
\hline 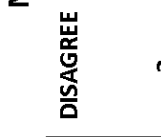 & & & $\begin{array}{l}\times \\
\grave{X} \\
\grave{x} \\
\grave{x} \\
\grave{x}\end{array}$ & & & & & & & 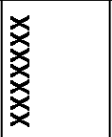 & & & & & \\
\hline 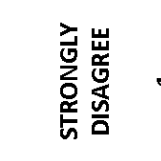 & - & & 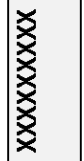 & & & & & & & 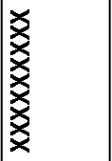 & & & & & \\
\hline 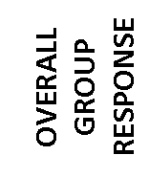 & in & in & 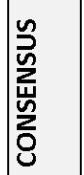 & in & in & in & in & in & in & 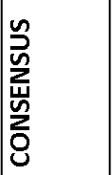 & in & in & nn & nn & | \\
\hline 号 & & & & & & & & & & & & & & & \\
\hline 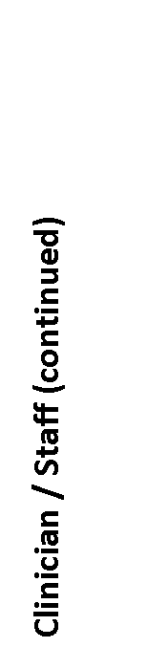 & 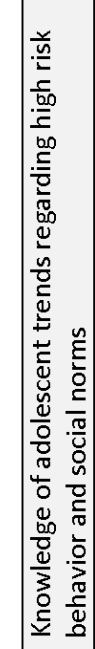 & 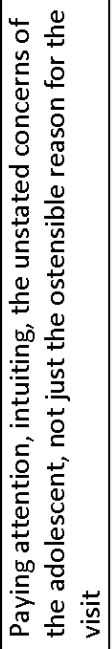 & 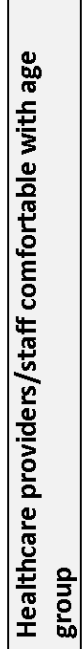 & 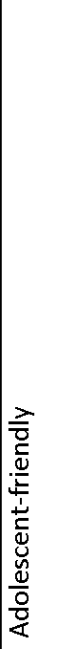 & $\sum_{\underline{1}}^{n}$ & 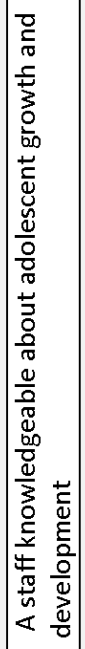 & 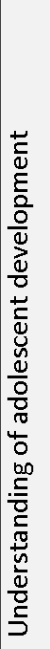 & 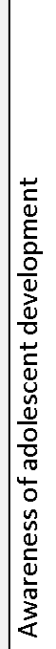 & 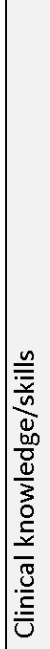 & 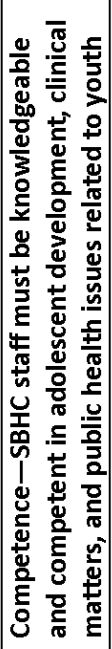 & 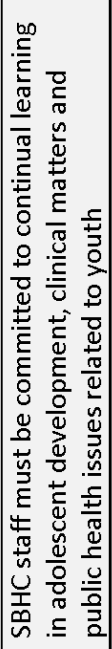 & 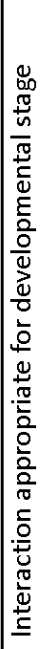 & 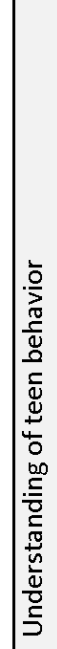 & 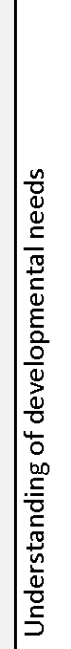 & 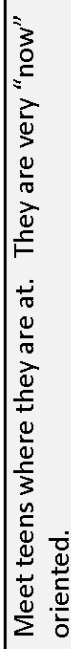 \\
\hline
\end{tabular}




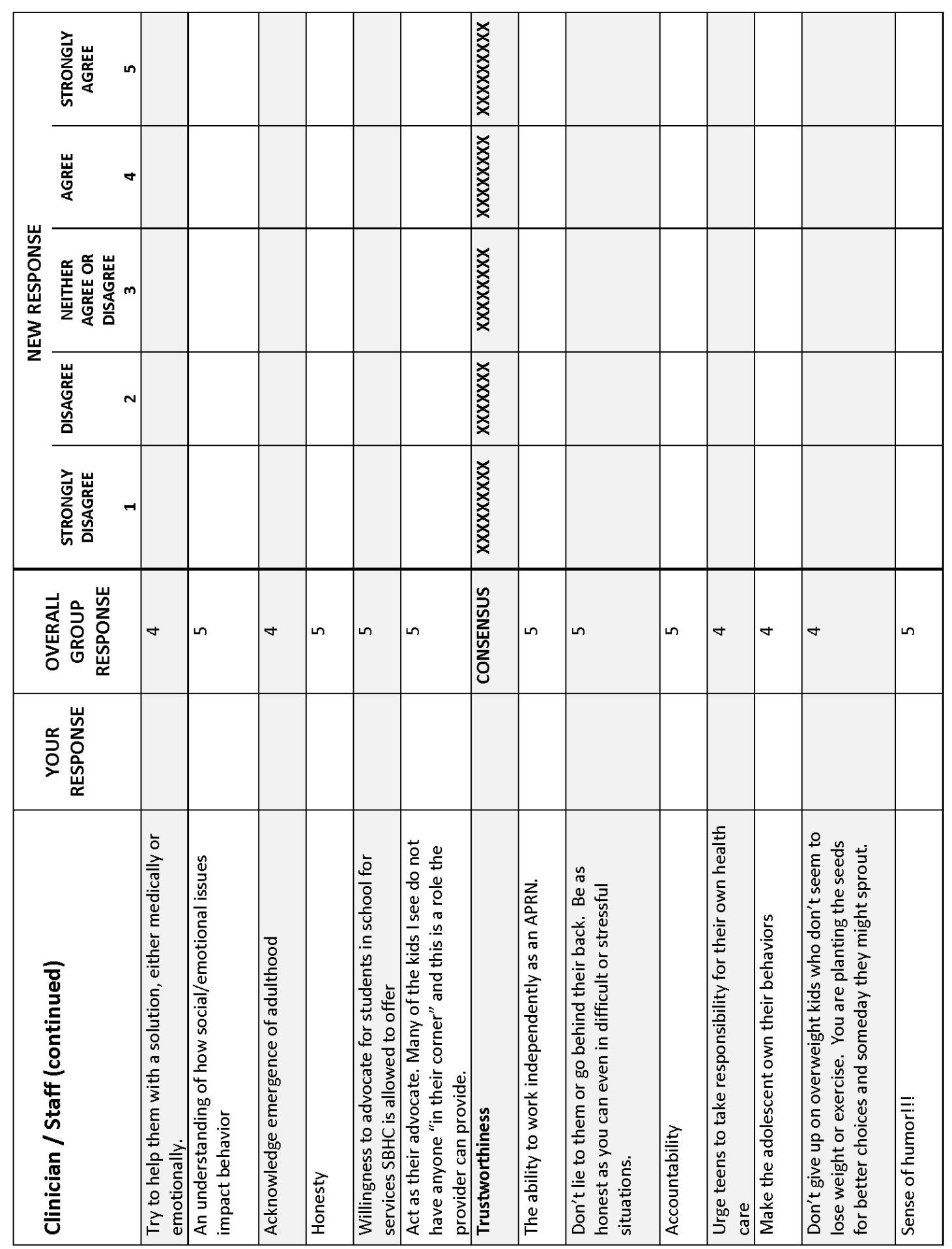




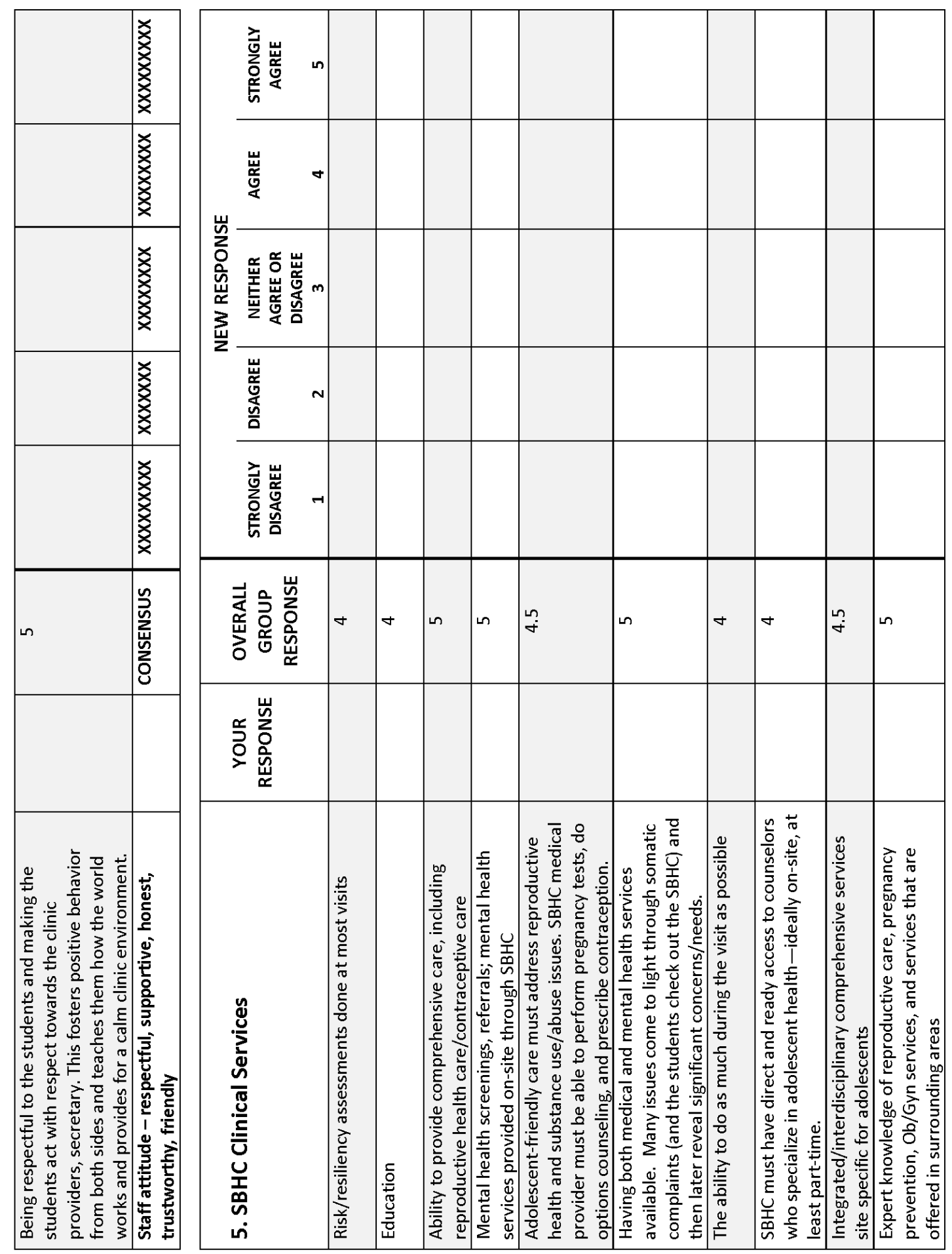




\begin{tabular}{|c|c|c|c|c|c|c|c|c|c|c|c|c|c|c|c|}
\hline 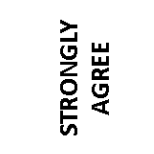 & $\operatorname{nn} \mid \begin{array}{l}x \\
x \\
x \\
x \\
x \\
x \\
x \\
x\end{array}$ & & & & & 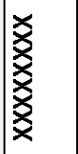 & & & & & $\begin{array}{l}x \\
x \\
x \\
x \\
x \\
x \\
x \\
x \\
x\end{array}$ & & 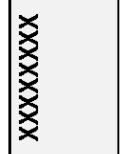 & & \\
\hline 崖 & 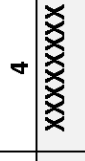 & & & & & 爻 & & & & & 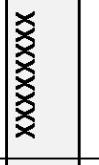 & & 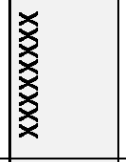 & & \\
\hline 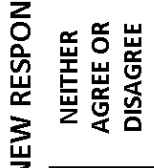 & 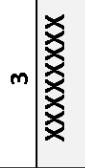 & & & & & 爻 & & & & & 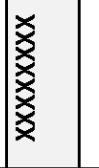 & & 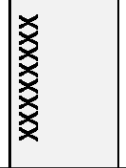 & & \\
\hline 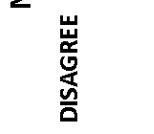 & 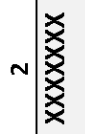 & & & & & $\begin{array}{l}x \\
x \\
x \\
x \\
x\end{array}$ & & & & & $\begin{array}{l}x \\
x \\
x \\
x \\
x \\
x\end{array}$ & & 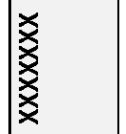 & & \\
\hline 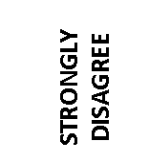 & $-1 \mid \begin{array}{l}x \\
x \\
x \\
x \\
x \\
x \\
x \\
x \\
x\end{array}$ & & & & & 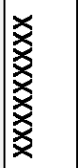 & & & & & $\begin{array}{l}x \\
x \\
x \\
x \\
x \\
x \\
x \\
x \\
x \\
x\end{array}$ & & 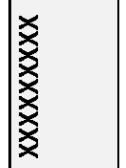 & & \\
\hline 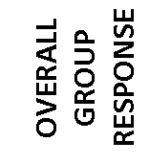 & 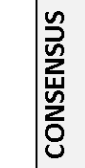 & in & in & $\theta$ & in & 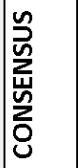 & o & in & in & in & 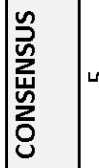 & in & 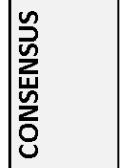 & $\theta$ & o \\
\hline 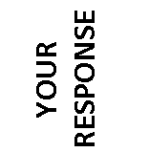 & & & & & & & & & & & & & & & \\
\hline 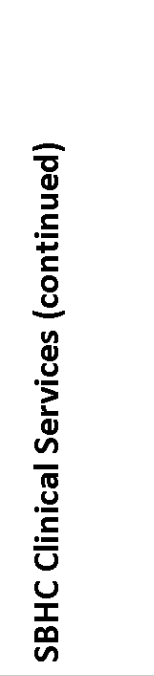 & 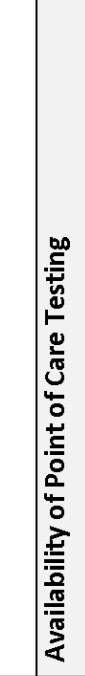 & 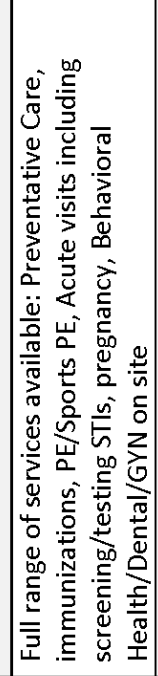 & 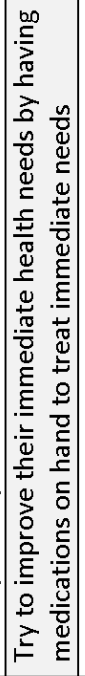 & 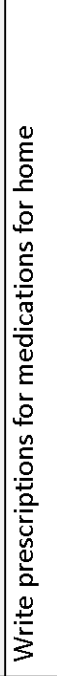 & 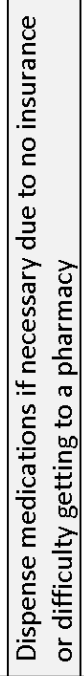 & 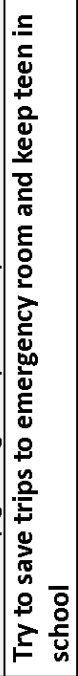 & 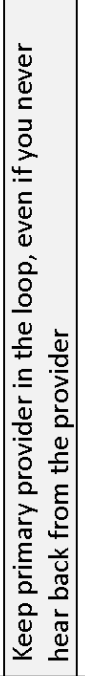 & 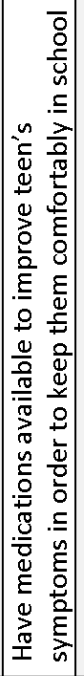 & 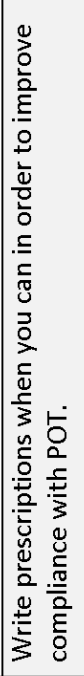 & 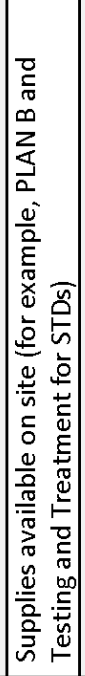 & 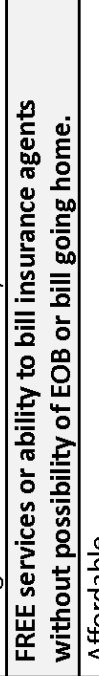 & $\begin{array}{l}0 \\
0 \\
\frac{0}{0} \\
\frac{0}{0} \\
\frac{10}{4}\end{array}$ & 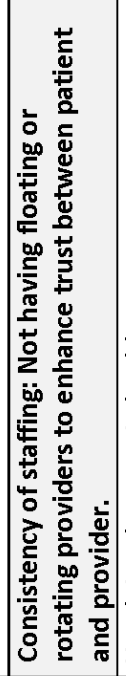 & 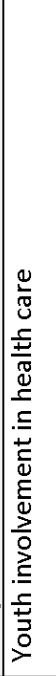 & 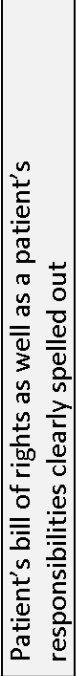 \\
\hline
\end{tabular}



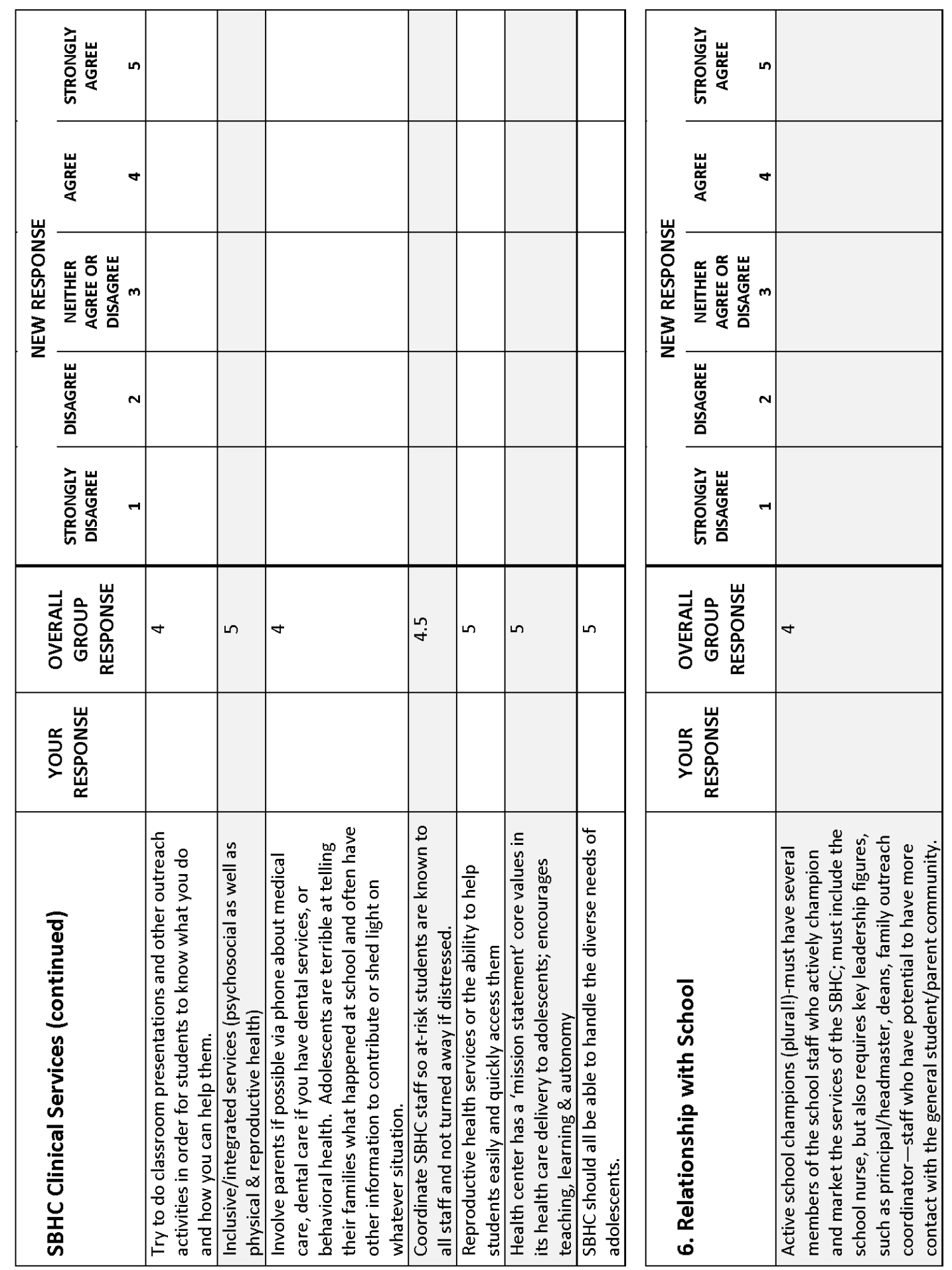


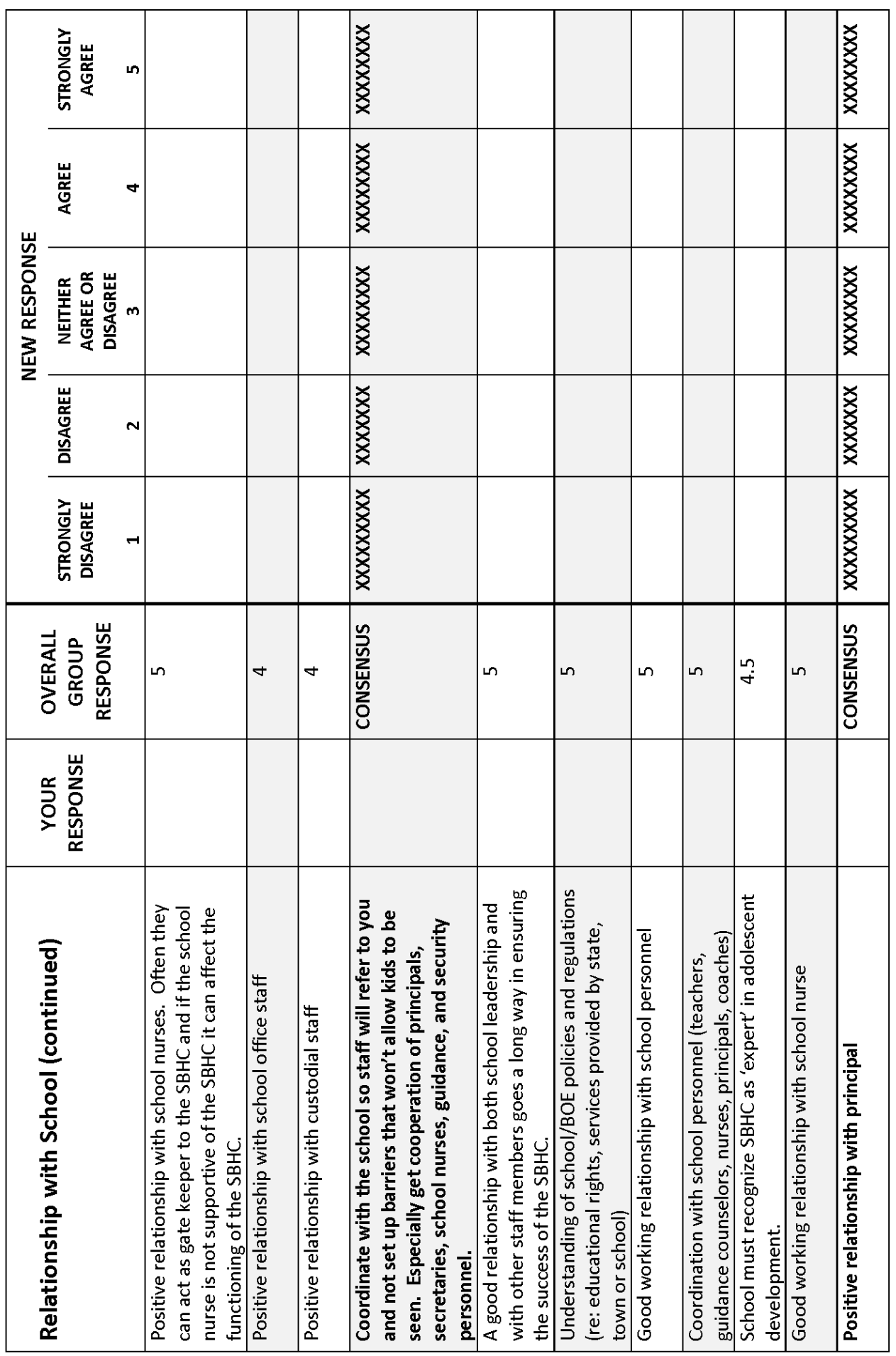

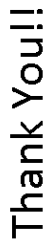


Appendix M

\section{Delphi Technique Round 4 Letter}

Dear Expert Panel Member,

Re: The Essential Elements of Adolescent-friendly Care in School-Based Health Centers

Thank you for returning the Delphi Round 3 questionnaire. You will find the Round 4 questionnaire attached. This is the final round for this study. The questionnaire for this round includes 23 items that were close to reaching consensus after Round 3. I have also included a list of all the items that have already reached consensus; no action is required on these items.

The instructions for this round and the questionnaire are attached. Read the instructions carefully and complete the questionnaire as fully as you can.

Please return your completed questionnaire ASAP and by [DATE] via email to alison.moriarty@uconn.edu. If you have any questions or need clarification, please contact me either by email or 860-XXX-XXXX.

Thank you for your continued participation in this study, your expert opinion is invaluable.

Sincerely yours,

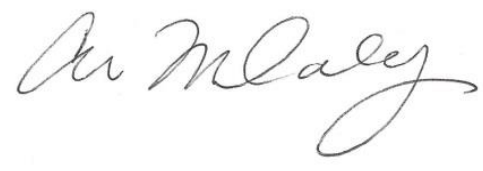

Alison Moriarty Daley, MSN, APRN, PNP-BC

University of Connecticut, Doctoral student 
8
ü
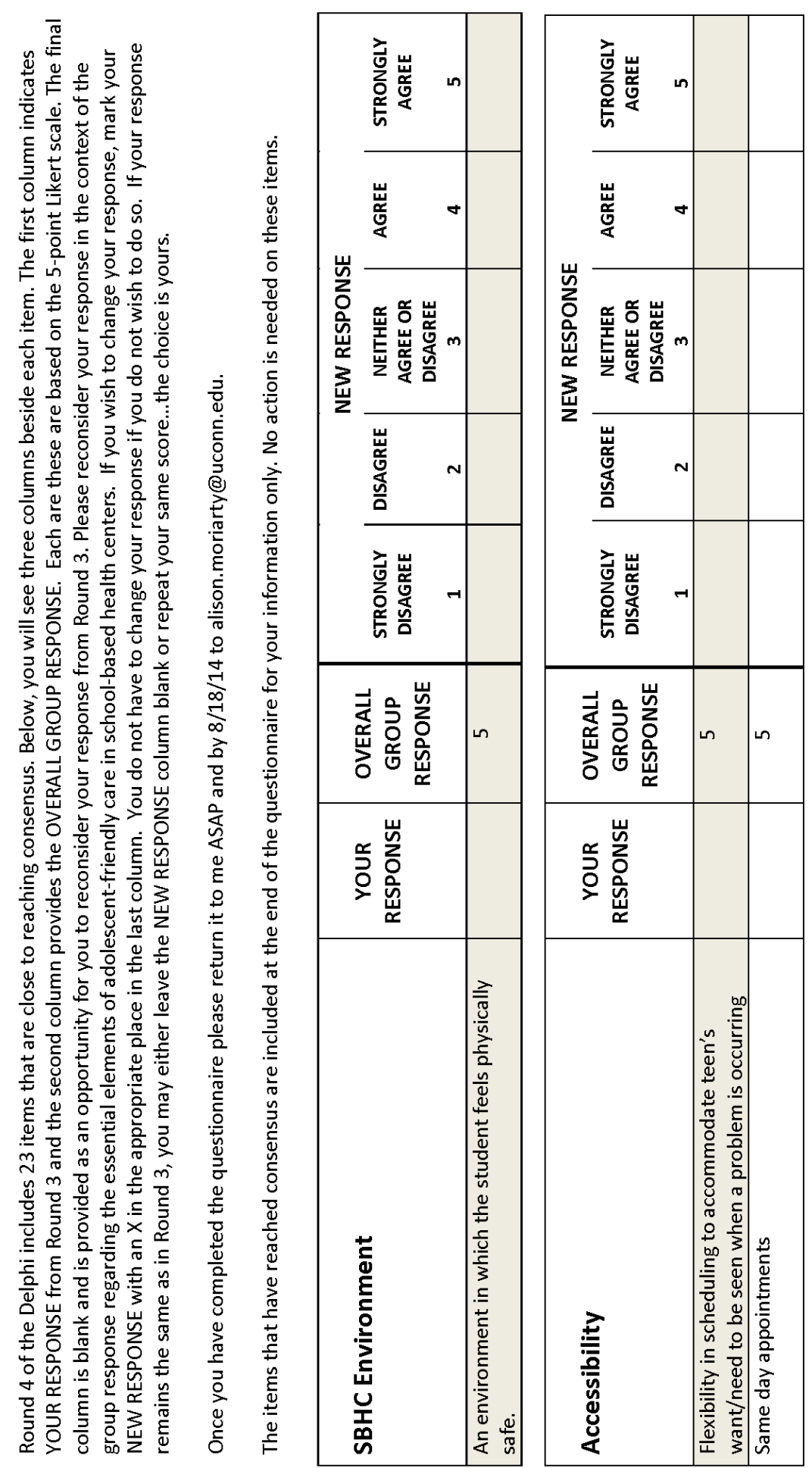


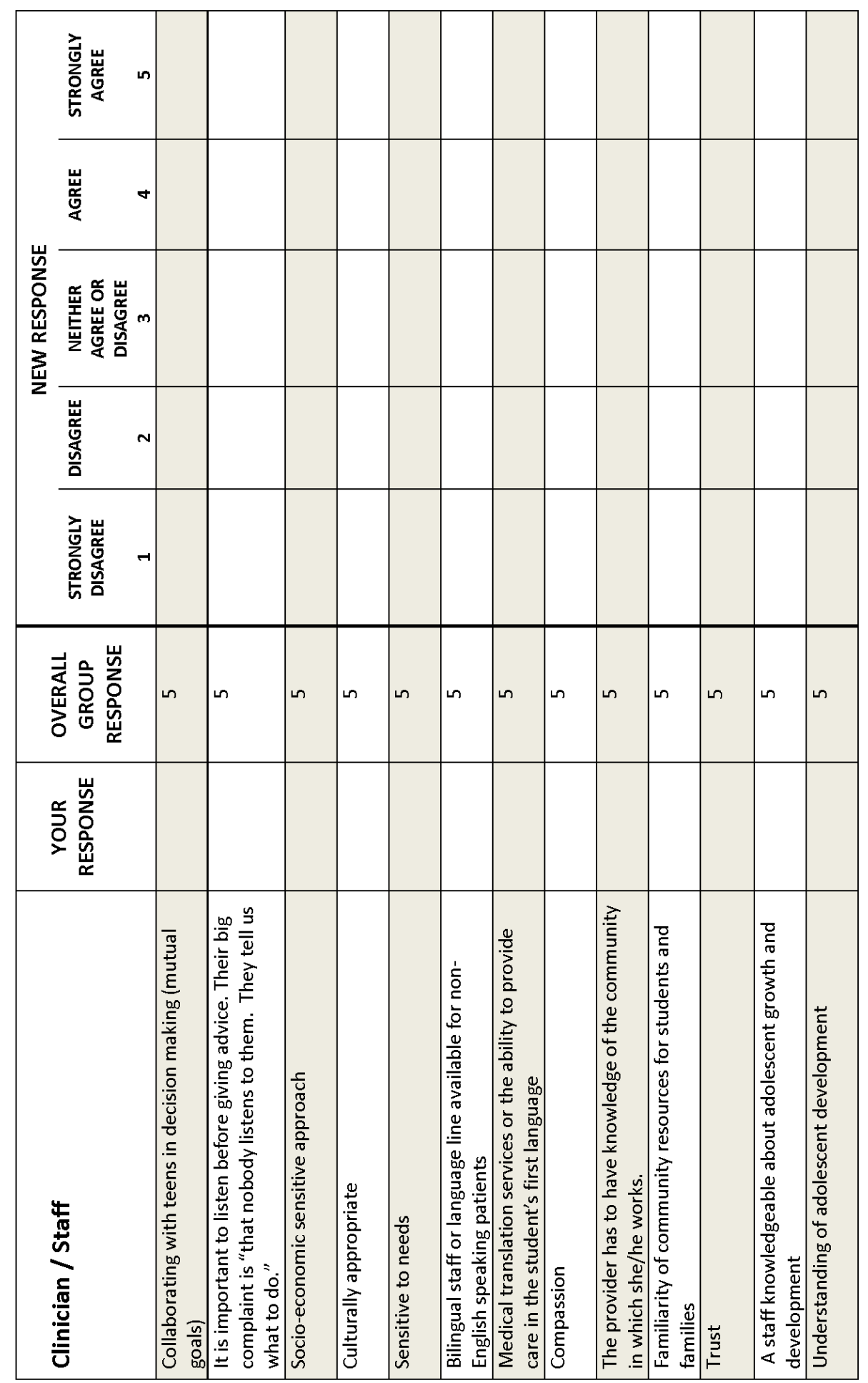



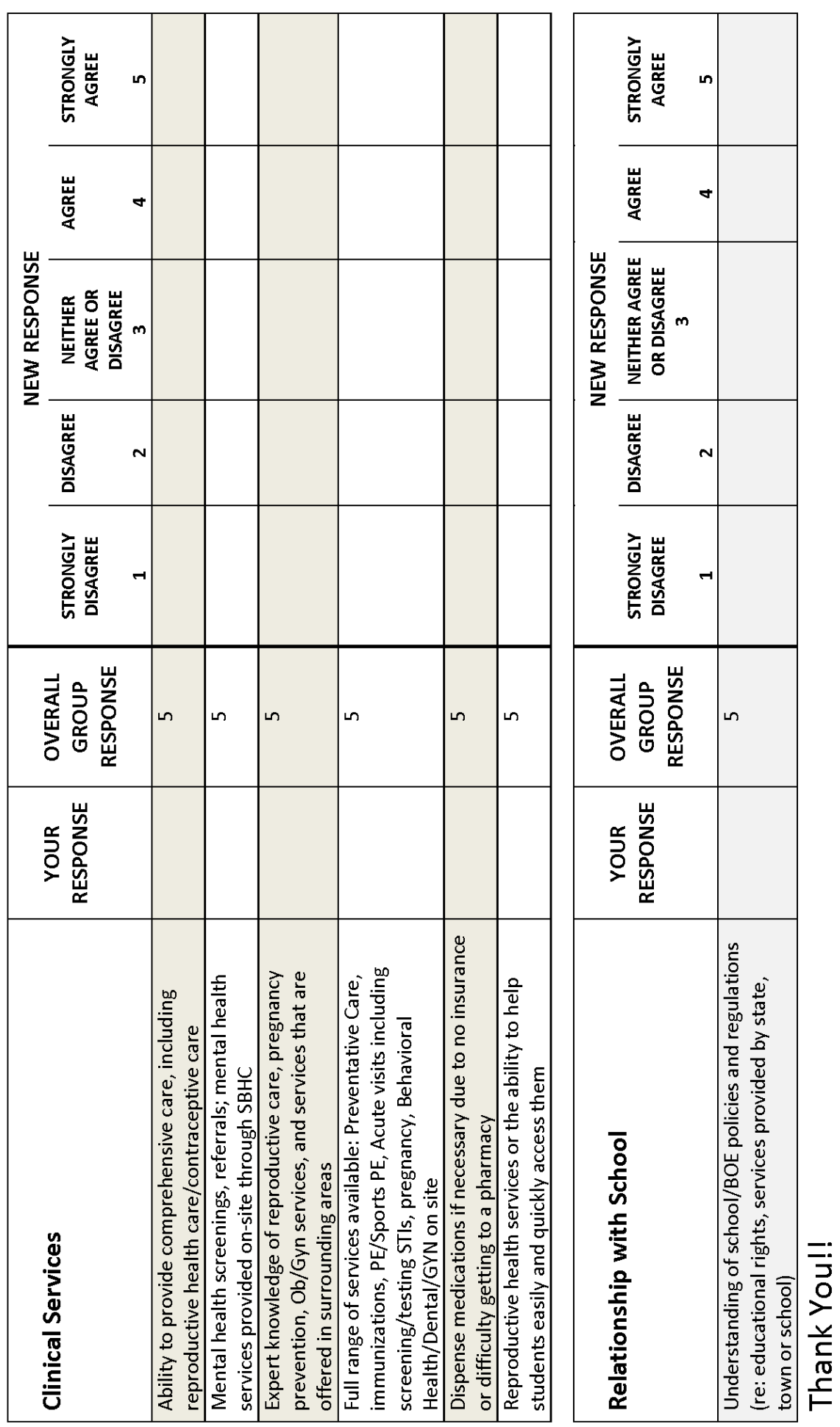

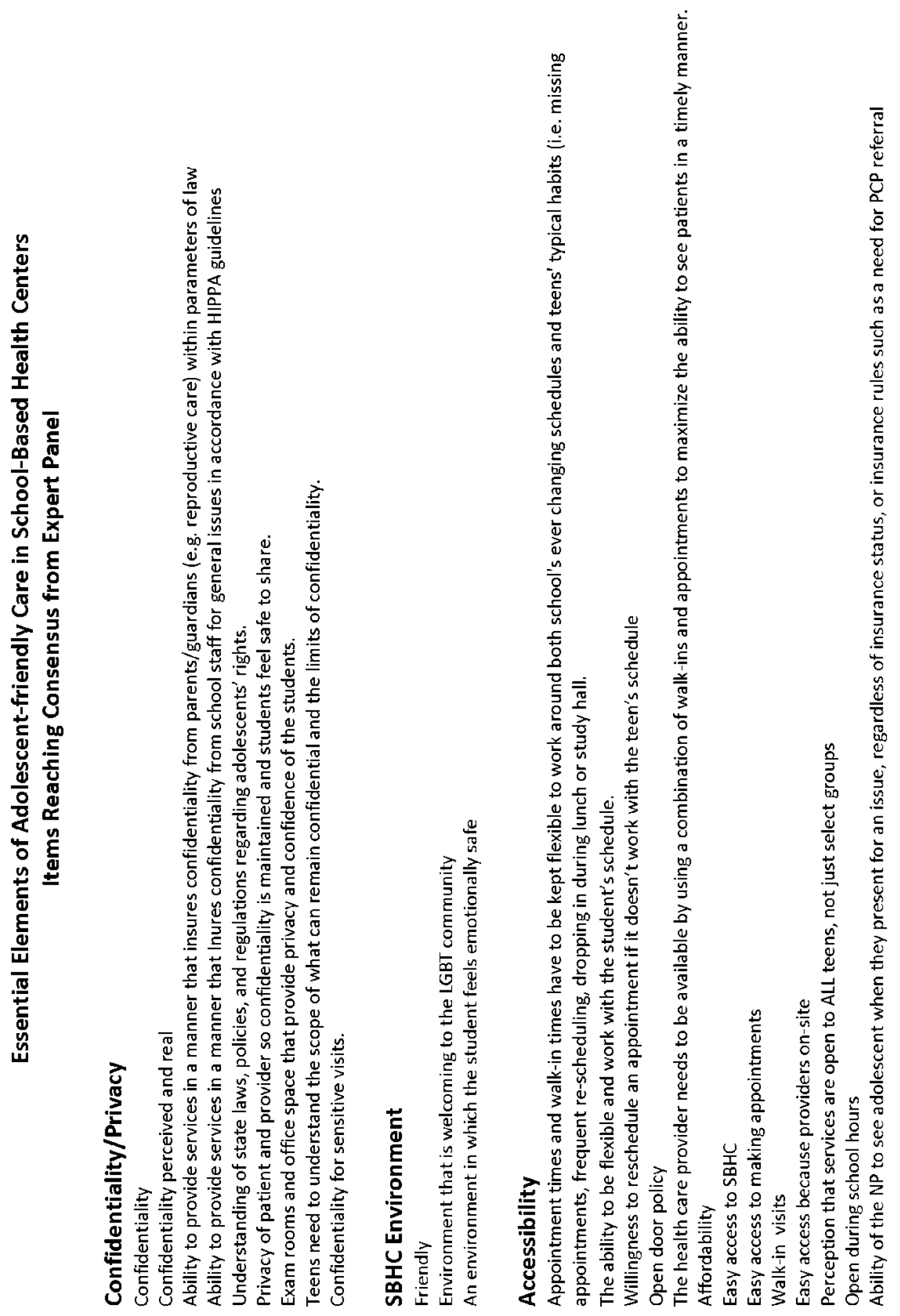


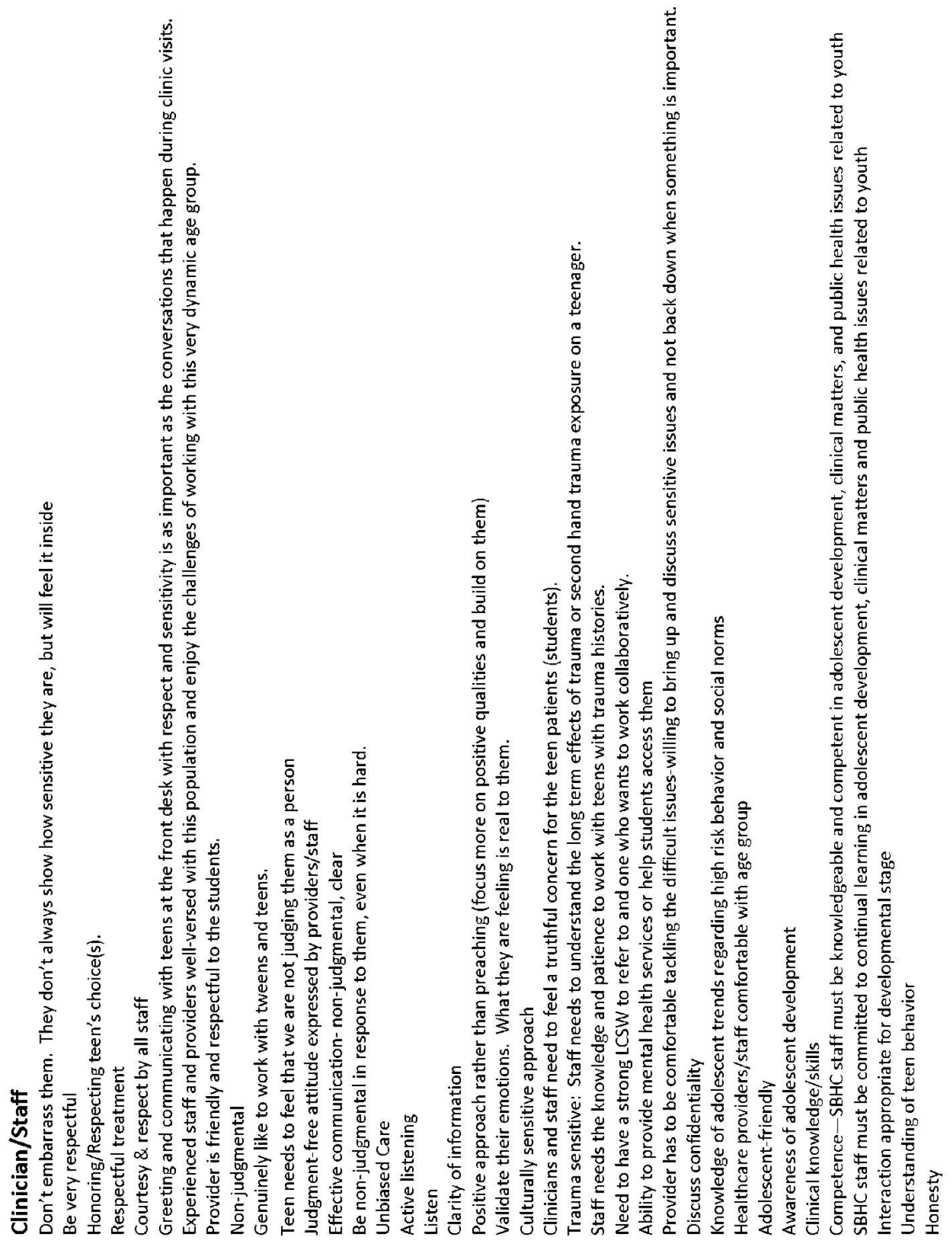




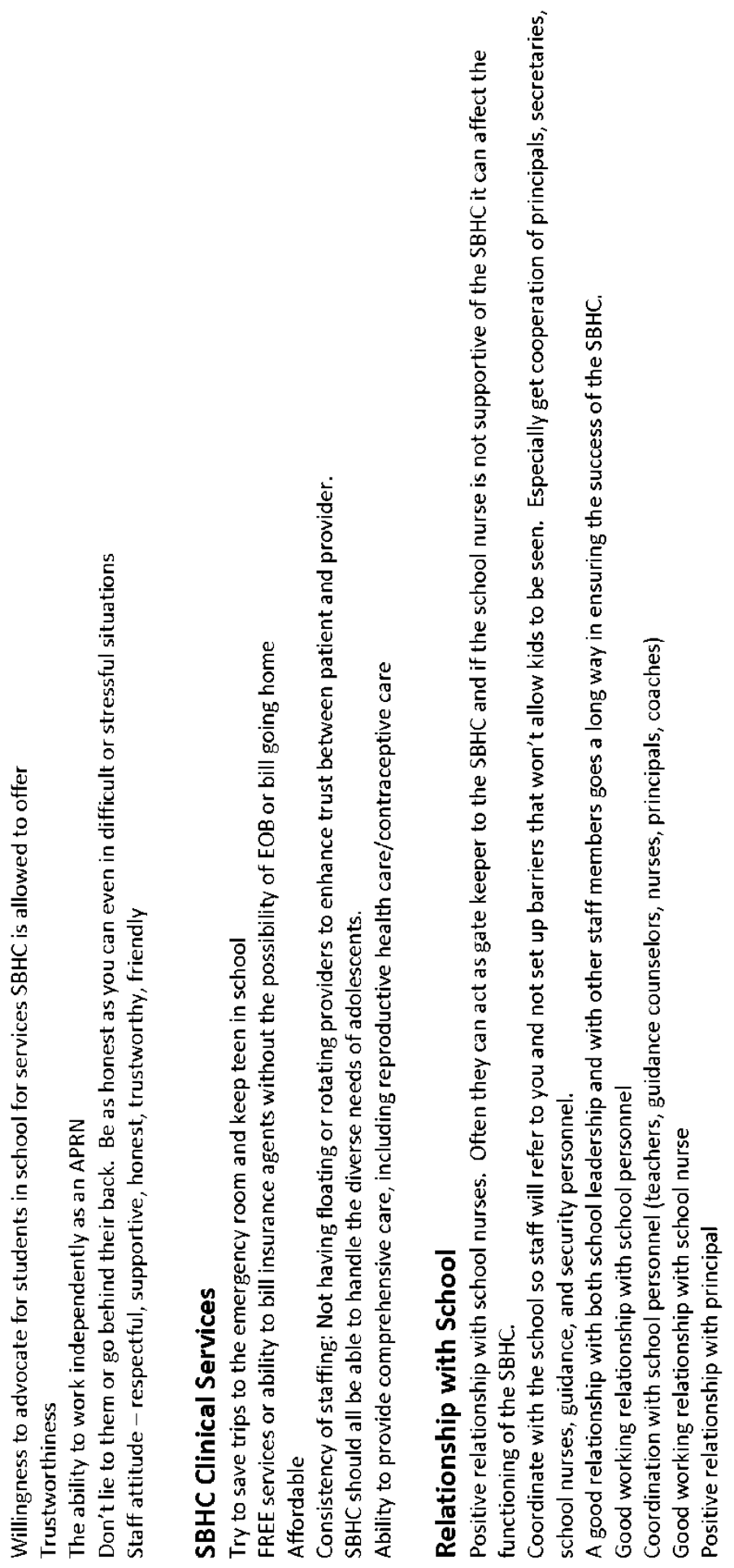




\section{Appendix 0}

\section{UNIVERSITY OF CONNECTICUT Volunteers Wanted for a Research Study: The Essential Elements of Adolescent-Friendly Care In School-Based Health Centers}

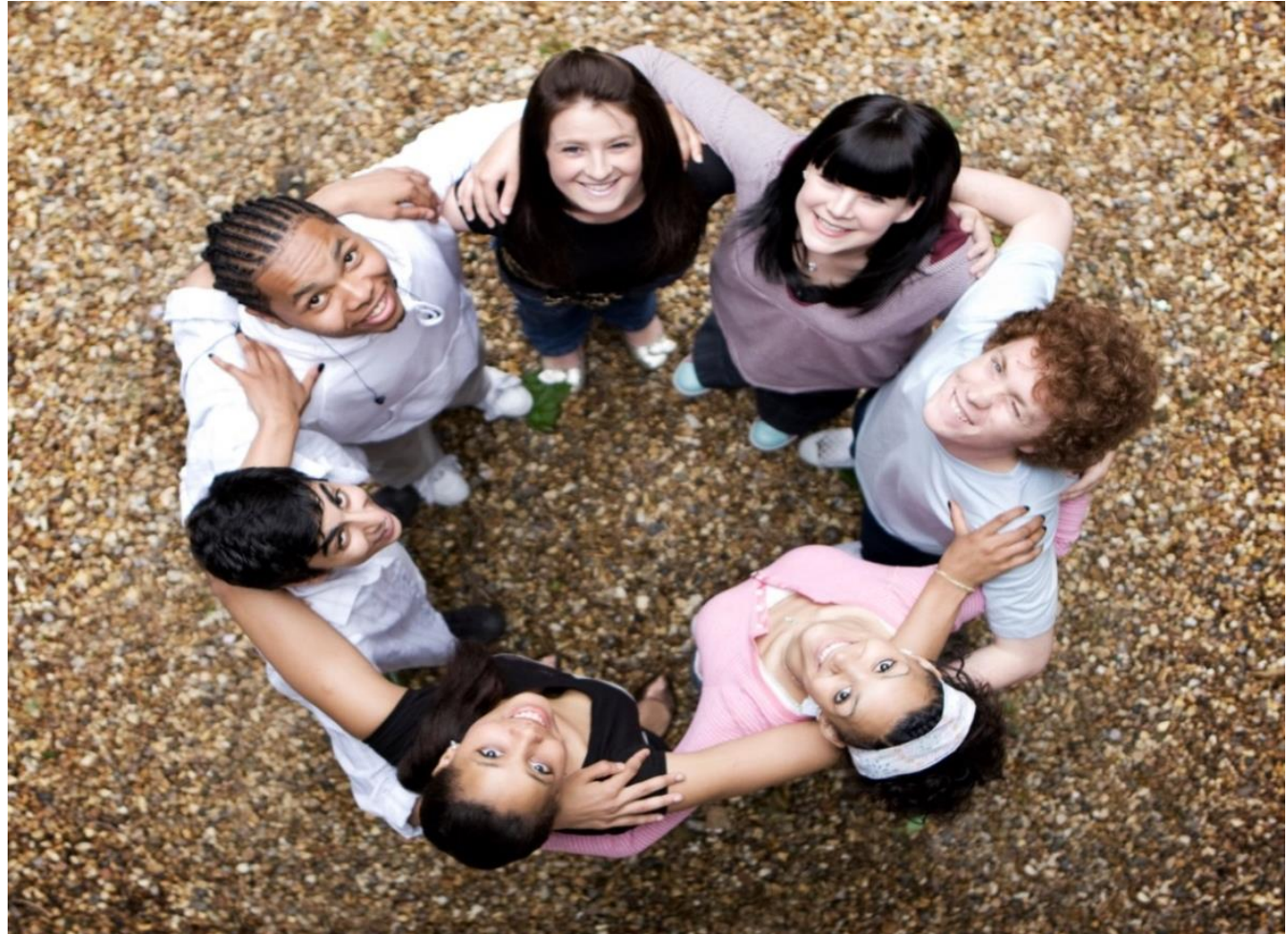

\section{What makes your School-Based Health Center Friendly?}

\section{Come to a focus group \& share your ideas! DATE / TIME}

GENDER /AGE years old who have received health care in a school-based health center are invited to participate in a research study. A focus group will be held to talk about what you consider to be important in the care you receive in the school-

based health center.

The group will take be about 1-1.5 hours. Food and drinks will be served.

Participants will receive a $\$ 10$ gift card and either bus fare or gas card.

Participation is voluntary. Results are confidential.

To sign-up and for more information contact: [NAME], APRN or

Alison Moriarty Daley, MSN, APRN at [NUMBER] or alison.moriarty@uconn.edu

This project will be conducted under the direction of

Carol Polifroni, Ed.D., RN, University of Connecticut, School of Nursing 
Appendix $P$

Focus Groups Recruitment Letter/Script

[Greeting],

I am a doctoral student at the University of Connecticut and I am conducting the study "The Essential Elements of Adolescent-Friendly Care in School-Based Health Centers." The aim of this research study is to identify what teens identify as the essential elements of adolescent-friendly health care provided in school-based health centers (SBHCs).

I would like to invite adolescents from your SBHC to participate in a focus group. The only requirements are that the teens recruited to participate are enrolled and have used the SBHC at least once. Six focus groups will be conducted in Connecticut and consist of either male or female adolescents from one of three age groups (13-14, 15-17 or 18-19). The group will be randomly selected for each participating SBHC. Participation is voluntary and the results are confidential. This research will be conducted under the direction of E. Carol Polifroni, EdD, RN, University of Connecticut School of Nursing.

If you would like to learn more about this study please contact me at alison.moriarty@uconn.edu or 860-XXX-XXXX.

Thank you,

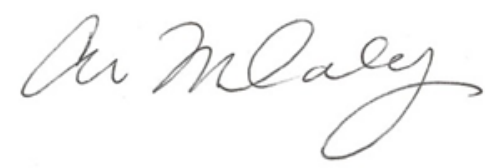

Alison Moriarty Daley, MSN, APRN, PNP-BC

University of Connecticut, Doctoral student 


\section{Appendix Q \\ University of Connecticut Parental Permission Form for Participation in a Research Study}

Principal Investigator: E. Carol Polifroni, Ed.D., RN

Student Researcher: Alison Moriarty Daley, MSN, APRN, PNP-BC

Study Title: The Essential Elements of Adolescent-friendly Care in School-Based Health Centers

\section{Introduction}

Your teen is invited to participate in a research study to understand his or her preferences regarding health care services provided in school-based health centers. Your teenager is being asked to participate because he/she has used the health care services at the school-based health center and I am interested in his/her opinions about what matters most in providing care to teens in this setting.

\section{Why is this study being done?}

The purpose of this research study is to understand, from the teen perspective, what services are important to include in the school-based health center.

\section{What are the study procedures? What will my child be asked to do?}

If you give permission for your teen to take part in this study, he/she will be asked to participate in a focus-group with approximately 8 other teens of similar age and gender. The researcher will ask questions of the teens in the group. The group will take place at

and will be conducted by a doctoral student from the University of Connecticut and a research assistant. The group will meet for 1 to 1.5 hours. The conversation will be audio-recorded and later transcribed. No names or school names will be included in the transcripts or in any reports or papers that are a result of the groups. Each participant will also be asked to complete a brief questionnaire prior to the start of the focus group. A copy of this form is attached. Prior to participation in the focus group, your teenager will also be asked to read this form, have any questions they may have answered, and then sign this form if they wish to participate. The teens will not be contacted after the focus group.

\section{What are the risks or inconveniences of the study?}

We believe there are no known risks to your teen's participation in this study. The only inconvenience is committing the time to the study itself by participating in the focus group discussion.

\section{What are the benefits of the study?}

Your teen may not directly benefit from this research; however, we hope that your teen's participation in the study may provide valuable information about their preferences for the care they receive in school-based health centers. 


\section{Will my teen receive payment for participation? Are there costs to participate?}

There are no costs to you and your teen for participating in this study. A light meal will be provided to participants. Teens will be given a $\$ 10$ gift card to Target as a thank you for participation. They will also be offered a bus token, if needed, for transportation home after the study alternatively if you will be picking up your teen a $\$ 5$ gas card will be provided to a parent or teen driver if school transportation is not available after the focus group.

\section{How will my teen's information be protected?}

The following procedures will be used to protect the confidentiality of your data. The teens will informed of the importance of not be sharing the content of the group discussion with anyone outside of the group however, the confidentiality of the responses cannot be guaranteed $100 \%$. The transcriptionist will not transcribe real names so that the confidentiality of the responses will be protected. The transcriptionist will transcribe every word of our conversation and it will be saved in a word file for the researchers' use. The audio-recordings and the transcriptions will be stored in Dr. Carol Polifroni's locked office at the University of Connecticut. A copy of each focus group transcription will be provided the student researcher and locked in a file cabinet when not being analyzed. The audio-recordings and the transcriptions will be destroyed after one year. You should also know that the University of Connecticut Institutional Review Board (IRB) and the Office of Research Compliance may inspect study records as part of its auditing program, but these reviews will only focus on the researchers and not on your teen's responses or involvement. The IRB is a group of people who review research studies to protect the rights and welfare of research participants.

\section{Can my teen stop being in the study and what are my and my teen's rights?}

Your teenager does not have to be in this study if you do not want him/her to participate. If you give permission for your teen to be in the study, but later change your mind, you may withdraw him/her at any time. There are no penalties or consequences of any kind if you decide that you do not want your teen to participate. Your teen does not have to answer any question that he/she does not want to answer. Prior to the start of the focus group, the researcher will explain the rules of the focus group and will emphasize that each participant may answer any question they choose to answer but they are not required to provide an answer if they do not wish to do so or are uncomfortable. Your teen was asked to participate in this study because he/she has used the school-based health center at their school for health care services. If you or your teen does not wish to participate in this study, the care you receive from the school-based health center will not be changed or taken away.

\section{Whom do I contact if I have questions about the study?}

Take as long as you like before you make a decision. We are happy to answer any question you have about this study. If you have further questions about this study or if you have a researchrelated problem, you may contact the principal investigator, Carol Polifroni, EdD, RN 860-XXXXXXX or the student researcher, Alison Moriarty Daley 860-XXX-XXXX. If you have any questions concerning your teen's rights as a research participant, you may contact the University of Connecticut Institutional Review Board (IRB) at 860-486-8802. 


\section{Parental Permission Form for Participation in a Research Study Wuniversity of Connecticut}

Principal Investigator: E. Carol Polifroni, Ed.D., RN

Student Researcher: Alison Moriarty Daley, MSN, APRN, PNP-BC

Study Title: The Essential Elements of Adolescent-friendly Care in School-Based Health Centers

\section{Documentation of Permission:}

I have read this form and decided that I will give permission for my teen to participate in the study described above. Its general purposes, the particulars of my teen's involvement and possible risks and inconveniences have been explained to my satisfaction. I understand that I can withdraw my teen at any time. My signature also indicates that I have received a copy of this parental permission form. Please return this form to the school-based health center by (insert date).

Teen Signature:

Print Name:

Date:

Parent/Guardian Signature:

Print Name:

Date:

Relationship to Teen (e.g. mother, father, guardian):

Signature of Person

Print Name:

Date:

Obtaining Consent

Page 3 of 3 


\section{Appendix R \\ University of Connecticut \\ Consent Form for Participation in a Research Study \\ Teens 18-19 years old}

Principal Investigator: E. Carol Polifroni, Ed.D., RN

Student Researcher: Alison Moriarty Daley, MSN, APRN, PNP-BC

Study Title: The Essential Elements of Adolescent-friendly Care in School-Based Health Centers

\section{Introduction}

You are invited to participate in a research study to understand your preferences regarding health care services provided in school-based health centers. You are being asked to participate because you have used the health care services at the school-based health center and I am interested in your opinions about what matters most in providing care to teens in this setting.

\section{Why is this study being done?}

The purpose of this research study is to understand, from the teen perspective, what services are important to include in the school-based health center.

\section{What are the study procedures? What will I be asked to do?}

If you would like to participate, you will be asked to participate in a focus-group with approximately 8 other teens of similar age and gender. The researcher will ask questions of the teens in the group. The group will take place at

and will be conducted by a doctoral student from the University of Connecticut and a research assistant. The group will meet for 1 to 1.5 hours. The conversation will be audio-recorded and later transcribed. No names or school names will be included in the transcripts or in any reports or papers that are a result of the groups. Each participant will also be asked to complete a brief questionnaire prior to the start of the focus group. A copy of this form is attached. Prior to participation in the focus group, you will also be asked to read this form, have any questions they may have answered, and then sign this form if they wish to participate. No one will be contacted after the focus group.

\section{What are the risks or inconveniences of the study?}

We believe there are no known risks in participating in this study. The only inconvenience is committing the time to the study itself by participating in the focus group discussion.

\section{What are the benefits of the study?}

You may not directly benefit from this research; however, we hope that your participation in the study may provide valuable information about teens' preferences for the care they receive in school-based health centers. 


\section{Will I receive payment for participation? Are there costs to participate?}

There are no costs for participating in this study. A light meal will be provided to participants. You will be given a $\$ 10$ gift card to Target (or similar retail store) as a thank you for participation. If school transportation is not available after the focus group session, you will also be offered a bus token, if needed, for transportation home after the study. Alternatively if you will be driving home, a $\$ 5$ gas card will be provided to you or your parent if they will be picking you up.

\section{How will my information be protected?}

The following procedures will be used to protect the confidentiality of your data. All teens will informed of the importance of not be sharing the content of the group discussion with anyone outside of the group however, the confidentiality of the responses cannot be guaranteed $100 \%$. The transcriptionist will not transcribe real names so that the confidentiality of the responses will be protected. The transcriptionist will transcribe every word of our conversation and it will be saved in a word file for the researchers' use. The audio-recordings and the transcriptions will be stored in Dr. Carol Polifroni's locked office at the University of Connecticut. A copy of each focus group transcription will be provided the student researcher and locked in a file cabinet when not being analyzed. The audio-recordings and the transcriptions will be destroyed after one year. You should also know that the University of Connecticut Institutional Review Board (IRB) and the Office of Research Compliance may inspect study records as part of its auditing program, but these reviews will only focus on the researchers and not on your teen's responses or involvement. The IRB is a group of people who review research studies to protect the rights and welfare of research participants.

\section{Can I stop being in the study and what are my rights?}

You do not have to be in this study if you do not want to participate. If you wish to participate, but later change your mind, you may withdraw at any time. There are no penalties or consequences of any kind if you decide that you do not want to participate. You do not have to answer any question that you do not want to answer. Prior to the start of the focus group, the researcher will explain the rules of the focus group and will emphasize that each participant may answer any question they choose to answer but they are not required to provide an answer if they do not wish to do so or are uncomfortable. You were asked to participate in this study because you have used the school-based health center at your school for health care services. If you do not wish to participate in this study, the care you receive from the school-based health center will not be changed or taken away.

\section{Whom do I contact if I have questions about the study?}

Take as long as you like before you make a decision. We are happy to answer any question you have about this study. If you have further questions about this study or if you have a researchrelated problem, you may contact the principal investigator, Carol Polifroni, EdD, RN, 860-XXXXXXX or the student researcher, Alison Moriarty Daley 860-XXX-XXXX. If you have any questions concerning your teen's rights as a research participant, you may contact the University of Connecticut Institutional Review Board (IRB) at 860-486-8802.

$$
\text { Page } 2 \text { of } 3
$$




\section{Consent Form for Participation in a Research Study WUniversity of Connecticut}

Teens $18-19$ years old

Principal Investigator: E. Carol Polifroni, Ed.D., RN

Student Researcher: Alison Moriarty Daley, MSN, APRN, PNP-BC

Study Title: The Essential Elements of Adolescent-friendly Care in School-Based Health Centers

\section{Documentation of Permission:}

I have read this form and decided that I will give my permission to participate in the study described above. Its general purposes, the particulars of my involvement and possible risks and inconveniences have been explained to my satisfaction. I understand that I can withdraw at any time. My signature also indicates that I have received a copy of this permission form. Please return this form to the school-based health center by (insert date).

Participant Signature:

Print Name:

Date:

Signature of Person

Print Name:

Date:

Obtaining Consent 
Appendix S

Focus Group Demographic Questionnaire

Name:

Age:

Grade:

Gender: Male $\quad$ Female

Race/Etnicity:

School:

How many times have you used the school-based health center?

What is the best way to contact you prior to the focus group?

Transportation from the focus group:

Parent/Guardian emergency contact information:

Food preference:

PLEASE RETURN THIS FORM AND THE CONSENT FORM TO THE RESEARCHER. 


\section{Appendix T}

\section{Focus Group Follow-up Recruitment Letter}

Dear [Name of Participant],

Thank you for agreeing to discuss adolescent-friendly care in school-based health centers.

\section{DATE}

TIME

LOCATION

\section{DIRECTIONS}

Participants will be a small group teens. I will be providing food. If you have any preferences for food and snacks please let me know via email (alison.moriarty@uconn.edu) by [DATE]. You will also receive a $\$ 10$ gift card for your participation.

Your opinion is very important to this study and I am so grateful for your participation. If for some reason you are unable to join us, please call or email me as soon as possible so I can invite someone else. Additionally, if you have any questions please give me a call at 860-XXX-XXXX.

Sincerely,

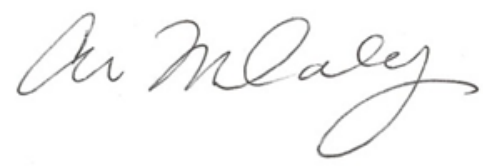

Alison Moriarty Daley

University of Connecticut, Doctoral Student 


\section{Appendix U}

\section{Welcome and Ground Rules}

\section{Welcome}

Good afternoon and welcome. Thank you for taking the time out of your day to join our discussion today. My name is Alison Moriarty Daley and I am a PHD student at the University of Connecticut. I would like to introduce [research assistant]. She will be taking notes and keeping us on time with the session, we know your time is valuable and we want to get you out on time.

\section{Overview}

Today we will be discussing adolescent-friendly care and school-based health centers.

\section{Ground rules}

There are no right or wrong answers. We expect and welcome different points of view. Please share your opinion even if it differs from others in this room. Feel free to have a conversation with each other about the questions we are going to ask you. I am here to ask the questions, listen and make sure everyone has a chance to talk. So if you are talking a lot I may ask that you give others a chance and if you are not saying much, I may call on you. We just want to make sure you all have a chance to share your experiences and thoughts.

We are recording this session because we do not want to miss any of your comments. No names will be included in any transcripts or reports. Your comments are confidential. We also will not be sharing your specific group comments with your employer or the school you work in. All information will be reported as group data from all the nurse practitioners involved in this project.

We also ask that each of you keep what is said in this room private and not discuss it with others. Is that agreeable?

If you have a cell phone, please turn it to quiet mode. If you need to take a call please do so outside the room.

If you would like food or drinks, feel free to help yourself at any time

So let's get started..... 
Appendix $\mathrm{V}$

\section{Focus Group Questions}

Icebreaker: If you were given a plane ticket to go anywhere in the world, where would you go?

Opening: $\quad$ 1. Tell us your name and something you like about your SBHC.

Introductory: 2. What do you like about coming to the SBHC?

Transition: $\quad 3$. How is the care you receive here different from other places you go for care?

Key Questions: In another study nurse practitioners identified 6 essential aspects of providing care to teens in SBHCs. I have placed each of these on a poster and they are hanging on the wall.

- Confidentiality and Privacy

- Accessibility (How teens get appointments or use the SBHC)

- Health Care Providers and Staff

- SBHC Environment

- Types of services offered and provided at the SBHC

- Relationship between the School (Teachers, Principal, School Nurse) and the SBHC

Each of you has 5 sticker dots to place on the posters of the 6 items. Think about this activity like the ratings given to movies or restaurants. You may place as many sticker dots as you wish on each poster to show how important you believe each element is to your experience receiving care in the SBHC. The more sticker dots you place on an item, the more important it is to you. You may divide the sticker dots up any way you wish. For example if you think accessibility is most important to you, you could place 5 dots on that poster or you could place 2 dots on environment and 3 dots someplace else or 1 dot on 5 different posters.

4. What does confidentiality in the SBHC mean to you?

5. What makes this SBHC easy for you to use?

6. Which of the staff members at the SBHC is most helpful to you? How are they helpful?

7. Think about this SBHC as a place, what do you like about it?

8. Here is a list of all the services available in this SBHC, please circle the 3 that are most important to you.

9. Does the relationship the SBHC staff has with the school staff including the principal, nurse, or teachers matter to you? Can you give me an example of how it matters?

Ending Questions:

10. Is there anything else you would like to share about your experience with the SBHC that we have not already discussed??

Wrap-Up: Summarize discussion

11. Did I miss anything? 
Appendix W

Focus Group List of SBHC Services

- Physical examinations for school, sports, or camp

- Routine check-ups

- Treatment of acute illnesses or injuries (colds, sore throats, rash)

- Care of chronic illnesses (asthma, diabetes)

- Immunizations

- Mental health care

- Reproductive care (pregnancy tests, contraception counseling, condoms)

- STD/HIV testing and treatment

- Nutrition counseling / Weight counseling

- Crisis intervention

- Prescriptions and dispensing of medications

- Laboratory testing

- Individual, group, family counseling

- Health education 


\section{Appendix X}

Comparison of NP and Adolescent Perspectives on Confidentiality and Privacy

\begin{tabular}{|c|c|}
\hline NP Perspective & Adolescent Perspective \\
\hline $\begin{array}{l}\text { What Happens in the SBHC, Stays in the } \\
\text { SBHC: } \\
\text { Confidentiality } \\
\text { Confidentiality perceived and real } \\
\text { Ability to provide services in a manner that } \\
\text { insures confidentiality from } \\
\text { parents/guardians (e.g. reproductive care) } \\
\text { within parameters of law } \\
\text { Understanding of state laws, policies, and } \\
\text { regulations regarding adolescents' rights. } \\
\text { Teens need to understand the scope of } \\
\text { what can remain confidential and the limits } \\
\text { of confidentiality. } \\
\text { Ability to provide services in a manner that } \\
\text { insures confidentiality from school staff for } \\
\text { general issues in accordance with HIPPA } \\
\text { guidelines } \\
\text { Confidentiality for sensitive visits }\end{array}$ & $\begin{array}{l}\text { What happens in the SBHC Stays in the } \\
\text { SBHC: } \\
\text { Makes more comfortable because won't } \\
\text { tell } \\
\text { Really important } \\
\text { Never leak anything } \\
\text { Give choice to share with parents or not } \\
\text { share } \\
\text { Don't call your house } \\
\text { Can talk to them if something is wrong and } \\
\text { don't want to talk to your parents } \\
\text { Keep it between them } \\
\text { Understand limits of confidentiality } \\
\text { agreement } \\
\text { Doctor would tell my mom and I don't want } \\
\text { him to do that } \\
\text { Can make an appointment for yourself so } \\
\text { do not have to tell parent why want an } \\
\text { appointment } \\
\text { They tell you from day one that it's private } \\
\text { and they are there to make you feel } \\
\text { comfortable about every situation. And it's } \\
\text { kind of like a guidance counselor. Not a } \\
\text { guidance counselor, but someone you can } \\
\text { actually talk to. Not just the services they } \\
\text { offer but also everything else. } \\
\text { Look out for you if need to tell } \\
\text { Open up more if you can trust } \\
\text { Main key in friendship } \\
\text { Examples of services considered } \\
\text { confidential: Mental health, STDs, } \\
\text { pregnancy or concern and HIV }\end{array}$ \\
\hline $\begin{array}{l}\text { A Private Setting: } \\
\text { Privacy of patient and provider so } \\
\text { confidentiality is maintained and students } \\
\text { feel safe to share. }\end{array}$ & $\begin{array}{l}\text { A Private Setting: } \\
\text { Door shut, one person at a time } \\
\text { Wall there } \\
\text { No family members to see you or answer } \\
\text { phone } \\
\text { Actual door, not a curtain } \\
\text { "And you could hear -- like, say you are in } \\
\text { exam room one, you can hear what they } \\
\text { are saying in exam room two. So it's not -- } \\
\text { it's not -- at the same time, it's not that } \\
\text { very private and confidential because if }\end{array}$ \\
\hline
\end{tabular}

(Table continues) 
somebody is a loud person, you could just hear everything they are saying."

Dental office so small feet stick out the door, friends might know your shoes 
Appendix $Y$

Comparison of NP and Adolescent Perspectives on Accessibility

\begin{tabular}{l} 
NP Perspective \\
\hline Inclusive Environment: \\
Perception that services are open to ALL \\
teens, not just select groups \\
Flexibility: \\
Appointment times and walk-in times have \\
to be kept flexible to work around both \\
school's ever changing schedules and \\
teens' typical habits (i.e. missing \\
appointments, frequent re-scheduling, \\
dropping in during lunch or study hall) \\
The ability to be flexible and work with the \\
student's schedule \\
Willingness to reschedule an appointment \\
if it doesn't work with the teen's schedule \\
The health care provider needs to be \\
available by using a combination of walk- \\
ins and appointments to maximize the \\
ability to see patients in a timely manner \\
Flexibility in scheduling to accommodate \\
teens' want/need to be seen when a \\
problem is occurring \\
\end{tabular}

Adolescent Perspective

Positive Energy:

Friendly

"I just walk in and she is always friendly and chill, always be glad to help you"

Always happy to help you

"she is going to take care of you. Even

then, she will give you a pass. ... Help

comes first"

"I can see what I can do. I can't promise

anything, but let me see what I can do."

"It's a positive energy, it's a positive

impact."

"You feel like you are home"

Flexibility:

"Like, we started out like, me going down to him and talking to him. It started late, it started last week. So he said, like, during the summer time, like, he was going to find a way, like, to get a hold of me and stuff like that."

"Flexible treatments. She is flexible, she gives you -- if you don't want to do something, she will offer you something else."

"She's not like, one, two or three. She is, A, B, C, D and E."

Services are Available When We Need Them:

Strict about sending you home, wants you to stay in school

Sick visits

Physical for sports that week

Can get care right then and there or only wait a few days

Need more exam rooms to be treated fast Fast when they present for an issue, regardless of insurance status, or insurance rules such as need for PCP referral Walk-in visits 
Open during school hours
"If the door is shut, it could be 15 to 20 minutes. Or sometimes longer. But then again, if it's open, you are in and out fast." "You just come down here. You just go or if they are busy, they will be like, we will call you down."

"They call your classroom and you come down, no more than two or three people gotta wait. Even probably just two at the most. Well, three, with the patient being in there and two outside."

"No lines"

"One time my ear was hurting and I didn't call down there, but I was just coming from the bathroom and her door was open and I walked in and she allowed me to stay and she checked me out you don't really have to make appointments" "Basically, you can go at any time that you feel like you need to go. The only thing is that, you can't really basically go on first period because when you just enter -they said if we go down there -- they basically either call us down or tell us to come back in a certain amount of time." "Unless we were like, really, really panicked. They open up when pre-school opens up, so basically they are not ready until -- they are not here for us. They are not our school health center, they are $X X X X$, so when they leave, we get new school health centers for our school." "I feel a safety net because there is a nurse here full time, rather than partial. A nurse that is not going to give up."

"It's open all the time. Open from 7:25 to 2:00. We have unlimited access."

"Takes you out of class"

"The health clinic you need a pass to get in there too, if you don't have a pass, they make you leave."

"Say you are feeling sick or whatever and go straight there from a first floor class and you don't have a pass, you have to go all the way to your current class to get a pass to go all the way back to the clinic." "Here, you can actually come down whenever it is. Do it now instead of having to wait for a very long time."

(Table continues) 
Easier to get an appointment rather than other places

"Just go in and take care of your business New to the school, easiest way to get an appointment"

"You don't have to wait for your parents to come and fill out anything. You can get yourself there fast and get what you need quickly"

"Free, we don't get charged for visits" "she's there from the time that school starts until the time that school ends and actually and then some, a small bit. So she's like never -- she's usually within reach whenever we are on school property, so -"

Open during the summer "I would come here and then get sent home"

"It makes it easier for those students that aren't so credible to get the credibility that they need to get the care that they need" Hurt shoulder in school, lucky the SBHC was open

Call transferred from main clinic

"You could call when you are like, outside your house too and talk to 'em."

Location, location, location:

"I like how it's already at the school, I'm in school every day. So like, it's just right there for me to use."

"you don't have to drive to other places, you just have to stay here and just go" Easier to get it done during school "When your parents work a lot, they don't have time to bring you, you can just come here and get it done" Central location in the school 
Appendix Z

Comparison of NP and Adolescent Perspectives on SBHC Clinicians and Staff

NP Perspective Adolescent Perspective

Showing Respect:

Be very respectful

Courtesy \& respect by all staff

Greeting and communicating with teens at the front desk with respect and sensitivity is as important as the conversations that happen during clinic visits.

Provider is friendly and respectful to the students.

Honoring/respecting teen's choice(s)

Respectful treatment

Non-judgmental

Judgment-free attitude expressed by

providers/staff

Effective communication-non-judgmental, clear

Be non-judgmental in response to them, even when it is hard.

Unbiased Care

Teen needs to feel that we are not judging them as a person

Don't embarrass them. They don't always

show how sensitive they are, but will feel it inside

Culturally sensitive approach

Socio-economic sensitive approach

Genuinely like to work with tweens and teens.

Don't lie to them or go behind their back.

Be honest as you can even in difficult or

stressful situations

Honesty

Clinicians and staff need to feel a truthful concern for the teen patients (students)

Sensitive to needs

Compassion

Trust

Trustworthiness

Staff attitude-respectful, supportive, honest, trustworthy, friendly

Working Together:

Collaborating with teens in decision-

making (mutual goals)
Make Me Feel Comfortable:

Cheerful

Always friendly

She is outgoing

Makes conversation

Always happy to see you

They make the environment comfortable

"She treats you with respect"

"Treats you like an adult"

"She treats you like if she's in your own

shoes at that moment"

Always interested in what you have to

say and the situation that you are

presenting to them.

"Always asks you why you are coming. So

like, if it's very private, she will

understand. And like, when it was with

me, we like, stepped out and I told her

what this is about, so she could tell

[name]. And I felt fine. Like, it was -- like, I trust you so."

Reliable:

Persistent

Very persistent

"And if the medicine that she was giving you wasn't strong enough, she would give you a bit stronger. She would make sure that the medicine that she was giving out was always -- if it didn't work the first time, then she would try again harder the next time. She wouldn't give up."

"She would like, take care of it. But if she doesn't have it, then she would tell you where you could get it."

"she don't forget anything and if she tells you, I'm going to give you the results the next day -- at the time she says it to you, she makes sure it's done at the end."

Working Together:

Makes all your appointments

(Table continues) 
It is important to listen before giving advice. Their big complaint is that "nobody listens to them. They tell us what to do."

Active listening

Listen

Clarity of information

Positive approach rather than preaching (focus more on positive qualities and build on them)

Discuss confidentiality

\section{Competence:}

Awareness of adolescent development

Clinical knowledge/skills

SBHC staff must be committed to

continual learning in adolescent

development, clinical matters and public

health issues related to youth

Interaction appropriate for developmental

age

Understanding teen behavior

Willingness to advocate for students in

school for services SBHC is allowed to

offer

The ability to work independently as an

APRN

A staff knowledgeable about growth and development

Understanding of adolescent

development

Familiarity of community resources for

students and families

Trauma sensitive: Staff needs to understand the long term effects of
"Any issues at home, they try to give you like - give you help, counsel, counseling like some of them are trained in the same thing. Like, more than one thing. So that is actually really good" (crisis intervention) "when isn't she" Counselors are very helpful "She talks you through like, how many times you are supposed to floss or how many times is good for you" "I remember, not that long ago, I was feeling these asthmatic problems. I went in there and asked her to like -- again, listen to my chest and she was like, you sound really bad. Now, I have been pretty worse, like conscientious, with me for an asthma attack start to finish before. She was like, really helpful. Even though it wasn't as bad as that asthma attack, she gave me like, some Albuterol to keep me going. Even though I ended up going home at the end of that day, it was like still -- well, it really touched me that she was actually there and that she would give me the medicine."

"If you go in panic, they calm you down right away."

Knows Me:

"They were actually very helpful. Those were the people that I was close was. It was like, every day, a party."

"She wouldn't just worry about you that one time and forget. She will remember it from last year, like, and be more helpful"

"It feels good walking into this place and seeing that same person every time because when I used to go to my doctor, there would be a different lady at the desk every time and it's just like-gosh, I have to tell you my whole life story. And it's just like here, like, oh, hey, [name] l'm just going to bring up your information. Oh, what's wrong? Why do you need to be here? Like, it's better here."

"She treats you like if -- the worst that you think, even if she knows what you -how bad you think it is, is not that bad.

(Table continues) 
trauma or second hand trauma exposure on a teenager.

Staff needs the knowledge and patience to work with teens with trauma histories

Ability to provide mental health services or help students access them Need to have a strong LCSW to refer to and one who wants to work collaboratively

Competence-SBHC staff must be knowledgeable and competent in adolescent development, clinical matters, and public health issues related to youth Knowledge of adolescent trends regarding high risk behavior and social norms

Experienced staff and providers wellversed with this population and enjoy the challenges of working with this very dynamic age group.

Provider has to be comfortable tackling the difficult issues-willing to bring up and discuss sensitive issues and not back down when something is important. Healthcare providers/staff comfortable with age group

Adolescent-friendly
She will treat it as it as. That way it makes you feel better about it." 
Appendix AA

Comparison of NP and Adolescent Perspectives on Clinical Services

NP Perspective $\quad$ Adolescent Perspective

Comprehensive Care:

Full range of services available:

Preventative care, immunizations, PE/Sports PE, Acute visits including screening/testing STls, pregnancy, Behavioral Health/Dental/GYN on site Ability to provide comprehensive care, including reproductive health/ contraceptive care

SBHC should be able to handle the diverse needs of adolescents

Mental Health:

Mental health screenings, referrals; mental health services provided on-site through SBHC

Reproductive Care:

Reproductive health services or the ability to help students easily and quickly access them

Expert knowledge of reproductive care, pregnancy prevention, OB/GYN services, and services that are offered in surrounding areas

Easy Access to Services:

Availability of Point of Care Testing

Try to save trips to emergency room and keep teen in school

Affordable

FREE services or ability to bill insurance agents without possibility of $\mathrm{EOB}$ or bill going home.

Dispense medications if necessary due to no insurance or difficulty getting to a pharmacy

Continuity:

Consistency of staffing: Not having floating or rotating providers to enhance trust between patient and provider
Medications:

"So if you needed a certain medication that you, prescribed for you, you can just go right down and get it, instead of having to get picked up by an ambulance or your parents at the school." "give you some medication to hold you off" "I feel like prescript -- yeah -- I feel like prescriptions. Like, the -- I don't know how to explain it. How like, [name] could like write out prescriptions for people. I feel like that's like really important because if there is like, something wrong with me, like, I can just like to go to CVS and like, pick it up and like, my mom doesn't really have to know. I mean, my mom knows about everything when I get like, prescriptions for it. It's okay. But it's just like -- it's kind of nice to think about the like -- she could do that and it -"

Depo-provera

prescriptions

Dispensing medications

Dispensing medications because no insurance

Immunizations:

HPV vaccine/Gardasil

H1N1

Laboratory Tests:

STD/HIV testing

Pregnancy test

Throat cx

Blood draw

Mental Health:

I also picked mental health care because sometimes people feel like, you know, bad about themselves and things like that. So they are always there to tell them, you know, you are not alone, just whatever. I picked mental health care because um, they really talk to you and help you with -

(Table continues) 
if you are feeling bad about yourself or something.

Counseling

Mental health

Because there is times where I have mental breakdowns in school. Like, I have anxiety and stuff, so I have moments where I like -- my heart starts racing and I start crying out of nowhere and it's because I can't breathe and stuff like that. Then I start thinking stupid things that I shouldn't and now that there is somebody here that can actually see me and help me calm down, it helps me more because now I don't have to wait and try and do it on my own inside of school. I have somebody who I can see instead of waiting until I get out of school. And then it's like hours from now and then it's just pointless. I want somebody who I can come to and talk to automatically and I don't do something stupid because my mind is racing".

"They are my support for everything, because they know a lot, so they support me through a lot. That's why when school ends I going to go fuckin' crazy. They keep -- they hold me down most of the time."

Crisis Intervention:

"My grandfather died recently"

Family problems

"Because there are times where I have mental breakdowns in school."

Collaboration among staff for students in crisis so have access to care if needs it crisis intervention

Acute Illnesses or Injuries:

"Treatment of acute illnesses and injuries, because that is every day with colds and sore throats and stuff like that. Especially you are in a school, so you come in contact with people daily. And so I feel like you need to get treated with that ASAP and it's good that they are for that, so you don't spread it around the school."

"Say you go there and you have like a big illness or like you were, like, a big incident

(Table continues) 
or got hurt. They would take the time out of their day to like, call you out of class or when they see you in the hall, to come and ask how you are or if you still need any help or if you got any better from them when they helped you."

"if you have a broken limb or something, they will take the time out of their day, and like, change the bandages and apply whatever needs to be done to the wound to make sure it heals properly."

Nutrition and Weight Counseling:

"I picked nutrition counseling, weight counseling because like, I feel like, like a regular place -- like where you usually would get your appointments and stuff, like they care more for their job. Where they don't -- like, here, they don't -- they just do it to benefit you, not -- I don't know."

Nutrition counseling

Physical Examinations:

Physicals

Sports physicals

"Yeah. 'Cause -- I don't know. I feel like sometimes it's hard for people to get like, physicals. Especially since like, the whole Obamacare thing, people -- a lot of people lost their -- what is it? Insurance, yeah. So I mean, this is like a free and easy way to do it."

Physicals for sports, school, camp

Reproductive Care:

The shot

"And reproductive care, like, if you were pregnant and you didn't know and like, you didn't want your parents to know yet. Like, they will keep the secret and like, they will tell you."

"Pregnancy tests--here I'm very comfortable with talking about that stuff with her."

"Reproductive care because if you think you are pregnant, but you don't know, you could go"

"I think uh, that reproductive care ahh....so you can be sure to be safe" 
"I think it's a good idea, the fact that they give out condoms and stuff like that, to make sure that they prevent teen pregnancies and things that they can take care of. They want the kids to have a future and not to become parents at early age"

Condoms

"drilling it in my head constantly"

STI Testing and Treatment:

"I did STD and HIV testing, because uh, I feel like -- well, here I feel you kind of have to be tested and other places, not really, it's more of your decision. So, I feel like that is good, because it's better to be safe than sorry.

"Yeah, they shouldn't be doing that, but in the case they do, the treatment should be there for them."

"If I were to put something on the bottom of the list, it would be reproductive care, actually. Or STD. Or not STD, but HIV testing. Because if you do that, that is your own problem, personally. Because you shouldn't be taking that risk -- those risks at this age anyway, so. And that should be your own problem."

"Well, I think in the compromising, I think you should have testing, but then further treatment should be taken outside" "Yeah, back to the HIV treatment that we were talking about. I don't think that it's really required in high school, because most cases are older people. But it would be good to have it anyway because you may be in that small group of the people that are young and contracting it and the people in the SBHC try and help you." "I think honestly the most important one would be the STD, HIV, because it would be good to know that you don't have anything and you could find a way not to catch it. STD treatment. I wouldn't go to my real doctor for that."

"We are all sexually active and there is -like, we may have a boyfriend or we may do other partners, but like, I remember, I didn't trust my boyfriend at one point that I'm with now. So, one time we did it

(Table continues) 
without a condom and now instead of going all the way to Grand General Hospital, waiting, making an appointment, I came here the next day, asked her to do it, she pricked me, send it in, next day it was back. Instead of sitting here and waiting a long time. Because that's a scary thing to think about."

"I think that's really good that you can get the results right there and then rather than going all the way to the hospital." "I feel like that's -- that has been presented more than anything else on this list, to us. Because we have had meetings about stuff like that -- about ten meetings this year about HIV and STD testing and how they help you with that in the school health clinic"

Referrals:

"Yeah, she will send you -- if it's really, really, really serious, she will send you to community health -- she will put it in herself that you need to go there." Sent to physical therapy 
Appendix AB

Comparison of NP and Adolescent Perspectives on the SBHC Environment

NP Perspective Adolescent Perspective

Welcoming to All Teens:

An environment in which the student feels safe

An environment in which the student feels emotionally safe

Environment that is welcoming to the LGBT community

Friendly
Comfortable but Tiny:

Dental room so small have to have feet out the door, cramped in there

Waiting room it's comfortable, but it's tiny

And it's kind of hard to sit down

sometimes.

Can't pass anyone in the hallway

Need to take your backpack off before you

enter the door

Clean place

"It's like a nice environment. Like, it's clean and there is like, pictures and everything else. Instead of just like, dirty and boring"

"It's not messy"

Clean, nice

"So with it looking like, decent and clean and everything, you are going to be like, okay, maybe they are going to do what they gotta do what they gotta do and everything."

Organized

Thin walls

"And sometimes I feel they are for little kids and little cartoons, but then after a while you really get into it. Like, the way they put it and the little comments and everything. So you start going around and you want to read it."

"Because they make it like, attractive. Like, it could look like it's for little kids, but when you like, read it, like, you know that they are just doing that, it will make you want to actually read it and understand it more. Because some people, if they look at a poster and it's plain like that, they don't want to read it, just because it's plain. So when you put, like, things on it, it makes you look at it like, oh, I actually want to read this. So there is things in there that change your mind about other things"

"There is like, drawings like, of students, they make it and then they give to them. It

(Table continues) 
makes you feel comfortable"

"I personally don't want to walk into a nurse's office or a school-based health place and just see like, a picture of guy with corroded arteries and drinking and doing other drugs. I don't want to see that. I want to see something calming."

Can be hard to find

Need more rooms, larger space

Good Vibes:

"Feel safe around the people around you." "You have to be like, comfortable with the people who are around you."

"It's like l'm comfortable walking in. Like, my heart is not beating"

"Good vibes"

"And very relaxed sitting in here talking.

You are not like, oh my God!"

"You just walk in and you just feel like, oh, I'm home"

"Cool people"

"Yeah, like, they are always smiling. Like, there is not one moment where they are not smiling and it's just like -- when you walk in here, you just automatically feel like, cheered up, because they are just like, happy people. They are good people."

when you walk in, they ask you right away"

"People make you comfortable."

"They smile a lot. I don't know, that makes me feel really comfortable because like my doctors, like, they never smile. It's like, oh, you are here again? They judge you like"

"Really loving and kind"

Understanding Non-judgmental "I come here a lot for really little things. I will have a paper cut and I will come in she will be like, what's going on? l'm like, I have a paper cut. She's like, oh, okay. But my doctor would be like, why are coming here?"

"You feel like you have a very strong connection after like, one visit. Like, you are going to walk back in here and be like, oh, okay, I know her. Like, we are cool."

(Table continues) 
"Oh, you are here, it's nice to see you again. Like - it's comfortable." "When you walk in there, you are like, "Hi [name]!" She will be like, how you doing?" 


\section{Appendix AC}

Comparison of NP and Adolescent Perspectives on the Relationship Between the SBHC and School

NP Perspective

Working Collaboratively:

A good relationship with both the school leadership and with staff members goes a long way in ensuring the success of the SBHC

Coordinate with the school so staff will refer to you and not set up barriers that won't allow kids to be seen. Especially get cooperation of principals, secretaries, school nurses, guidance, and security personnel. Good working relationship with school personnel Coordination with school personnel (teachers, guidance counselors, nurses, principals, coaches)

Good working relationship with school nurse

Understanding of the school/BOE policies and regulations (re: educational rights, services provided by state, town or school) Positive relationship with school nurses.

Positive relationship with principal Often they can act as gate keeper to the $\mathrm{SBHC}$ and if the school nurse is not supportive of the SBHC it can affect the functioning of the SBHC.
Adolescent Perspective

Working Collaboratively:

"I figured out about it from the nurse because she told me that instead of my mom having to schedule like, an appointment somewhere else, like, she could just schedule it fast there."

"She talked me into it. She was like, they are good people there. And then I went in" "It's more like the nurses that are like, more like, connected with the health center."

"I went to -- I was gonna go there for medication, they said not to go to the nurse, to go to the school health based center because they don't give medication at the nurse. So I did decide to go to the school based health center to get the medication for like a headache" "Sometimes it's like, if like, um, [name] is on lunch break and she can't take care, [name] will send us over there. But it's not very -- like, why did they send you guys over here? It's always like, oh, well do you guys have your papers signed? Because if you have the papers signed, then we can give you stuff."

"I remember one time, like, I had like a really bad headache....and they are just like, oh, are you signed up to the health center? They could help you out more. Like, maybe [24:00] they could like, run some tests like, to see like, why like, you have a headache."

"They help each other out. Like, when I first came here, before I was signed up here, I went to the um, to the nurse, because like, I felt really lightheaded and I felt sick. My throat was just killing me. So I went to the nurse and they um, they couldn't really do anything about it. And then I didn't know I had the papers signed for here and it turned out that I did. So they sent me over here and they both

(Table continues) 
went and checked on me and stuff. So they like, helped each other out. They work together."

"They work together."

"Make sure you stop by the school health center just to make sure, because they know better. And I was like, oh, okay. So I came here"

"Actually they are very friendly with each other."

"The nurse, she -- yeah, most of the time when I go there, she actually tells me to come to the health center."

The School Supports the SBHC:

Referred to SBHC for a physical by the coach for football

New student referred by school to SBHC for physical exam

School announcements

Athletic trainer sent for physical

Everything is neutral

"If they know like, something is wrong with you, like, they will tell you, like, go to the school-based health center."

"I feel like if they didn't have a good relationship, they wouldn't still be here." "There is really no relationship between our school and that health center."

"My basketball coach told me one time to try to go there and get a physical to play basketball."

"The past few times I have been to a class and like, people are like, I don't feel good. They go like, go to the health center. They don't even say the nurse anymore." "Well, one my friends -- she um, she's going through something and she is in the mental -- she said that like, they are really good there and they are trying to help her."

"I think it's more important for it to be more -- the relationship to be between the school-based health center and the students. I don't really know about the school nurse or the principal and teachers."

All Teachers Don't Know about the SBHC: "I don't really feel like there is like, a 
relationship. I mean, there are kind of different people. I don't think teachers like -- I'm not sure if teachers understand." "I think they just think it's basically like a nurse. Just the nurse to them, basically." "I have said, "oh, can I go to the health center?' And they are like, 'The what?'” "Teachers just really don't know about the SBHC" 